\title{
CITY OF MERCED BELLEVUE COMMUNITY PLAN
}

\author{
A Project \\ presented to \\ the Faculty of California Polytechnic State University, \\ San Luis Obispo
}

In Partial Fulfillment
of the Requirements for the Degree
Master of City \& Regional Planning and Master of Science in Engineering

by

Patrick Gary Gilster

June 2014 
(C)2014

Patrick Gary Gilster

ALL RIGHTS RESERVED 


\section{COMMITTEE MEMBERSHIP}

TITLE: $\quad$ City of Merced Bellevue Community Plan

AUTHOR: $\quad$ Patrick Gary Gilster

DATE SUBMITTED: June 2014

COMMITTEE CHAIR: Chris Clark, J.D.

Lecturer in City and Regional Planning

COMMITTEE MEMBER: Lisa Wise

Adjunct Lecturer in City and Regional Planning and President of Lisa Wise Consulting, Inc.

COMMITTEE MEMBER: Menka Sethi

Faculty at California Polytechnic State University, San Luis Obispo and Senior Associate at Lisa Wise Consulting, Inc. 


\section{ABSTRACT \\ City of Merced Bellevue Community Plan \\ Patrick Gilster}

The Bellevue Community Plan (BCP) was developed to be consistent with the Merced Vision 2030 General Plan, and is highly reflective of its policies, illustrative plans and guiding features, such as providing significant employment generating uses that would benefit from being in close proximity to the UC Merced campus. The BCP establishes a high-level planning framework that strikes a balance between certainty and flexibility by anchoring key land uses while allowing their size to adapt to changing market conditions in response to economic growth and the expansion of UC Merced. While the BCP provides a broad range of uses and densities that could occur throughout the plan area, it emphasizes the foundational building blocks of street connectivity, functional mobility choices, active and passive recreation open space corridors and bikeways, gateway street designs, and attractive business park settings to create a great sense of place with investment certainty. 


\section{ACKNOWLEDGMENTS}

I would sincerely like to thank my boss and mentor, Lisa Wise, for allowing me to take charge of this project and guiding me throughout its creation. I have learned more in my time with her at Lisa Wise Consulting, Inc. then I have throughout my graduate education.

I would additionally like to thank Chris Clark for advising me throughout this whole process and for continually making our meetings one of the highlights of my time at Cal Poly.

I would finally like to thank my friends and family, especially Evan Hendrickson, who put up with many long hours of working and writing to complete this milestone of my life. Without them this process would have been a lot more stressful and difficult. 


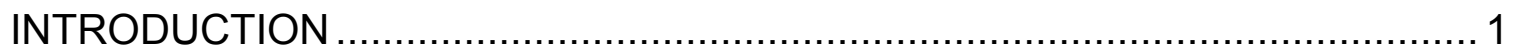

CONTEXTUAL SUPPORT AND LITERATURE REVIEW ................................. 3

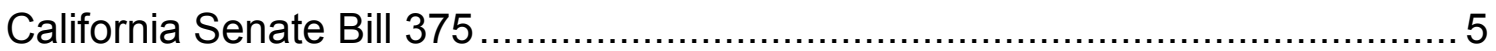

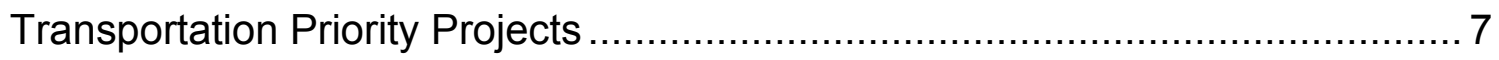

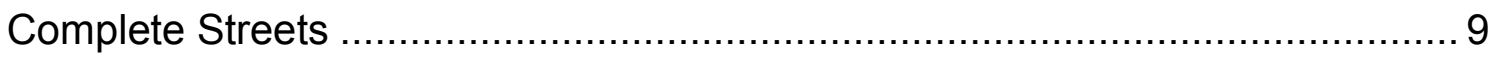

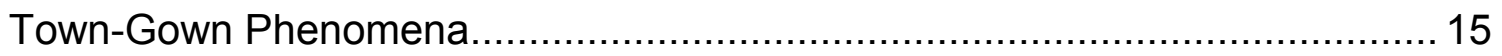

Financing Infrastructure and Development in California................................ 19

Economic Competition of Proximate Plans with Downtowns.......................... 24

Interconnected Land Use and Transportation Planning ............................... 28

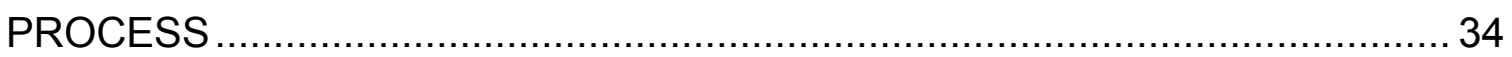

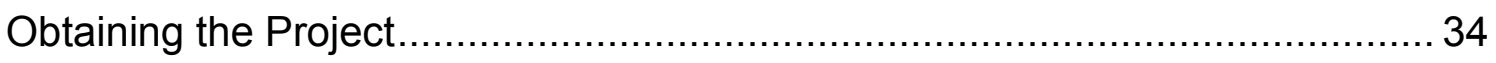

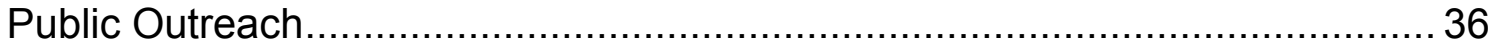

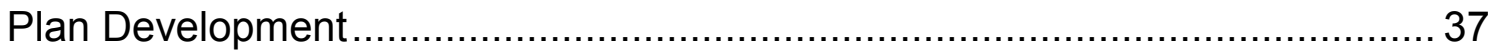

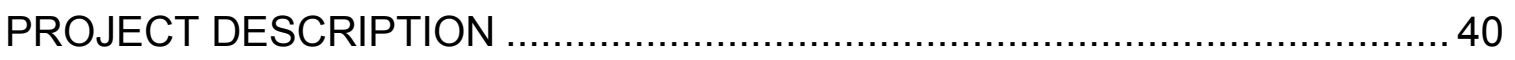

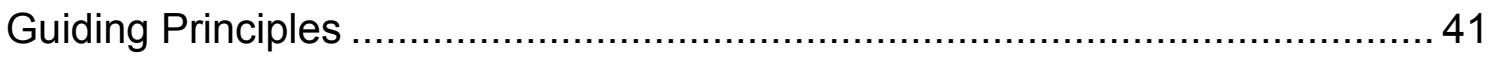

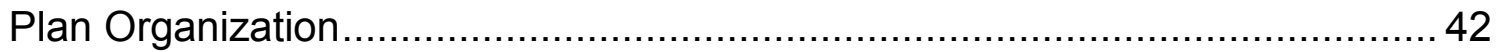

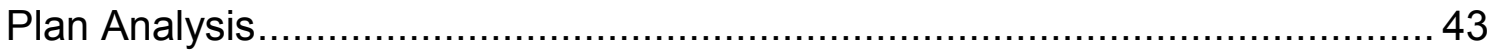

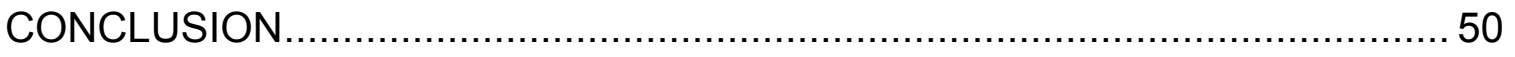


Appendix I. Bellevue Community Plan Public Review Draft ............................ 56

Appendix II. City of Merced Staff Report ………......................................... 57

Appendix III. Bellevue Corridor Community Plan Request for Proposal ............. 58 


\section{INTRODUCTION}

The work by Lisa Wise Consulting, Inc. began in the City of Merced before I was brought on at the company. Upon being hired, I worked continuously on this project and eventually was responsible for managing the project. It was then that I was able to fulfill the California Polytechnic State University, San Luis Obispo Master of City and Regional Planning / Master of Science Engineering Transportation culminating experience requirement through a profession project by helping manage, design, and complete the City of Merced Bellevue Community Plan. This process involved working many long hours to meet deliverable deadlines and efficiently communicating with both the client (City of Merced) and sub-consultants. As part of this process, I was able to hone my design, community engagement, writing, and management skills.

In managing the project, it was my job to ensure that the client was pleased with product deliverables and that we were receiving the necessary information from sub-consultants to complete all tasks on time. Aside from helping to manage the project, I was personally responsible for the document design and layout and was tasked with helping to create public outreach materials, attend meetings, provide input on solutions, and help write and edit multiple chapters of the document. Through being given the freedom to take charge of the project and run with my ideas, I was able to take the input we received from the client, project stakeholders, the general public, and the 
consultant team and combine it all into a functional, working plan that could be adopted by the City Council.

This document is structured to provide an overview of the process that was undertaken to complete the project and meet the requirements of the Master of City and Regional Planning / Master of Science Engineering - Transportation degree requirement for a professional project. This document begins by detailing an analysis of key contextual and supporting information combine with a review of pertinent literature and best practices concepts that provide the foundation for many of the concepts included in the Bellevue Community Plan. A description of the process involved to complete the Bellevue Community Plan and a more detailed narrative of the work that I contributed are also included. The project description includes explanations of the various components that were included in each chapter. Finally, the conclusion draws together how the completion of the document works to provide the City of Merced with the proper tools to ensure sustainable development and details how this professional project supplied me with a unique culminating experience. 


\section{CONTEXTUAL SUPPORT AND LITERATURE REVIEW}

The City of Merced Bellevue Community Plan was originally commissioned by the Merced City Council in order to guide the future development of agriculture land near a powerful new local attractor. Just outside of the City of Merced boundaries lies the newly formed University of California, Merced, which will attract students and visitors from all over the state and the country. This campus is set to provide a standard of education comparable to the rest of the UC system. While the campus provides an excellent opportunity to support the Central Valley, and the entire State, the City of Merced wanted to ensure that the land next to the campus would develop in an agreed upon pattern by the current landowners and the City. The Plan is supported by a Sustainable Communities Strategies Grant and in accordance was guide the development of the area in such a way as to meet certain standards for both land use density and transportation connectivity. In order to meet these standards, the landowners and the City had to go through many rounds of community and advisory committee meetings to discuss many issues that affected the unique circumstances of the long-range planning area. The following issues were the most challenging to face and will be vetted out in this literature review:

- Senate Bill 375

- Transportation Priority Projects

- Complete Streets

- Town Gown Phenomena 
- Financing Development in California

- Economic Competition of Proximate Plans with Downtowns

- Interconnected Land Use and Transportation Planning

While all of these issues had to be discussed at great length by the City and the Committee, the process of green field transportation planning was the one key issue that was difficult to get community members to understand and come to consensus on. For this reason, green field transportation planning and the key options that it presented to the City of Merced is discussed in greater length at the end of this literature review. The building blocks that provide the foundation for many of the concepts portrayed throughout the City of Merced Bellevue Community Plan are explored throughout this literature review. 
California Senate Bill 375

To ensure Merced is complies with recent state legislature and is viewed as an environmentally conscience city, many standards were included in the Bellevue Community Plan to support this vision. In 2008 the California Legislator and Governor Arnold Schwarzenegger introduced into law the California Senate Bill 375 (SB 375), also known as the Sustainable Communities Act, which provides important legislation to support the statewide goal of reducing greenhouse gas emissions (California Environmental Protection Agency , 2014). The intent of SB 375 is to simultaneously create or update land use and transportation plans in order to promote better coordination between the two. The California Air Resources Board sets regional reduction targets for greenhouse gases that metropolitan planning organizations (MPOs) must use to create "Sustainable Communities Strategies". The Sustainable Communities Strategies can then be incorporated into an MPO's Regional Transportation Plan. It is therefore important for local jurisdictions to identify how they can help to fulfill the Sustainable Communities Strategies if they would like to qualify for transportation funding under the Regional Transportation Plans.

While the primary focus of SB 375 is to connect land use and transportation, the Sustainable Communities Strategies also need to incorporate plans for housing in order to reduce the distance to work or reduce the distance to transit options from where people live. This is essential in reducing greenhouse gas emissions because, "According to the California Air Resources Board, transportation accounts for some 40 percent of greenhouse gas 
emissions, with cars and light trucks accounting for almost three-quarters of those emissions (30 percent overall)," (Institute for Local Government, 2014). By coordinating plans for transportation, land use, and housing, a reduction in vehicle miles traveled (VMT) can be achieved. The less people need to use their personal automobiles to access work, personal errands, and services, the greater the potential becomes for reducing VMT and, in turn, reducing greenhouse gas emissions.

Another driving force for local agencies to establish Sustainable Communities Strategies under SB 375 is to provide incentives to projects that align with broader regional plans to reduce emissions. Offering streamlined review of projects under the California Environmental Quality Act (CEQA) mostly provides these incentives. Streamlined CEQA review incentives can be provided for some residential and mixed projects or transportation priority projects, which will be discussed further in the next section. Local agencies must also include the community in which they serve through public participation during the creation and adoption of Sustainable Communities Strategies. In order to guarantee public participation the state legislator, "Requires the MPO to conduct extensive outreach with local government officials and adopt a public participation plan for the SCS that includes a minimum number of workshops in each county as well as three public hearings on the draft SCS prior to adoption of a final RTP," (One Bay Area). Public participation and stakeholder outreach is the best way to ensure that future projects proposed in the Sustainable Communities Strategies 
and RTPs will not face substantial opposition when, or if, developers wish to build projects consistent with the plans.

\section{Transportation Priority Projects}

In order to provide a concrete framework for future development to meet environmental and transportation standards, the Bellevue Community Plan established specific areas for Transportation Priority Projects. As a part of SB 375, developers can take advantage of CEQA streamlining incentives if they propose projects consistent with the approved Sustainable Communities Strategies. This is achieved by establishing projects as Transportation Priority Projects (TPPs). The first phase of establishing a TPP is to ensure that the, "TPP must be consistent with the general use designations, density, building intensity, and applicable policies specified for the project area in either a SCS or APS for which CARB has accepted an MPO's determination that the SCS or APS would, if implemented, achieve the greenhouse gas emission reduction targets," (Sacramento Area Council of Governments). This can be accomplished through aligning a specific project with previously established plans or through creating a new plan that establishes the TPPs and can be adopted into a Sustainable Communities Strategy and Regional Transportation Plan. In the case of Merced, an entire community plan was established to delineate where and how TPPs should be located. Upon adoption of the Plan, the components of the plan can be added into the next update of the Merced County Association of Governments RTP. 
In addition to the abovementioned requirements that TPPs must meet, SB 375 also requires TPPs to be located near transit facilities. Specifically, SB 375 necessitates that projects meet the following: "(1) At least $50 \%$ of total building square footage for residential use or if $26-50 \%$ of total building square footage is nonresidential, a minimum FAR of 0.75 , (2) Minimum net density of 20 du/acre, (3) Within 0.5 miles of major transit stop or high-quality transit corridor included in the regional transportation plan (No parcel more than 25\% further, and less than $10 \%$ of units or no more than 100 units further than 0.5 miles)," (Sacramento Area Council of Governments). This ensures that new developments will provide walkable access to transportation options and continue to decrease the necessity of auto ownership. Through locating mixed-use and infill developments or higher intensity office uses near transit lines, it is possible to locate residential, retail/commercial, and employment uses near enough to minimize the largest contributor to VMT, which is home-based work trips. This provides an additional quality of life benefit of potentially reducing commute times. Centralizing jobs along transit corridors will help to increase transit ridership and encourage more developers to invest in transit-oriented developments that can take advantage of the incentives provided through TPPs.

While CEQA streamlining is the largest advantage to planning and creating TPPs under SB 375, there is another Senate Bill (SB 628) currently under consideration that would, "Eliminate the requirement of voter approval for the creation of an infrastructure financing district, the issuance of bonds, and the establishment or change of the appropriations limit with respect to a transit 
priority project," (California Legislative Information, 2013). This would allow jurisdictions the opportunity to help finance transportation projects faster and utilize public funds to promote TPPs. The bill also proposes that certain affordable housing and green building requirements be included whenever these strategies are utilized. The California legislature is working hard to reduce barriers to smart transportation and land use projects throughout the state and TPPs are slated to be one of the most effective ways of encouraging a reduction in VMT statewide.

\section{Complete Streets}

To provide future residents and students in the Bellevue Community Plan area with multiple transportation options, it was necessary to design a street and transportation network that support all modes including bicycles, walking, driving, and transit. While SB 375 and TPPs provide a framework for encouraging effective long-range transportation planning, there has been an ever-increasing need to plan for all modes of transportation in street design. Born out of a desire to increase the amount of bicycle infrastructure, America Bikes developed the policy initiative now known as Complete Streets: "A Complete Streets policy ensures that the entire right of way is routinely designed and operated to enable safe access for all uses. Pedestrians, bicyclists, motorists, and transit riders of all ages and abilities must be able to safely move along and across a complete street," (American Planning Association, 2010). Eventually a Complete Streets Task Force was established to work toward changing language in SAFETEA-LU, 
a federal transportation funding mechanism. With backing from the Center for Disease Control and Prevention, American Planning Association, AARP, American Public Transportation Association, Smart Growth America, Institute of Transportation Engineers, and a plethora of bicycle and pedestrian advocacy organizations, the National Complete Streets Coalition was created to provide a platform to advance the inclusion of Complete Streets policies and infrastructure nationwide.

Complete Streets can be implemented in a variety of ways and include local solutions to specific transportation problems or deficiencies. These street design and accessibility principles can be incorporated into law through: "City council resolutions, local ordinances, and state laws; comprehensive plan updates; criteria included within funding measures; internal agency policy directives; and extensive rewrites of manuals, standards, and subdivision ordinances," (American Planning Association, 2010). The implementation method and requirements varies widely due to the level of authority that a jurisdiction may have to incorporate such principles. While states seem to be further ahead of the federal government in adopting Complete Streets laws, a non-profit group, Smart Growth America, is working to pass the Safe Streets Act in 2014 (S. 2004/H.R. 2468). The bill would require, "States and Metropolitan Planning Organizations to adopt inclusive transportation policies for future projects within two years. Federal legislation will ensure consistency and flexibility in the processes and standards that direct road-building at all levels of governance. It will help ensure effective practice and proven safety measures become federal 
guidelines, leading to improved safety on community streets," (Smart Growth America, 2014). This legislation would make roads and roadway design safer for all users and modes of transportation. The intent of the bill is to also help shift federal transportation spending patterns that are main auto- and roadwayoriented toward providing more funding for active and mass transit infrastructure.

While federal policy is necessary to help shift transportation funding patterns, local support of policy change is equally as important. At the state level, the California Department of Transportation (Caltrans) issued Deputy Directive 64 "Complete Streets: Integrating the Transportation System" on October 2, 2008. The directive addressed the importance of advancing state practices: "The California Department of Transportation (Department) provides for the needs of travelers of all ages and abilities in planning, programming, design, construction, operations, and maintenance activities and products on the State Highway System. The Department views all transportation improvement (new and retrofit) as opportunities to improve safety, access, and mobility for all travelers and recognizes bicycle, pedestrian, and transit modes as integral elements of the transportation system," (California Department of Transportation , 2010). The importance of this Implementation Plan is that it set updating the statewide Highway Design Manual and Pavement Design Guidance Manual as the top priority. As part of the directive, multiple other guides have been created to provide context sensitive solutions and main street design for local jurisdictions to use when coordinating with Caltrans or to develop their own guidelines. Also at the state level, the Governor's Office of Planning Research (OPR) is requiring 
county and city jurisdictions to include complete streets policies when updating their General Plan Circulation Elements due to the passing of Assembly Bill 1358 in 2008, known as the California Complete Streets Act. The OPR Update to the General Plan Guidelines: Complete Streets and the Circulation Element details how and what is required to be included new versions of circulation elements. With the General Plan Guidelines update, the state has reinforced that, "Circulation includes all systems that move people, goods, energy, water, sewage, storm drainage, and communications. As a result, the circulation element should contain objectives, policies, and standards for transportation systems, including multimodal transportation networks, airports and ports, military facilities and operations, and utilities, (Governor's Office of Planning and Research, 2010). The guidelines provide an array of policy areas to be considered for inclusion in an update, which can include identifying a mix of transportation options, development of roadway infrastructure in coordination with smart land use patterns, creating an interconnected street grid or pattern, availability of sidewalk and bicycle lanes, landscaping and street trees, and street furniture or pedestrian amenities. The City of Merced Bellevue Community Plan is not a part of a General Plan, but is provided guidance through the City of Merced General Plan that is required to consider the issues presented by OPR. Therefore, the Bellevue Community Plan opted to include these issues for the context of the plan area.

Complete Streets not only encourage people to use active transportation options, they have been proven to create safer environments, healthy 
communities, reduce greenhouse gas emissions, help disadvantaged persons, and revitalize neighborhoods. According to the American Planning Association, a thorough Complete Streets Policy should set a vision for the jurisdictional context, include all users, create a complete network, discuss all roads and paths, include all proposed projects, specify any potential exemptions, address specific design standards, prescribe performance measures, and provide implementation and funding methods (American Planning Association, 2010). To accomplish this task, many jurisdictions develop new cross sections and specific dimensional requirements in order to build complete streets. Re-writing entire design manuals may not be necessary, but updating the designs and particular requirements will help to reduce costs of implementation. For example, a case study presented by the American Planning Association from Sacramento, California highlighted that, " Residents were weary of the high levels of fast moving traffic on residential streets resulting from previous street standards. Developers also found existing standards too rigid. In response, the city engineer drafted new street sections that required sidewalks separated by landscaped strips for all street types and dedicated bike lanes for collector and arterial roads," (American Planning Association, 2010). These common problems can be fixed through updates to existing standards, while working to satisfy concerns of the general public and developers alike. Other principles of Complete Streets, in terms of design, include reducing street widths to slow down traffic and provide pedestrians with shorter crossings and median refuges, managing vehicle 
speeds to ensure multimodal compatibility, and accommodating multiple types of users.

The users of Complete Streets are generally accommodated in one of four zones: pedestrian zone, auto-oriented zone, landscape zone, and bicycle zones. The pedestrian zone is generally an area kept clear from obstructions and allows two or more people to walk shoulder to shoulder freely. Pedestrians can also be accommodated with safer, smaller intersection and mid-block crossings, useractuated crossing signals, and refuges. The auto-oriented zone can include lanes for both automobiles and transit vehicles together or separately, depending on local conditions, and can be managed with lane widths, Transportation Demand Management strategies, Intelligent Transportation Systems, bulb outs or curb extensions to reduce the visual width of the road and reduce speeds, and providing separation from the other modes. Additionally, transit vehicles generally have limited turning capabilities that will need to be considered and transit users need proper shelter and seating near transit stops. The bicycle zone needs to provide either a Class I, II, or III facility along a roadway or network. Depending on the type of street, a shared lane can be used to provide bicyclists and auto user a slower shared-zone. The landscape and street furniture zone is an area, or set of areas, that provides ample places for pedestrian benches or tables, lighting, transit shelters, street trees, store frontages or outdoor eating spaces, and bicycle parking. The goal of Complete Streets standards and implementation should be the result of context specific analysis of the existing facilities and 
infrastructure, combined with community-backed policies and plans to create a balanced network of functional streets.

\section{Town-Gown Phenomena}

With the University of California, Merced campus set to continue to grow over the next few decades the City of Merced wanted to work with the campus early on to establish a cohesive and cooperative atmosphere between the students and the rest of the city to avoid future problems. Many colleges in the United States, and globally, are located in cities or communities where the college plays an integral role in city life. College campuses are increasingly becoming more integrated into the city fabric. This is especially evident in smaller college towns where there is little separation between the college and an economic or cultural city center. According to recent statistics, "More than 50 percent of all degree-granting public and private institutions are in central cities [...] Until recently, most urban colleges and universities remained enclaves of intellectual pursuit, seldom collaborating with surrounding neighborhoods and host cities to address urban problems. Now universities are adopting a perspective that puts more focus on surrounding communities," (Sungu-Eryilmaz \& Greenstein, 2010). The students who attend such universities interact with the local residents in various ways. Town-gown effects are best understood as problems that are derived from a university or students' impact upon a town. However, the impacts can vary widely: "On the positive side, college town typically have a lower median age, higher educational attainment, greater white- 
collar employment, lower overall unemployment, higher family income, and more cosmopolitan and diverse environment. Conversely, college towns typically have more people renting and living in group housing with living habits that can cause entire areas around the college to be eschewed by the community (often called 'student slums') and higher transiency rates that lead to a disconnect between students and townspeople," (Weill, 2008). In many towns, this juxtaposition of effects often leads to tension among long-time residents and students living both on and off campus. Many jurisdictions are attempting to find ones to integrate student life into the urban fabric in order to provide students with a greater stake in the communities surrounding college campuses, instead of separating the two uses.

While universities pose potential problems for cities and residents, they are undeniably a major economic driver in most towns large and small. While most cities do not directly derive a property tax base from the university lands themselves, universities can provide a great amount of sales tax base indirectly: "Among the most significant economic impacts are enhancing the industry and technology base, employing large numbers of people, and generating revenue for local governments through expenditures on salaries, goods, and services," (Sungu-Eryilmaz \& Greenstein, 2010). Universities are also large, permanent landholders who invest in the long-term viability of their campuses and even the surrounding neighborhoods. For this reason, many universities engage with the larger community to create a mutually beneficial partnership. There are many ways to build effective partnerships with local jurisdictions and foster healthy 
cooperation between residents, students, and faculty. Motivated universities Presidents can effectively and positively influence the relationship between students and the town. Such motivation was exemplified by a case study about the President of Gordon College in Barnesville, Georgia when he created an open committee to address the issue: "The first step in creating a cooperative town-gown partnership is to identify and create a committee of interested stakeholders, including college personnel, students, community leaders, and appropriate media," (Weill, 2008). The committee started a dialogue of concerns between opposing parties that could work together to find solutions or compromises. This public relations tactic was able to begin changing how residents viewed the university simply by providing a place to vent concerns about the discord. Town-gown interactions can also see positive mutual benefits when campuses host events that benefit smaller towns or, vice versa, when a college encourages or supports events within the city. This case study served to show how the built environments connecting the university and the city could be altered to allow a greater exchanged of services and flow of people between the two places. The walled-in school acted as a separate entity with little positive interaction with the city; however, when there were interactions it was normally due to negative student behavior in the neighborhoods surrounding the campus.

Similarly, an analysis of the town-gown phenomena between the California Polytechnic State University, San Luis Obispo (Cal Poly) and the City of San Luis Obispo can shed light on how to plan for positive community involvement. The motivation of the partnership between the school and the local 
jurisdiction is to work to fix a poor image of the students living in the neighbors surrounding the school and better prepare students to be good neighbors to local residents while attending the institution. The Cal Poly campus is fairly isolated from the downtown, economic center of San Luis Obispo but the City and the school have strived to provide adequate connections between the two places. However, the immediate neighborhoods surrounding the campus receive a large surplus of undergraduate students who look for off-campus housing. The Cal Poly Master Plan reiterates this goal by stating the following objective: "The Plan is designed to meet the educational needs of the campus, respond to the growing demand for higher education - particularly in scientific and technical fields - and address the role of the University as a member of its larger community," (California Polytechnic State University, San Luis Obispo, 2001). Cal Poly is working to reduce its impact on the surrounding neighborhoods by building more on-campus housing facilities. Though this helps to alleviate some of the stress on the local housing and rental market, the school cannot provide an adequate supply of housing to meet all of its students needs. Cal Poly students, especially graduate level and seniors, often wish to live in a residential or urban setting that the isolated campus cannot provide. For this reason, the last Master Plan update incorporated a Neighborhood Task Force Committee that helped to provide key insights as to what Cal Poly's neighbors deemed necessary to maintain a healthy relationship with the university and the students. Specifically, the Task Force recommended the following key principles to optimistically engage the community: "There shall be a new, ongoing process by 
which representatives of residential neighborhoods, neighborhood associations, and the University regularly discuss issues which may impact University/neighborhood relations. Existing University, City and Public Advisory Committees should be continued [...] The University should work proactively with the City and residential neighborhood associations to review existing "good neighbor" guidelines, develop additional guidelines where necessary, educate students about these guidelines, and enforce and implement these guidelines on an ongoing basis," (Master Plan Neighborhood Task Force, 1999).

Recommendations from the Task Force have since been included in the Master Plan and the Cal Poly Office of University Housing works to educate students on how to be good neighborhoods and provides students with resources to deal with off campus housing issues. Universities and cities must work together to create an environment that works well for the both parties. Positive interactions between the two parties can work to provide residents and students with a better, more socially and environmentally responsible atmosphere.

\section{Financing Infrastructure and Development in California}

The City Council in Merced wanted to create the Bellevue Community Plan to establish a unified vision for the area to be able to secure future funding to finance and build necessary infrastructure. To keep California competitive in a global economy, it is necessary to find ways to ensure that infrastructure and development can keep pace with those economies. This is especially important when attempting to finance such endeavors in an attempt to meet the demand of 
the population. However, there is an ever-pressing need to maintain, develop, and operate public infrastructure in order to encourage private developers to invest in new areas. At the most basic level, infrastructure is necessary for everyday life and business to occur but currently, "There is a gap between the needs of California's economy, the services required for its citizens, and the capacity of its existing infrastructure. Our transportation systems, water systems, courts, fire and police stations, prisons, and other forms of infrastructure were built for 25 million people, but we have a population of 37 million now and are projected to grow to 60 million by 2050," (Crane D. , 2007). With such a large amount of infrastructure needed at very high costs, there is an ever-growing competition between city and county jurisdictions for funding from state and federal sources. This forced local governments to pursue alternative sources or through utilizing creative solutions to finance projects.

In the State of California, there exist many options available for jurisdictions to finance infrastructure projects and aide private or public developments. In terms of greenfield development, a large portion of the overall costs of development is the public infrastructure that supports private development. The prevalent method of financing infrastructure and urban development was established through California Redevelopment Agencies (RDAs) for a long period time: "For more than 60 years, local governments used RDAs for planning and financing projects. To fund themselves, RDAs received a large percentage of the increase in property taxes (known as the tax increment) that was attributable to the rise in land values in redeveloped areas," (Merewitz \& 
Walsh, 2013). The Community Development Law of 1946, which created RDAs, set the stage for local jurisdictions to fix blighted areas identified locally. RDAs allowed local jurisdiction to collect the difference in property taxes, known as tax increment financing, from before redevelopment and after development from those living in the redeveloped area to help pay for projects within the area. The use of tax increment financing pledged money to developers that would front portions of the cost of public infrastructure or other developments. In certain circumstances, funding for such projects was often matched by a variety state and federal programs. The use of RDAs additionally allowed jurisdictions to direct acquire lands and encouraged private development: "RDAs also could exercise the power of eminent domain and brownfield cleanup authority to support projects. Redevelopment financing provided local governments with the funds for developments that otherwise might have been infeasible," (Merewitz \& Walsh, 2013). Unfortunately, Governor Jerry Brown dissolved RDAs in February 2012. The money previously apportioned for the RDAs was needed to help fund educational needs in the state. This controversial political move left many California jurisdictions seeking new types of funding sources or new methods to legally provide development assistance.

The ability of jurisdictions to support development was not expressly taken away through the dissolution of RDAs. Local governments could assist private development through leasing city-owned properties: "Cities may lease property for up to 55 years for commercial development for business purposes or for 55 to 99 years if procedures regarding public hearings and competitive bidding are 
complied with. Cities may also lease property for up to 99 years for stadium, park, recreational, fair, exposition, exhibition, or sport purposes, subject to certain limitations. Charter cities are not constrained by these limitations," (Merewitz \& Walsh, 2013). When RDAs were dissolved, the lands they owned transferred to the jurisdiction in which they were located. For this reason, many cities have the potential to sell or lease lands that they own, including the former RDA properties. Cities also retain the ability to create Infrastructure Financing Districts (IFDs), "To pay for regional scale public works. IFDs can divert property tax increment revenues for 30 years to finance highways, transit, water systems, sewer projects, flood control, child care facilities, libraries, parks, and solid waste facilities," (California State Senate, 2001). However, many jurisdictions have not used IFDs due to the difficulty in forming them. In fact, IFDs must be ballot approved by two-thirds of voters and all local agencies that will contribute their increment property tax revenue to the IFD. With the eradication of RDAs, these financing districts may offer a tax increment financing option that may become more feasible if or when new legislature makes them easier to utilize.

Alternatively, there still exists new ways to fund infrastructure and private development through using both pay as you go methods and financing. According the United States Environmental Protection Agency's report on TOD infrastructure financing, there are six categories to fund and finance projects that include the following: direct fees, debt, credit assistance, equity, value capture, and grants or other philanthropic sources (United States Environmental Protection Agency, 2013). Direct fees charges the users of a given type of 
infrastructure for the use or access to the infrastructure. Depending on the infrastructure or development, the prices charged can vary with the demand for the infrastructure. Cities or counties can also use debt, or borrowing money, to fund projects and the money can come from a variety of sources including private institutions, bond financing, federal or state revolving loan programs, and potentially grant anticipation revenue vehicle bonds (GARVEE) for certain projects that are not attempted to generate revenue. Federal and state agencies may offer ways to support local jurisdictions through credit assistance, which helps to improve the borrower's creditworthiness for large projects and obtain better interest rates. One of the most successful ways to finance projects is through public-private partnership that equity can be returned on, meaning that private investments can recoup costs through infrastructure with the ability to produce significant returns. These types of infrastructure generally include parking facilities, toll roads, utilities, etc. Value capture methods, such tax increment financing mentioned earlier, are widely used in various forms. The most prevalent form of value capture is utilizing developer fees and exactions such as impact fees, system development charges, facility fees, infrastructure reimbursement agreements, and other exactions to cover upfront development costs but not maintenance and operations costs. Another popular option of value capture is often promoted by cities in order to create special districts, such as Community Facilities Districts in California, in which property owners or businesses agree to pay an assessment to fund a project that will specifically benefit them or their local community. The final funding mechanism consists of 
obtaining grants from other public agencies or private philanthropic sources. Large federal grant programs for infrastructure includes the Congestion Mitigation and Air Quality Improvement Program, Transportation Alternatives Program, Urbanized Area Formula Funding Program, Community Development Block Grant Program, and Economic Development Administration Grant Program. While all of these methods provide options for funding infrastructure and encouraging private development or partnerships, most jurisdictions employ multiple forms of these potential monetary sources simultaneously in order to implement or construct their project goals.

\section{Economic Competition of Proximate Plans with Downtowns}

The Bellevue Community Plan allows for a large students and resident population to be near the University of California, Merced campus. However, the City Council feared that this would put another economic driver away from an already established downtown and create multiple economic centers. With the expansion of the highway network and the increasing amount of Americans moving to suburbs in the post World War era, the form of the built environment was shifting. This shift also affected how and where Americans preferred to shop. Downtowns in smaller cities were the cultural and economic centers of many local communities. These smaller downtowns than flourished to support the local community: "Thanks to a shortage in urban housing, government subsidies in highway building and home construction or purchase, and pent-up consumer demand and savings, a new residential landscape began to take shape in 
metropolitan areas, with large numbers of people commuting into cities for work and then back to homes in the suburbs," (Cohen, 1996). When population growth or other expansion drivers cause growth in smaller communities, even those smaller downtowns may not be able to support the entirety of the community. It is then necessary to identify whether or not the City would like to retain the downtown as the only major economic driver within a community or if it is feasible to allow multiple, competing economic centers. Many people who moved to suburbs did not account for where they would be able to access commercial and other services: "New suburbanites who had themselves grown up in urban neighborhoods walking to corner stores and taking public transportation to shop downtown were now contending with changed conditions. Only in the most ambitious suburban tracts built after the war did developers incorporate retail stores into their plans," (Cohen, 1996). This need to provide neighborhoodserving commercial uses was not normally accounted for in giant suburban home development tracts. The sprawl approach to create cheaper houses perpetuated the need for new residents to drive to commercial shopping areas and especially small downtown economic centers. Often times, smaller communities had a singular downtown strip of restaurant and commercial retail uses that supplied most of the resources for the entire community.

Traditionally, when new industrial operations or other major employment attractors relocate outside of close proximity to these smaller downtowns, there is often of shift of where new residential communities will be located. In order to provide these new communities with accessible services, the New Urbanism 
concept of villages began to form. The village concept creates a separate area where one can, "Live without a car, since the compact layout makes it easy to get around on foot, bicycle, rollerblades, or by trains \& light rail. These compact villages are a drastic contrast to our sprawling suburbs where everything is spread out, separated by uses, and connected only by roads and highways," (NewUrbanism.org). While this supports the new employment attractor, it is possible that it will compete with, or detract from, the economic vitality of an existing local downtown. With more people obtaining jobs in office or serving industries, it is possible to locate homes nearer to employment centers: "People are willing to live near the office now, whereas they were reluctant to live near factories that were dirty, noisy, and visually unattractive. Traditionally the poor and the working class have lived near factory districts. Across the nation office buildings and high-tech business parks have appeared in middle-class and even exclusive suburbs," (Leinberger \& Lockwood, 1986). If this is truly believed to be the case, then small towns need to employ methods to ensure that any new proximate long or short range planning documents do not entirely shift all of the employment or retail away from a downtown.

Protecting downtowns of smaller communities while promoting new areas of development in non-metropolitan areas is necessary to prevent a "ghost town" within the downtown. If businesses and retail shops move to new proximate plan areas, than the downtown environment will decay. The larger the downtown or population base, the better a jurisdiction can support new urban villages with employment characteristics. For example, a case study of the City of San Jose, 
California provided evidence that the use of long-range planning techniques can work preserve the downtown as the major employment center while establishing urban villages through deciding that, "Each of the growth areas have a planned capacity for jobs and housing," (City of San Jose , 2013). The case study also necessitated the use of transit connections between urban villages and downtown economic centers. Thus, these urban villages were to function as transit-oriented or transit-supportive areas that would allow people to live or work within an urban village but retain easy connections with the major downtown employment and retail area. The City of San Jose found that by providing residents with the opportunity to live outside of the main downtown in pedestrianoriented, transit-connected areas with local neighborhood serving uses, that a portion of residents would still need to travel to the downtown due to the large employment attraction of the downtown.

While these techniques are generally applied to large metropolitan downtowns and the supporting urban villages, it is essential to recognize that these techniques must also be adapted carefully for smaller city downtowns. Problems with small downtowns that need to be accounted for when creating proximate plans includes: attracting new development, encouraging a mix of day and nighttime uses, competition from discount stores or malls, vacant retail or office space, and traffic and parking supply (Robertson, 1999). It is possible that these problems, which have been cited by multiple jurisdictions, can be reduced or eliminated through strategic revitalization plans. The impact of new planning areas in cities, such as Merced, need to ensure that they detract from important 
areas of the revitalization efforts. This can be accomplished through limiting uses and square footage, creating an alternative sense of place, providing housing near transit that easily connects with a downtown, and providing space for alternative activity generators that do not fit in a downtown environment.

\section{Interconnected Land Use and Transportation Planning}

The City of Merced wanted a Plan that would provide a balanced land use and transportation network. To support a reduction in greenhouse gases and reduce the amount of vehicle miles traveled, as encouraged by SB 375 and transportation priority projects discussed earlier, the entire industry-wide approach to land use and transportation planning needs to be adjusted. For much of the history of the planning profession, land use and transportation have not directly been planned in conjunction with each other. The result is that one or the other forms as an afterthought that tries to adapt to the context of the other. This has perpetuated not only suburban sprawl, but also produced inefficient transportation systems, including both roadways and transit, that cannot adequately realize their full economic potential. Thus, it is necessary to understand where the problem originated and to identify new techniques or methods that should be included while planning for greenfield areas.

Throughout the Industrial Era, the urban form of cities has developed in a way to maximize economic prosperity of businesses by allowing competition for land acquisitions near transportation and trade areas such as ports or rail yards. Land uses somewhat segregated themselves naturally before zoning with this 
competition because the price of land falls as one travels further from the major port or trade area: "Locations closer to the city center have the advantage that commuting costs less. People who live farther from the city center have to get something to compensate for their long commute," (Moore, Thorsnes, \& Appleyard, 2007). This implies that people highly value accessible transportation connections when considering where to develop different types of land uses. High priced land values drive a higher intensity development, and this directly correlates to locations along transit lines. Additionally, businesses also economized on agglomerating near each other to reduce the cost of transporting goods and services. This agglomeration also increased urban employment growth and encouraged jurisdictions to provide better transportation access to these areas. This can be exemplified by analyzing the general behavior of manufacturers and retailers that: "Manufacturers are willing to trade low land prices for proximity to other manufacturers and to businesses that provide inputs to the manufacturing firms. Retailers cluster to take advantage of the traffic that each of them generates. Clustering reduces the non-land cost of doing business," (Moore, Thorsnes, \& Appleyard, 2007). This clustering produces multiple sub-centers based on land uses to maximize efficiency and visibility between those uses. The sub-centers allow businesses the opportunity to capitalize on a trade-off between agglomeration and travel costs for nondowntown locations. However, when moving outside of a downtown, other transportation problems arise. 
In order to accommodate a shift of people and businesses away from a downtown, most jurisdictions constructed a system of highways to connect outer areas of residential and rural areas with business and trade centers. These high capacity highways unintentionally shifted the pattern of development because, "extensive highway improvements yielded big reductions in the per-mile time costs of travel by car and truck. Time savings encouraged more travel and more dispersed, low density, polycentric urban land development," (Moore, Thorsnes, \& Appleyard, 2007). The highway provided a means for more people to travel faster between lower density residential areas to downtowns or sub-centers. While this provided many people with the opportunity to escape the negative attributes of dense city life to find cheaper housing, it increased the amount of vehicle miles traveled immensely. As more and more people left cities to find better schools and safer streets, they but did not take into account the amount of time and cost for commuting for themselves or for the transportation system as a whole. Eventually, congestion reappears and spillover externalities are generated that people do not adequately assess. While fuel taxes generate enough funds to cover the general construction of roads, a study was conducted to create a model that would, "Estimate the gasoline tax needed to cover the social costs of infrastructure, congestion, auto air pollution (global and local), and safety [...] Using best estimates of various costs, such as time costs, they estimated the optimal tax at about $\$ 1$ per gallon in the U.S., or about two-and-half times current state and federal gas taxes combined," (Moore, Thorsnes, \& Appleyard, 2007). Therefore, the system of providing the roadway infrastructure through gas 
taxation alone to business and residential areas is not adequately paying for itself. Additionally, building more roadways and adding capacity will only perpetuate the initial problem of providing better access to more areas and repeat the cycle of urban sprawl.

In an attempt to correct the problems created through highway expansions and accommodate people who now live in these outlying communities, jurisdictions can encourage connected, accessible, and cheaper transportation options that better account for their total costs. An initial way to reduce highway dependency is to expand the capacity of alternatives modes of travel. As highlighted in the Complete Streets section, traffic congestion can be reduced through accommodating modes such walking or bicycling. The focus needs to remain on connectivity and accessibility. It is also possible to reduce congestion in the long-term by taking into account not only transportation regulations, but by incorporation of new land use regulations. In order to encourage denser, transitaccessible residential development it is possible to limit where development can occur: "An explicit urban growth boundary (UBG), or simply strong agricultural or natural resource zoning outside of urban areas, prohibits or discourages exurban development," (Moore, Thorsnes, \& Appleyard, 2007). By either creating an urban growth line or creating a buffer through open space or agriculture, it is possible to direct where development can occur. Regulations on floor space or dwelling units also provide ways that zoning codes and long-range plans can protect areas near transit for higher density developments. By encouraging these 
transit-oriented developments guidelines, new residents would have greater access to transit and be more likely to reduce their trips by car.

While it is important to consider the external effects of what driving an automobile does, it is also essential to analyze the effect that parking those automobiles has on land use and transportation planning. It is estimated that, "There are at least four parking spaces per car in the U.S. [...] the midpoint of high and low estimates of the total annualized cost of off-street parking is about 6 percent (+/- 3 percent) of the total cost of driving, almost double the cost of fuel," (Moore, Thorsnes, \& Appleyard, 2007). However, unlike how fuel taxes pay for infrastructure, there is no tax on parking and the driver does not normally directly pay for the cost of parking. While many urban dwellers pay for parking, the cost of parking in suburban areas is indirectly passed on to the driver by a developer or a retailer. Jurisdictions can reduce the over abundance of parking lots that were created by standards that tried to meet peak parking demand by reducing these standards and by encouraging publicly owned parking which can be charged at market rates. Parking charges also encourages residents of many localities to drive less, therefore encouraging a reduction in vehicle miles traveled or increasing a shift to other modes.

To create a greenfield development based around a transportation system, the urban form has to be established that will complement the system. The main priorities for development should be focused around the following: "(1) Creating boundaries: zoning and urban growth containment, (2) creating centers: transit-oriented development (TOD), (3) Creating corridors: retrofitting 
major urban arterials, (4) pricing public infrastructure and services: concurrency and impact fees, and (5) playing the market: incentives and public investment," (Moore, Thorsnes, \& Appleyard, 2007). These areas of focus can be accomplished through urban design guidelines and long-range development plans in addition to updates to streetscape plans, which would dictate that form of the community. By establishing a connected, grid pattern of streets that provide easily walkable distances to transit, buildings must be encouraged that are designed to be at the appropriate pedestrian scale and not encroach on the public realm. That being said, residential densities have a significant influence on transit use and mixing residential land uses with other uses only further increases the ridership. High quality transit systems with stations in markets that support development can further reduce vehicles miles traveled and provide new opportunities for affordable housing. 


\section{PROCESS}

To develop the City of Merced Bellevue Community Plan the methodology and process employed were based upon how the Merced City Council

envisioned the final document. This section highlights the overall process to create the document and describes the necessary steps taken to construct a plan that all parties could agree upon and that the City Council could adopt.

\section{Obtaining the Project}

On November 1, 2011 the City of Merced (City) released a Request for Proposal (RFP) for consultants to send their proposals to the City for the Bellevue Corridor Community Plan. The City Council's intent was to create a community plan for the three square miles of agricultural area located directly next to the newly formed University of California, Merced campus. The RFP stated that the goal of the plan was to compliment the development of the campus by providing sustainable circulation and land use design concepts into a comprehensive planning document, based on grounded market rates. The original intent was that the plan was to be created in conjunction with City Staff. Funding for the project was made possible by a grant from the State of California Strategic Growth Council (SGC) in the amount of $\$ 143,264$. The City Council wanted the project to be completed by August 2014. This would provide an ample amount of time for the chosen consultant team to conduct the necessary 
amount of background research, conduct public outreach, and draft the Administrative and Public Review versions of the plans.

In an effort to obtain the project work in Merced, Lisa Wise Consulting, Inc. (LWC) submitted a complete proposal package to the City on December 2, 2011. The proposal included a team of consultants that were to be lead and managed by LWC including: Sargent Town Planning, Tony Perez Associates, Nelson Nygaard, and Economic \& Planning Systems. As the Project Lead, LWC has significant experience in managing and completing many different long-range planning documents including Specific Plans, Master Plans, and Corridor Revitalization Plans. Sargent Town Planning was to create urban design solutions for the project that would focus on forming sustainable pedestrian and transit-oriented neighborhoods. Tony Perez Associates, now a part of Opticos Design Inc., was to take charge of creating a form-based code for the plan area. Nelson/Nygaard was to construct mobility and circulation plans that would accommodate the proposed land uses and intensities in the Bellevue Corridor Community Plan and satisfy the City of Merced Vision 2020 General Plan. Economic \& Planning Systems was to document the current economic conditions surrounding possible development in the Plan area and analyze possible future economic drivers for the Plan area. Together, the Consultant Team believed that they could accomplish all of the needs of the project on time and on budget. The proposal package included an overview of the consultant team including firm descriptions and team bios, a project understanding and scope of work, an estimated timeline and budget, key staff resumes, and firm qualifications. 
Upon being awarded the project, the consultant team held a kickoff meeting in Merced. There, they worked with the City to formalize the contract and agree upon a revised project budget and timeline. Once the project agreement was signed, it was time for the consultant team to start formalizing a public outreach plan and collecting background data.

\section{Public Outreach}

A Project Management Plan was created to guide the accumulation of input from both the general public and from employees of the City of Merced and to guide the project process altogether. It was necessary to establish the different contexts or forums in which each stakeholder group was to participate. By encouraging the general public to participate, it allowed the residents of Merced to help define how they wished to see their city grow and address their key concerns during the creation of the plan. The public participation process also established a Citizen's Advisory Committee (CAC) and a Technical Advisory Committee (TAZ). The CAC consisted of 21 members including landowners, developers, and other interested parties. The TAC was assembled using various staff from different departments within the City of Merced. This group was responsible for ensuring that the plan met the specific requirements or standards each department was in charge of overseeing.

Multiple public outreach meetings were held and underrepresented groups were contacted to encourage their participation during the creation of the plan. Three separate design workshops were held to incorporate as much public input 
as possible in how the land uses and form should be planned within the plan area. A separate workshop was also held to allow people to critique the plan. Throughout the process the committees and City staff were consistently updated about changes to the plan and about how the development of the plan was progressing.

Effective community engagement throughout the progression of the plan development created a sense of trust between the consultant team, the City, and the committees. By making a good amount of the outreach materials myself, I was able to help foster this relationship and help to clearly communicate what the plan would achieve. It was prudent for me to create presentations, handouts, information packets, and attend meetings to be able to help write and layout the design of the plan later on. Additionally, by being encouraged to directly communicate with the client, I was able to edit materials to meet their satisfaction.

\section{Plan Development}

I was given the opportunity to work with the Principal Planner from the City of Merced and the Consultant Team to lay out the pattern of development and infrastructure within the Plan area. As mentioned previously, when I was brought on at Lisa Wise Consulting, Inc. the project had already been started. However, I was given the freedom to take the input from previous public outreach meetings and help begin to form a clear image of how the land uses and transportation systems would take shape. The document itself was co-written between the City 
of Merced Principal Planner, Lisa Wise, and myself. In order to maintain consistency with the Merced Vision 2030 General Plan, the land uses were developed and placed to maximize access to the planned transportation systems.

Over the course of eight months, the document was written chapter by chapter in cooperation with the Principal Planner. The Principal Planner would outline and draft a portion of the initial text in order to maintain consistency with Merced Vision 2030 General Plan. I was then tasked with supplementing the remainder of the text and laying out the document design. Lisa Wise would then review the initial draft of each version and recommend necessary changes and additions. Upon making those changes, I would then contact any necessary members of the Consultant Team to help further review or revise each chapter before a final version was sent back to the Principal Planner for his review. The graphics for the Plan were mainly constructed or supplied in conjunction with Sargent Town Planning. Once the text was near completion and the graphics were agreed upon or complete, I would begin to design the final document.

To put the final document together, I spent a total of about two weeks time arranging the necessary text, images, maps, graphics, and call outs in a cohesive fashion. This was accomplished using Adobe InDesign because it allowed for a greater degree of flexibility and control in laying out the document. Adobe InDesign also helped to easily label graphics and create in-text reference links. The program also automatically generated a complete Table of Contents, List of Figures, and List of Tables for the document. The layout was designed 
with the intent that the document would be printable and not solely available online. For this reason, the page structure was setup to be oriented toward the binding.

The complete Administrative Review Draft was submitted to the City on December 11, 2013. The document was then circulated to City Staff and presented to the advisory committees. Once the document was reviewed and recommendations were submitted, the Consultant Team reviewed the comments about the Plan. It was then my job to update the document to reflect agreed upon changes to the document and insert updated graphics. The Public Review Draft was then sent to the City for release to the general public on March 28, 2014. The Public Review Draft included all of the necessary appendices to support the proposed land use densities, retail square footage, and corresponding automobile trips generated from each land use. The final version of the document will be created after the public comment period ends and will address any new issues presented. The Merced City Council should then adopt the Final Draft of the document sometime in the summer of 2014. 


\section{PROJECT DESCRIPTION}

The City of Merced Bellevue Community Plan (BCP) was developed to be consistent with the Merced Vision 2030 General Plan, as described in the Process chapter of this document. The BCP strives to reflect the policies in the General Plan while creating a more detailed illustrative plan with descriptive guiding standards and implementation strategies. One of the most important guiding principles in producing the BCP was to provide significant employment generating uses that would benefit from being in close proximity to the UC Merced campus that would act an innovation hub. The BCP establishes a highlevel planning framework that strikes a balance between certainty and flexibility by anchoring key land uses while allowing their size to adapt to changing market conditions in response to economic growth and the expansion of UC Merced. As a Community Plan, the BCP fuses input from landowners, the general public, City officials, and specific direction from the General Plan to establish a unified vision for the Plan area. While the BCP provides a broad range of uses and densities that could occur throughout the plan area, it emphasizes the foundational building blocks of street connectivity, functional mobility choices, active and passive recreation open space corridors and bikeways, gateway street designs, and attractive business park settings to create a sense of place and investment certainty. This chapter provides an overview of the guiding principles that support the creation of the plan, a summary of how the plan is organized, and an analysis of key findings from each chapter of the plan. Specific images and supporting 
materials can be found in the Public Review Draft of the Bellevue Community Plan in the Appendix.

\section{Guiding Principles}

The City of Merced's General Plan details necessary principles that Community Plans must take into account during the creation of a plan. The following Principles from the Merced Vision 2030 General Plan (Section 3.7.2) play a vital role in every chapter of the BCP:

- Community Plans which include or are adjacent to established neighborhoods will address the needs of these neighborhoods and potential adverse impacts resulting from plan implementation.

- Public participation by area residents and property owners in the planning process will be emphasized.

- Community Plan areas need connectivity with existing and planned urban areas.

- Community Plans will include all elements determined necessary to ensure consistency with the General Plan. These elements may include, but not be limited to, Land Use, Circulation, Open Space, and infrastructure phasing. Community Plans will include a land use and infrastructure phasing plan.

- The "Urban Villages" concept should be incorporated into the planning of these areas as much as feasible. 
- The Community Planning process should be focused on the planning issues or concerns which need to be resolved for that planning area and, to this degree, provide data, information, or policy clarification necessary to carry out the goals of the Merced Vision 2030 General Plan.

Using this direction as a baseline for the creation of the plan, the BCP strives to focus on providing a vision and framework for implementing sustainable transportation, infrastructure, and open spaces. The BCP also builds on the direction of the General Plan by providing the right mix of land uses and intensities that can adapt to the needs developers and future residents that will build and live next to the University of California, Merced.

\section{Plan Organization}

The BCP consists of eight chapters that provide the foundational concepts to implement future development in the Plan Area. In addition to the 169 page Plan, there are 14 supporting Technical Appendices and Environmental Review documents. The eight chapters of the BCP include the following:

- Chapter 1: Introduction

- Chapter 2: Vision and Urban Design

- Chapter 3: Mobility

- Chapter 4: Open Space, Conservation, and Recreation

- Chapter 5: Community Character

- Chapter 6: Urban Expansion

- Chapter 7: Public Facilities 
- Chapter 8: Plan Maintenance

The Plan chapters each contain a consistent structure. The unified structure makes the document more easily readable and implementable. The sections in each chapter are an introduction to the concepts presented in the chapter, a General Plan consistency analysis, the setting in which the topic of the chapter functions, core elements and concepts employed in creating standards, the plan for each topic, and supporting goals and policies. Each chapter includes either illustrative mockups of proposed concepts and plans or supportive imagery from other locations that best exemplify the intent of the section. By using specific imagery the plan can visually detail what the final implementation should be similar to. The Plan was organized and developed to address the overlap of land use and transportation issues and create a pattern of development that maximizes land use intensities while providing adequate, sustainable multi-modal transportation infrastructure.

\section{Plan Analysis}

The "Introduction" chapter of the BCP describes the purpose of the community plan and describes how the Plan area falls within the purview of the City's planning powers. The Plan area is currently outside the city limits, but due to the development that will occur near the University of California, Merced, the City and the County of Merced have worked together to plan for possible annexation by the City. For this reason, the City of Merced has included it within the City's planned growth area in both the Specific Urban Development Plan 
(SUDP) and the Sphere of Influence (SOI). The Plan area is located northeast of the City and covers an area of approximately 2.4 square miles. The Plan area is located 3.5 miles from downtown Merced and is located directly adjacent to the University of California, Merced (UC Merced). The existing Bellevue Road connecting the Plan area with UC Merced, is currently a rural road and is what the Plan area is named after. Most of the Plan area consists of agriculture and grasslands with some existing rural residential housing. In addition to establishing the setting, the introduction informs the reader of the Plan about key features and issues that will be presented throughout the Plan and describes applicable direction from the Merced Vision 2030 General Plan. Through recognizing many of the over-arching assumptions, constraints, and opportunities for the $\mathrm{BCP}$, the introduction establishes a context in which to prepare a guiding urban design vision.

The "Vision and Urban Design" chapter describes how regional features such as planned Expressways, economic conditions, and the California High Speed Rail influence the necessity of high-quality, connected, transit-oriented development. For this reason, the concept of urban villages was used to establish areas that could be transportation priority projects (TPPs), discussed previously in this document. TPPs could then provide adequate densities to support well connected transportation systems and provide a proper pedestrianscale built environment and form. Through illustrating an interconnected block structure, the Plan shows how a network of "complete streets" forms the underlying framework of the BCP. The intent is to provide residents with a 
relatively quiet, low-speed driving environment that is safe and comfortable for pedestrians and bicyclists by organizing the area into walkable blocks, which are variable in size and shape to accommodate a wide range of land uses and development types. Automobile capacity for the Plan area is maintained by increasing capacity of connector roads and is discussed in the "Mobility" chapter. To highlight the new "college town" atmosphere that the area will undoubtedly create, the Plan provides urban design features along the major arterial roads that create a gateway to the college, giving the area a unique identity with the region. The gateway feature is a design overlay and the Plan provides illustrations of how this can be accomplished with variable land uses. The main arterials are also planned to provide research and development office space to take advantage of the close proximity to UC Merced and establish the area as an innovation hub to attract new business to Merced that would like to be located near the college. The creation of collaborative work environments interlaced with walkable, transit-oriented places to meet, network, and provide housing for employees is essential to supporting entrepreneurial businesses who value faceto-face interaction. The overall urban design approach of the Plan is meant to foster a collaborative environment between residents, businesses, and the college.

The "Mobility" chapter builds upon the urban design characteristics and provides a mobility plan that integrates a multi-modal system comprised of automobiles, a public transit system, bicycles, and pedestrians. Based on the concept of Complete Streets, the plan strives to provide supportive features that 
are foundational to the success of each mode of transportation and encourage the use of alternative modes of transportation other than the automobile. To align legislation such as the State of California Senate Bill 375 (SB 375) to reduce greenhouse gas emissions, the BCP includes innovative ways to reduce vehicle miles traveled (VMT) and to shift from short trips in the automobile to alternative modes. Through utilizing the connected block structure established in the "Vision and Urban Design" chapter, the "Mobility" chapter disperses all modes of transportation over the Plan area to reduce congestion. To promote transit use, the $\mathrm{BCP}$ incorporates a high quality transit corridor that is separate from the major automobile corridor to allow for higher density near transit stations. The transit corridor is designed to be able to provide a dedicated right-of-way for future Bus Rapid Transit (BRT) or light rail facilities, depending on the population size and available funding. This is essential to maintain that pedestrians would not have to traverse large automobile rights-of-way to reach transit infrastructure. The majority of housing provided in the Plan area is planned within five-minute walks from transit stations to meet TPP standards. The Plan provides illustrative cross-sections to depict how the rights-of-way should be designed and operated to include the proper modes in the proper places. A system of arterial, collector, and local streets incorporates bicycle, pedestrian, and parking facilities. A table featuring the specific design standards and dimensions for each level of street provides direct guidance to construct the mobility network. Low impact development features and traffic calming solutions are also used create a street environment that eco-friendly and welcoming to all users and modes. 
The "Open Space, Conservation, and Recreation" chapter takes an integrated approach through managing and planning for open space resources. The BCP aims to create an open space that is connected to reduce the impact of development on wildlife and provide natural areas for residents to recreate. The open space plan helps to ensure that as development occurs throughout the BCP area, the inclusion and placement of open space will not occur haphazardly. Within the BCP open space lands are also designated to protect scenic corridors and protect biological resources and sensitive species. In the Central Valley, water resources must be protected and conserved. The open space place helps to encourage drought tolerant plants in design. To provide an adequate amount of open space for future residents and utilizes the City of Merced's historical standard of providing five acres of City park land for every thousand residents. This standard does not include school grounds, church grounds, or Lake Yosemite directly adjacent to UC Merced and the Plan area. The standard is also separate from any open space lands that were required to be set aside to conserve sensitive habitat. To meet this standard, five park types were included in the plan: Regional Parks, Community Parks, Neighborhood Parks, Mini-Parks and Urban Plazas, and Linear Parks and Corridors. Used together, these park types are mapped so that future development can be designed in harmony with open space features, and not break or develop disconnected parks or detention basins that would then become the baseline standard for the area.

The "Community Character" chapter lays the groundwork for how land uses are organized to complement the desired urban design features and 
adequately support the mobility network. The chapter establishes land uses as Place Types to represent a desired form over a specific use due to mixed-use nature of most areas within Plan boundaries. The illustrative place type plan was then designed to be able to adapt to future market conditions in response to economic growth or expansion of UC Merced. The ranges provided within the Plan remain consistent with the Merced Vision 2030 General Plan. The BCP also protects the character of existing rural residential neighborhoods within the Plan area. The illustrative plan designates large stretches of Bellevue Road within the project area as "Mixed-Use" and a "Business Park" to support a dynamic assortment of future employment generating uses, housing options and commercial and office uses. Surrounding Bellevue Road are areas of Low Density Residential (LD) and Rural Residential (RR). Closer to the UC Merced campus, land uses transition from Low to Medium Density Residential (LMD), High to Medium Density Residential (HMD), and then to High Density Residential (HD). The southern portion of the project area contains an established Rural Residential (RR) center. The BCP works to create compatible development directly adjacent to the UC Merced campus and would provide housing and entertainment resources to support students and residents. The BCP ensures that development within the BCP does not compete with existing development and community focal points, including Downtown Merced and other regional retail areas by limiting the total retail square footage allowed in the Plan area and by directing where the majority of retail opportunities should be located. In addition to the Community Character Place Type Plan, the BCP further depicts how 
multiple variations of the place types can function within the connected block structure proposed earlier in the plan and includes a "Flex-Mixed Use" place type boundary that allows land uses to adapt to market conditions. This diagrams the adaptability of the BCP place types and can allow transitions between place types. To ensure that a future development code will include the proper standards, examples of place types and form were included to clearly depict the intent of the chapter and a neighborhood master planning standard was included. Ultimately, the place types should be able to provide a wide range of options for future development and allow future residents multiple types of housing, shopping, and entertainment options.

The last three chapters describe how the BCP will be implemented, adopted, facilitated, and updated. The "Urban Expansion" chapter provides guidance to adapt to several growth scenarios and details necessary infrastructure financing components that will help to bring the plan to life and encourage investment in the area. The "Public Services and Facilities" chapter addresses what types of services and infrastructure the City of Merced will need to be prepared to work with developers to ensure the safety, health, and educational needs of future residents. The "Plan Maintenance" chapter designates when and how the BCP should be updated and provides a platform to monitor the implementation of the plan. 


\section{CONCLUSION}

The City of Merced Bellevue Community Plan was still under its final round of public review when this report was written. It is set to be adopted by the Merced City Council in the summer of 2014. Upon the adoption of the plan, existing long-range planning documents should be updated to reflect the information provided in the BCP. The intent of the BCP is to create a common vision and approach to guide inevitable development needed to support students, faculty, businesses, and future residents. With the adoption of the plan, its unified vision should help to provide certainty to investors and developers. While there is no way to guarantee funding and financing for all of the necessary infrastructure that will be needed to support the full build out proposed in the plan, many options are presented to encourage active cooperation between developers, UC Merced, the City of Merced, and public utilities providers. Hopefully, the BCP will allow the City of Merced to grow its population base and connection with UC Merced over the course of its implementation.

This plan has provided a unique opportunity to participate in active community engagement and be given the freedom to write large amounts of a Plan that will be adopted and implemented. As part of a Consultant Team, the experience has provided me with a better skill set to work collaboratively in the planning profession. Planning work is rarely done alone and, through working on this plan, the importance of working on a team has become ever clearer. This project provided an opportunity to make a high-quality plan that supports my 
educational foundation while attending California Polytechnic State University, San Luis Obispo. 


\section{BIBLIOGRAPHY}

American Planning Association. (2010). Complete streets: best policy and implementation practices. (B. McCann, \& S. Rynne, Eds.) American Planning Association.

California Department of Transportation . (2010). Complete Streets Implementation Action Plan. California Department of Transportation , Sacramento.

California Environmental Protection Agency . (2014, 4 1). 1. Retrieved 4 9, 2014 , from Air Resources Board: http://www.arb.ca.gov/cc/sb375/sb375.htm California Legislative Information. (2013). SB-628 Infrastructure financing: transit priority projects. California State Senate. Retrieved from California Legislative Information .

California Polytechnic State University, San Luis Obispo. (2001). Cal Poly Master Plan and EIR. San Luis Obispo: California State University Board of Trustees.

California State Senate. (2001, November 30). Infrastructure Finance Districts. Retrieved May 5, 2014, from California State Senate: http://senweb03.senate.ca.gov/committee/standing/GOVERNANCE/IFDIN FORMATION.HTM

City of San Jose . (2013). Urban Village Implementation . City Council Study Session. Sane Jose: City of San Jose. 
Cohen, L. (1996, October). From Town Center to Shopping Center: The Reconfiguration of Community Marketplaces in Postwar America . The American Historical Review, 101(4), 1050-1081.

Crane, D. (2007, December 31). California's Infrastructure Deficit. Public Works Management \& Policy, 12(3).

Crane, R., \& Boarnet, M. (1998, February 28). Public Finance and TransitOriented Planning: New Evidence from Southern California. Journal of Planning Education and Research, 17(3), 206-219.

Filion, P., Hoernig, H., Bunting, T., \& Sands, G. (2003, November 30). The Successful Few - Healthy Downtowns of Small Metropolitan Regions. Journal of the American Planning Association, 70(2), 328-343.

Governor's Office of Planning and Research. (2010). Update to the General Plan: Complete Streets and the Circulation Element. State of California, Governor's Office of Planning and Research. Sacramento: State Clearinghouse.

Institute for Local Government. (2014, 1 1). The Basics of SB 375. Retrieved 49 , 2014, from Institute for Local Government: http://www.cailg.org/post/basics-sb-375

Leinberger, C., \& Lockwood, C. (1986, October). How Business is Reshaping America. The Atlantic Monthly, 258(4).

Master Plan Neighborhood Task Force. (1999, June 1). Administration and Finance. Retrieved May 2, 2014, from California Polytechnic State University, San Luis Obispo: https://afd.calpoly.edu 
Merced, C. o. (2012). Merced Vision 2030 General Plan. Merced.

Merewitz, S., \& Walsh, E. J. (2013, February). Redevelopment After RDAs: The Demise of California's Redevelopment Agencies Obliges Local Governments and Developers to Explore New Financing Methods. Los Angeles Lawyer, 35(11), 24-28.

Moore, T., Thorsnes, P., \& Appleyard, B. (2007). The Transportation/Land Use Connection (2007 Edition ed.). Chicago, Illinois : American Planning Association .

NewUrbanism.org. (n.d.). Urban Villages. Retrieved May 9, 2014, from New Urbanism: http://www.urbanvillages.com/urbanvillages.html

One Bay Area. (n.d.). SB 375 Fact Sheet. Retrieved 4 9, 2014, from One Bay Area: http://www.onebayarea.org/pdf/SB375_OneBayAreaFact_Sheet2.pdf

Robertson, K. A. (1999). Can small-city downtowns remain viable?: A national study of development issues and strategies. Journal of the American Planning Association, 65(3), 270-283.

Sacramento Area Council of Governments. (n.d.). Blueprint for Sustainable Communities. Retrieved 4 8, 2014, from MTP/SCS: http://www.sacog.org/2035/implementation/

Smart Growth America. (2014). Support the Safe Streets Act. National Complete Streets Coalition . Washington, D.C.: Smart Growth America.

Sungu-Eryilmaz, Y., \& Greenstein, R. (2010). Town-Gown Cooperation in Community Development. Communities \& Banking, 21(3). 
United States Environmental Protection Agency. (2013). Infrastructure Financing Options for Transit-Oriented Development. Office of Sustainable Communities, Smart Growth Program. Washington, DC: US EPA. Weill, L. V. (2008, November 30). The President's Role in Cultivating Positive Town-Gown Relations. Planning for Higher Education, 37(4), 37-42. 
Appendix I. Bellevue Community Plan Public Review Draft 

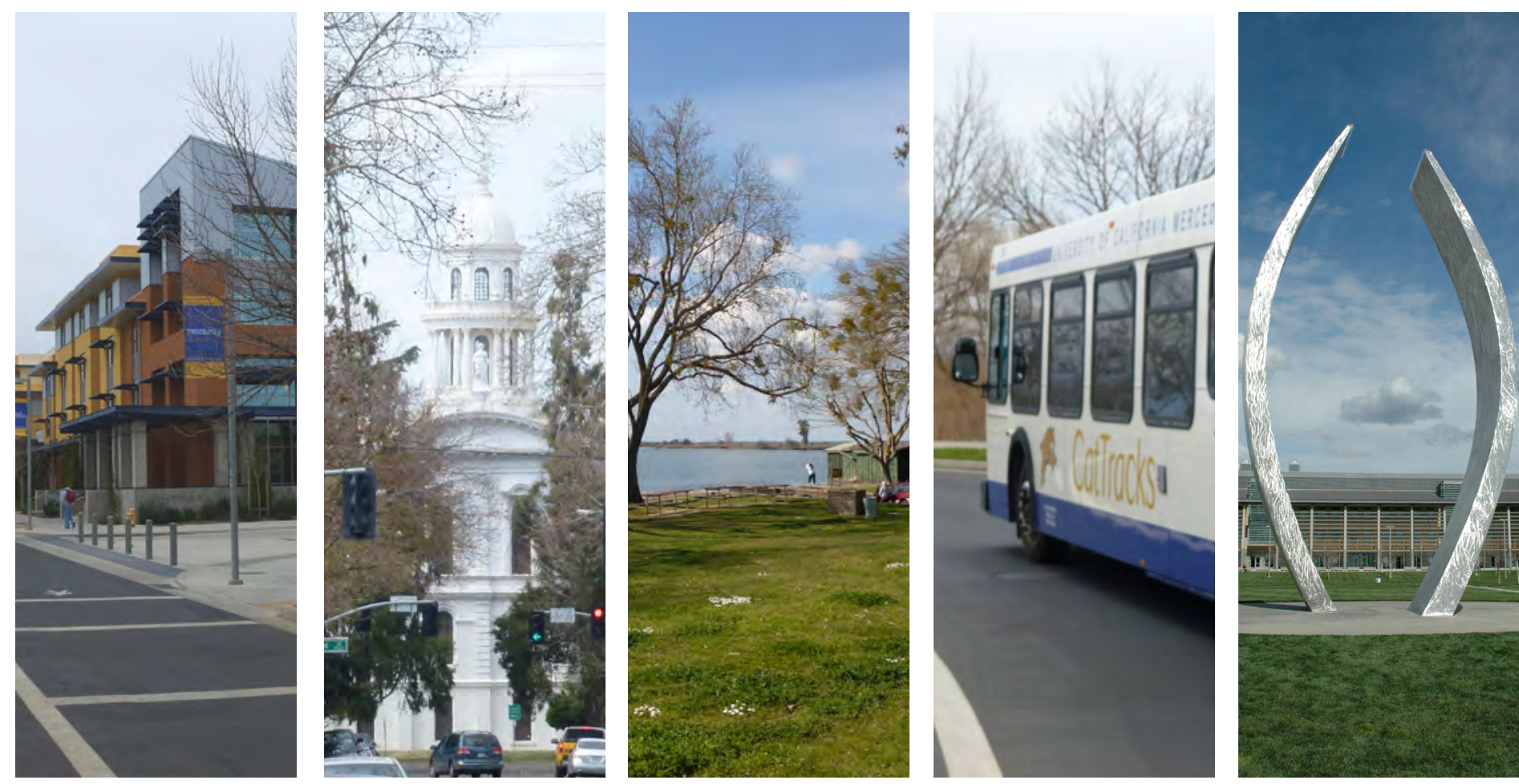

\section{CITY OF MERCED}

Bellevue Community Plan

Public Review Draft

MARCH 2014

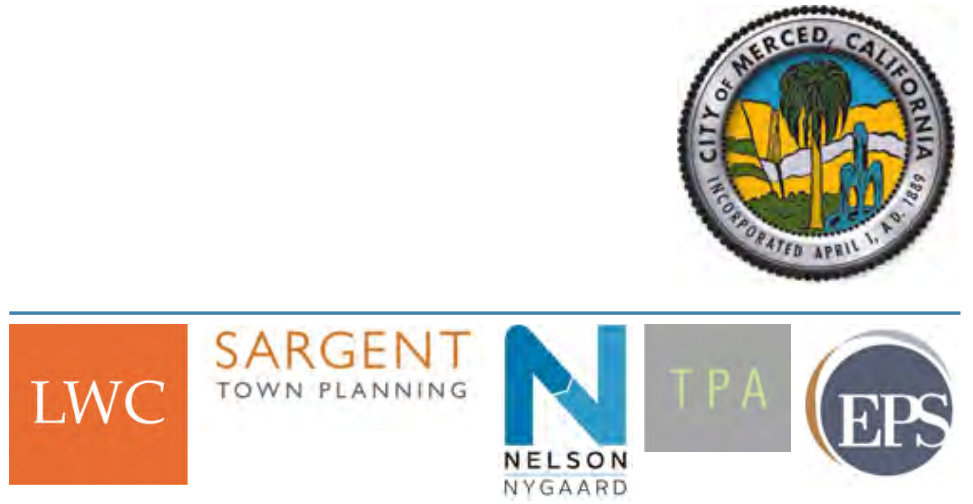




\section{CITY OF MERCED | Bellevue Community Plan}

Lead Consultant

Lisa Wise Consulting, Inc.

Lisa Wise, President

983 Osos Street

San Luis Obispo, CA 93401

805.595.1345

\section{Sub Consultants}

Sargent Town Planning

David Sargent, Principal

448 South Hill Street, Suite 418

Los Angles, CA 90013

213.599 .7680

Nelson $\backslash$ Nygaard Consulting, Assoc.

Colin Burgett, Principal

116 New Montgomery Street, Suite 500

San Francisco, CA 94105

415.284 .1544
Tony Perez Associates

Tony Perez, Principal

225 Camino La Madera Avenue

Camarillo CA 93010

805.377.1209

Economic \& Planning Systems, Inc. Jason Moody, Principal

2501 Ninth Street, Suite 200

Berkeley, CA 94710

510.841 .9190

MARCH 2014

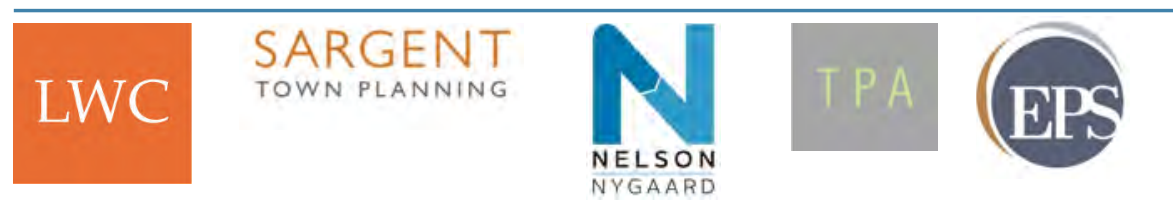




\section{ACKNOWLEDG EMENTS}

Special thanks to the City Council, Citizen Advisory Committee, Technical Advisory Committe, and City Staff who generously gave their time to help create the Bellevue Community Plan. Special thanks to the

UC Merced Resource Center for the Community Engaged Scholarship (ReCCES program) - "Planning an Innovation Hub," Dr. S.A. Davis, and Geneva Skram for their continued support and assistance.

City Council
Stan Thurston
Noah Lor
Kevin Blake
Tony Dossetti
Mike Murphy
Josh Pedrozo
Michael Belluomini

City Council

Stan Thurston

Noah Lor

Kevin Blake

Tony Dossetti

Josh Pedrozo

Melluomini

Citizen Advisory Committee
Jerry Callister
Susan Gerhardt
Melbourne Gwin, Jr.
Dan Holmes
Sharon Hunt-Dicker
Richard Kirby
Lee Kolligian
Walt Lopes
Carol McCoy
Steve Simmons
Justi Smith
Bill Spriggs
Greg Thompson
Steve Tinetti
Jeff Pennington
Diana Westmoreland-Pedrozo
Mary Ward
Janet Young

\author{
Technical Advisory Committee \\ Norm Andrade \\ Gene Barerra \\ Michael Conway \\ Richard Cummings \\ Ken Elwin \\ Kim Espinosa \\ Kraig Magnussen \\ Matthew Fell \\ David Gonzalves \\ Rod Ghearing \\ Richard Green \\ Mark Hamilton \\ Mark Hendrickson \\ Bill King \\ Thomas Lollini \\ Michael McLaughlin \\ Maria Mendoza \\ Stan Murdock \\ Bill Nicholson \\ Ron Price \\ Frank Quintero \\ Steven Rough \\ Ken Rozell \\ John Sagin \\ Julie Sterling \\ David Spaur \\ Mike Wegley \\ Phillip Woods
}




\section{CONTENTS}

\section{Exec utive Summary}

Plan Development and Community Partic ipation

Plan Organization and Contents

Core Findings a nd Policy Recommendations

Next Steps

\section{Introduction}

Community Plan Overview

Setting

General Plan Guidance

2. Vision \& Urban Design

Plan Framework and Flexibility

Plan Vision and Strategies

Bellevue Community Plan Goals and Polic ies

\section{Mobility}

Setting

BCP Circulation Plan Components

Bellevue Community Plan Goals and Polic ies

4. Open Space, Conservation, and Recreation

Open-Space Servic e Stand ard

Park Types

Conceptual Open-Space Diagram

Bellevue Community Plan Goals and Policies 
Setting

General Plan Consistency

Core elements for Community $\mathrm{C}$ haracter Areas

Place Types/Character Areas:

Neighborhood Master Planning

BCP Regulatory Framework

Bellevue Community Plan Goals and Policies

\section{Urban Expansion}

109

Govemance and Terminology

Growth Factors

Community Plan Growth Scenarios

Public Facilities Financing and Next Steps

Bellevue Community Plan Goals and Polic ies

\section{Public Senvices and Facilities}

Public Facilities Financ ing

\section{Plan Maintenance}

A. Bellevue Community Plan Consistency with the City's General Plan $\quad$ A-1

$\begin{array}{lcl}\text { B. Development Projects and Plans } & \text { B-1 }\end{array}$

C. Applic able Merced Vision 2030 General Plan Goals, Polic ies and Actions $\quad$ C-1

$\begin{array}{lc}\text { D. Technical Circ ulation Memorandum } & \text { D-1 }\end{array}$

$\begin{array}{lll}\text { E. Foundation Report } & \text { E-1 }\end{array}$

$\begin{array}{lr}\text { F. Plan Development and Community Participation } & \text { F-1 }\end{array}$

G. Merced's Loop Road $\quad$ G-1

H. Innovation Hub Elements, Relevance and Suggested Policies $\quad H-1$

I. Findings Report with Supporting Background Reports $\quad$ I-1

J. Relevance of the Urban Land Institute to the BCP J-1

$\begin{array}{lc}\text { K. Anticipated Research and Development } & \text { K-1 }\end{array}$

L University Community Plan Town Center $\quad$ L-1

M. Plan Assessment Tool $\quad M-1$ 


\section{LSTOF FIG URES}

Figure 1. Bellevue Community Plan Area in Relation to Downtown Merced 5

Figure 2. Proximate Development Plans and Projects surrounding the Bellevue Community Plan Area 6

Figure 3. Bellevue Community Plan “Illustrative Plan” 10

Figure 4. Urban Design Framework 17

Figure 5. Merced Loop System 18

Figure 6. City of Merced Transit Comidor 19

Figure 7. Califomia High Speed Rail Proposed Alignment 22

Figure 8. Illustration of an Interconnected Block Structure 23

Figure 9. Illustration of Possible Gateway Design Overlay Along Bellevue 25

Figure 10. UCM Triple Zero Commitments 26

Figure 11. Existing Regional Bus Connectivity 37

Figure 12. Complete Street Components in the Bellevue Community Plan 40

Figure 13. BCP Street Classification 42

Figure 14. Bellevue Road with Two-way Side Access Road 44

Figure 15. Example of a Boulevard with One-way Side Access Slip Road and Intersections in Berkeley, CA 44

Figure 16. Example of a Boulevard with One-way Side Access Slip Road in Berkeley, CA 44

Figure 17. Gardner Road in Single Family Character Area 45

Figure 18. Collector Street through a Typic al Multi-Family Character Area 46

Figure 19. Collector Street through a Typic al Mixed-Use Character Area 47

Figure 20. Collector Street through a Typic al Single-Fa mily Cha racter Area 47

Figure 21. Mandeville Road- Transit Avenue - T.O.D. Center 48

Figure 22. Typical Edge Drive with Side Parking 51

Figure 23. Lake Road - Natural Rural Edge Drive 51

Figure 24. Lake Road - Edge Drive with Mixed-Use CharacterArea 51

Figure 25. BCP Gateway Overlay at Bellevue Road \& G Street 52

Figure 26. Five Minute Walk from Proposed Transit Line 54

Figure 27. Bic ycle Transportation Map 56

Figure 28. Pedestrian Transportation Map 57

Figure 29.Examples of Street Landscape Features 58

Figure 30. Example of an Urban Plaza and Festival Streets 58 
Figure 31. Crosswalks

Figure 32. Bulb-outs

Figure 33. Pedestrian Rea Im

Figure 34. Sensitive Habitats and Conservation Lands within and near the Plan Area

Figure 35. Site Topography and Drainage Features Within and Near the Planning Area

Figure 36. Wetland Features with and near the Plan Area

Figure 37. Existing and Planned Recreational Facilities Within and Near the Plan Area

Figure 38. BCP Open-Space Diagram

Figure 39. Community Character Place Type Plan

Figure 40. Illustration of a R\&D Employment District

Figure 41. Illustration of a Typic al Neighborhood Center

Figure 42. Illustration of Multi-Fa mily Neighborhood Character Area

Figure 43. Illustration of Single Family Residential

Figure 44. Bellevue Community Plan Area

Figure 45. Merced City Limit, Sphere of Influence (SOI), Sphere of Specific Urban Development (SUDP), and Area of Interest (AOI) 


\section{USTOF TABLES}

Table 1 Land Use Designations from the Merced Vision 2030 General Plan

Table 2 Citizen Advisory Committee Desired Outc omes of the Bellevue Comidor Community Plan

Table 3 Vision and Urban Design Goals and Policies Specific to the Bellevue Corridor Community Plan consistent with the City's

General Plan

Table 4 Street Classifications within the Bellevue Community Plan

Table 5 Pedestrian Way Standards

Table 6 Mobility Goals and Policies Specific to the Bellevue Corridor Community Plan Consistent with the City's General Plan

Table 7 Open Space, Conservation, and Recreation Goals and Policies Specific to the Bellevue Corridor Community Plan consistent with the City's General Plan

Table 8 Place Type Characteristics

Table 9 BCP Character Area Descriptions and Regulatory Framework

Table 10 Community Character Goals and Policies Specific to the Bellevue Community Plan consistent with the City's General Plan

Table 11 Urban Expansion Goals and Policies Specific to the Bellevue Corridor Community Plan consistent with the City's General Plan Regarding Urban Expansion

Table 12 Public Services and Facilities Goals and Policies Specific to the Bellevue Corridor Community Plan consistent with the 
This page intentionally left blank. 


\section{EXECUTIVE SUMMARY}

The Bellevue Community Plan (BCP) was developed to be consistent with the Merced Vision 2030 General Plan, and is highly reflective of its policies, illustrative plans and guiding features, such as providing significant employment generating uses that would benefit from being in close proximity to the UC Merced campus. The BCP establishes a high-level planning framework that strikes a balance between certainty and flexibility by anchoring key land uses while allowing their size to adapt to changing market conditions in response to economic growth and the expansion of UC Merced. While the BCP provides a broad range of uses and densities that could occur throughout the plan area, it emphasizes the foundational building blocks of street connectivity, functional mobility choices, active and passive recreation open space corridors and bikeways, gateway street designs, and attractive business park settings to create a great sense of place with investment certainty.

\section{PLAN DEVELOPMENTAND COMMUNITY PARTICIPATION}

The development of the Bellevue Community Plan (BCP) was designed to be a dynamic process built on:

- $\quad$ Realistic assessments of past and future conditions;

- Consistency with the Merced Vision 2030 General Plan and other guiding documents;

- Professional planning and engineering guidance;

- Stakeholder participation, outreach to underrepresented groups, and public workshops; and,

- Actions of an ad-hoc advisory committee, with input from an engaged community.

Technical Memorandum F (Appendix F) includes a detailed description of

\section{Public Workshop}

Presentation

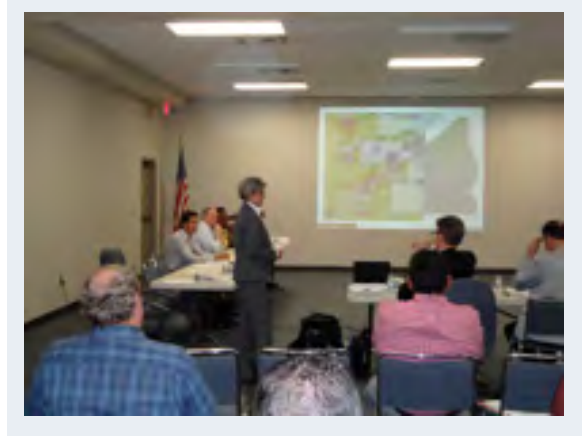
plan development process and the community participation program that helped shape the BCP.

\section{PLAN ORG ANIZATION AND CONTENTS}

The Bellevue Community Plan is comprised of Plan Chapters, Technical Appendices and Environmental Review Documents. The Plan Chapters, described below, include narratives, images and policy language.

\section{PLAN CHAPIERS}

Chapter 1 - Introduction identifies the context which the plan was developed, including descriptions of the community and physical setting, the parameters and relevant issues of the plan area established by the City's General Plan, and plan area assumptions, opportunities and constraints.

Chapter 2 - Vision and Urban Design provides the long-term vision of the Plan and policy direction about core design principles which broadly influence mobility, open space, land use and public services and facilities in the plan area. 
Chapter 3 - Mobility emphasizes the development of a municipal circulation and transportation system, integrated with open spaces and land uses, and accommodates all modes of transit (automobiles, transit, bicycles, and pedestrians), including provision for Transit Priority Projects (TPP). Chapter 3 includes rights-of-way templates and graphics depicting future streets, pathways and transit corridors within the Plan Area.

Chapter 4 - Open Space, Conservation, and Recreation elements are designed in a comprehensive multiuse approach addressing recreation, storm-drainage, joint use school facilities, connectivity of uses, and natural resource needs of the planning area and surrounding lands.

Chapter 5 - Community Character anticipates and identifies locations for future land uses, and arranges them in a pattern that is both complementary and compatible with nearby uses including the UC Merced, Rural Residential Neighborhoods, and planned communities.

Chapter 6 - Urban Expansion describes governance challenges, growth factors and several growth scenarios for the plan area. The Urban Expansion Chapter emphasizes a comprehensive and collaborative approach, identifying infrastructure planning and fiscal responsibility as key drivers in future decisions concerning urban expansion.

Chapter 7 - Public Services and Facilities addresses the public service and facility needs of an expanding City population.

Chapter 8 - Plan Maintenance describes how the Bellevue Community Plan may be implemented, monitored, and updated, as needed.

On the topics of sustainable development, housing, noise and safety, the Bellevue Community Plan defers to the Merced Vision 2030 General Plan.

\section{TECHNICALAPPENDICES}

Plan Appendices contain detailed background information that is foundational to the discussion and policies of the Bellevue Community Plan, and includes the following topics:

A. Bellevue Community Plan Consistency with the City's General Plan.

B. Development Projects and Plans.

C. Applicable Merced Vision 2030 General Plan Goals, Policies and Actions.

D. Technical Circulation Memorandum.

E. Foundation Report.

F. Plan Development and Community Participation.

G. Merced's Loop Road.

H. Innovation Hub Elements, Relevance and Suggested Policies.

I. Findings Report with Supporting Background Reports.

J. Relevance of the Urban Land Institute to the BCP.

K. Anticipated Research and Development.

L. University Community Plan Town Center.

M. Plan Assessment Tool. 


\section{CORE FINDINGS AND POLICY RECOMMENDATIONS}

\section{DERNED YETREXIBIE}

The Bellevue Community Plan is a long-term document with a tremendous amount of uncertainty. To counter this, the plan has a policy framework for future master planning that is comprehensive and is supported by the community. The policy and development framework will deliver an interconnected transit-oriented development pattern, clarity of urban character and flexibility of use to respond to changing markets.

\section{INVESTMENTCERTAINTY}

While the Bellevue Community Plan provides a broad range of uses and densities that could occur, it also emphasizes the development of a great sense of place with investment certainty. The BCP is geared to make projects that are connected to their neighbors and to the transit spine with complete, walkable streets. So the City creates a systematic development pattern where the next development is framed by the preceding development site that implements the overall vision, rather than a smattering of projects.

\section{A STRONG DOWNTOWN}

Downtowns are sensitive to market forces, particularly to urban growth in other areas. Initially, an identity distinct from Downtown Merced will need to be fostered by the City to develop a separate and non-competing center in the BCP plan area. Over time, as the market expands, greater flexibility in land uses may be achieved.

\section{ATIRACTING J OBS-BASED ECONOMIC DEVELOPMENT}

The Merced Vision 2030 General Plan includes numerous policies and narratives concerning the anticipation for significant jobs-based land uses within the BCP. Following the lead of the General Plan, the BCP includes a "Research and Development Park Character Area" that could accommodate up to 2.9 million square-feet of Research and Development floor space. The Plan is flexible, supporting the size of this land use to adjust depending upon market conditions. The Research and Development employment corridor is infused with innovation hub design elements to attract new firms and industry wishing to locate near the campus.

\section{HOUSING}

The Bellevue Community Plan relies on the housing-related narrative, images, diagrams and policies of the Merced Vision 2030 General Plan to guide planning, provision and development of future housing units in anticipation of Merced's increased population. The BCP includes a wide variety of housing types ranging from rural residential estate homes to high-density multifamily dwellings.

\section{A TAILOR-SUITED LAND USE MODE}

The Merced Vision 2030 General Plan contains policy direction to utilize the Urban Village as a design template for future growth areas within the Bellevue Community Plan area. Statements in the General Plan and comments received from the community made it clear that the urban design of the BCP would be unique, however. General Plan Policy UD-1.1h calls for unique "Urban Village" designs to be developed for increased opportunities for job-based land uses attracted by a university climate. The community also expressed concerns about the amount of low-density residential that has traditionally been located in the City's Urban Villages, and the location and intensity of commercial uses. Thus, a unique design is recommended that is consistent with the General Plan while responding to concerns of the community, and is discussed in greater detail in the land use section of Technical Appendix A. 


\section{CONSERVATION OF NATURALLANDS}

In that the Bellevue Community Plan contains sensitive species and habitat areas, the Plan considered and recommends several methods to conserve these natural resources. Consistent with adopted mitigation measures of City's General Plan EIR, property owners are required to prepare delineations of Waters of the U.S. and Wetlands prior to annexation, and to obtain permits from relevant state and federal agencies. Property owners also need to comply with the adopted Memorandum of Understanding between the City of Merced and the United States Fish and Wildlife Service. Additionally, the Open Space Master Plan of the BCP establishes several open space corridors that include identified sensitive habitats. For example, the Plan proposes a large corridor extending from Cardella Road to Lake Road at a point north of Bellevue Road. These may shrink or expand depending upon the findings and actions of the permitting process described above.

\section{OPEN SPACE FOR OUIDOOR RECREATION}

The Bellevue Community Plan includes several active parks including three neighborhood parks, a community park and several urban plazas. Neighborhood parks are recommended to be combined with future school sites to serve the anticipated population, and urban plazas will add open space opportunities to high-density populations along Mandeville Avenue. Open space corridors featuring pedestrian and bicycle pathways connect to parks and other destinations.

\section{SUPPORT CIRC ULATION MODES THROUGH LAND USE DESIGN}

Along Bellevue Road the goal is to emphasize smooth traffic flow and provide access to adjacent uses at appropriate intervals and through innovative means, while also creating a distinct gateway appearance through attractive building designs and associated landscaping. Within the Mandeville transit route, which links the planned transit stations in Bellevue Ranch and UC Merced. New development should be organized in the form of complete neighborhoods and districts and be oriented to pedestrians and transit. Higher-intensity development and activities should be concentrated near planned transit stops. This arrangement supports regional automobile trips on Bellevue Road, while creating a pedestrian-oriented corridor along Mandeville Avenue, and enhances the value of the research and development area that is to be located between these roads.

\section{NEGHBORHOOD MASTER PLANNING}

The Bellevue Community Plan recommends that the City create a dynamic "neighborhood master plan" process to ensure that each new increment of development is well-connected to existing and future adjacent development, while responding to market. The framework for new development would be a clear and interconnected - yet flexible - network of complete streets and community open spaces. This process acts as the fundamental tool to ensure that the overall physical community structure is developed as envisioned in the BCP.

\section{NEXT STEPS}

\section{PLAN INTEGRATION}

Upon adoption of the Bellevue Community Plan, the City should begin the process to integrate it with existing master plan documents and processes, including but not limited to the following:

- $\quad$ Merced Vision 2030 General Plan.

- City of Merced 2013 Bicycle Transportation Plan.

- 2003 Parks and Recreation Master Plan.

- Capital Improvement Planning.

- $\quad$ Public Utility Master Plans.

- Transit Planning Documents.

- $\quad$ Regional Transportation Plans (as appropriate). 


\section{COORDINATED DEVELOPMENT}

A common vision and approach to urban expansion creates certainty, and certainty attracts investments, and investments create jobs. Yet, as evidenced in the growth scenarios of the BCP (Chapter 6, Urban Expansion), along with concerns raised by the BCP Ad-hoc Advisory Committee, there are numerous unanswered questions and challenges concerning infrastructure, financing and phasing of growth in and adjacent to the BCP planning area. The BCP is a collaborative effort to create a multijurisdictional infrastructure and service plan to support growth in a manner that serves the interest of the community as a whole, in a fiscally sound manner. Partners with the City in this effort would include Merced County, the University of California, as well as the Merced Irrigation District, local schools and the Merced County Association of Governments. The UC Merced Long Range Development Plan (LRDP), the University Community Plan (UCP), and the Bellevue Community Plan, among other plans, provide the necessary information and options from which a unified development phasing plan could be crafted. Future outcomes of this collaborative effort could include:

- $\quad$ Select a growth scenario, or combination thereof.

- Develop a strategic phasing plan and plan for services that coordinate expenditure of resources, provides certainty in the marketplace, and leads to an efficient use of public infrastructure and services.

- Update financing and master plans and programs to align with the broad decisions concerning financing, infrastructure, and phasing in the northeast Merced SOI. 


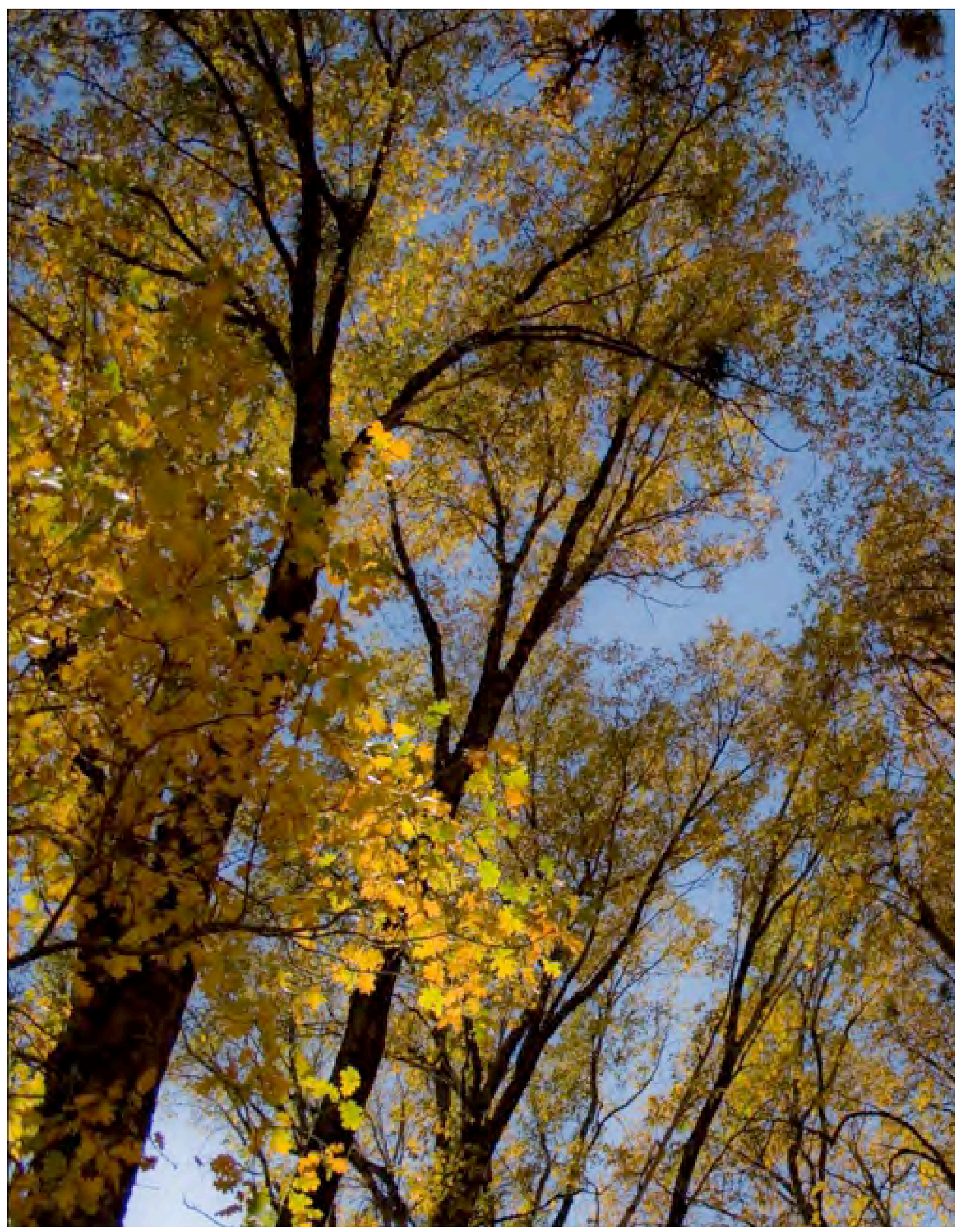




\section{INTRODUCTION}

\section{COMMUNITY PLAN OVERVIEW}

\section{PURPOSE}

The Bellevue Community Plan (BCP or Plan) provides policy direction to the decision making process for development within a defined geographic portion of the Planning area of the City's General Plan. The plan forms a broad framework for mutual understanding among citizens, public agencies, and the development community. Preparing a community plan serves the following purposes:

- To facilitate the Planning Commission and City Council concurrence on long-range development policies;

- To provide a basis for evaluating the level to which private development proposals and public projects are consistent with these policies;

- To better enable the public and government entities to design projects that are consistent with City policies, or to seek changes in these policies through the General Plan Amendment process;

- To record the City's policies and standards for the maintenance and improvement of existing development and the location and characteristics of future development;

- To better inform citizens on land use policy issues and promote opportunities to participate in the local planning and decisionmaking process;

- To serve as a blueprint for future growth and development within a defined area of the City of Merced's Sphere of Influence (SOI) ${ }^{1}$ and,

- Community Plans may, but are not required to, identify components of infrastructure needed to support planned land uses, as well as appropriate financing mechanisms. ${ }^{3}$

The BCP focuses on providing a vision and framework for coordinating transportation, infrastructure, and open space, with varied land use mixes and intensities.

\section{A “Community Plan" serves as}

a blueprint for future growth and development within a defined area of the City of Merced's growth boundary.

\section{Aerial View of Merced}

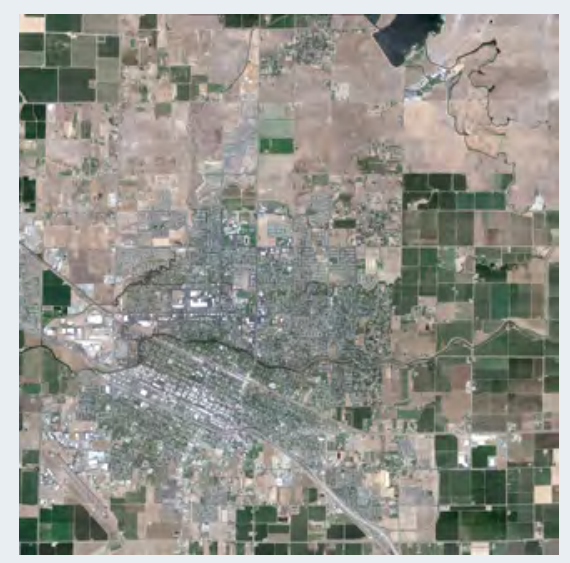




\section{THE CITY'S GUIDING PRINCIPLES FOR COMMUNITY PLANS}

General plan's provide a policy framework upon which community plans are constructed and a foundation to build more detailed implementation tools including community plan diagrams, policies, maps and illustrative plans.

The City's Guiding Principles for local community plans (Section 3.7.2, Merced Vision 2030 General Plan) are:

- Community Plans which include or are adjacent to established neighborhoods will address the needs of these neighborhoods and potential adverse impacts resulting from plan implementation.

- Public participation by area residents and property owners in the planning process will be emphasized.

- Community Plan areas need connectivity with existing and planned urban areas.

- Community Plans will include all elements determined necessary to ensure consistency with the General Plan. These elements may include, but not be limited to, Land Use, Circulation, Open Space, and infrastructure phasing. Community Plans will include a land use and infrastructure phasing plan.

- The "Urban Villages" concept should be incorporated into the planning of these areas as much as feasible.

- $\quad$ The Community Planning process should be focused on the planning issues or concerns which need to be resolved for that planning area and, to this degree, provide data, information, or policy clarification necessary to carry out the goals of the Merced Vision 2030 General Plan.

\section{BCP RELATIONSHIP TO FUTURE ANNEXATIONS AND GROWTH}

The BCP is not a project that will annex unincorporated properties into the City of Merced. That action occurs through a separate process usually initiated by private property owners with specific development interests, and then only after a formal annexation request is granted by both the City of Merced and the Merced County Local Agency Formation Commission (LAFCO). For more information on annexation and implementation of the Plan see Chapter 6 (Urban Expansion).

\section{FRAMEWORK PLAN VS. DEVELOPMENT PLAN}

The BCP is not a development project. A development project contains specific land-use entitlements with specific standards. As with the City's General Plan, the $\mathrm{BCP}$ is a conceptual framework within which future decisions about development projects would be made when more information is in place. The BCP does not include the specificity or rigidity that comes with a development plan as does, for example the Bellevue Ranch Master Development Plan. 


\section{PLANNING VS. ZONING}

The Bellevue Community Plan does not rezone property. Upon adoption of the Plan, properties within the planning area will remain in Merced County and will retain their current zoning designations. As there is no City zoning within the plan boundaries, the BCP effort does not affect current property rights. The $\mathrm{BCP}$ provides a foundation for future development in a manner that will benefit the property owners and the community.

\section{VISION VS. CONSTRUCTION}

The BCP planning process allowed the community to take a comprehensive approach to examining land use, circulation, and other issues. As the City's urban fabric expands with market demand, the BCP offers guidance for growth that is grounded in the community's vision, takes advantage of existing resources, and avoids potential constraints. However, for future urbanization to occur in the Plan Area, additional input will be needed from the community as the scope and scale of development becomes influenced by market conditions, decisions from local landowners, and the availability of public services.
Tour of Bellevue Corridor Project Area and Presentation

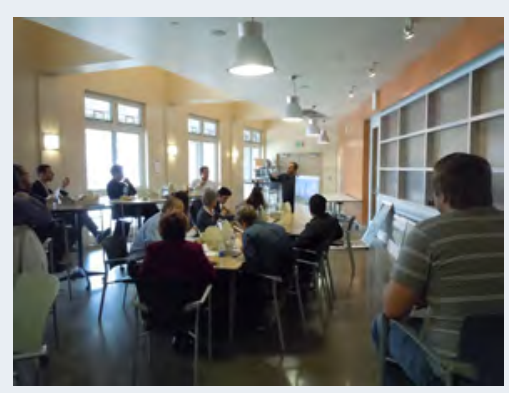




\section{SEITING}

\section{COMMUNTIY SETING}

The Bellevue Community

Plan study area is located

outside but adjac ent to the

Merced City limits, and within

the City's planned growth

area, otherwise known as the

Spec ific Urban Development

Plan (SUDP) and Sphere of

Influence (SOI).
The City of Merced is approximately seven miles long from north to south and six miles at its widest point from east to west. In January 2012, the City of Merced covered approximately 23 square miles and had an estimated population of 79,328. The Bellevue Community Plan area is located to the northeast of the City of Merced, and covers an area of approximately 2.4 square-miles. The planning area is generally bounded by "G" Street on the west; Farmland Avenue on the north; Lake Road on the east and Cardella Road on the South (between Lake Road and Gardner Road), and generally $1 / 2$ mile south of Bellevue Road (between Gardner Road and "G" Street). Lake Yosemite, UC Merced and the northern part of the UC Community Plan area abuts the eastern edge of the BCP study area. From the project boundary, Downtown Merced is 3.5 miles to the southwest, and Castle Airport and the City of Atwater are 6 miles to the west.

The Bellevue Community Plan study area is located outside but adjacent to the Merced City limits, and within the City's planned growth area, otherwise known as the Specific Urban Development Plan (SUDP) and Sphere of Influence (SOI).

\section{PHYSICALSETING}

The northeastern portion of the City's planned growth area is characterized by gently rolling terrain while the remainder of the City is relatively flat. The northern, western, and eastern portions of the City contain a number of creeks and canals including Bear Creek, Black Rascal Creek, Fahrens Creek, and Cottonwood Creek. These creeks all traverse the City from east to west. With the exception of a few pockets of rural residential homes, the BCP planning area is predominately grasslands. 


\section{Figure 1. Bellevue Community Plan Area in Relation to Downtown Merced}

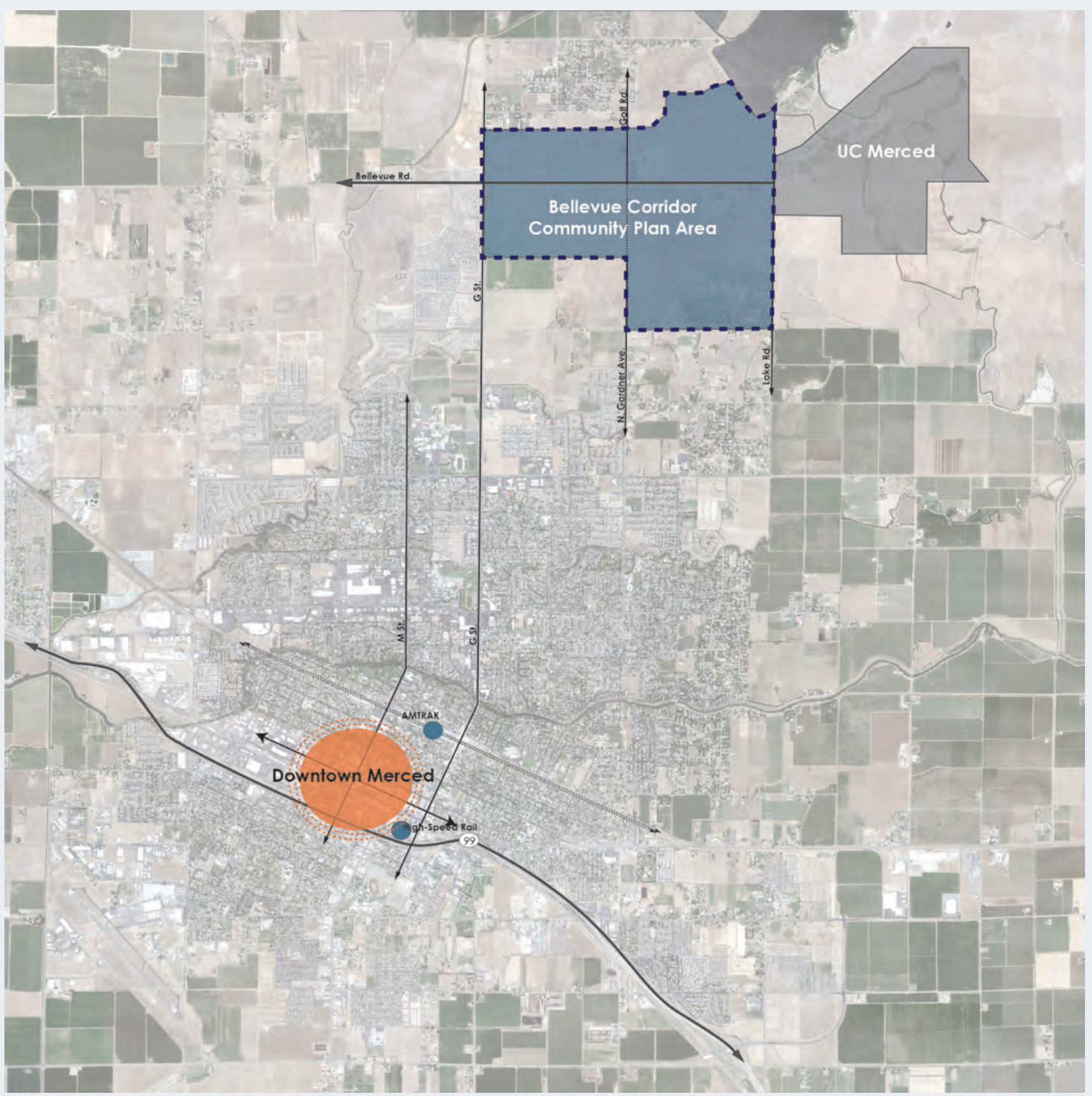




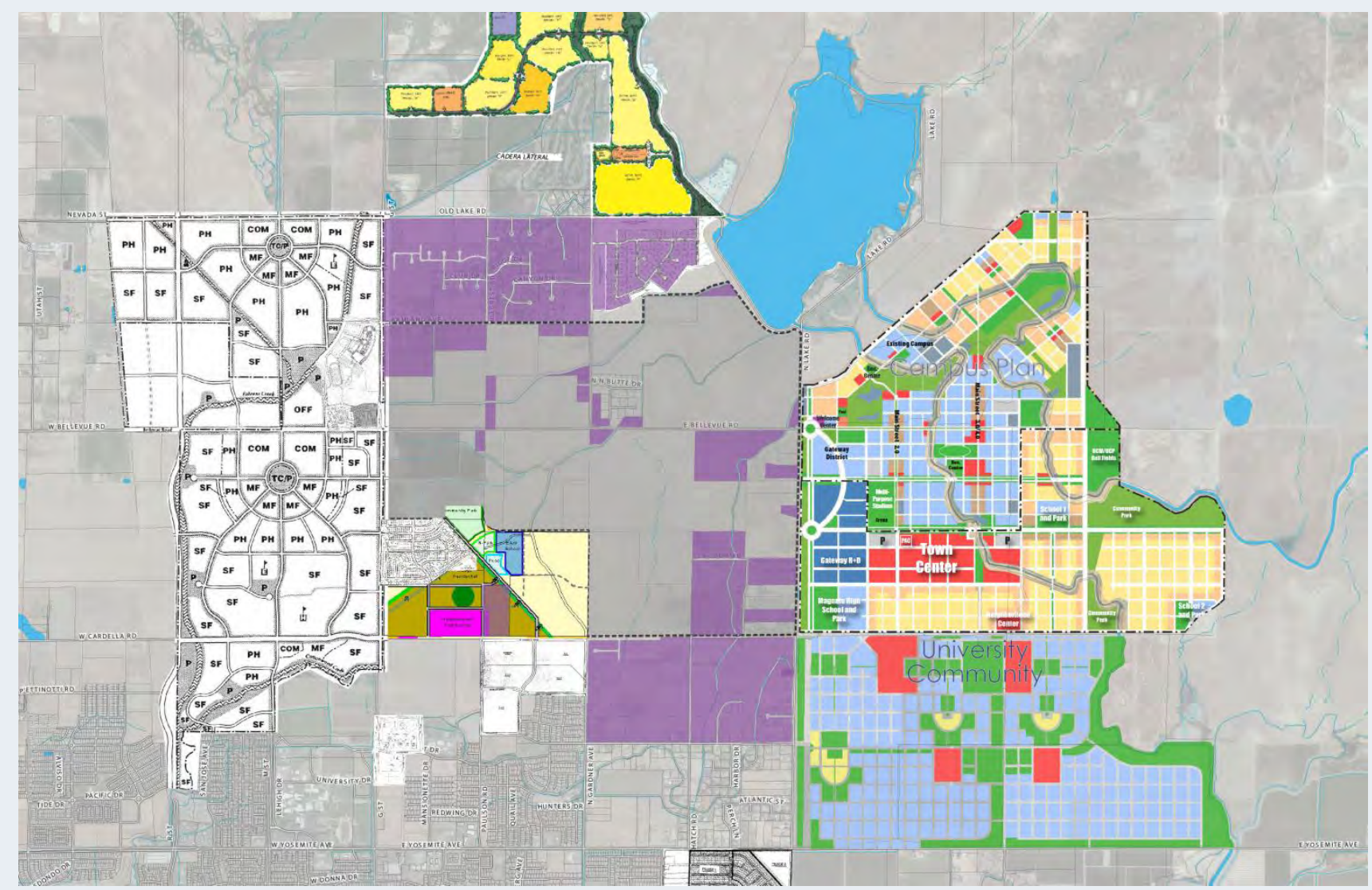

The community of Merced has partic ipated in important planning initiatives over the past several years including the City's Merced Vision 2030 General Plan, UC Merced's Long Range Development Plan, and Merced County's University Community Plan.

\section{PROXIMATE DEVELOPMENTPLANS AND PROJ ECTS}

The community of Merced has participated in important planning initiatives over the past several years including the City's Merced Vision 2030 General Plan, UC Merced's Long Range Development Plan, and Merced County's University Community Plan. The outcomes of these and other planning initiatives serve as an important basis for the BCP. A detailed description of development plans and projects occurring within and near the Bellevue Community Plan area is provided in Technical Memorandum B (Appendix B) of the BCP. The "Projects and Plans" document identifies and describes recent and anticipated growth patterns. 


\section{G ENERAL PLAN G UIDANCE}

\section{CONSISIENCY WTH THE MERC ED VISION 2030 GENERAL PLAN}

The Bellevue Community Plan was developed to be consistent with the Merced Vision 2030 General Plan, and reflects key criteria detailed in the General Plan. The following sections from the General Plan created the foundation of the BCP and established the Core Principles discussed in Chapter 2 (Vision and Urban Design chapter):

- Key Goals, Policies and Implementation Actions

- Key Features and Issues of the Bellevue Community Plan

- The Bellevue Community Plan "Illustrative Plan"

\section{KEY GOALS, POLCIES, AND IMPLEMENTING ACTIONS}

A complete and full listing of Merced Vision 2030 General Plan goals, objectives, policies, and implementing actions that have notable relevance to the $\mathrm{BCP}$ project area and/or plan objectives are listed in Technical Memorandum C (Appendix C) of the BCP. This appendix also includes policies crafted as a part of the $\mathrm{BCP}$, which offer greater detail and refinement of the broader General Plan language. The policies in Technical Memorandum C are a key part of the BCP and are intended to guide and inform development-related activities in the project area.

\section{KEY FATURES AND ISSUES OF THE BEUEVUE COMMUNITY PLAN}

The Merced Vision 2030 General Plan (Section 3.7.4) identified several key features and related direction for the BCP, including: economic development, land use, transportation, public facilities, environment and urban design.

\section{ECONOMIC DEVELOPMENT}

The City's General Plan describes Bellevue Road as a gateway to UC Merced connecting the campus to Castle Airport Aviation and Development Center, other employment centers, and to Downtown Merced via the " $G$ ", " $M$ " and " $\mathrm{R}$ " Street corridors, and that (1) their economic development strategies should be compatible and complementary; and (2) they should connect to one another via a network of transportation and communications systems that optimize access between and among them.

The Merced Vision 2030 General Plan also describes the Bellevue Corridor as likely to contain significant employment generating uses that would benefit from being in close proximity to the UC Merced campus (Section 3.5.5), and is identified as a Commercial and Industrial Employment Corridor to contain heavy concentrations of commercial and industrial development.

The emphasis on economic development also appears in a General Plan discussion to adjust the City's Urban Village concept near UC Merced. The General Plan states, "The composition and pattern of land uses in the Urban Villages near UC Merced along Bellevue Road will have unique designs
Merced Vision 2030 General Plan

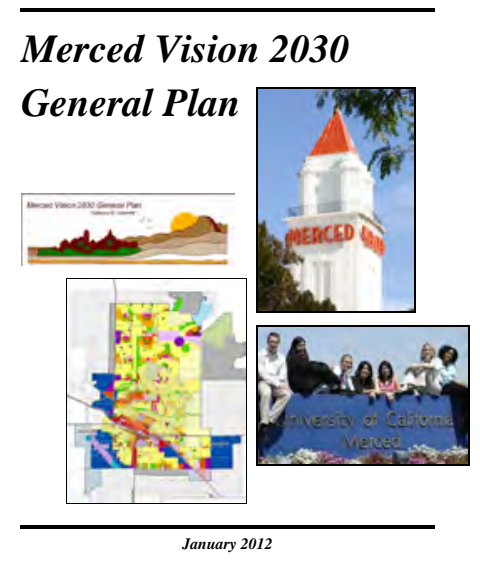

January 2012 


\section{Urban Village Design}

Urban Villages are described in the Merced Vision 2030 General Plan as mixed-use, mixed-density neighborhood developments incorporated into and planned in conjunction with a network of interconnected, walkable streets. This design allows for a variety of land uses including jobs-based land uses attracted to a university climate to be intermixed within the $\mathrm{BC} P$ framework. and functions due to the economic opportunities and connectivity to the university. Each of the "Urban Villages" between Lake Road and "G" Street should contain, in addition to "Neighborhood Commercial," "Village Residential," and "Professional Commercial -Office," the opportunity for an expanded urban core comprised of a jobs-based office, business park or research and development type land use supported or spun-off from UC Merced. This additional land use potential is represented in Figure 38. Community Character Place Type Plan.

\section{LAND USE}

The City's General Plan describes the Bellevue Corridor as one that should be designed as a place where services, shops, schools, businesses, public uses, and residences mix in a vibrant setting. The BCP should assess the viability of expanding office, commercial, and research and development land use capacities in the plan area. The City's Urban Village will be the backbone concept model for creating core commercial nodes along Bellevue Road and a connection to neighborhoods to the south and north. Some of the land uses could connect to research and development activities associated with the campus research programs or professional services associated with the campus's professional schools. The City's General Plan specifically identifies that the following features should be included in or influence the creation of the BCP:

- Special "Urban Village" designs suited to the "Bellevue Corridor Planning Principles" and potential expansion thereof to provide for increased opportunities for job-based land uses attracted by a university climate while still maintaining the basic concept of mixed-use, pedestrian, and transit oriented communities. These "Urban Villages" may differ from others in the Community in the mixture of business park, research and development, office, public/ cultural uses, and retail uses within the Village Core areas instead of the retail/office/public facilities focus of other Villages which are more residential in nature; and,

- Land Uses should be compatible and complimentary with one another and planned as integrated, coordinated mixed-use neighborhoods and communities; and,

- The influence and effects of the UC Merced and University Community land use and circulation plans on adjacent (western) properties; and,

- Interface issues and infill land use patterns adjacent to and within pre-existing "Rural Residential” properties; and,

- A variety of housing types and densities should be encouraged within the Community Plan area in addition to job-generating uses consistent with the City's overall economic strategy and the Bellevue Corridor Economic Analysis (see Appendix I). 


\section{TRANSPORTATION}

Per the City's General Plan, it will be essential that adequate rights-of-ways be reserved along all major corridors. The design cross-section of these corridors may vary depending upon the adjacent land uses, but they should have two characteristics in common. They should be designed as multimodal access corridors that accommodate both automobiles and a public transit system (rubber tire or light rail), as well as bicycles and pedestrians. Further, they should be designed to unify, rather than separate, the elements of the community located on opposite sides of the road. These roads should be designed as landscaped, multimodal boulevards.

Establish "Bellevue Parkway Planning Principles" describing the design [including appropriate right-of-way, function and land use pattern along Bellevue Road] recognizing two key traits: (1) multi-modal access corridor that accommodates both automobiles and public transit systems, as well as bikes and pedestrians; and (2) designed to unify rather than separate the community located on opposite sides of the road.

Establish a system of collector streets and arterials with appropriate rightsof-ways to encourage internal circulation within the Community Plan area. This would include determining the proper alignment and right-of-way for Gardner Road.

\section{PUBUC FACIUTIES}

The City's General Plan states the BCP should establish adequate public facilities to accommodate growth within the area. The General Plan states the BCP provide the, "Location and financing of public facilities including a fire station, schools, roadways, off-street bike and pedestrian paths, and parks/ open space."

\section{ENVIRONMENT}

The BCP addresses specific environmental issues and vulnerable areas relevant to the plan area which necessitate protection or preservation. The City's General Plan states that the BCP should address the following: "Lake Yosemite Inundation Area and Sensitive species and habitat conservation."

\section{CHARACTER/DESIGN}

The General Plan states the BCP should include design parameters to guide the future development of the plan area. The General Plan identifies the following characteristics be included in the BCP:

- $\quad$ Establish, through the Community Plan process, design guidelines for development along the Bellevue Corridor in accordance with the City's Urban Design principles outlined in Chapter 6 of the General Plan.

- The natural hill, which occurs on the south side of Bellevue Road between G Street and Gardner Road, should be considered as a focal point for the Corridor.
It will be essential that

adequate rights-of-ways

be resenved along all major

comidors. The design cross-

section of these comidors

may vary depending upon

the adjacent land uses,

but they should have two

c ha rac teristics in common.

They should be designed as

multi-modal access comidors

that accommodate both

automobiles and a public

transit system (rubber tire or

light rail), as well as bicycles

and pedestrians. Further, they

should be designed to unify,

rather than separate, the

elements of the community

located on opposite sides of

the road. These roads should

be designed as landsc aped,

multimodal boulevards. 


\section{THE BEUEVUE COMMUNITY PLAN "IUUSTRATIVE PLAN"}

The Merced Vision 2030 General Plan includes "illustrative plans" as an appendix to its Land Use Chapter. Illustrative plans are not adopted plans and are only included in the Merced Vision 2030 General Plan to inform the public of preliminary land use concepts under consideration in each of the Plan areas. No land use entitlements are granted by including illustrative plans in that appendix. The land uses shown in the northwest corner of Lake Road and Bellevue Road are a part of the formally adopted Land Use Diagram of the City of Merced, and not considered "illustrative." The "Illustrative Plan" (Figure 3) below from the General Plan shows a conceptual land use plan for the BCP area.

\section{Figure 3. Bellevue Community Plan "Illustrative Plan"}

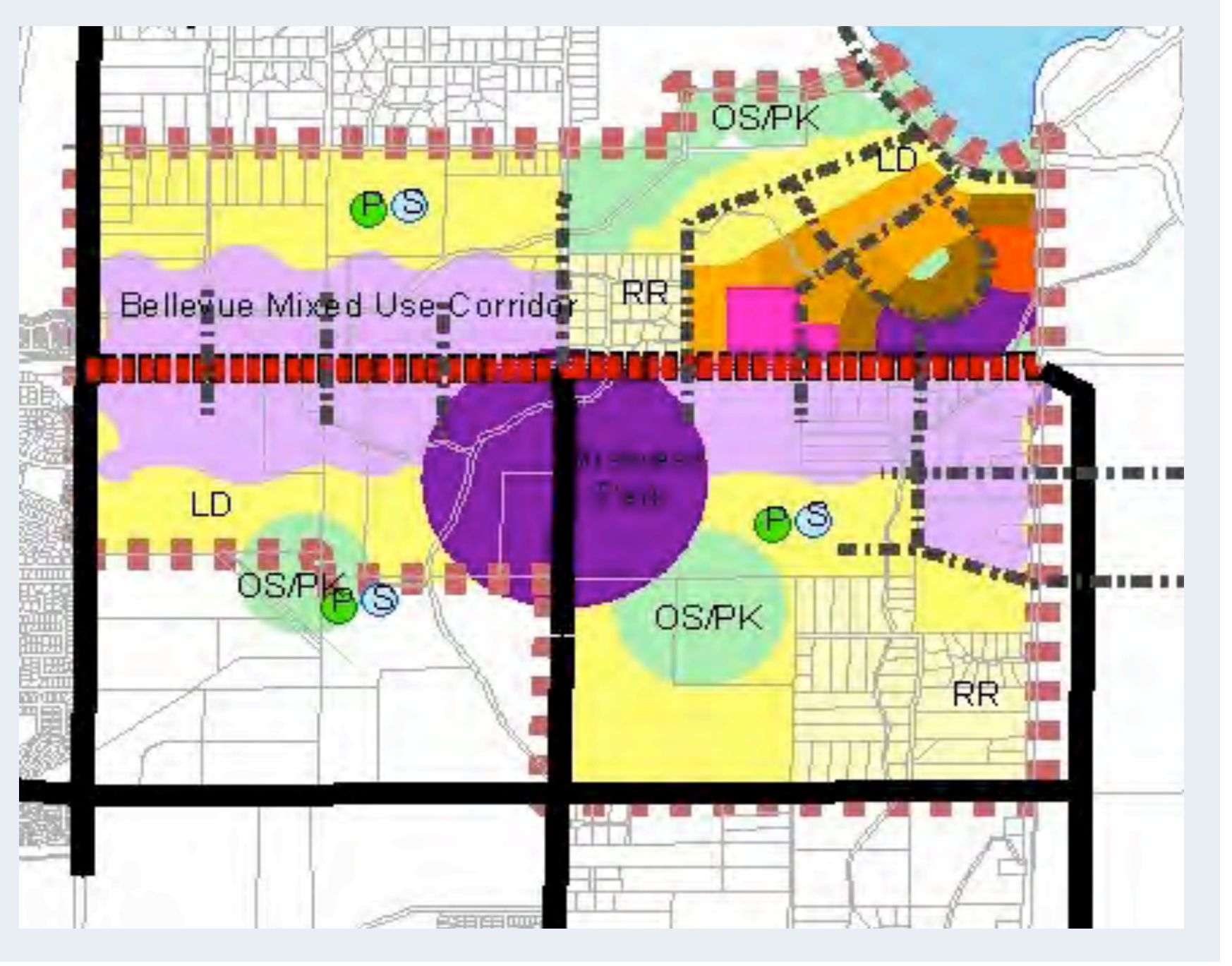




\begin{tabular}{|c|c|c|c|}
\hline Land Use Designations & Key & Intended Uses & Density \\
\hline Low Density Residential (LD) & Yellow & $\begin{array}{l}\text { Residential: single-fa mily detached, } \\
\text { condominium, and zero-lot line }\end{array}$ & $2-6$ units peracre \\
\hline $\begin{array}{l}\text { High-Medium Density Residential } \\
\text { (HMD) }\end{array}$ & Light Brown & $\begin{array}{l}\text { Residential: multifa mily, a partment, } \\
\text { cond ominium, triplex, foumplex }\end{array}$ & 12.1 - 24 units peracre \\
\hline High Density Residential (HD) & Dark Brown & Residential: multifa mily & 24.1 - 36 units peracre \\
\hline Thoroughfare Commercial (CT) & Red & $\begin{array}{l}\text { Commercial: auto-oriented commerce, } \\
\text { large recreational facilities, some heavy } \\
\text { commercial, lodging and hospitality, } \\
\text { automobile sales and services }\end{array}$ & 0.35 Floor Area Ratio \\
\hline Business Park (BP) & Purple & $\begin{array}{l}\text { Commercial and industrial: heavy } \\
\text { commercial, office, research and } \\
\text { development, light ma nufacturing, } \\
\text { wa rehousing, information-ba sed and } \\
\text { service-based activities }\end{array}$ & 0.40 Floor Area Ratio \\
\hline $\begin{array}{l}\text { Open Space - Park/Recreation } \\
\text { Facility (OS-PK) }\end{array}$ & Green & $\begin{array}{l}\text { Recreation: public parks, golf courses, } \\
\text { greens, commons, playgrounds, and other } \\
\text { public and private open spaces }\end{array}$ & 0.10 Floor Area Ratio \\
\hline
\end{tabular}

\section{BEUEVUE COMMUNITY PLAN (BCP)}

The General Plan conceptual land use plan (for illustrative purposes only) for the BCP is shown on the previous page. This illustrative plan also appears on the City's Official Land Use Diagram. Through the development of the BCP, the General Plan "Illustrative Plan" and land use designations (Table 1), described above, were refined in order to develop the community's vision for the BCP area in the following chapters of this community plan. 


\section{ASSUMPIIONS, OPPORTUNITIES, AND CONSTRAINTS}

The Bellevue Community Plan was guided by the following assumptions and the assessment of opportunities and constraints regarding anticipated future conditions to the year 2030 listed in the Merced Vision 2030 General Plan and developed through the community engagement process.

\section{ASSUMPTIONS}

- Although essentially vacant today, the BCP is surrounded by existing and proposed urban and suburban land uses. All lands within the City's adopted Sphere of Influence within and near the BCP will be developed.

- Development within the BCP area will be guided by "Urban Expansion" policies in the City's Merced Vision 2030 General Plan as well as Merced County Local Agency Formation Commission's (LAFCO) procedures, codes, and actions.

- $\quad$ Significant amounts of job-generating land uses will be located in close proximity to the UC Merced Campus.

- The University of California Merced (UCM) campus will continue to expand in the vicinity of Lake Yosemite on the northeastern edge of the Merced growth boundary or SUDP/SOI along with a future University Community.

- Urban development (residential, commercial, and industrial) will continue to be focused within the City of Merced's growth area (SUDP/SOI) and not in the unincorporated areas surrounding the City.

From City Council Resolution \#2006-89 regarding the University Community:

- $\quad$ The University Community will be incorporated into the City of Merced and will not be a separate city or part of the unincorporated County.

- Annexation along the Bellevue Corridor is encouraged to provide contiguity between UC Merced and the City of Merced. It is realistic to expect development proposals in the $\mathrm{BCP}$ planning area in the near-term.

- Though no separate wastewater treatment plant should service the University Community, consideration of innovative methods of wastewater treatment for that area may occur.

- The City will encourage annexation along the Bellevue Corridor to provide contiguity between the University Community and the City of Merced.

\section{OPPORTUNITIES}

The BCP presents important opportunities for the City of Merced. The continued growth of UC Merced will provide an influx of people, ideas, and energy. The plan should capitalize on this growth and ensure that new development meets the needs and desires of new and existing residents. Potential opportunities include the following: 


\section{Growing University-Oriented Population}

At full buildout, UC Merced is expected to grow to approximately 25,000 students and over 6,500 faculty and staff members. As the population grows, there will be an expanding market for housing, goods, and services.

\section{Future Research and Development Park Sites}

The plan should anticipate and prepare for the market demands caused by a growing University, including identifying sites for future job generating research and development parks and encouraging multiple interests to collaborate for long-term economic and fiscal benefits.

\section{Home for Entrepreneurs}

The plan should help foster a living and working environment to attract a new generation of entrepreneurs, leading to innovations, technologies, and expansion of local investment and job-generators.

\section{Alternative Transportation}

The plan should identify and implement circulation and land use standards that encourage multi-modal transportation including walking, biking, transit, and driving. By implementing the complete transportation network and shifting away from auto-centric mobility patterns, it is possible to compliment and build upon the UC Merced investment while moderating the environmental impacts of increased development within the BCP area. It is essential to offer multi-modal access to the student population of UC Merced and to future $\mathrm{BCP}$ residents.

\section{Leverage New Investment}

The expanding University community has and will continue to spark associated investment in Merced. The plan should identify opportunities to leverage new investments in the University to improve citywide economic vitality.

\section{Low-Impact Development}

Well-planned growth in the BCP area can ensure that development minimizes impacts to natural resources, air quality, and water quality. The plan should identify and incorporate concepts for development patterns and solutions that conserve and enhance resources from which a community prospers.

\section{Community Character}

There is little existing development within the BCP area, thus the BCP presents an important opportunity to elaborate on General Plan vision concepts for developing a unique community character. The plan should encourage memorable livable, human-scale public spaces and distinctive community centers that facilitate positive interaction and idea sharing. 
The scale of the Plan area

and timing of the UC campus

build-out will make phasing

an important consideration

in Plan implementation. The

pattem and timeframe in

whic $h$ the area develops will

impact transit opportunities,

development feasibility, and

interim community character.

\section{Existing Rural Residential Communities}

Though primarily located outside the Plan Area, existing "ranchette neighborhoods" provide a semi-rural lifestyle defined by open space and agricultural uses. The BCP provides an opportunity to maintain and strengthen the character of these neighborhoods with appropriate soft transitions to new higher intensity development; these neighborhoods can also provide development themes for some areas of the $\mathrm{BCP}$, such as equestrian-oriented facilities and trails.

\section{CONSTRAINTS}

While there are many opportunities for the City to capitalize on, the following constraints and challenges have been taken into account during the development of the Plan.

\section{Development Phasing}

The scale of the Plan area and timing of the UC campus build-out will make phasing an important consideration in Plan implementation. The pattern and timeframe in which the area develops will impact transit opportunities, development feasibility, and interim community character.

\section{Natural Resource and Habitat Disruption}

Portions of the Plan area are home to sensitive natural resources such as vernal pools that must be considered and which have the potential to enhance unique public open spaces.

\section{Multiple Interests}

BCP standards and policies must address the needs and concerns of individual property owners and local jurisdictions, while ensuring each unique development contributes to a unified whole. The project area is within the City's SOI and SUDP, but is currently under County jurisdiction.

\section{Multiple City Focus Points}

The City has important existing resources including the charming downtown and several historic neighborhoods. The BCP must ensure that development within the BCP complements, rather than competes with these and other existing or future community focal points.

\section{Campus Parkway Regional Traffic (Loop Road)}

Bellevue Road is part of Merced's planned loop road to carry regional traffic. While this serves an important regional transportation need, it limits the use of the road for transit, bicycling, and pedestrian-scale development. 


\section{View of Bellevue Road}

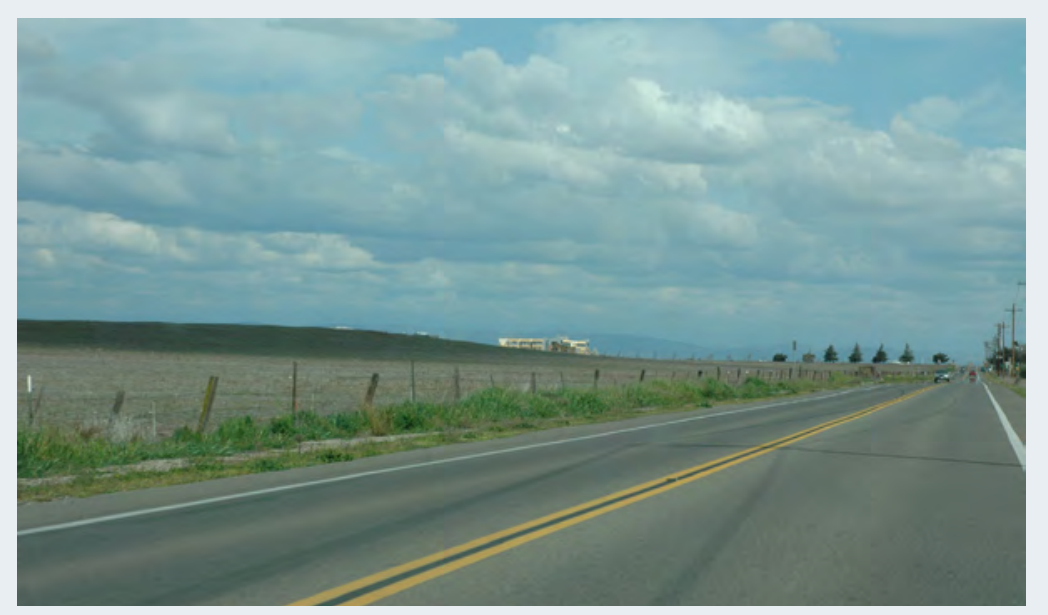

\section{An Uncertain Economy}

The current economy is still uncertain and growth forecasts for Merced and the $\mathrm{BCP}$ vary widely.

\section{Competition to Serve the UCM Market}

The BCP area and the University Community will potentially be competing for valuable economic development and expensive infrastructure capacity for many decades to come.

\section{Affect on Downtown}

Downtowns are sensitive to market forces, particularly to urban growth in other areas, including the development of the BCP.

\section{Disparate Visions}

The BCP area will be developed by many property owners and developers over the course of several decades. A focused and consistent effort will be needed on the part of decision makers to ensure successful, long-term implementation. This Plan provides an overall vision and general framework for new development, and also provides procedures for the preparation of more detailed neighborhood master plans to help coordinate and connect new development among and between multiple property owners.

\author{
A foc used and consistent \\ effort will be needed on the \\ part of decision makers so \\ ensure succ essful, long-term \\ implementation.
}




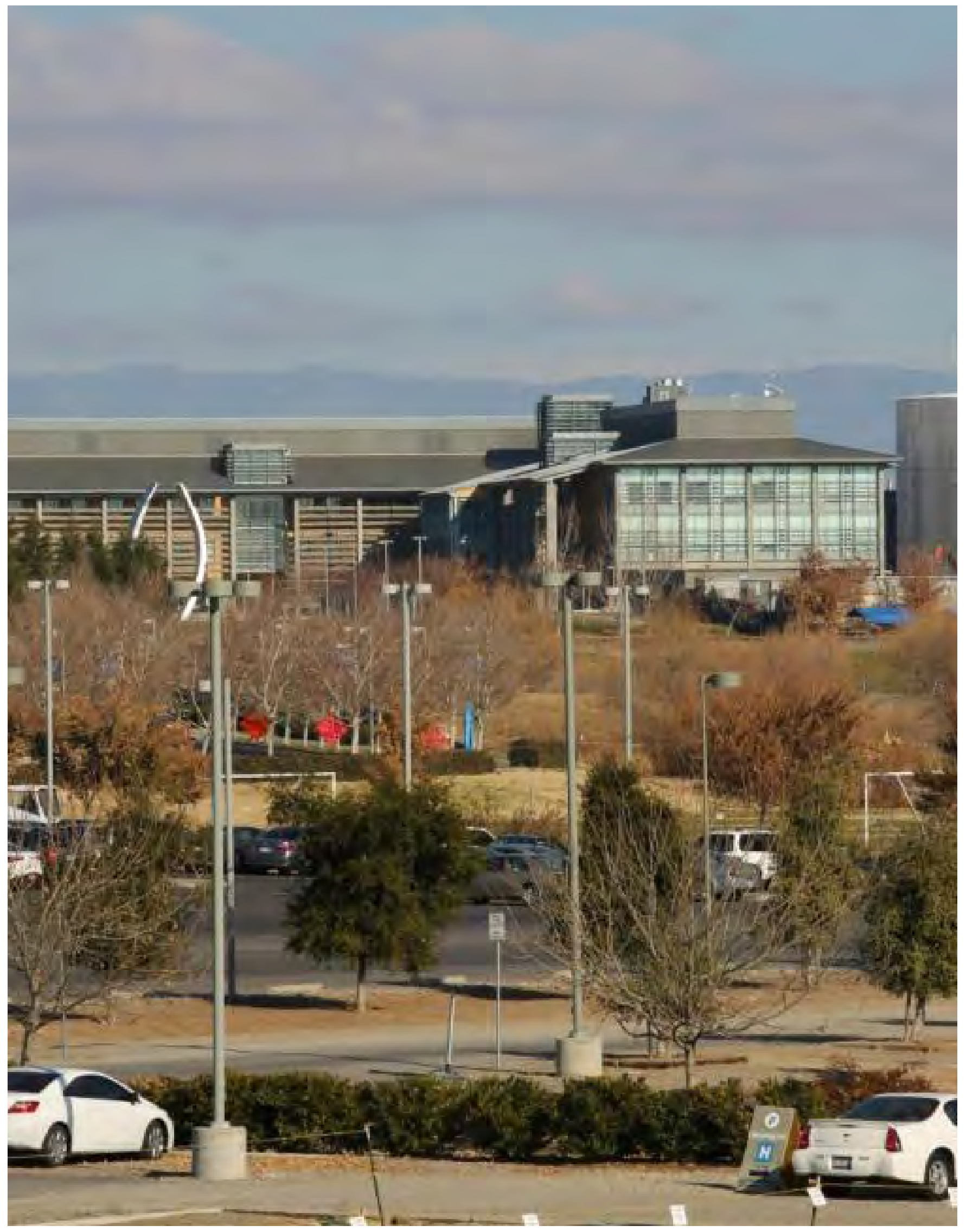




\section{VISION \& URBAN DESIGN}

The Merced Vision 2030 General Plan provides valuable direction for the Bellevue Community Plan (BCP) and is the starting point for this plan. The General Plan identifies regional features that will shape the community plan area, for example, the Merced Loop Road and interest to identify sites for future job-generating uses near UC Merced. From the City's General Plan, five core principles establish the urban design framework upon which the remainder of the structure (urban expansion, land use, transportation, public facilities and services and urban design) of the plan is based.

\section{REGIONALFATURES}

This section describes how the $\mathrm{BCP}$ implements the goals of the Merced Vision 2030 General Plan and integrates with other planning efforts in the community, specifically:

- Linkages with the Atwater-Merced Expressway / Loop Road

- Research and Development Sites

- Preservation of Downtown Cultural Center

- City of Merced Transit Corridor

- Expanded Community Arterial Network

- High Speed Rail Connection 


\section{As part of the loop road}

\section{network, Bellevue Road has the}

potential to be a much more

signific ant regional route in the

foreseeable future than other

east-west arterials shown on

the City's Circulation Plan.

\section{ATWATER-MERCED EXPRESSWAY / LOOP ROAD}

The loop concept came from the Highway 99 Major Investment Study which began in 1993 and was adopted by the Merced County Association of Governments (MCAG) in 1997. It was derived from the idea that State Highway 99 through Merced/Atwater could only fit 6 lanes on the existing footprint, although 8 lanes would be needed in the future. However, with a full loop-road, 6 lanes would suffice. The Campus Parkway segment of the loop idea came from the City of Merced's "Eastern Beltway" study. The Atwater-Merced Expressway segment originated from plans for a functional north-south state highway to replace the existing Highway 59 alignment. The components of the loop were drawn where they seemed most reasonable.

As part of the loop road network (see Figure 4 below), Bellevue Road has the potential to be a much more significant regional route in the foreseeable future than other east-west arterials shown on the City's Circulation Plan. This makes it imperative that necessary rights-of-way (ROW's) be obtained throughout its corridor, in order to ensure its future viability. Bellevue Road will also connect to the Merced-Atwater Expressway project west of Highway 59, which will ultimately connect Bellevue Road to Highway 99.

\section{Figure 4. Merced Loop System}

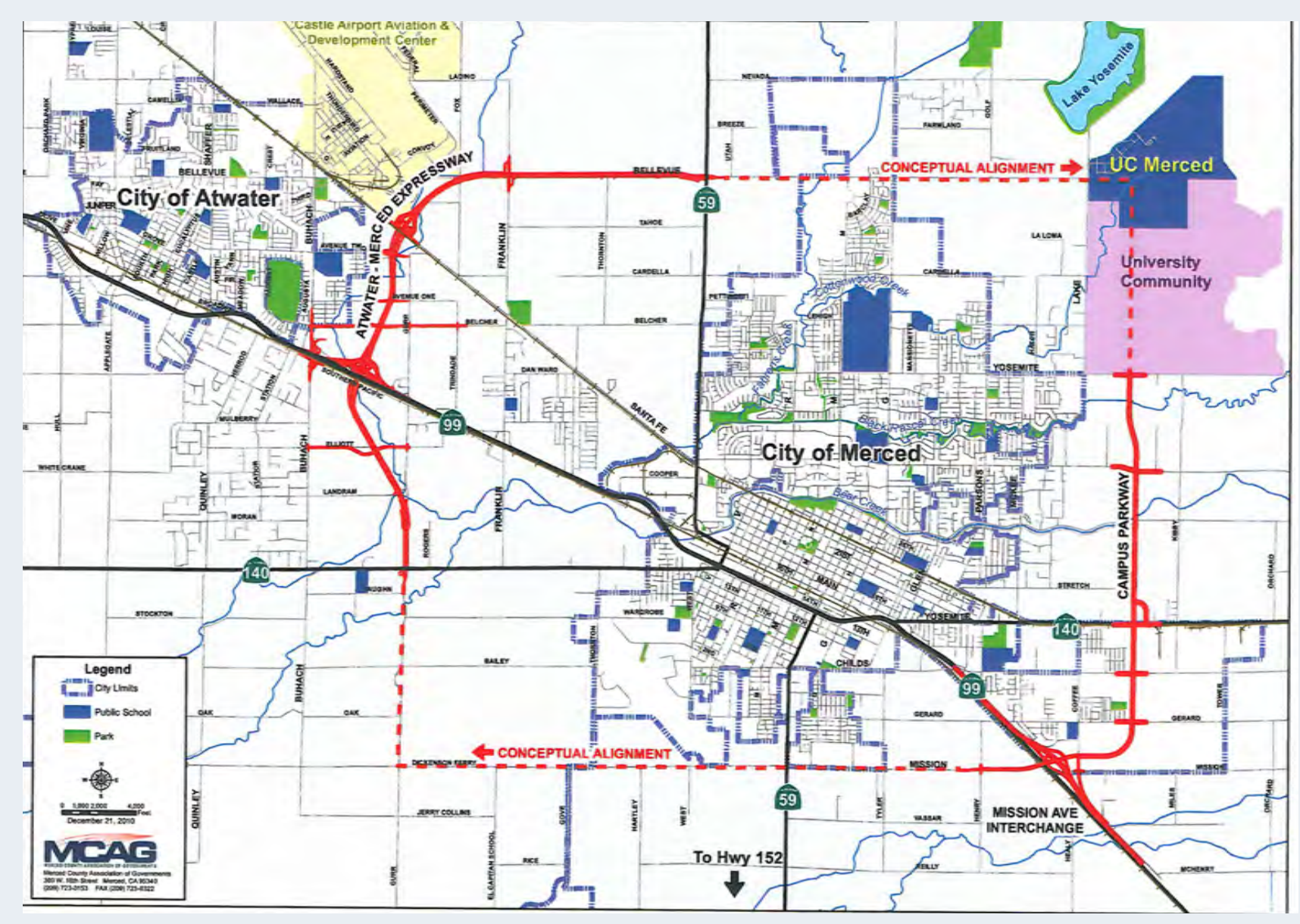

Merced County Association of Govemments, 2013 


\section{Figure 5. City of Merced Transit Conidor}

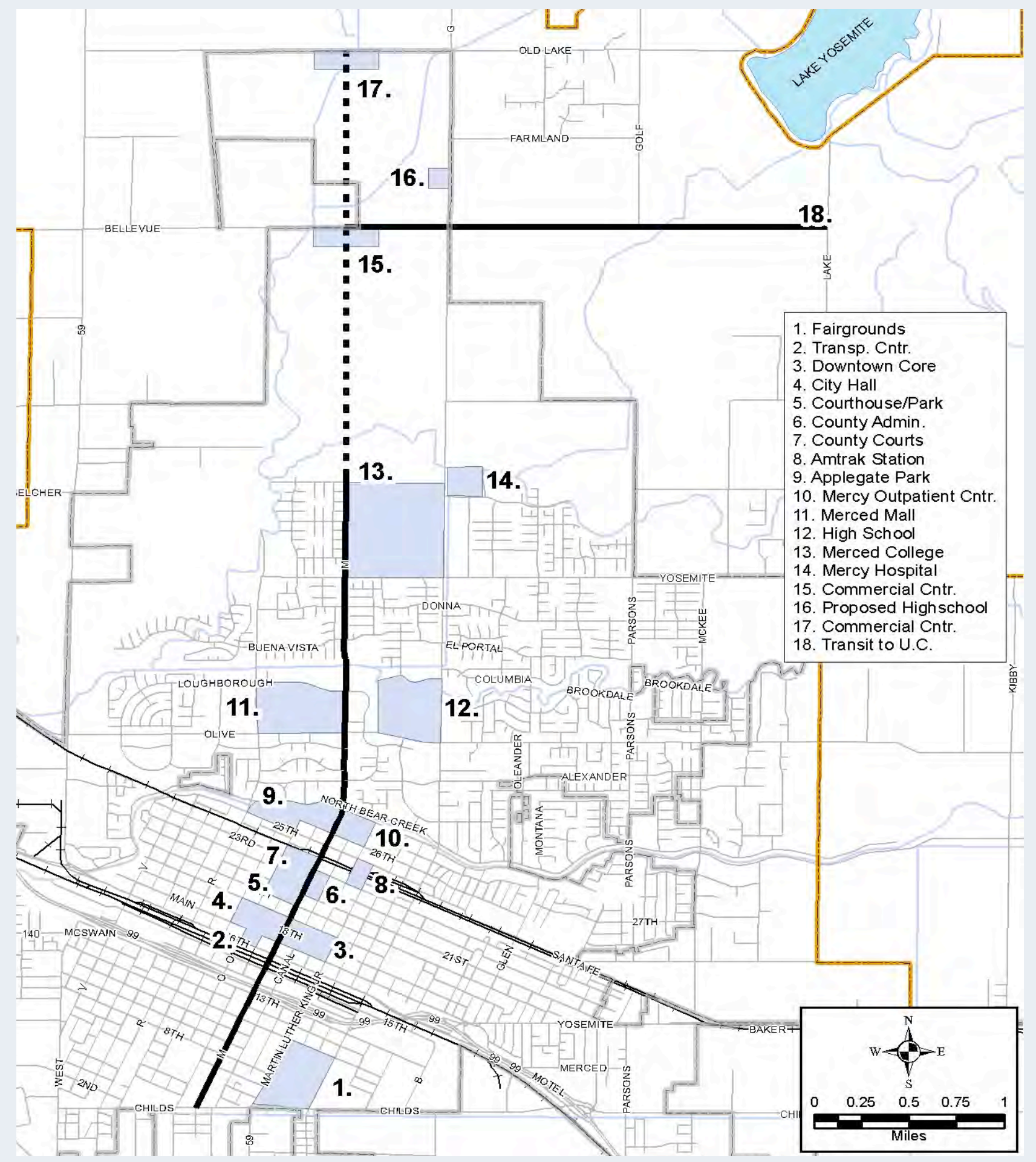


The Bellevue Community Plan

forms a critic al link in the

provision of Merced's transit

senvice, including a link to

the potential high-speed rail

station in downtown.

\section{CITY OF MERC ED TRANSITC ORRIDOR}

Numerous policies of the Merced Vision 2030 General Plan identify the need to plan for a transit corridor to connect downtown Merced with UC Merced, specifically mentioning the Bellevue Road corridor (see Figure 5). Future transit stations are proposed within UC Merced and the Bellevue Ranch Development. As such, the Bellevue Community Plan forms a critical link in the provision of Merced's transit service, including a link to the potential highspeed rail station in downtown. Building upon this foundation of a transit corridor the BCP planning process set out to examine Transit Priority Project (TPP) needs, potential locations, and design solutions, notably, to define TPPs in keeping with SB 375 and to describe anticipated transit needs for use as a key driver in establishing the land use and design elements of the Plan. Transit Priority Projects are eligible for various levels of CEQA-based permit streamlining, encouraging development that is consistent with the goals of the BCP. (See Mobility and Land Use chapters for additional information on TPPs).

\section{EXPANDED COMMUNITY ARTERIAL NETWORK}

The BCP planning area includes two arterial streets that are essential parts of regional and community-wide infrastructure needs. First, the roles and values that Bellevue Road brings to the community are numerous and essential. Already a major conduit for UC Merced related-traffic, this role will dramatically increase in the near and long-terms as improvements link the Atwater-Merced Expressway to Bellevue Road. In addition, a major entryway to UC Merced, Bellevue Road provides the community with the opportunity to create an inviting gateway to UC Merced and the City of Merced. The extension of Gardner Road to Bellevue Road in the BCP planning area will complete the City's easternmost arterial road, which when complete, will extend from Highway 99 through Southeast Merced, the eastern edge of Central Merced and all of North Merced. The completion of Cardella Road will provide important east-west traffic flow for the community. Together, these roads will serve as important linkages between UC Merced and the rest of the City of Merced. Development of these roads will also minimize traffic impacts on Lake Road. 


\section{RESEARC H AND DEVELOPMENT SITES}

The Merced Vision 2030 General Plan describes seven "Commercial and Industrial Employment Corridors" with heavy concentrations of commercial and industrial development; the BCP is one of these areas, and is described as likely containing significant amounts of job generating uses that wish to be located in close proximity to the UC Merced campus. In numerous locations, the Merced Vision 2030 General Plan describes a vision for future jobs-based land uses in the BCP planning area:

- $\quad$ Provide for increased opportunities for job-based land uses attracted by a university climate while still maintaining the basic concept of mixed-use, pedestrian, and transit oriented communities. (pages 3-71 to 3-73)

- Each of the "Urban Villages" between Lake Road and "G" Street should contain in addition to "Neighborhood Commercial," "Village Residential," and "Professional Commercial -Office," the opportunity for an expanded urban core comprised of a jobs-based office, business park or research and development type land use supported or spun-off from UC Merced. page 3-56.

- The plan should assess the viability of expanding office, commercial, and research and development land use capacities in the plan area (pages 3-71 to 3-73)

- Some of the land uses could connect to research and development activities associated with the campus research programs or professional services associated with the campus's professional schools. (pages 3-71 to 3-73)
The City of Merced Vision 2030

General Plan enc ourages the expansion of office, commercial, and research and development land use capacities in the Bellevue Conidor Plan Area.

\section{Example of R\&D Site}

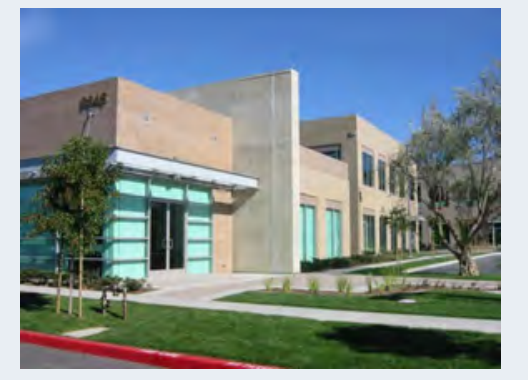




\section{CA High Speec Rail}

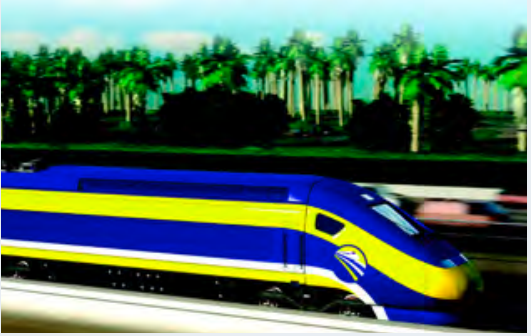

The construction of the proposed High Speed Rail system would provide new jobs for Merced residents and help connect Merced to lange population and job centers throughout the State.

To balance the need for regional vehic ular access to UCM and the BCP area with the imperatives of pedestrianoriented, transit-ready mixed-use neighborhood development, a conceptual network of "c omplete streets" forms the framework of the BCP.

\section{HIGH SPEED RAIL}

The proposed High Speed Rail system will connect San Francisco to Los Angeles, with a large portion of the system running through the Central Valley with a station in Merced, see Figure 6.

\section{Figure 6. Califomia High Speed Rail Proposed Alignment}

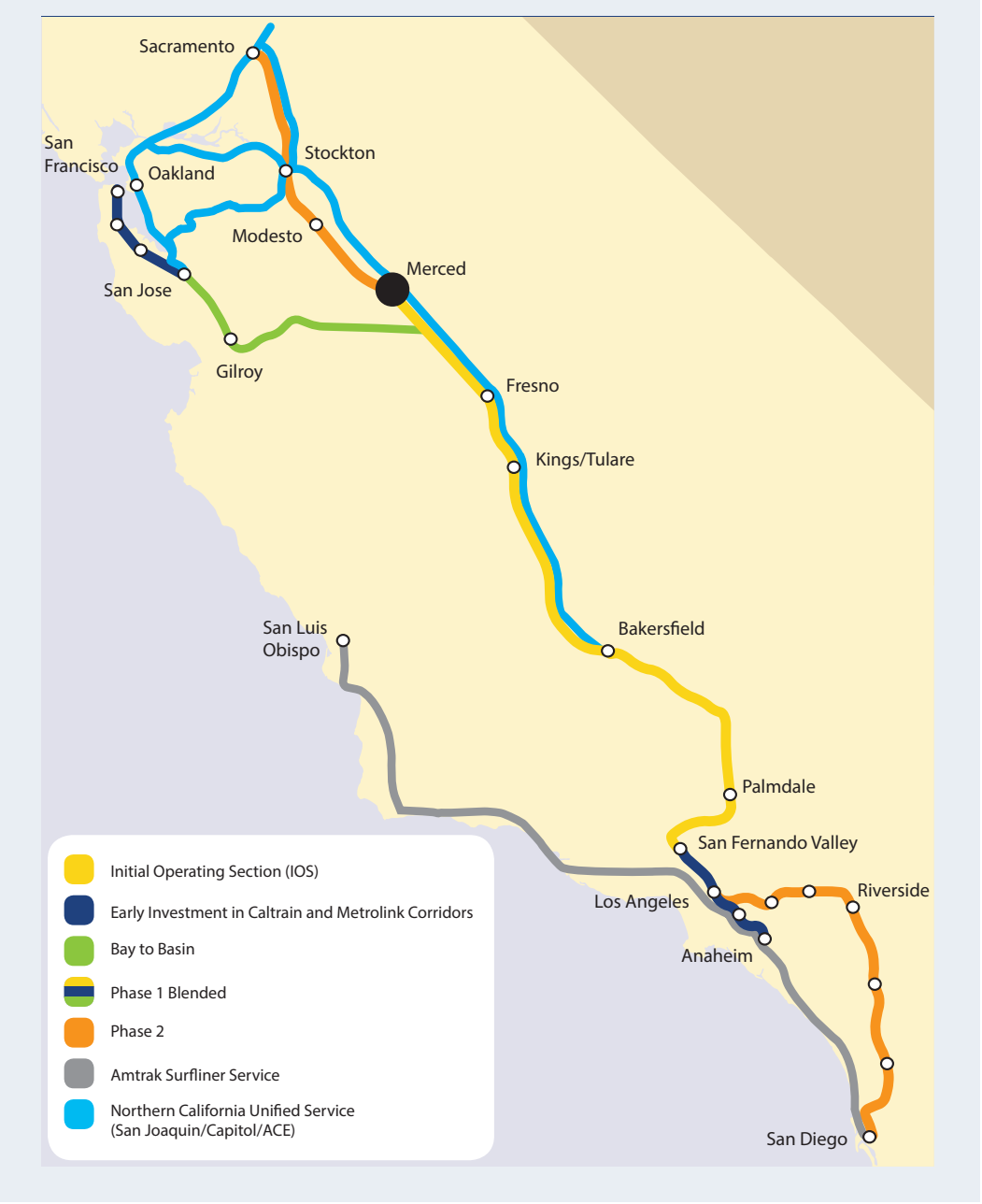

Since UC Merced would be a significant attraction for potential riders of the HSR, demand for transportation linkages between the HSR station and UC Merced will develop. Thus, the BCP will need to include designs and infrastructure that accommodate transit and supporting modes of transportation linked to the proposed High Speed Rail station in Merced.

\section{CORE PRINCIPLES}

\section{INTERCONNEC TED NETWORK/COMPLETE STREETS}

To balance the need for regional vehicular access to UCM and the BCP area with the imperatives of pedestrian-oriented, transit-ready mixed-use neighborhood development, a conceptual network of "complete streets" forms the framework of the BCP. Complete local and collector streets - 
designed to provide a relatively quiet, low-speed driving environment that is safe and comfortable for pedestrians and bicyclists - organize the area into walkable blocks, which are variable in size and shape to accommodate a very wide range of land uses and development types. This network of local and collector streets is carefully connected to the major cross-town arterial corridors at widely spaced intersections to ensure that the vehicular capacity of those corridors is maintained. Frontage roads (also known as side access lanes) may be appropriate along Bellevue Road to allow abutting development to face the corridors to create an attractive urban "gateway", rather than turning their backs to face local streets.

\section{Figure 7. Illustration of an Interc onnected Block Stucture}

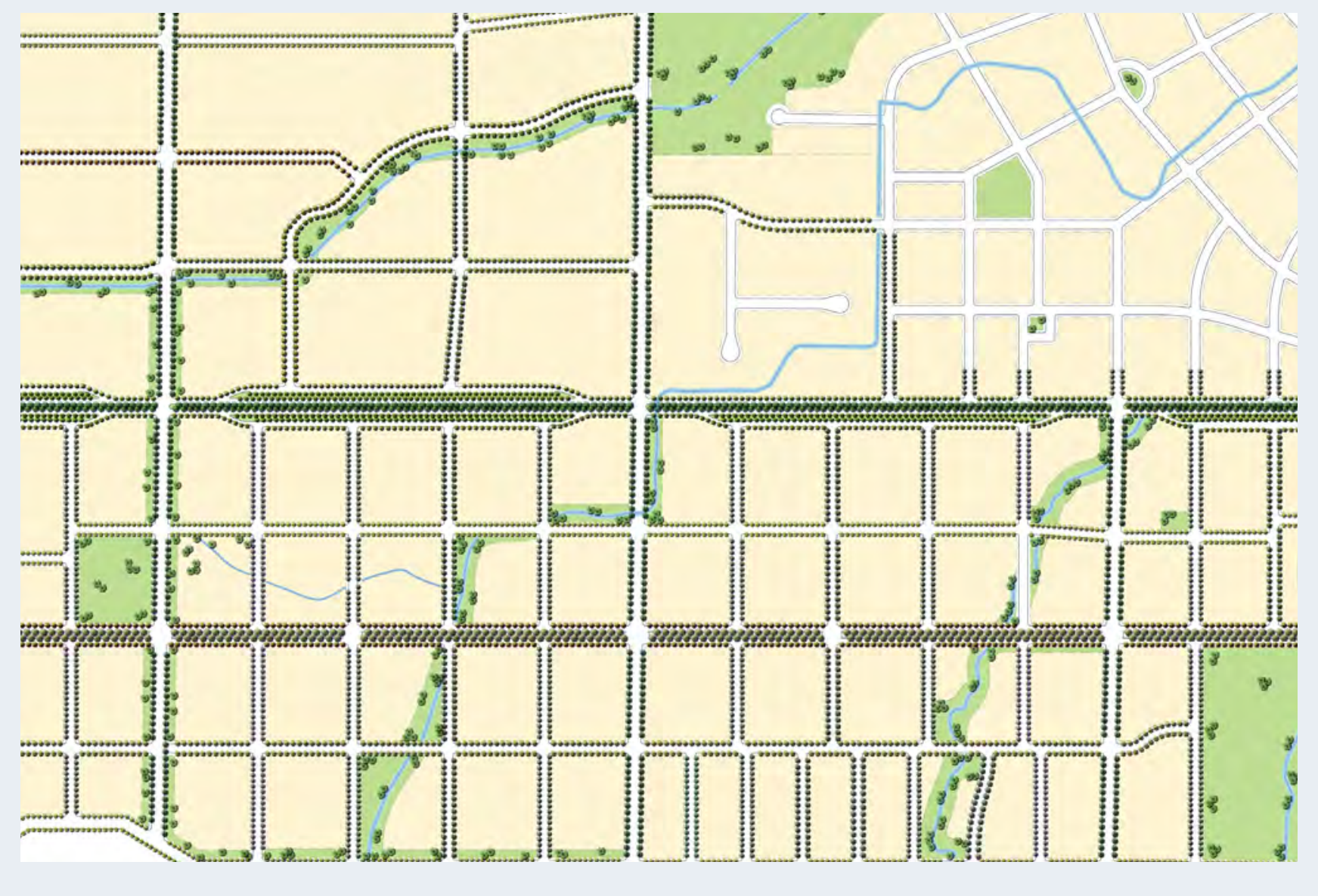

\section{NATURAL LANDFORMS}

The conceptual street network is shown to generally follow the natural contours of the site to preserve the natural landforms of the BCP. These subtle but distinctive landforms include a number of natural drainages and a low hill at the center of the BCP area, just south of Bellevue Road and straddling Gardner Road. Because Gardner Road is a major north-south circulation corridor - and because the grades along its trajectory are not severe - it is not diverted to follow topographic contours, but streets to the east should bend to conform to the natural contours and adjacent seasonal creek. The pattern of curving streets is truncated to the west of Gardner, because the southwest 


\section{Innovation Hub to Promote STEM Employment and Attract R\&D Development}

\section{Excerpt from the Brookings Institute Report The Hidden STEM Economy:}

"Today, there are two STEM (Science, Technology, Engineering, \& Math) economies. The professional STEM economy of today is c losely linked to graduate school education, maintains close links with research universities, but functions mostly in the corporate sec tor. It plays a vital function in keeping Americ an businesses on the cutting edge of technological development and deployment. Its workers a re generally compensated extremely well. The sec ond STEM economy draws from high schools, workshops, vocational schools, and community colleges. These workers today a re less likely to be directly involved in invention, but they are critical to the implementation of new ideas, and advise researchers on fea sibility of design options, cost estimates, and other practic al aspects of technological development. Skilled technicians produce, install, and repa ir the products and production machines patented by professional researchers, allowing firms to reach their markets, reduce product defects, create process innovations, and enhance productivity. These technicians also develop and mainta in the nation's energy supply, elec tric al grid, and infra struc ture."

By providing a mple space in the BCP for innovative businesses to thrive, the City of Merced can better position itself to support both levels of STEM economies. Through connecting with both UC Merced and Merced College, businesses will be able to access a range of STEM workers to support direct flows of information between the universities and surrounding enterprises. quadrant of the hill lies outside the BCP. However a similar pattern in that area would help to implement the General Plan intentions that development be designed in harmony with the natural land.

\section{Natural Hill Landform near UC Merced within the BCP}

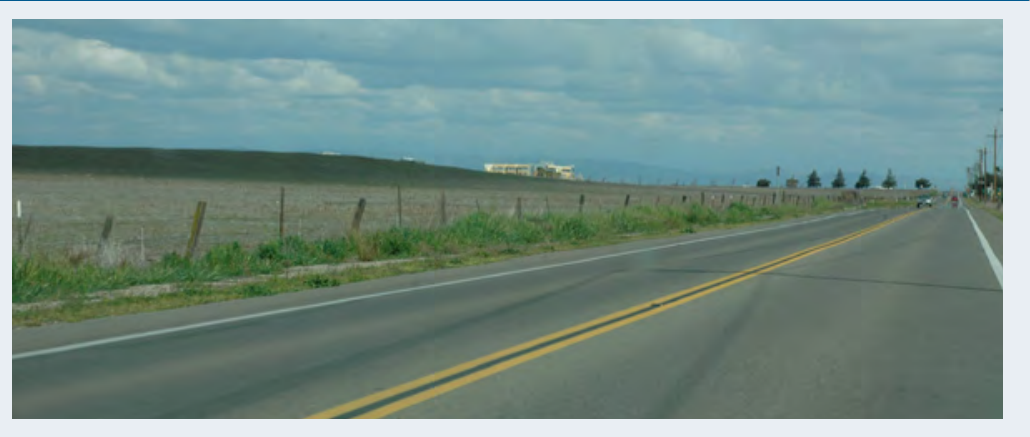

Single-loaded "drives" are recommended for selected creekfront stretches of these streets, affording motorists, pedestrians, and cyclists views of natural greenways containing preserved and enhanced creeks, rather than relegating the creeks to "drainage alleys" running along the back sides of private properties.

\section{Example of a Single-loaded Drive}

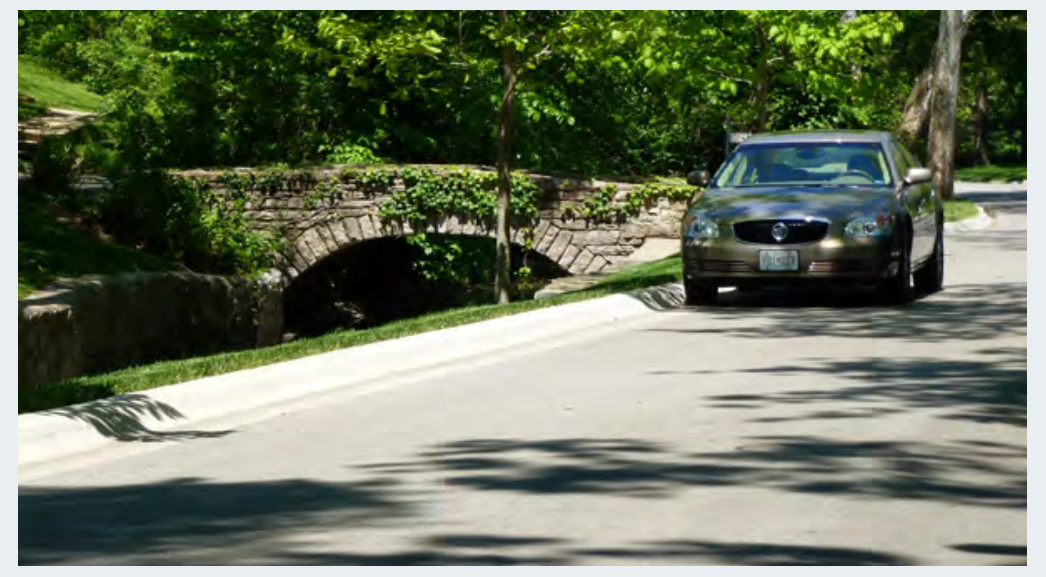

The land uses prioritized for the hilltop area include research and development and potentially multi-family housing as well, either or both of which could benefit from such a central and attractive location.

\section{INNOVATION HUB}

The BCP provides an opportunity for UC Merced and the community to fuse and become a hub for innovation in the Central Valley. An innovation hub is a place that supports the flow of information. Innovation can be any groundbreaking approach, idea, or advancement that changes the way we live, work, and play. Through this direct flow of information among the University and surrounding enterprises original ideas can manifest from an educational thought to a service or product on the market. 
Figure 8. Illustration of Possible Gateway Design Overlay Along Bellevue

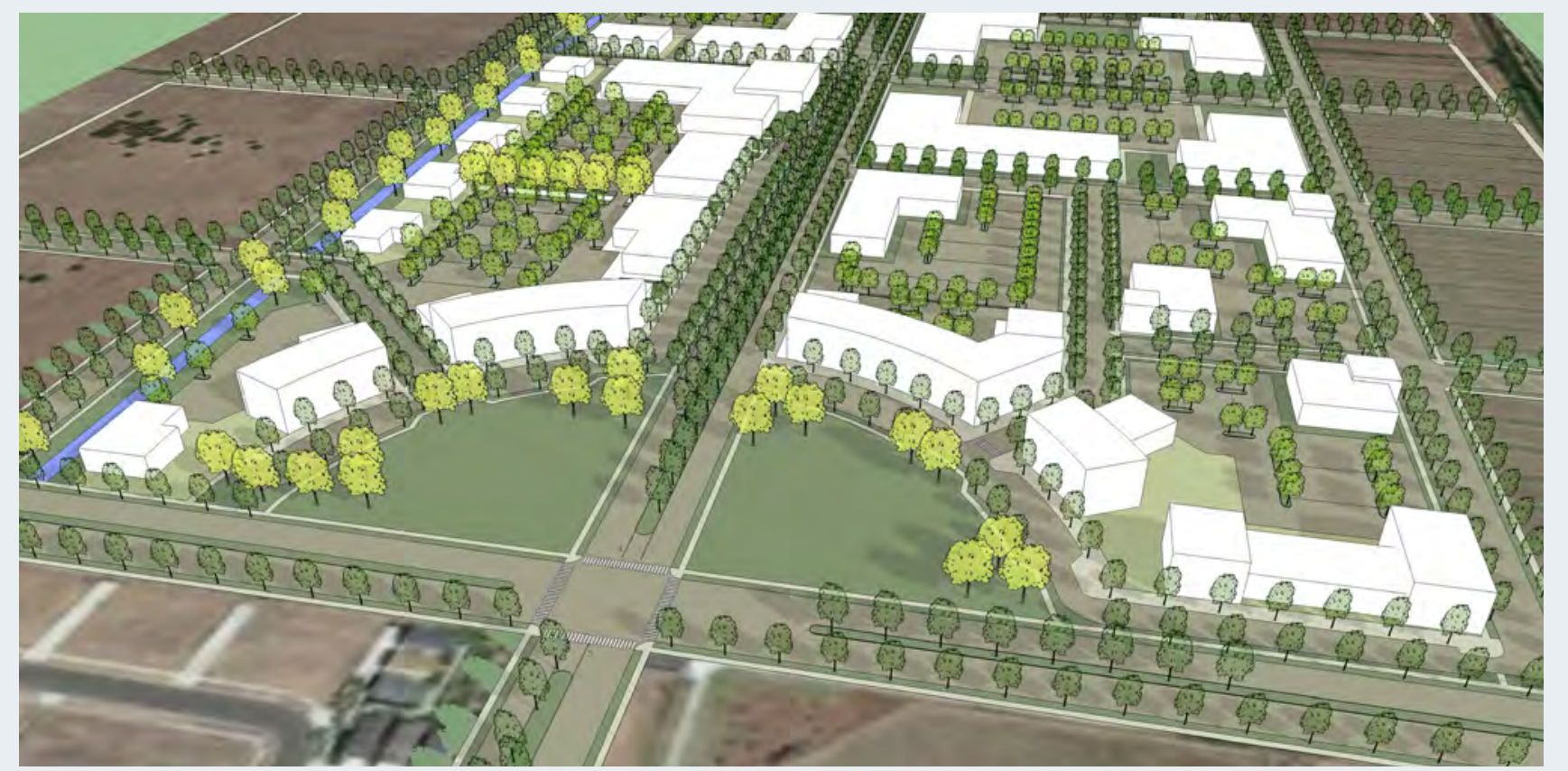

By planning the BCP as an innovation hub it is possible to increase the potential for businesses to take innovative ideas from mind to market using this type of environment. Innovation starts with the under-story of the economic food chain, the entrepreneurs, which would located in this type of setting.

The creation of collaborative work environments interlaced with walkable, transit-oriented places to meet, network, and provide housing for employees is essential to supporting entrepreneurial businesses who value face-to-face interaction. This type of physical environment encourages groups of diverse, future-oriented thinkers who have the potential to advance the economy despite downturns to locate in Merced. Innovation is about people, and it is important to foster an environment that facilitates interaction among individuals. Thus, it is important to create public spaces of interest to attract a variety of people with varying ideas and perspectives. Tech firms value public realms that foster a melting pot of ideas.

\section{GATEWAYS TO UC MERCED}

Both Lake Road and Bellevue Road are identified as scenic corridors in the Merced Vision 2030 General Plan. The position of UC Merced at their intersection further emphasizes the need to enhance the visual character of these roads and to create attractive entryways. In the long-term, Bellevue Road will accommodate regional vehicular traffic, whereas Lake Road will be a local road emphasized by low vehicle speeds and continuous pedestrian and bicycle pathways. Collaboration between the City of Merced and Merced County is needed to craft detailed design standards for these roadways and adjacent properties.
Both Lake Road and Bellevue

Road are identified as scenic comidors in the Merced Vision 2030 General Plan. The position of UC Merced at their intersection further emphasizes the need to enhance the visual character of these roads and to create attrac tive entryways. 
Image of UC Merced's Centrial Plant received a LEED Gold rating

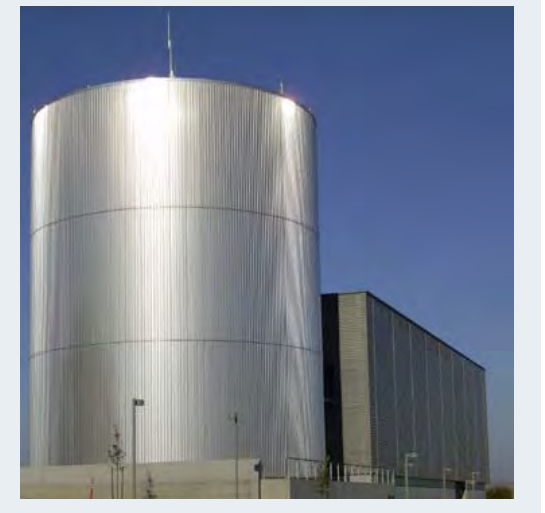

\section{BELLEVUE BOULEVARD}

The BCP envisions Bellevue Road as a landscaped boulevard to UC Merced, and sufficient room for 4-lanes or 6-lanes (if needed). Bellevue Road would also be defined by a cohesive design for buildings that address the street to create an awe-inspiring and eye-pleasing gateway to the Central Valley's only UC campus. As an important gateway, a boulevard to UC Merced, the character of the Bellevue corridor should be attractive and not a default solution. Land uses at the G Street and Gardner Road intersections should exhibit a proud welcoming gateway to the Bellevue Corridor and "driveway" towards UC Merced.

\section{LAKE ROAD}

In the long-term, regional and community north-south oriented traffic will occur on the Campus Parkway Expressway to the east of Lake Road. Consistent with the traffic study for UC Merced and the northern portion of the University Community, the function of Lake Road will serve local traffic, creating an opportunity to emphasize a linear open space corridor with strong pedestrian and bicycle facilities, along with a landscaped buffer between the rural residential properties to the west of the more intensely developed University Community.

\section{NATURAL RESOURC ES AND ENERGY UTUZATION}

The University of California, Merced has set standards in sustainable planning and environmentally forward design. In order to build upon the framework established by UCM, the BCP carries forward many of the UCM Long Range Development Plan goals and strategies for sustainability while adapting them to address the constraints of the plan area. The UCM Long Range Development Plan principles were created using a triple net zero commitment:

\section{Figure 9. UCM Thiple Zero Commitments}

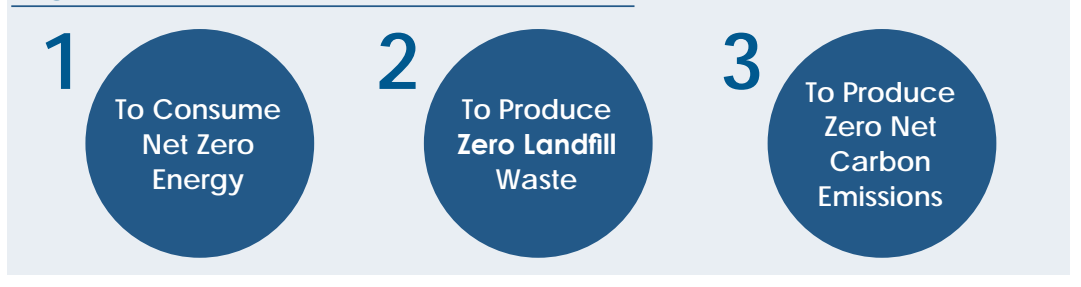

Using the model set by $\mathrm{UCM}$, the $\mathrm{BCP}$ should also encourage and utilize renewable sources of energy including solar, wind, biomass, and geothermal power. UCM plans to acheive all three triple net zero commitments shown above by 2020. The City of Merced and the BCP are commited to adhering to principles of sustainable environmental stewardship, conservation and habitat protection in the planning, design, and construction phases of the $\mathrm{BCP}$ area. While protecting the natural environment and conserving resources is of the utmost importance, newly constructed buildings should maximize energy efficiency and include passive environmental systems such as shading, orientation, and roof configuration. Buildings should also strive to achieve U.S. Green Building Council LEED certification. Landscaping should also be designed to conserve water and recharge groundwater supplies. Likewise, roadways, parking lots, and circulation pathways should minimize, detain, and filter stormwater run off. 


\section{PLAN STRUCTURE \\ URBAN DESIGN}

The focus of new development will be mixed-use, pedestrian and transit-ready communities, with standards that make the BCP area a gateway to UC Merced and encourage employment-generating uses. Lower-density residential land uses to the north and south of the focus area will form a compatible transition to the existing residential neighborhoods.

\section{MOBIUTY}

The circulation network for the BCP should balance the need for efficient regional access for motorists with the need for safe and efficient local circulation by pedestrians, bicyclists, transit and automobiles. Innovative designs for the major roadways - including Bellevue Road - and for an interconnected network of local streets and collectors are encouraged to achieve this balance.

\section{OPEN SPACE, CONSERVATION, AND RECREATION}

The BCP takes an innovative approach to ensuring an interconnected network of parks, trails, and multi-use open space areas. This approach understands that connectivity between open space and recreational areas is as important as the quantity of space.

\section{COMMUNITY CHARACTER}

New development should take the form of complete, mixed-use, mixeddensity, walkable, bikable and transit-oriented neighborhood patterns. These patterns, based on the City's urban design principles, should integrate singlefamily, multi-family and commercial development, along with significant employment centers for new research and development businesses related to the growing success of UC Merced. To ensure well-connected and integrated development patterns, require that each sub-area be master planned prior to development of individual projects. (See Chapter 6 for more information on implementation.)

\section{URBAN EXPANSION}

Urban expansion should be contiguous with existing developed areas to avoid fiscally unsustainable "leap frog" development. New development should employ compact, efficient and mixed-use urban forms that do not unnecessarily or prematurely consume or fragment agricultural land, rural land, or other non-renewable resources. Expansion in the BCP area should be coordinated with the UCM campus and other community plans, and should be oriented in relation to the existing and planned corridors connecting the City with UCM.

\section{PUBUC FACIUTIES AND SERVICES}

Plan for the orderly, phased expansion of urban services - including but not limited to utility systems and public safety facilities - in coordination with new development. The capital cost and operating expenses of such systems should be fiscally sustainable and equitably borne by the benefiting parties. 
While the BCP provides a broad range of use and densities that could occur, it emphasizes the foundational building blocks (of street connec tivity, transit use, etc.) to create a sense of great place with investment certainty.

\section{PLAN FRAMEWORK AND FLEXIBILITY}

The BCP is a framework and a set of principles/strategies to help the City expand in a more fiscally sustainable manner and to manage a number of "critical uncertainties" to increase the chances of building an interconnected set of valuable pedestrian and transit-oriented places over a long time. These uncertainties point to the need for the BCP to be flexible, but to establish a vision so that when the area develops, the BCP guides new growth toward the community vision for the area. The BCP faced many critical uncertainties during the creation of the plan including the following:

- The timeline for build out of the plan area is not known. Any improvement or condition that is conceived of as "interim" may last a year or 25 years.

- $\quad$ The timeline for buildout of the adjacent University Community Plan area is unknown.

- The growth rate for UC Merced may vary and could grow at a rate as planned, faster, or even slower than predicted.

- The development of the California High-Speed Rail is unpredictable and could impact the demand for space in the city.

- Location, timing, and funding of sewer and water line improvements could prevent buildout of the plan area if not adequately identified or established.

\section{A RAMEWORK OF CERTAINTY}

The BCP is a long-term document with a tremendous amount of uncertainty as described above. As such, the plan has a policy framework so when future master planning occurs there is a comprehensive approach in place that is supported by the community. However, since development in the BCP will occur over the long-term, it is important to build flexibility into the plan document. The intent of plan is to be flexible and to adapt to market changes. The BCP contains minimum and maximum development standards that are crafted with flexibility to enable the plan to respond to future markets.

While the BCP provides a broad range of uses and densities that could occur, it emphasizes the foundational building blocks (of street connectivity, transit use, etc.) to create a great sense of place with investment certainty through the neighborhood master planning process as described in Chapter 5. The BCP is geared to make projects that are connected to their neighbors and to the transit spine with complete, walkable streets, so the City creates a systematic development where the next development is framed by the preceding development site, and the City is not left with a smattering of projects, but rather the development of a vision. 
This page intentionally left blank. 


\section{PLAN VISION AND STRATEG IES}

Throughout development of the Plan, members of the BCP Ad-hoc Citizen Advisory Committee and the community expressed their desired outcomes of the Plan, which can be summarized as a Plan that will create a community that is a beacon of pride for the San Joaquin Valley and the people of the State of California as a whole. Specifically, the community vision including achieving the following outcomes:

\section{Table 2 Citizen Advisory Committee Desired Outcomes of the Bellevue Conidor Community Plan}

\section{Community Support}

A plan developed out of public outreach and input

A plan reviewed by the development community

\section{Neighborhood Compatibility}

Plan elements that provide compatibility with existing 1-acre lots.

A plan that is not offensive to existing residents

A plan that maintains the quality of life for existing residents

\section{Mobility/Circulation}

A plan that includes an off-street pedestrian/bike path that parallels Bellevue Road.

A plan that provides a greater a wa reness of cyclists, pedestrians and users of a ltema tive forms of transportation as a legitimate part of the community, and for their safety as it rela tes to other vehic les.

A plan that includesa light rail easement to Castle Aiport and Atwater.

A plan that results in traffic flow, not congestion, in the area near the campus.

A plan that respects existing property owners a long Bellevue Road, and other plan elements that provide compatibility with existing 1-acre lots.

A Plan that connects with downtown at all transportation scales.

A Plan that motivates people to live and work in the Plan area and not migrate to other communities or into famland areas.

\section{Land Use}

A plan that includes economic ally feasible variety of land uses that are compatible with UCM.

A 21 st Century Plan looking to the future and with adequate flexibilitly to accomodate future technological developments.

An appropriate range of new neighborhoods, commercial centers and transition a reasthat are anticipated to occur due to UC Merced.

A Plan that is responsive to how the younger population wishes to live; not everyone wants to live in single family homes. How we live today is going to be different from how they choose to live in the future.

A Plan that looks at the long-term, and is not reactive to the immediacy of the current market. 


\section{Business Growth}

A plan that supports business growth.

A plan that maintains the quality of life for Merced, while providing economic development of the area.

A plan that emphasizes the establishment of susta inable jobs and creative uses.

A Plan that exhibits environmentally and technologic ally forward thinking, as demonstrated in the development of the UCM campus itself.

Design/ Aesthetics

Create an attractive gateway for UC Merced.

\section{A Comprehensive Long-Term Infrastructure Plan}

A plan that dovetails with University Community Plan a rea, and includes an infrastructure plan that is compatible with the larger planning area.

A comprehensive plan, integrated with other planning efforts, for example, the Atwater-Merced Expressway effort.

An infrastructure plan that provides for long-term future growth.

A plan that addresses the interface with the community of Merced, including small-scale connectivity between the City and Campus, not simply by regional improvements.

\section{Coordinated Growth}

A plan that coordinates rather than competes with other planning efforts.

A plan that addresses the interface between the Plan area and UCM, making sure there is proper synergy between the plan a reas.

Well thought out and careful planning approach for future growth that serves the City of Merced, County, and property owners.

\section{Govemance}

Plan elements that describe the regulatory "interface" (responsibility and obligations) between property owners and local governments 


\section{BELLEVUE COMMUNITY PLAN GOALS AND POLICIES}

The goal headings of this BCP chapter are grouped into the same policy topics as the Merced Vision 2030 General Plan. This approach fosters consistency and builds on the City's broader General Plan guidance. In furtherance of consistency with the City's General Plan, Appendix C, policies specific to the BCP planning area are described in greater detail and grouped with the goals and policies it shares in common with the City's General Plan. In additions to the goals and policies below, Master Plans/projects/permit applications need to take into account the BCP in its entirety and be consistent with the language herein.

Table 3 Vision and Urban Design Goals and Policies Specific to the Bellevue Corridor Community Plan consistent with the City's General Plan

\section{Goal Area UD-1: Transit-Ready Development or Urban Villages}

\section{Policy UD-1.1: Orient buildings to address the street}

Creating a physical environment that encourages pedestrian and transit tra vel is more than simply providing a sidewalk. Actual use is based on the design of a djacent uses and proximity to a va riety of uses. Positioning buildings next to the street and sidewalk (addressing) creates a pleasing environment for the pedestrian where they can enjoy proximity to build ing entrances, window displays, a rchitec tural interest, and other people. This context attracts pedestrians and provides a worthwhile retum of the City's investment to construct and occupy space within a public right-of-way.

Policy UD-1.2: Seek to provide inc ubator-spaces for small businesses.

Through zoning, site design planning and economic development tools, seek to provide spaces throughout the planning area, but notably within the Mandeville Corridor, that offer office, retail and small-scale manufacturing inc ubator-sites for entrep reneurs who a re attracted to a university setting.

Policy UD-1.3: Strive to meet the commercial services of not only students, but the local community as well.

Serving a diversified market guarantees services and related activities year-round, not just during the academic schedule. A variety of retail outlets should be present in the BCP to reflect the interests of a diverse population.

\section{Policy UD-1.4: Seek to attract and retain entrepreneurs and UCM graduates.}

Some of the most importa nt meetings are sponta neous. Sponta neous meetings occur when paths intersect while traveling from one place to a nother or standing in line for coffee orlunch. Chance interactions have the qualities of being informative, creative, and social in an important way that reinforces relationships. The Bellevue Corridor should be a place that enables such interactions, such as:

Housing: To encourage the flow of ideas, the BCP should not only have places to meet, but a population to fill such space. The population in the BCP will include: 1) researchers expanding on current and new research and development; 2) students and graduates; 3) young families seeking new business or research opportunities; 4) those wanting to embrace a lifestyle of creativity with the incorporation of thoughts inspired by surrounding people; 5) entrepreneurs who wish to be part of an innovative community; and, 6) small business owners in an innovative community (restaurants, coffee shops, boutiques, apparel stores).

Events and Activities: Support a nd encoura ge famers-ma rkets for loc al farmers and shop pers, live music to showcase local talent, or other events available to community residents, hosted by local businesses throughout the BCP.

Pedestrian-Related Street Components: Develop streetsc a pes with a mple a menities such as la nd sc a ping, sha de trees, generous sidewalks, street fumiture, signage, lighting, and art to promote pedestrian movement, community attractiveness, and infomal meeting spaces. Done right, pedestrian-related street components can spark street-level intera ction and maximize the potential for informal contact of the average person in a given public space at a ny given time.

Scale: To assure frequent interactions, ensure that pedestrian-sc ale design exists throughout the plan area, but partic ularly in highly populated areas. At the ind ividual space level, indoor a nd outdoor spaces will be intimate and active enough to encourage people to meet or stop to engage when they encounter one another. 


\section{Goal Area UD-2: Overall Community Appearance}

\section{Policy UD-2.1: Development of private and public lands will seek to maintain existing topographical features.}

The hilly terra in in the planning a rea is unique to the City of Merced and should be maintained. The vista and swale topography provide opportunities for open space corridors, curving roadways, and distinct place-making opportunities whether on public or private lands. Removal of large amounts of soil should be avoided; rather the development should fit the character of the land.

Policy UD-2.2: Working in cooperation with the County, the City shall propose development standards for Bellevue Road and Lake Road.

Both Lake Road and Bellevue Road and adjacent environs should be constructed as important gateway roads. Development standards should include a unique roadway cross-section, a ppropria te siting and aesthetic a rchitecture of adjacent buildingsand required yard a reas, a complementary street fumiture zone (where appropriate), and landscaping both within and along the rights-of-way. The character of these streets should be unique and attractive, and be asmuch a gateway to UC Merced as a gateway to the City of Merced. Landscaping shall be included within these rights-of-way to create a Boulevard appearance. 


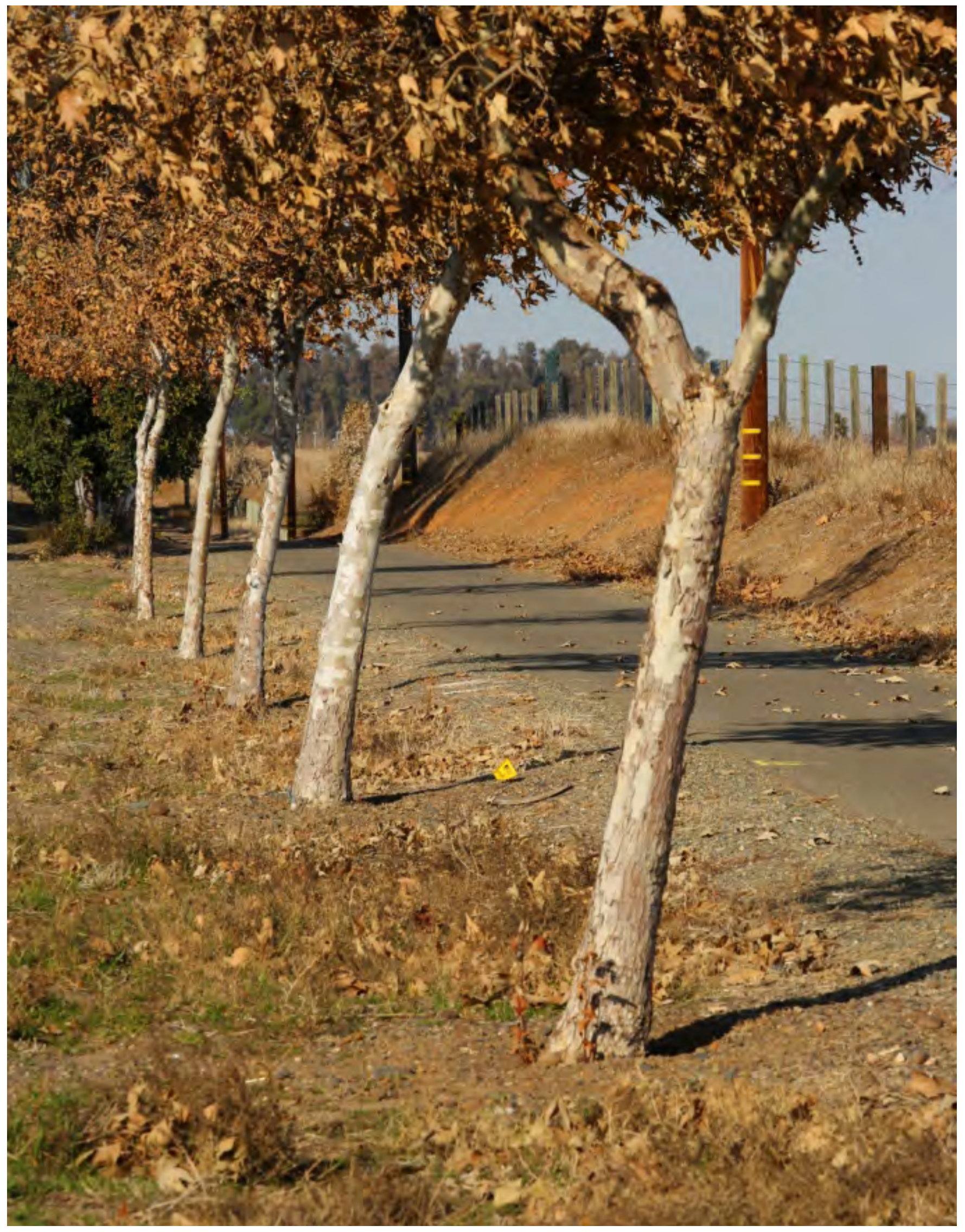




\section{MOBILTY}

Consistent with State Law and building on the goals of the City's Merced Vision 2030 General Plan, the BCP mobility plan integrates a multi-modal system comprised of automobiles, a public transit system (rubber tire or light rail), as well as bicycles and pedestrians. Each mode is a component of a comprehensive mobility plan. Hinged to this goal of Complete Streets are many supportive features that are foundational to the success of each mode of transportation. In this context, the $\mathrm{BCP}$ provides a greater awareness of cyclists, pedestrians and users of alternative forms of transportation as a legitimate part of the community, and for their safety as it relates to other vehicles.

Circulation planning is more than including a sidewalk for pedestrians, travel lanes for automobiles, a bus stop for transit or a painted marking for bikes. While these features create spaces for various transportation modes, the essential aspect of circulation planning is attracting mode users to these spaces, which is accomplished by including supportive features in the design of the BCP. Among others, supportive features for all modes of transportation include the following, and are discussed in this chapter:

- Safe travel corridors and street crossings.

- Space for landscaping, particularly to provide a buffer for pedestrians and motor vehicles.

- Transit-ready developments.

- Connection to destinations

- Grid street pattern; and

- Parking facilities.

The use of street-related design elements vary throughout the BCP. While all forms of mobility should be represented in the design of the public rights-of-way, some areas emphasize the need to accommodate heavy loads of auto traffic, whereas others emphasize transit and associated pedestrian travel. Figure 11 indexes the various Complete Streets designs components incorporated in the BCP.

In addition, as described in Appendix D the traffic volume generated by anticipated development in the $\mathrm{BCP}$ is anticipated to be almost twenty percent lower than traffic volumes projected in the General Plan. This is primarily the result of modifications to the mix of land uses in the BCP as compared to the General Plan. However, greater reductions in traffic volumes could be achieved if future traffic studies take into account more dispersed traffic patterns and mobility mode splits. The overall benefits of the potential reductions in traffic volumes are reflected in the Plan in terms of recommendations for reductions in the number of traffic lanes (and possibly right-of-way), which could result in lower capital costs for future infrastructure and lower ongoing maintenance costs.

\section{The $B C P$ is based on the \\ "Complete Streets" concept, \\ which emphasizes use of \\ all forms of transportation, \\ inc luding automobiles, \\ pedestrians, bic ycles, and \\ public transit.}


Amtrak Service Through Downtown Merced

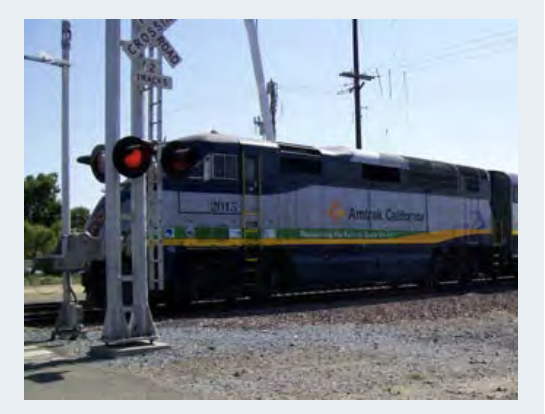

\section{SEITING}

The BCP aims to develop an integrated roadway network which achieves the City's goals while accommodating future population growth and development in the BCP area. In order to achieve a high level of multi-modal connectivity, it is important that the BCP be fully integrated into the existing and planned local and regional circulation network. The Vision and Urban Design Chapter already highlighted important regional elements of this mobility network including the Atwater-Merced Expressway/Loop Road, the City of Merced planned transit corridor, the extension of the City's community arterial network, and the potential high speed rail line and station. The section below discusses planned mobility networks in the area of the community plan.

\section{CONNECTION TO UC MERCED AND THE UNIVERSTY COMMUNIY}

The BCP area borders the UC Merced campus which is a key trip generator. The proximity to UC Merced, which is projected grow to approximately 25,000 students and 6.500 employees at full buildout, will have a significant impact on the circulation network within and around the BCP area. In order to address the future growth of UC Merced and the University Community, the BCP takes a pro-active approach to accommodating additional vehicle trips. Consistent with the complete streets focus and General Plan principles of compact and efficient development patterns, the BCP plans for future mobility needs through a multi-modal circulation network and by dispersing automobile traffic on a connected grid system. Connection points from the Bellevue Community Plan to these plan areas to the east include Cardella Road, Foothill Road, Mandeville Road (connecting with the planned transit center at UC Merced), and Bellevue Road. Bikeways are also planned to connect (see Figure 26).

\section{TRANST}

The BCP provides for increased public transit options and creates a greater ability to connect other regional transit systems, such as regional rail services or bus routes, which depart from downtown Merced and connect to surrounding cities.

\section{EXISTING TRANSITSYSTEM}

The Merced County Association of Governments (MCAG) Short Range Transit Plan 2012-2017 shows the existing network of public transit options available in Merced. Connections also provide access to Atwater, Winton, and Los Banos. Figure 10 shows existing local and regional transit routes. 
Figure 10. Existing Regional Bus Connectivity

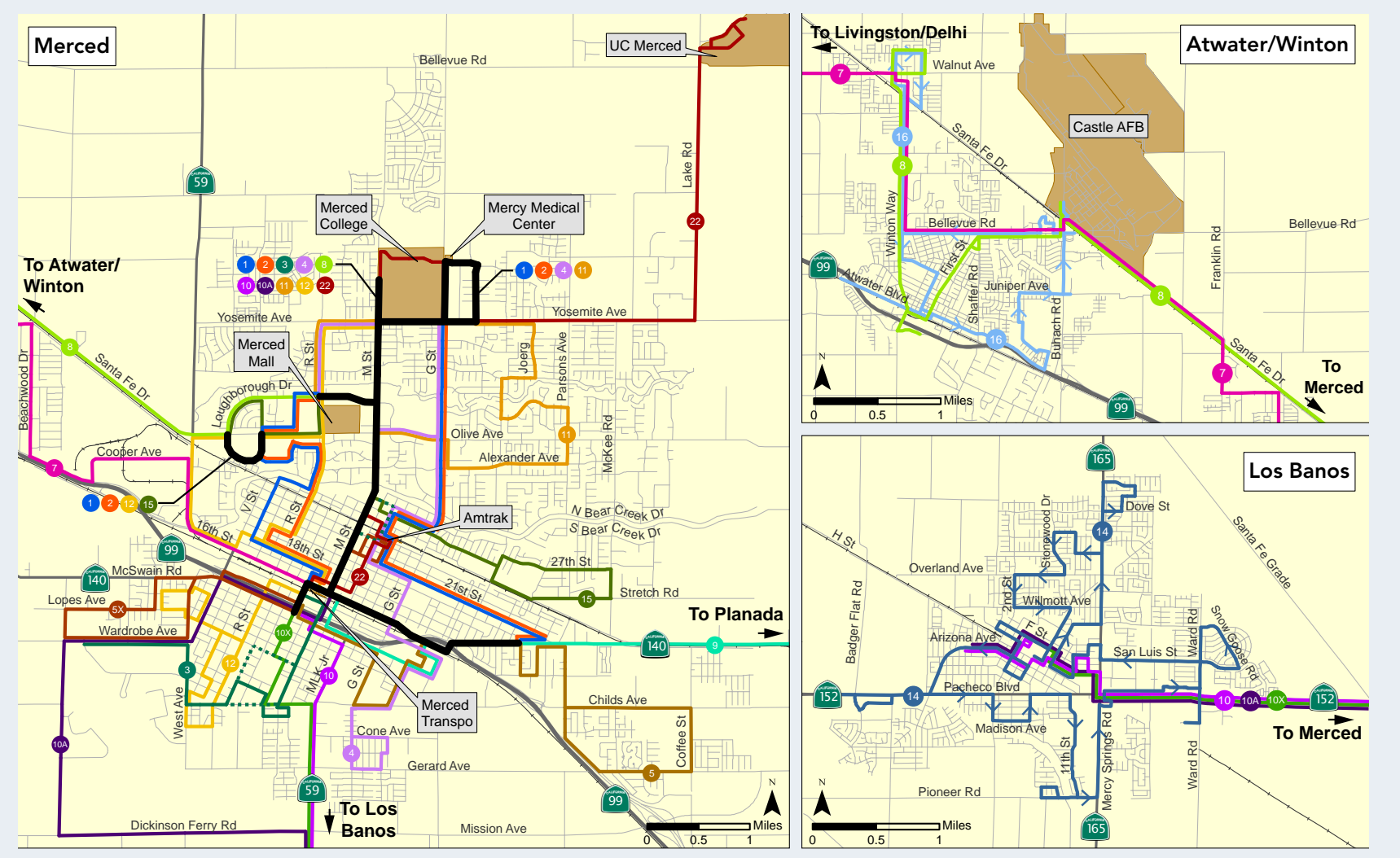

MCAG Short Range Transit Plan 2012-2017

\section{BICYCLE TRANSPORTATION NEIWORK}

Through the BCP, the City of Merced bikeway network of 22 miles of bike paths and 29 miles of bike lanes will be expanded and connect to bicycle resource rich locations, namely the Lake Road Bike Path and linkage to Lake Yosemite, and to the UC Merced campus. To match anticipated use of bicycle transportation facilities within the BCP is anticipated to be extensive. Bikeways will serve pedestrian traffic too, and together support an active lifestyle within the community.

\section{TRAFC REDUCTION STRATEGIES}

Based on the Merced Vision 2030 General Plan traffic volumes are anticipated to increase. Bellevue Road may experience traffic volumes up to 50,000 to 60,000 daily vehicles trips (DVT) with 30,000 to 40,000 DVT on Cardella Road, and over 30,000 DVT on G Street. To maintain adequate levels of service while encouraging complete streets and walkability, the BCP emphasizes alternative strategies to meet this increased demand, including the development of a smaller street grid network. Additionally, the General Plan 50,000 to 60,000 DVT estimate is based on employees and consumers commuting from outside of Merced. The BCP addresses the imbalance between jobs and housing, reducing the inflow of vehicle trips, as many of these trips could be accommodated locally, with other forms of transportation. 


\section{COMPLEIE STREEIS}

\section{MULTI-MODAL}

On September 30, 2008, Governor Arnold Schwarzenegger signed Assembly Bill 1358, the California CompleteStreets Act. The Act directs local jurisdictions to find innovative ways to reduce vehicle miles traveled (VMT) and to shift from short trips in the automobile to biking, walking, and use of public transit through the establishment of a balanced multi-modal transportation network.

There are many "Complete Street" Implementing Actions in the City's General Plan that also apply to the $\mathrm{BCP}$ area, including Implementation Action 2.1.d, which states, "The Bellevue Corridor and other important corridors should be designed using the "Complete Streets" concept, which emphasizes use of all forms of transportation on streets, including automobiles, pedestrians, bicycles, and public transit."

These principles emphasize planning, design, and construction for all modes in a manner that results in high usage levels. As such, roadways are treated as the essential element in the urban fabric that connects rather than separates neighborhoods located on opposite sides of a road.

\section{CONNECTED}

The full and varied use of all forms of transportation not only reduces traffic, but also enables active lifestyles, results in cleaner air, an increase in disposable income, and attracts a population that values these qualities. The degree to which people choose to utilize transit, bicycling, and walking as a viable form of transportation is grounded in the design of a community's street network, which can be summarized as "walkable-urban," and "driveable-suburban." The BCP includes both forms by providing the necessary community and regional scale arterial streets for long-distance travel, and by infusing an interconnected format of roads at the collector and local street level through the use of the grid-street pattern. Interconnected streets with pedestrian scale features create transit, bike, and pedestrian-friendly environments, and offer an amazing amount of flexibility for land use development (intensity and a horizontal and vertical mixing of land uses), and potential to remove street segments to create super blocks where necessary.

\section{DISPERSAL}

The multi-modal and connected nature of the circulation system in the BCP will also tend to disperse all modes of traffic. Not only does this reduce congestion and associated noise and pollution that tends to form with other forms of street networks, but it also maximizes the utility of land set aside as right-of-way, resulting in a cost-effective use of public funds.

\section{TRANST-READY DEVEOPMENT}

Transit connects passengers to destinations and is an integral component of shaping future growth into a more sustainable form. The creation of truly transit-oriented land uses along transit corridors can be a challenge and often results in transit-adjacent development (TAD) that is not truly transit oriented. 
TAD is characterized by land use patterns that do not promote compact, which fosters multi-modal transportation. TAD characteristics include: a suburban street pattern; low densities; dominance of surface parking; limited or no pedestrian access; single-family homes; industrial land uses; segregated land uses; and gas stations, car dealerships, drive-thru stores, and other autofocused land uses. For example, newer segments of the M Street Transitway Corridor have been developed with characteristics of TAD. Land uses are internally oriented with sound walls separating the transit corridor from adjacent residences.

The BCP discourages the formation of TADS, and encourages the creation of transit oriented development (TOD). A TOD is characterized by land use patterns that are oriented to maximize access to transit stations within a halfmile radius (a ten-minute walk). Characteristics include: a grid street pattern, high densities, mostly underground or structured parking, pedestrian-focused design, bicycle access and parking, multi-family homes, office and retail land uses (especially along main streets), vertically and horizontally mixed land uses, and stores and local-servicing land uses designed for pedestrian access. Older segments of Merced's street network were developed with land uses oriented toward adjacent streets, a desirable trait for promoting TOD.

Whereas the entire BCP utilizes these strategies at varying levels, at the core of the BCP is the High Quality Mandeville Transit Corridor, one-half mile wide between Bellevue Ranch Master Planned Development and UC Merced, which maximizes these strategies to their fullest (see Figure 25 on page 54).

\section{BCP CIRC ULATION PLAN COMPONENTS}

The BCP sets up the framework for an interconnected street network which can accommodate transit, bicycle infrastructure, and pedestrian amenities. This network will be the foundation for establishing and enhancing walkability of the area. A multi-modal street network is a vital component to encouraging increased and efficient use of public transit and transit oriented development. This section introduces the four components of the BCP Circulation Plan that will implement the City's Complete Streets vision, and include 1) the Auto-Oriented Component; 2) the Transit-Oriented Component; 3) the Bicycle Oriented Component; and 4) the Pedestrian-Oriented Component. Depending upon the context of the road, varying use of these nodes occur throughout the Plan area. For example, the circulation network emphasizes automobiles along Bellevue Road, but emphasizes transit along Mandeville Road. The design cross-section and streetscape design varies depending upon the street classification, its regional or community-wide context and adjacent land uses. Figure 11 depicts the BCP Complete Streets Components. 


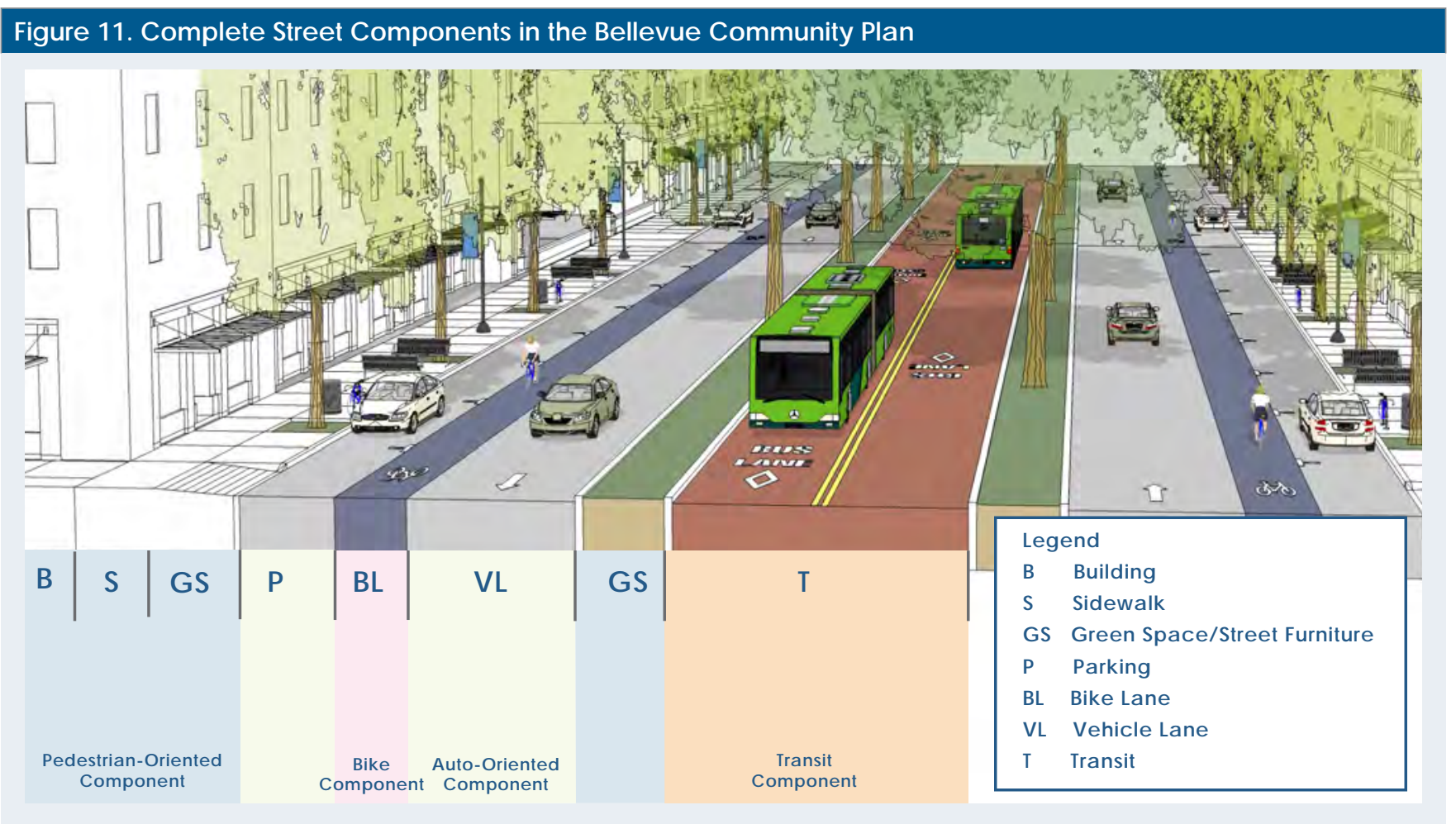

\section{AUTO-ORIENTED COMPONENT}

A street network can foster or constrain economic and social activity, enhance or limit social equity in ability to travel, and provide or negate a setting for high quality design at all scales: building, neighborhood, and region. The BCP proposes a grid street network which creates equality in modal type without diminishing regional connectivity or flow of traffic on major arterials. Grid circulation networks provide many route options, reduce vehicle speed, are more conducive to walking and cycling, reduce vehicle miles traveled, and are associated with compact development and conservation of open spaces.

Table 4 describes the proposed roadway network in the BCP, and Figure 12, the Official BCP Street Classification Map, illustrates the street and roadway types included in the BCP. These include arterial, collector and local streets. All roadway alignments proposed under this plan are conceptual and may be varied, curved, or otherwise realigned as appropriate. Intersections on Bellevue with collectors will be appropriately spaced to accommodate signalized intersections, if need. It is important to ensure the BCP roadway network as a whole generates an interconnected network that supports pedestrian, bike, and transit travel, and that high volumes of high-speed automobile traffic, while necessary on some roads, does not preclude functional multi-modal travel on others. The proposed grid-type street network, especially at the local street scale, creates walkable pedestrian scale blocks. 


\begin{tabular}{|c|c|c|c|c|c|c|}
\hline $\begin{array}{l}\text { Streets in the } \\
\text { BCP }\end{array}$ & $\begin{array}{l}\text { Proposed Street } \\
\text { Classification }\end{array}$ & Right-of-Way & \# of Lanes & $\begin{array}{l}\text { Driveway } \\
\text { Access } \\
\text { Restrictions }\end{array}$ & $\begin{array}{l}\text { Street } \\
\text { Intersection } \\
\text { Spacing }\end{array}$ & Parking \\
\hline \multirow[t]{2}{*}{ Bellevue Rd. ${ }^{1}$} & Major Arterial & $110^{\prime}-140^{\prime}$ & $\begin{array}{l}6 \text { lanes with } \\
\text { median / left- } \\
\text { tum pockets }\end{array}$ & Full & $\begin{array}{l}\text { 1/4 mile for } \\
\text { signa lized } \\
\text { intersections }\end{array}$ & No \\
\hline & $\begin{array}{l}\text { Major Arterial with } \\
\text { Side Access Roads }\end{array}$ & $\begin{array}{l}150^{\prime}-200^{\prime} \text { (dependent on } \\
\text { side access roads on } 1 \text { or } \\
\text { both sides) }\end{array}$ & $\begin{array}{l}6 \text { lanes with one- } \\
\text { way or two-way } \\
\text { frontage roads }\end{array}$ & $\begin{array}{l}\text { Full (driveway } \\
\text { access from } \\
\text { frontage roads) }\end{array}$ & $\begin{array}{l}\text { 1/4 mile for } \\
\text { signa lized } \\
\text { intersections }\end{array}$ & $\begin{array}{l}\text { No (parallel } \\
\text { or diagonal } \\
\text { permitted } \\
\text { on side } \\
\text { access } \\
\text { roads) }\end{array}$ \\
\hline Cardella Rd. & Major Arterial & $80^{\prime}-128^{\prime}$ & $\begin{array}{l}4 \text { lanes with } \\
\text { median / left- } \\
\text { tum pockets }\end{array}$ & Full & $\begin{array}{l}\text { 1/8 mile to } \\
\text { 1/2 mile (see } \\
\text { General Plan) }\end{array}$ & No \\
\hline G St. & Major Arterial & $128^{\prime}$ & $\begin{array}{l}4 \text { lanes with } \\
\text { median / left- } \\
\text { tum pockets }\end{array}$ & Full & $\begin{array}{l}\text { 1/8 mile to } \\
\text { 1/2 mile (see } \\
\text { General Plan) }\end{array}$ & No \\
\hline Gardner Ave. & Major Arterial & 118' Divided & $\begin{array}{l}4 \text { lanes with } \\
\text { median / left- } \\
\text { tum pockets }\end{array}$ & Full & $\begin{array}{l}1 / 8 \text { mile to } \\
\text { 1/2 mile (see } \\
\text { General Plan) }\end{array}$ & No \\
\hline \multirow[t]{3}{*}{$\begin{array}{l}\text { Mandeville } \\
\text { Ave. (New) }\end{array}$} & Transit Avenue & $120^{\prime}-130^{\prime}$ & 2 lanes & $\begin{array}{l}\text { No (rear } \\
\text { alley access } \\
\text { recommended) }\end{array}$ & As needed & Permitted \\
\hline & Collectors & $60^{\prime}-80^{\prime}$ & $\begin{array}{l}2 \text { lanes with } \\
\text { median / left- } \\
\text { tum pockets }\end{array}$ & $\begin{array}{l}\text { No (rear } \\
\text { alley access } \\
\text { recommended) }\end{array}$ & As needed & Permitted \\
\hline & Local Roads & $51^{\prime}-62^{\prime}$ & 2 lanes & No & As needed & Permitted \\
\hline
\end{tabular}

Notes:

1. The Merced Vision 2030 General Plan designates Bellevue Road as a six lane facility; however, the BCP recommends a future study to reduce Bellevue Road to a preferred four-lane facility.

2. The Merced Vision 2030 General Plan designates Gardner Avenue as a four lane facility; however, the BCP recommends a future study to reduce Bellevue Road to a three-lane boulevard with limited driveway access. Depending on the results of the study, Garder Avenue/ Golf Road, north of Bellevue Road, could be reduced to a two-lane street.

3. The street right-of-ways (ROWs) may vary depending on the final design characteristics chosen for each street type. 


\section{Figure 12. BCP Street Classification}

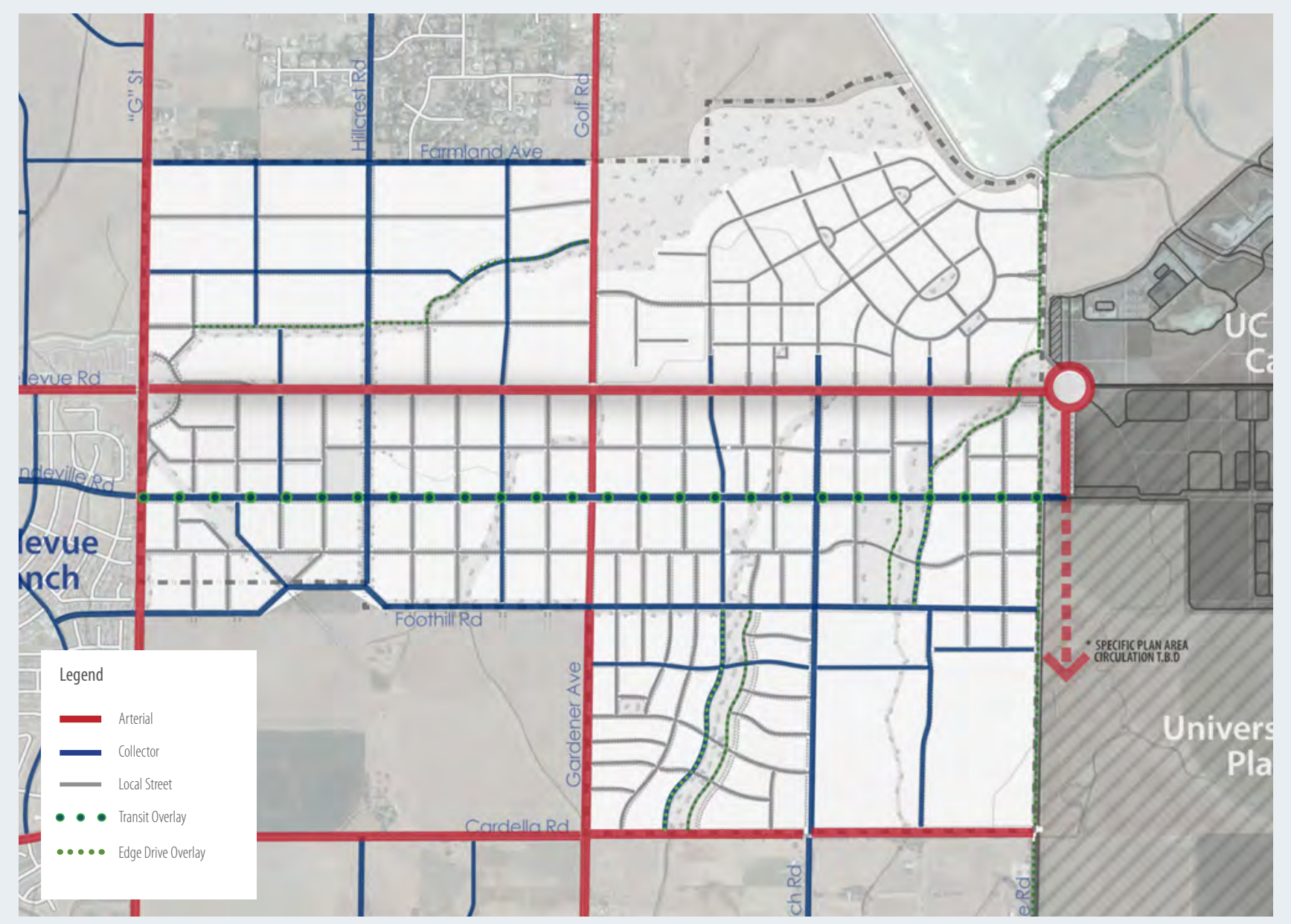

Each type of roadway located within the BCP area is described in the narratives on the following pages.

\section{Arterial Streets - RED SOLID \& DASHED}

Within the BCP, arterial streets fall into two categories. Class S (Standard) Arterials are those that are consistent with the City's adopted General Plan and Official Design Standards. These roads include G Street and Cardella Road. Class V (Variable) Arterials incorporate variations in street design that are needed to be consistent with and to support design objectives specific to the $\mathrm{BCP}$, namely to create a gateway image and to create a transit supportive setting. Variable Arterials include Bellevue Road and Gardner Avenue. After Plan adoption, an important next step will be to set road plan lines for arterial streets in order to ensure adequate future ROW with minimal impact to existing structures. 


\section{Bellevue Road}

Although Bellevue Road is a part of the regional traffic serving Merced Loop Road, it will serve future local land uses with access needs. The Bellevue Road standard balances these needs, and provides an aesthetic gateway design component. The Merced Vision 2030 General Plan designates Bellevue Road as a six lane facility; however, the BCP recommends a future study to reduce Bellevue Road to a preferred four-lane facility. Nonetheless, Bellevue Road will have adequate right-of-way for a landscaped median, up to three travel lanes each direction, a bikeway, a parkway, and a sidewalk. Sound walls would not be allowed.

Urban design features that emphasize accessibility and views of buildings are encouraged within the BCP. In terms of accessibility, development of adjacent properties would conform to one of the following options: 1) access by internal connection to local area streets; 2) where additional side-road access is planned, required, or desired by the owner, the buildings will be located adjacent to a one-way side access slip road that branches off of and runs parallel to Bellevue Road or a two-way, larger side access road (see Figure 13, Figure 14, and Figure 15). Angled back-in parking is encouraged along one-way side access roads and parallel parking is encouraged on the side of the street adjacent to buildings for two-way side access roads, or 3) in areas where additional vehicular access is not needed, the buildings could be located along the sidewalk, provided housing units adequately buffer or shield noise impacts. For purposes of planning, Option 1 is considered the standard design unless changed by the City through the Neighborhood Master Planning process outlined in the Community Character Chapter. The benefits of side access roads include:

- $\quad$ Allows buildings to face or address the street, creating a more visually pleasing setting and gateway environment, as opposed to a long blank sound wall or loading dock;

- Creates a space for pedestrians to access buildings and to use mobility options (transit, bike lanes, sidewalks);

- $\quad$ Provides a place for on-street parking; and

- $\quad$ Provides a place for local traffic to maneuver without slowing thrutraffic on Bellevue Road.

Alternatively, creating large streets without the provision for "address making" along it, reduces development flexibility and increases the odds of creating an impaired visual environment. 
Figure 13. Bellevue Road with Two-way Side Access Road

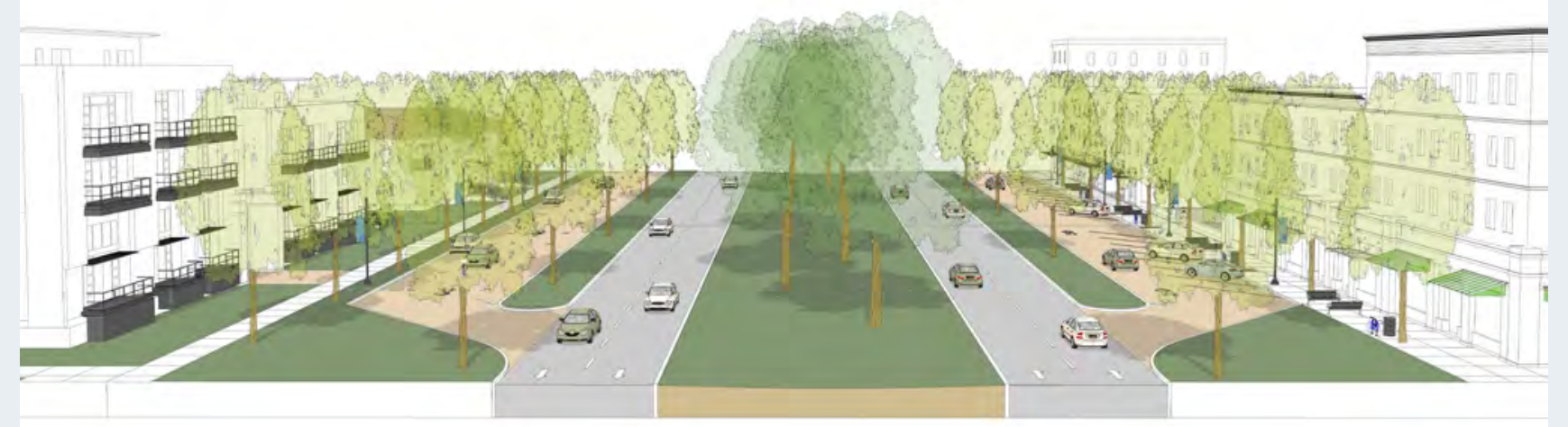

Figure 14. Example of a Boulevard with One-way Side Access Sip Road and Intersections in Berkeley, CA

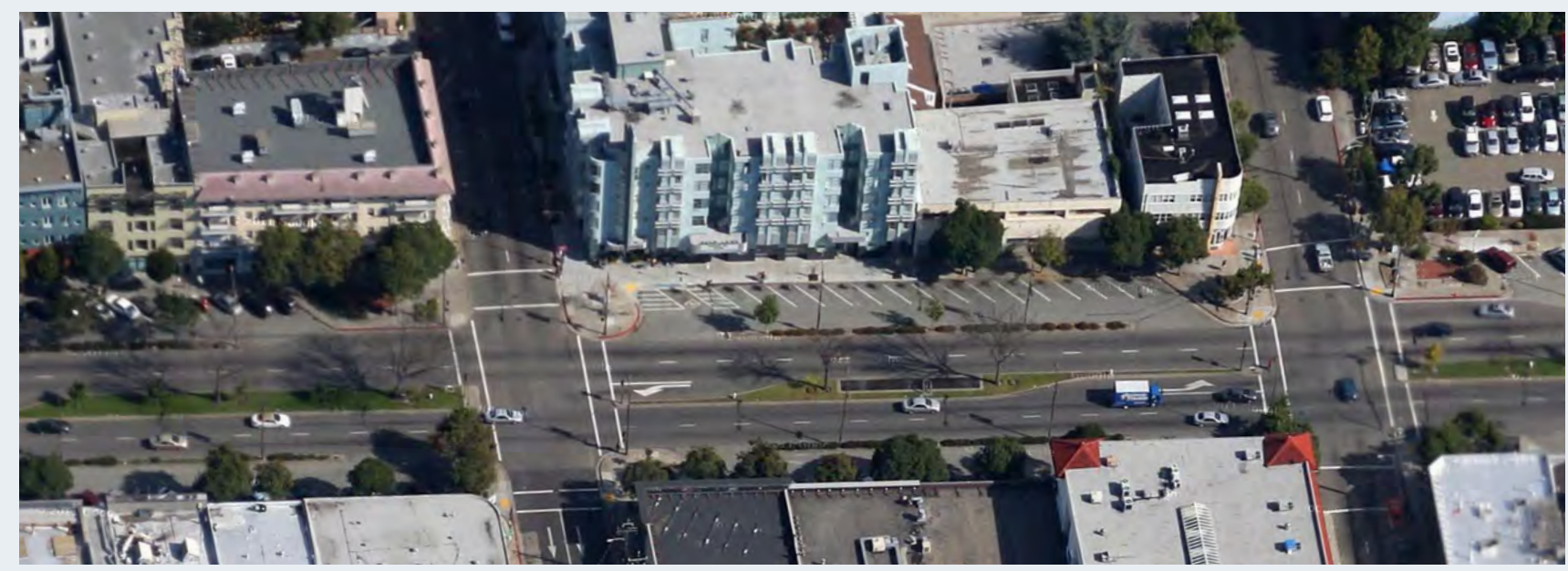

\section{Figure 15. Example of a Boulevard with One-way Side Access Sip Road in Berkeley, CA}

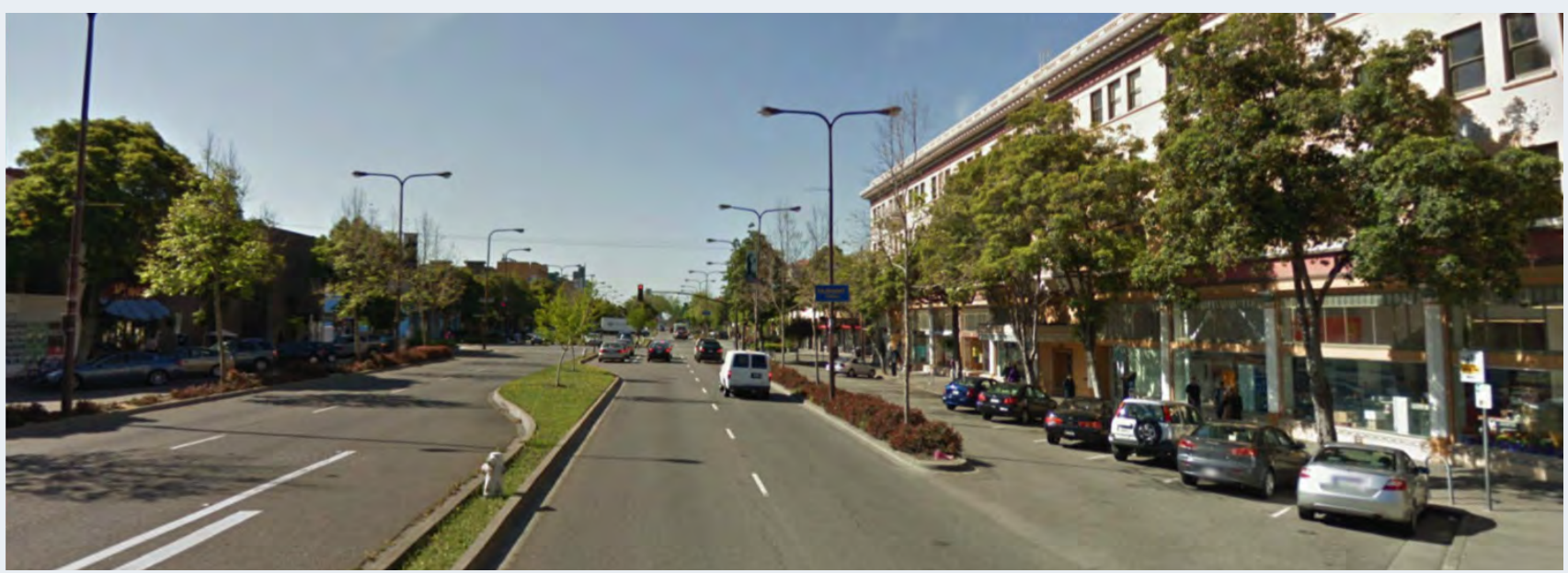




\section{Gardner Avenue}

The Merced Vision 2030 General Plan classifies Gardner Avenue as a Minor Arterial with up to four lanes and a median with left-turn pockets. Subject to future study, the BCP recommends transitioning the road, north of Foothill Drive, into a three-lane boulevard with limited driveway access, balancing the need to accommodate high-traffic capacity with neighborhood compatibility. (Note: North of Bellevue Road, Gardner Avenue/Golf Road could become a two-lane road subject to a future study.) The proposed lane configuration, to one lane in each direction plus a center turn lane, is compatible with the smaller block network of the residential areas north of Foothill Drive. Buildings would be oriented facing the street according to the standards of the character area. Residences would have large front yards in the Single-Family Character Area (Figure 16) and in high-intensity areas between Foothill Drive and Bellevue Road the yards would be replaced by a wider sidewalk, treewells and a furniture zone.

South of Foothill Road, Gardner Avenue is envisioned to remain a four lane Minor Arterial as described by the General Plan. This section will have limited driveway access to adjacent properties with right-turn-in/right-turnout access a $1 / 8$ mile intervals.

\section{Figure 16. Gardner Road in Single Family Character Area}

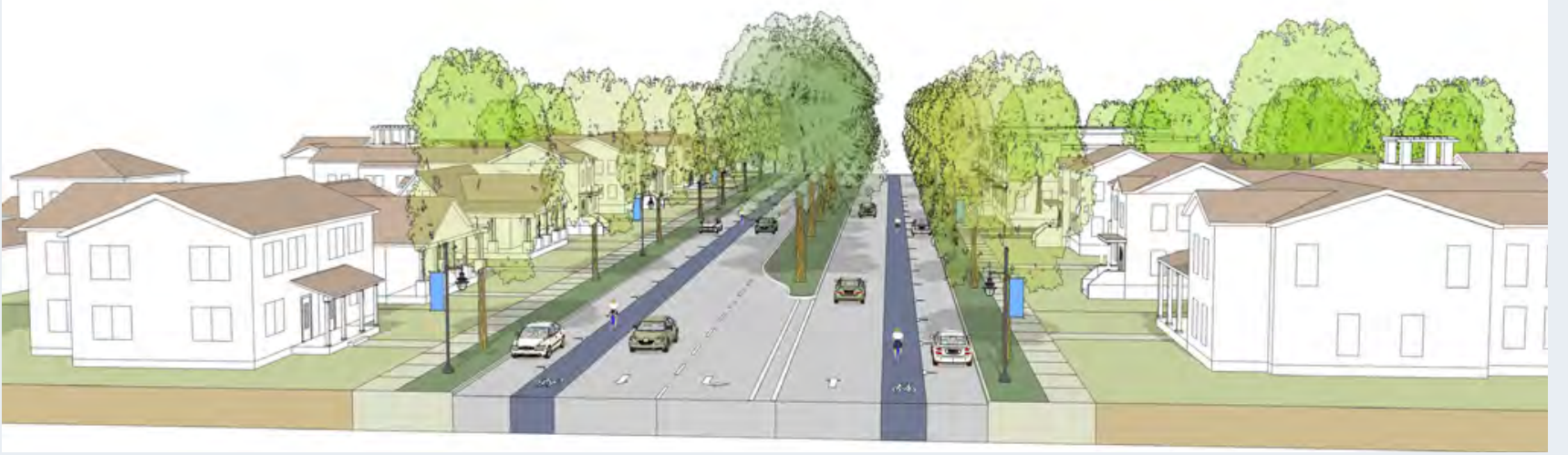




\section{Cardella Road}

Consistent with Table 4.2 of the City's General Plan, this road is planned to be a divided arterial with a 118 foot right-of-way to contain 4 lanes with partial driveway access restrictions. Outside of the BCP, a 6-lane segment of Cardella Road is planned between M street and R street. Collector street intersection spacing ranges from $1 / 4$ mile to $1 / 2$ mile. On-street parking is not permitted.

\section{G Street}

Consistent with Table 4.2 of the City's General Plan, this road is planned to be a major arterial with a 128 foot right-of-way to contain 4 lanes with full driveway access restrictions. North of Bellevue Road, the General Plan plans for up to 6 lanes. Collector street intersection spacing ranges from $1 / 4$ mile to $1 / 2$ mile. On-street parking is not permitted.

\section{Collector Streets- BLUE SOLID \& DASHED}

Collector streets, including Foothill, Hillcrest, Paulson, Hatch, and Farmland, are generally spaced at $1 / 4$ mile intervals to facilitate traffic flow and signal timing, as needed. Collector streets should have one travel lane in each direction, curbside parallel parking, and parkway strips with street trees and sidewalks. Similar to major arterials, sound walls are not allowed and buildings will face the street. $\mathrm{BCP}$ collector streets have a unique cross section with wider parkway strips in residential areas. In high-intensity Character Areas (Mixed Use TOD, Business Park, Multifamily Neighborhood and FlexMixed Use), the travel lanes will be wider, bike lanes will be provided between the travel lanes and parking lanes, and the parkway strip would be replaced with a wide sidewalk (14 to 18 feet) with tree wells and street furniture. Intersections would be designed for pedestrian safety, incorporating cross walks and pedestrian bulb-outs, as appropriate.

\section{Figure 17. Collector Street through a Typical Mult-Family Character Area}

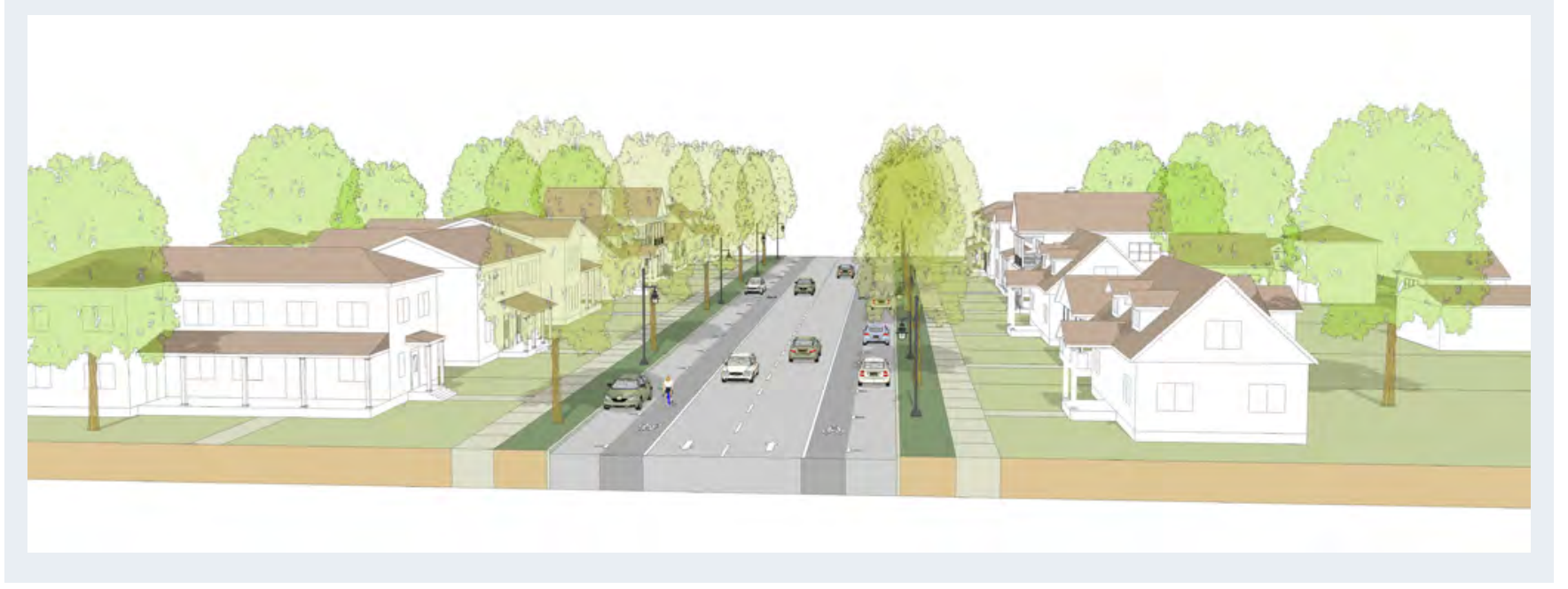




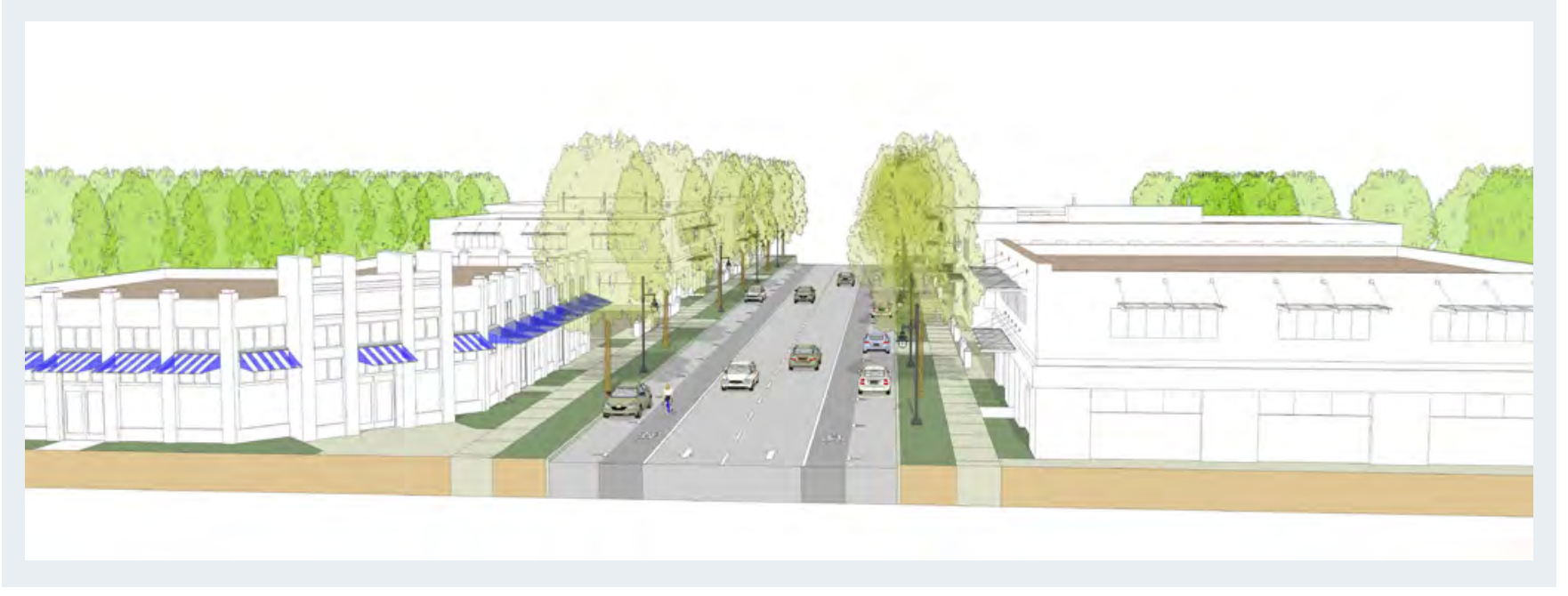

\section{Figure 19. Collector Street through a Typical Single-Family Character Area}

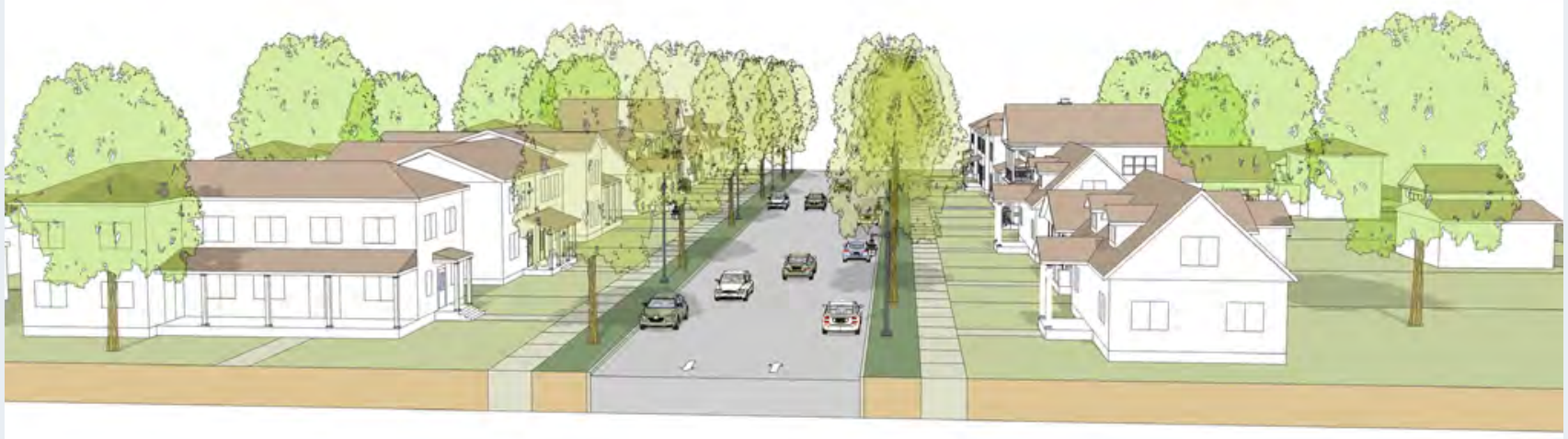

\section{Mandeville Road}

Mandeville Road is a collector road, and the recommended transit route. The alignment of Mandeville Road is designed to connect pedestrians and bicyclists to the transit route within five-minute, $1 / 4$ mile walking distances and, as shown in Figure 20, includes:

1. A dedicated bus guideway down the median east of $G$ Street (transit west of G Street will share travel lanes with automobiles).

2. One lane of traffic each direction, bike lanes on each side of the street, and on-street parallel parking on both sides of the street.

3. Left turn lanes at controlled intersections (signal or stop-sign). The parking lane would be removed to allow for the additional lane which would improve intersection performance. This could effect the curvature of the through traffic lanes and may reduce traffic speeds. 
4. Sidewalks and parkway strips. The sidewalk width and street furniture vary, depending on location. Sidewalks in residential areas shall have minimum 5 to 6 feet of walkable space area and wide landscaping strips. Along Mixed-use TOD, R\&D, and Neighborhood Centers, Mandeville Avenue shall have wider sidewalk widths, 1214 feet, to accommodate tree wells and street furniture while not blocking or impeding pedestrian movement.

Over time, the Mandeville Transit corridor could transition from a bus route to Bus Rapid Transit (BRT) service. BRT improvement and service options would provide dedicated travel lanes for bus service in combination with high-occupancy transit vehicles, enhanced boarding platforms and signal preemption measures to minimize travel time and maximize potential ridership. A main component of BRT is a dedicated travel lane, reducing conflict between cars and buses and also reducing time delays. BRT can be phased into the BCP area by use of a vegetated median strip in the interim. This strip can be turned into the dedicated bus lane as funding becomes available. By planning ahead and establishing the BRT design framework early in the planning stages, potential future retrofitting costs can be significantly reduced.

Several traffic control options are available for Mandeville Road, depending on the function of the roadway and the presence of BRT. The BCP recommends traffic signals where Mandeville Rd intersects with collector or arterial streets. Roundabouts could be an alternative option, and would require further study. In general, roundabouts would be a more feasible options on north/south collector streets, where the roundabout would not need to accommodate a transit stop, as on Mandeville Rd.

Figure 20. Mandeville Road- Tansit Avenue - T.O.D. Center

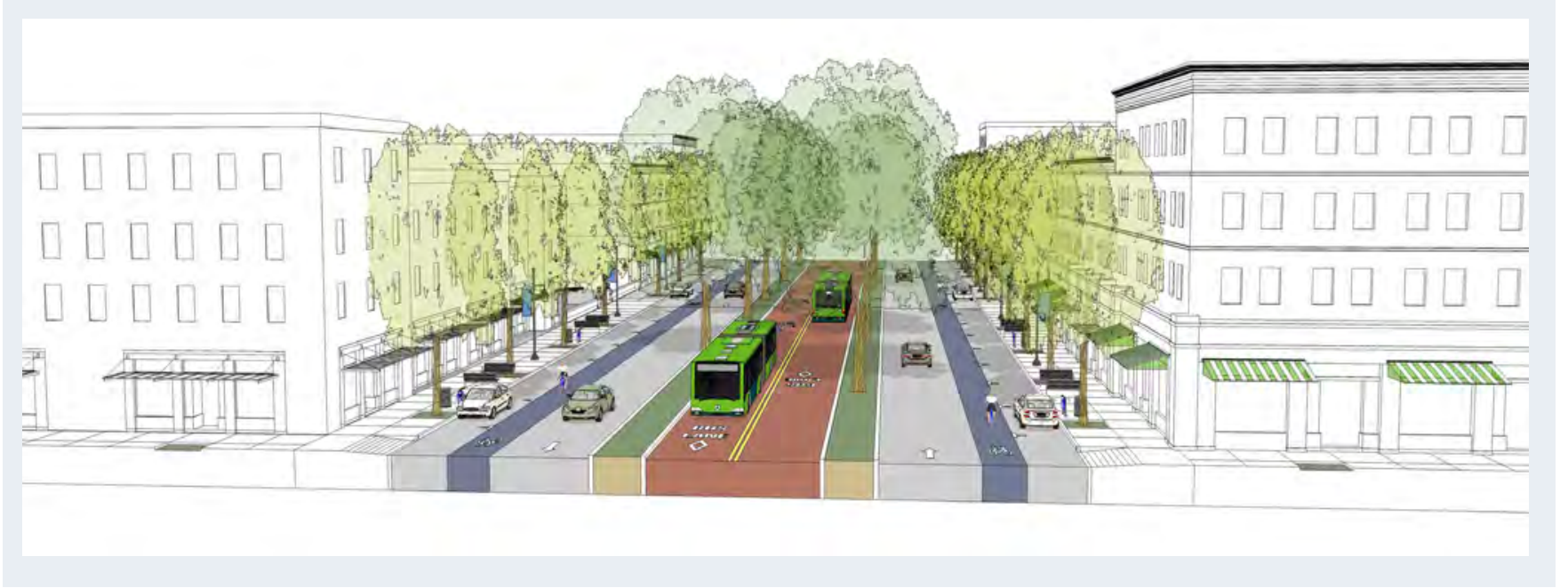




\section{Local Streets- GREY DASHED}

As mentioned earlier, the creation of a network of local streets with short blocks is necessary to encourage walking, biking, and transit use which is the foundation of any transit-oriented development. The Plan recommends small walkable blocks in the TOD core areas, with larger blocks permitted to accommodate larger buildings in the Research and Development Character Area. Local streets are highly interconnected to disperse traffic across the grid and provide pedestrian, vehicle, and bicycle direct access to a variety of destinations. The street cross-section is consistent with adopted City design standards. Figure 22 and Figure 23, illustrate the different characteristics depending on adjacent uses.

The local roads depicted on the Street Classification Map (Figure 12) represent a circulation concept and does not dictate specific form on any particular property. The actual location of local streets is flexible as long as it maintains a high degree of connectivity. Natural features and certain land uses may influence the trajectories of roads, and the map shows how variations may include curving roads along open space corridors or hillsides, and removal of local roads in research and development, entertainment or community commercial areas.

While continuity and interconnectedness are essential features to the overall local street network in the $\mathrm{BCP}$, there may be situations where providing public spaces or accommodating new development may result in dead-end local streets. For example, in mixed-use, research and development, and commercial centers local streets may be terminated in a close or a rosewalk (pedestrian-only street/green). In Single-Family and Rural Residential Characters Areas, select streets may end as open-ended cul-de-sacs. All configurations should allow pedestrians and bicycles to pass freely to maintain the transit-oriented design of the circulation network.

\section{Example of a Rosewalk}

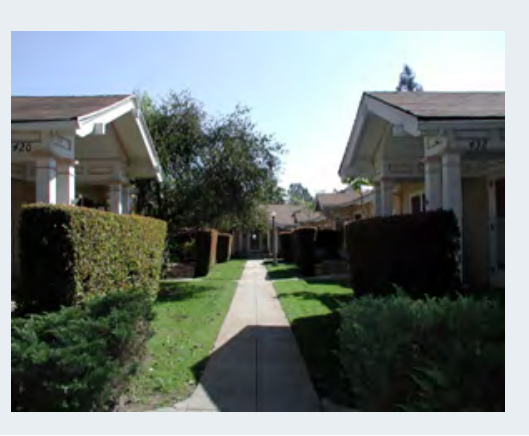

Example of an Open-Ended Cul-de-sac

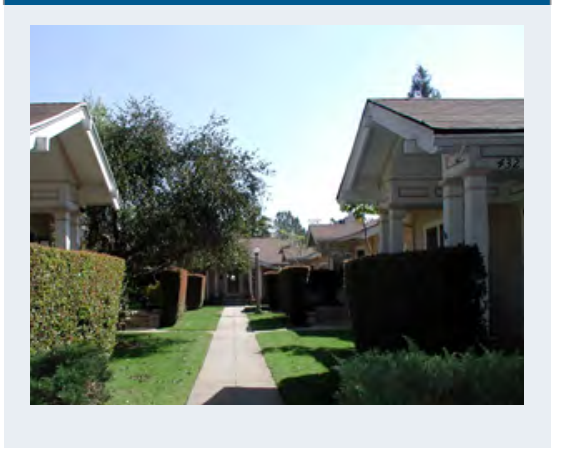




\section{These streets are highly interconnected to disperse traffic and to provide pedestrian, vehicle, and bic ycle access to a variety of destinations.}

\section{STREET OVERLAY DESIG NATIONS}

\section{High Quality Transit Corridor (Open Green Circle)}

Mandeville Road is positioned well to offer excellent transit service to the community and points beyond. In addition to the ease of connecting to future north-south transit routes, it directly connects the transit centers planned in the Bellevue Ranch Development and UC Merced. To either side of Mandeville Road for a distance of two miles, pedestrian-oriented land uses and street designs create a transit-ready development pattern that has the potential to generate a large demand for transit services. Mandeville Road should be designed to allow pedestrians to easily cross the street.

\section{Edge Drives (Green Dashed)}

Edge drives are single-loaded streets (can be local or collector streets) that run along the edges of significant community open spaces providing motorists, pedestrians, and bicyclists daily access to green space, such as creek greenways, parks, and the Lake Road greenway near the UC Merced Campus. These drives have a parkway strip and sidewalk. The residential side has a curb, with tree-wells and street furniture when the drive runs along mixed-use or commercial properties. The greenway side of the street will be designed to allow for natural runoff and storm water infiltration while also contributing to the natural setting. Parking on the green space side can be provided for park visitors using pervious pavement which still maintains the natural drainage features of the greenway side of the road. A Class 1 bikeway, jogging path, or equestrian trail can also be provided along the greenway.

Lake Road is a local road that runs alongside the Rural Residential and Mixed Use TOD Character Areas. In both, the road is a two-lane road with open space on the east side. The design elements on the west side of the road reflect the nature of the character areas (see Figure 22 \& Figure 23). In the Rural Residential Area, the road retains its rural character with no sidewalks and a drainage swale. In the Mixed-Use TOD Area, the urban side of the street has on-street parking, street trees, and a sidewalk. The transition from rural to urban frontages would occur around Foothill Drive. 
Figure 21. Typical Edge Dive with Side Parking

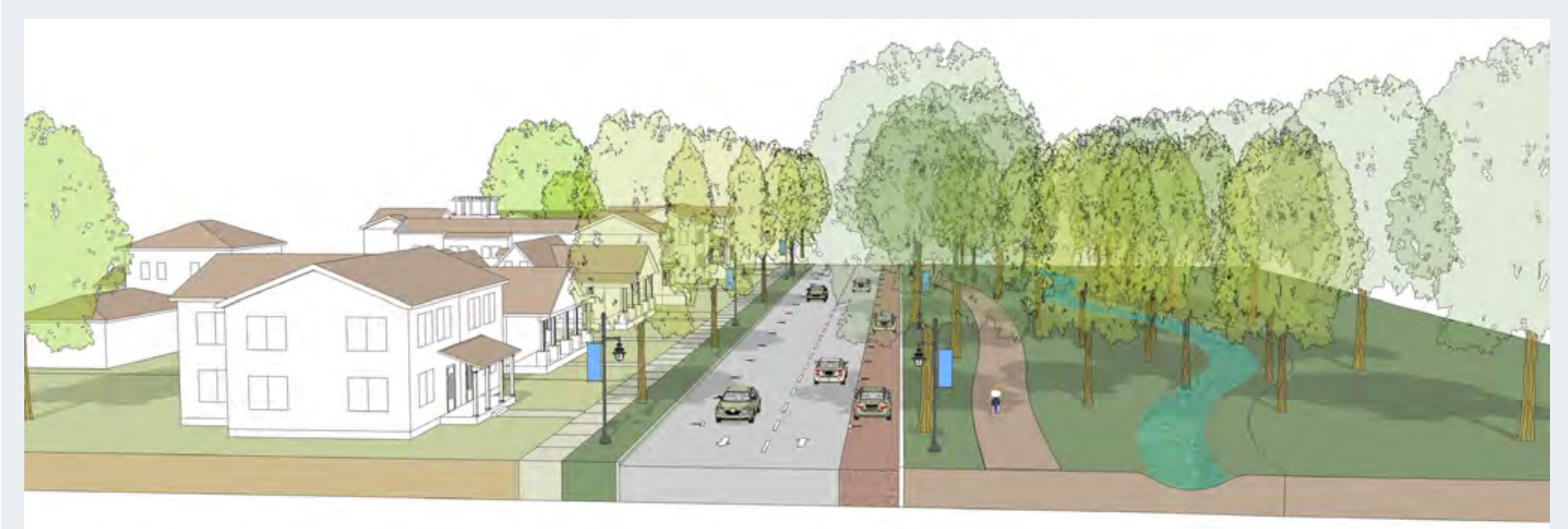

\section{Figure 22. Lake Road - Natural Rural Edge Drive}

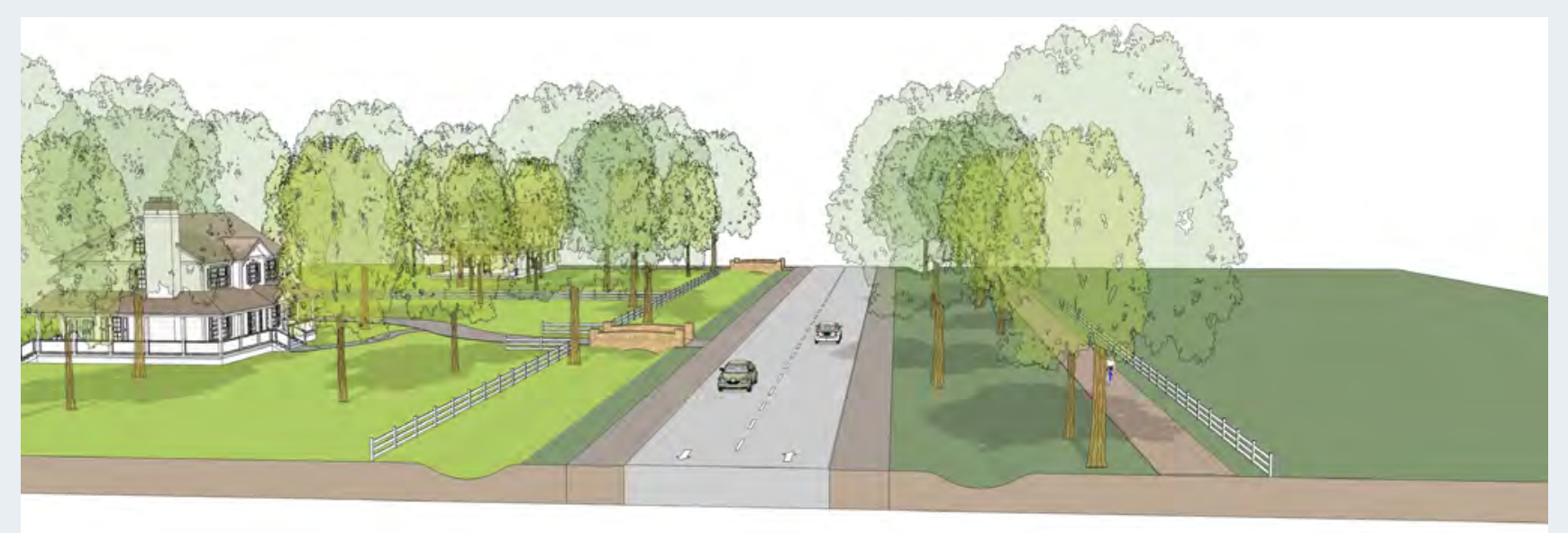

Figure 23. Lake Road - Edge Dive with Mixed-Use Character Area

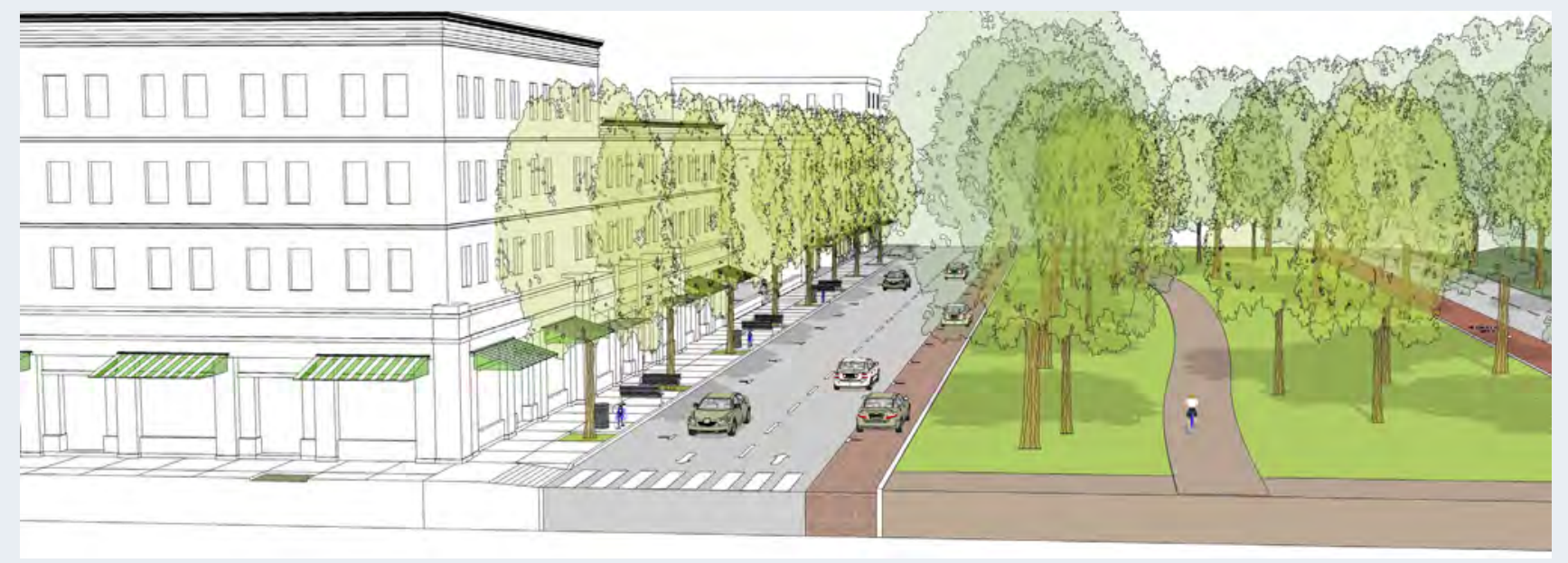




\section{Gateways}

Both Lake Road and Bellevue Road are identified as scenic corridors in the Merced Vision 2030 General Plan. The position of UC Merced at this intersection further emphasizes the need to enhance the visual character of these roads and to create attractive entryways. In the long-term, Bellevue Road will accommodate regional vehicular traffic, whereas Lake Road will be a local road characterized by low vehicle speeds and continuous pedestrian and bicycle pathways. Bellevue Road should create a gateway design at the intersection with G Street to create a sense of arrival while travelling to UC Merced through the BCP area. Figure 24 illustrates a gateway design concept for Bellevue Road. See Chapter 2 for more information on Gateways. Collaboration between the City of Merced and Merced County is needed to craft detailed design standards for these roadways and adjacent properties.

\section{Figure 24. BCP Gateway Overlay at Bellevue Road \& G Street}

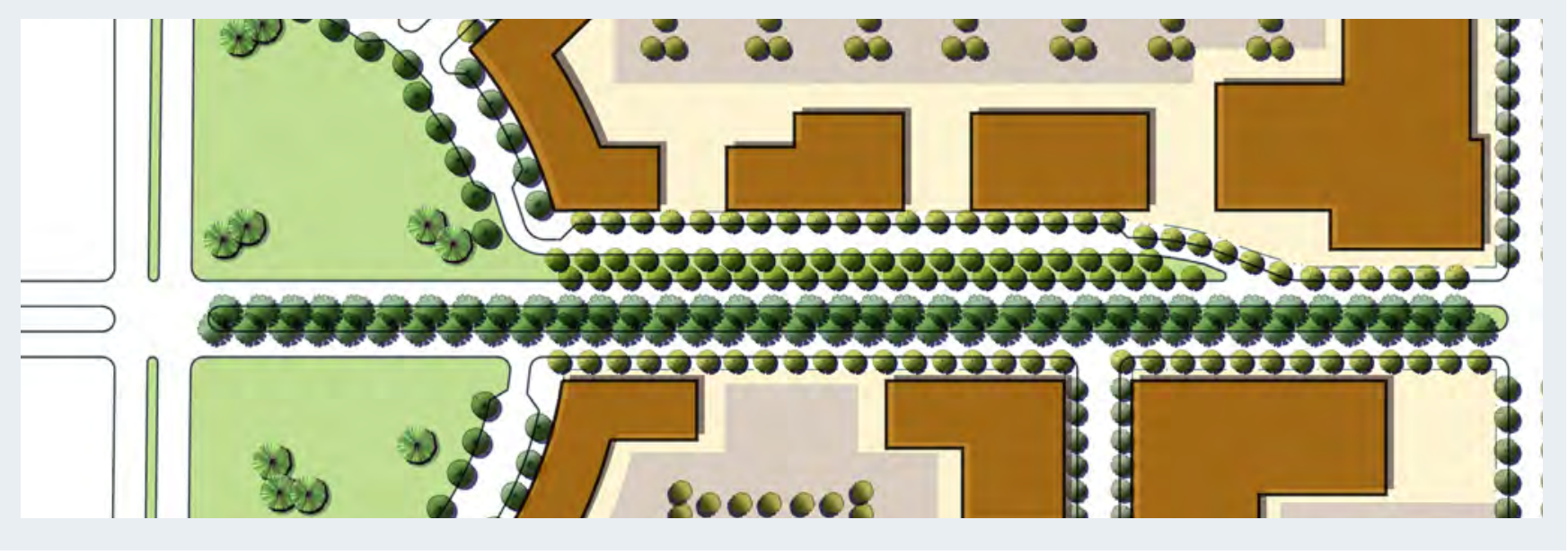

Example of Reverse-in Angled Parking

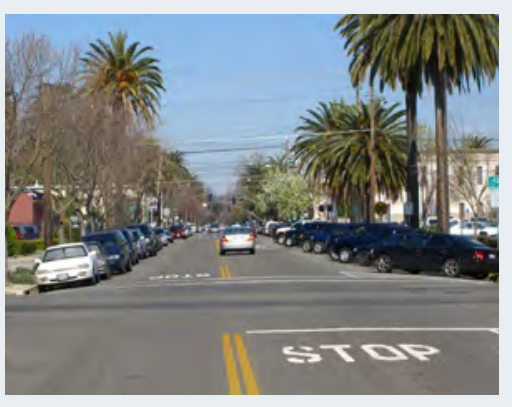

\section{PARKING}

On street parking can be important in the urban environment for the success of the retail businesses that line the street and to provide a buffer for pedestrians and help calm traffic speeds. On-street parking occupies about half the surface area per car compared to off-street facilities, which require driveways and aisles for access and maneuvering.

Where angled parking is proposed for on-street parking on frontage streets, designers should consider the use of reverse-in angle (or front out) parking in lieu of front-in angled parking. Motorists pulling out of reverse-in angled parking can better see the active street they are entering. This is especially important to bicyclists. Moreover, people exiting cars do so on the curb side and aren't likely to step into an active travel lane.

Another tool for on-street parking is the park assist lane. Often when onstreet parking is provided on busy roads, drivers find it difficult to enter and leave their parked vehicle. Where space is available, consideration should be given to adding a park assist lane between the parking lane and travel way to provide 3 feet of space so car doors can be opened and vehicles can enter or depart with a higher degree of safety and less delay. Parking assist lanes also narrow the feel of the travel lane and slow traffic. 
Parking within the BCP area is provided through a combination of on- and off-street parking. On-street parking varies with the street classification type, where appropriate. As the population within the BCP increases into the future, the flexibility of the BCP allows gradual transition to off-street, structured parking facilities. For details on type, and location of parking, see Table 4, and the description of each street type, above.

\section{TRANSTT-ORIENTED COMPONENT}

While necessary, operating buses and bus-stops do not constitute the full spectrum of a successful transit system. Land uses, from the perspective of origins and destinations, along with an environment that attracts pedestrian use are equally important. The extent of the transit system in the BCP encompasses all aspects of a successful system, which include transit-ready developments (discussed early in the chapter) and transit priority projects, a highly connected street system, transit accommodations, together with the "pedestrian-oriented" and bicycle-oriented components of the BCP Circulation Plan.

\section{CONNECTIVITY}

The recommended local street layout supports functional transit nodes that can be accessed within a five minute, $1 / 4$ mile, walking radius, and is an essential component of a successful transit system. The intent is to emphasize that a high degree of interconnected roads are needed to link a variety of places so people can walk to and from home, work, transit, and other destinations without being discouraged by having to walk a long distance. The actual design and placement of local streets is flexible; the intent is connectivity.

\section{HIG H QUAUTY TRANSIT C ORRIDOR}

The BCP establishes a transit route along a centralized transit-oriented avenue, Mandeville Road. This alignment establishes a direct connection between the adjacent Bellevue Ranch Master Plan transit center and the proposed UC Merced Transit Hub. Transit stations are proposed along Mandeville Road at $1 / 4$ mile intervals from Bellevue Ranch to the UC Merced Campus as depicted in Figure 25.

\section{TRANSIT ACCOMMODATIONS}

Public transit serves a vital transportation function for many people; it is their access to jobs, school, shopping, recreation, visitation, worship, and other daily functions. Public transit should be planned and designed as part of the street system. It should interface seamlessly with other modes, recognizing that successful transit depends on customers getting to the service via walking, bicycling, car, taxi, or transit.
Example of Back-in Angled Parking \& Assistance Lane

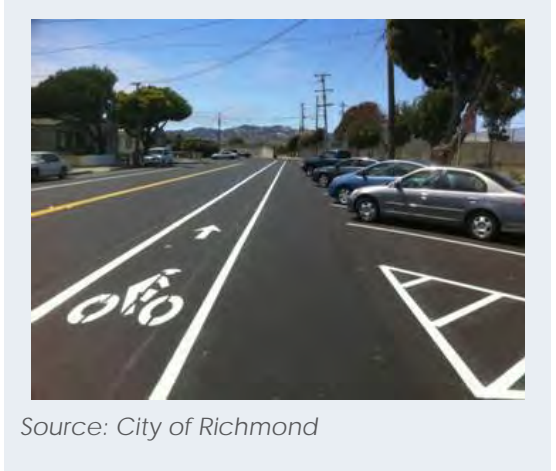

Full transit-senvice will be phased in over several years. Until BRT level senvic es are provided, a wide, landscaped median will reserve a site for the BRT guideway. 


\section{Figure 25. Five Minute Walk from Proposed Transit line}

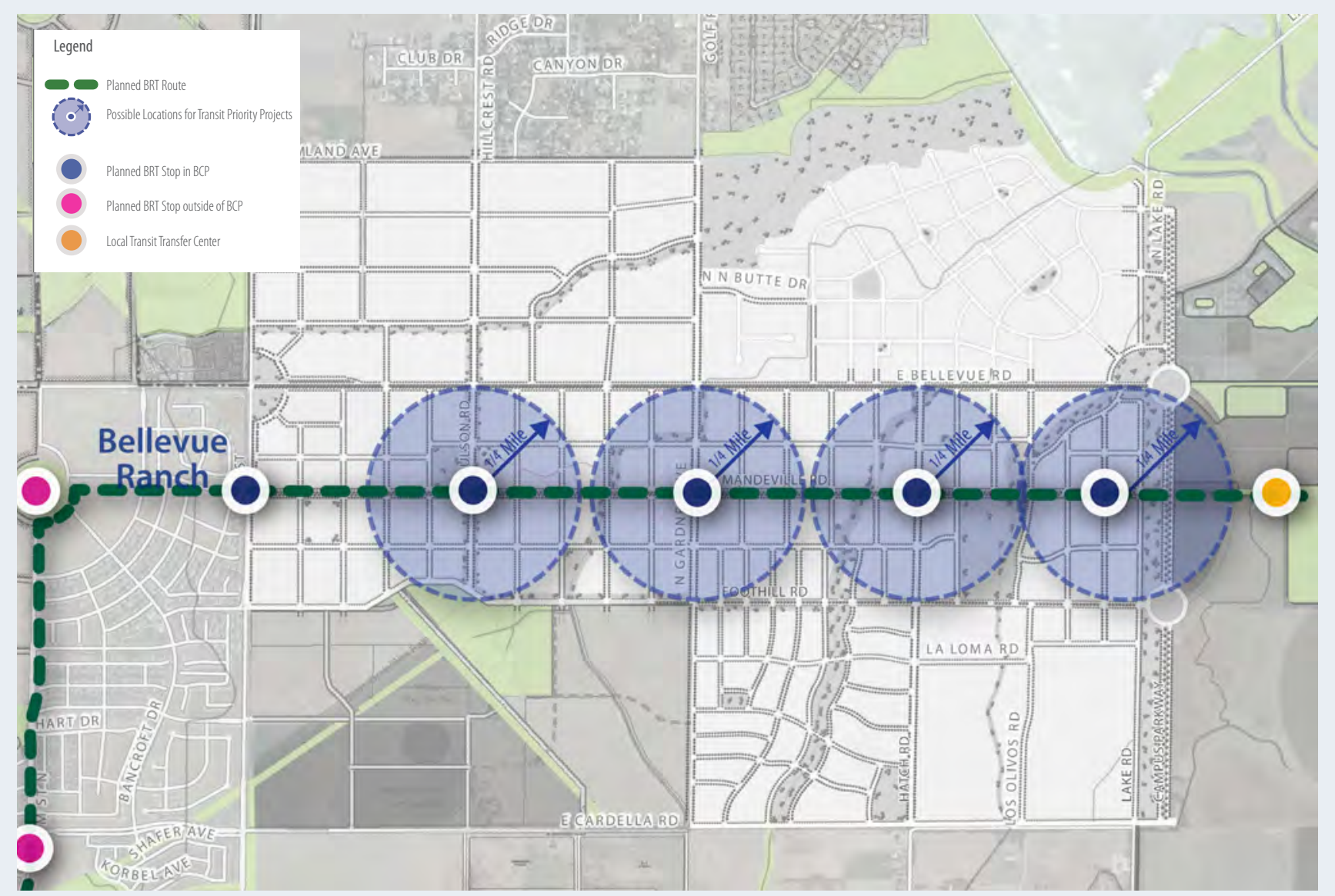

Transit stops should be planned following these principles:

- The essential streetscape elements for transit include signs, shelters, and benches. Shelters should be located in a sidewalk's furniture zone so they don't conflict with the pedestrian zone.

- Transit stops should be easily accessible, with safe and convenient crossing opportunities.

- Transit stops should be active and attractive public spaces that attract people on a regular basis, at various times of day, and all days of the week.

- Transit stops should also provide other amenities to make waiting for the next bus comfortable.

- Transit stops function as community destinations. The largest stops and stations should be designed to facilitate programming for a range of community activities and events.

- Transit stops should be attractive and visible from a distance.

- Streets that connect neighborhoods to transit facilities should be especially attractive, comfortable, and safe and inviting for pedestrians and bicyclists. 


\section{TRANSIT PRIORITY PROJ EC TS}

Transit Priority Areas were introduced in California's Senate Bill 375 (SB 375) intended to align regional transportation, land use, housing and greenhouse gas emissions planning. A key element of SB 375 is the option for regions and their local governments to provide significant California Environmental Quality Act (CEQA) regulatory streamlining incentives for Transit Priority Projects (TPP). CEQA streamlining can provide greater time certainty and reduce costs for infill and transit-oriented development. One main requirement of a TPP is that it be located within one-half mile of either a major transit stop or high-quality transit corridor included in a regional transportation plan (RTP), with service intervals of not less than 15 minutes during peak commute hours.

In addition to proximity to transit, a Transit Priority Project is required to be 50 percent residential, by square footage, with a minimum of 20 dwelling units per acre. If a TPP includes a commercial component, it must meet a floor area ratio (FAR) of 0.75 unless the commercial component accounts for less than $25 \%$ of the total TPP square footage. In which case, there is no minimum FAR requirement.

The BCP allows for densities and intensities to meet TPP requirements along the Madeville transit route (see also Table 9). However, since TPPs will be implemented at the project level, the exact size and locations have not been determined.

\section{BICYCLE-ORIENTED COMPONENT}

Utilizing the interconnected street and open space pattern, bikeways in the BCP should be placed along open space corridors, canal easements (where appropriate), and connect with Lake Yosemite and the Lake Road bike path. The close proximity to UC Merced supports the creation of a world-class bike system to accommodate students, residents, and employees within and surrounding the BCP area. Additionally, the City of Merced 2013 Bicycle Transportation Plan should be updated in conjunction with this plan to coordinate the BCP and Citywide efforts. Planned bikeways within the BCP are detailed in Figure 26.

Important bicycle planning elements should be considered during the development of the $\mathrm{BCP}^{\prime} \mathrm{s}$ circulation system:

- $\quad$ Coordinate bike planning and construction with UCM and Merced County;

- Explore provision of unpaved trails in rural residential areas;

- Placement of a bicycle boulevard in the area bounded by G Street, Bellevue Road, Lake Road and Foothill Drive;

- Connect bikeways to parks and schools; and

- Plan bike paths to encourage crime prevention through design.
Transit Prionity Projects (TPP) are housing or mixed-use residential projects which are loc ated within walking distance to transit senvices. TPPs are eligible for CEQA streamlining under Califomia

SB 375. 
Figure 26. Bicycle Transportation Map

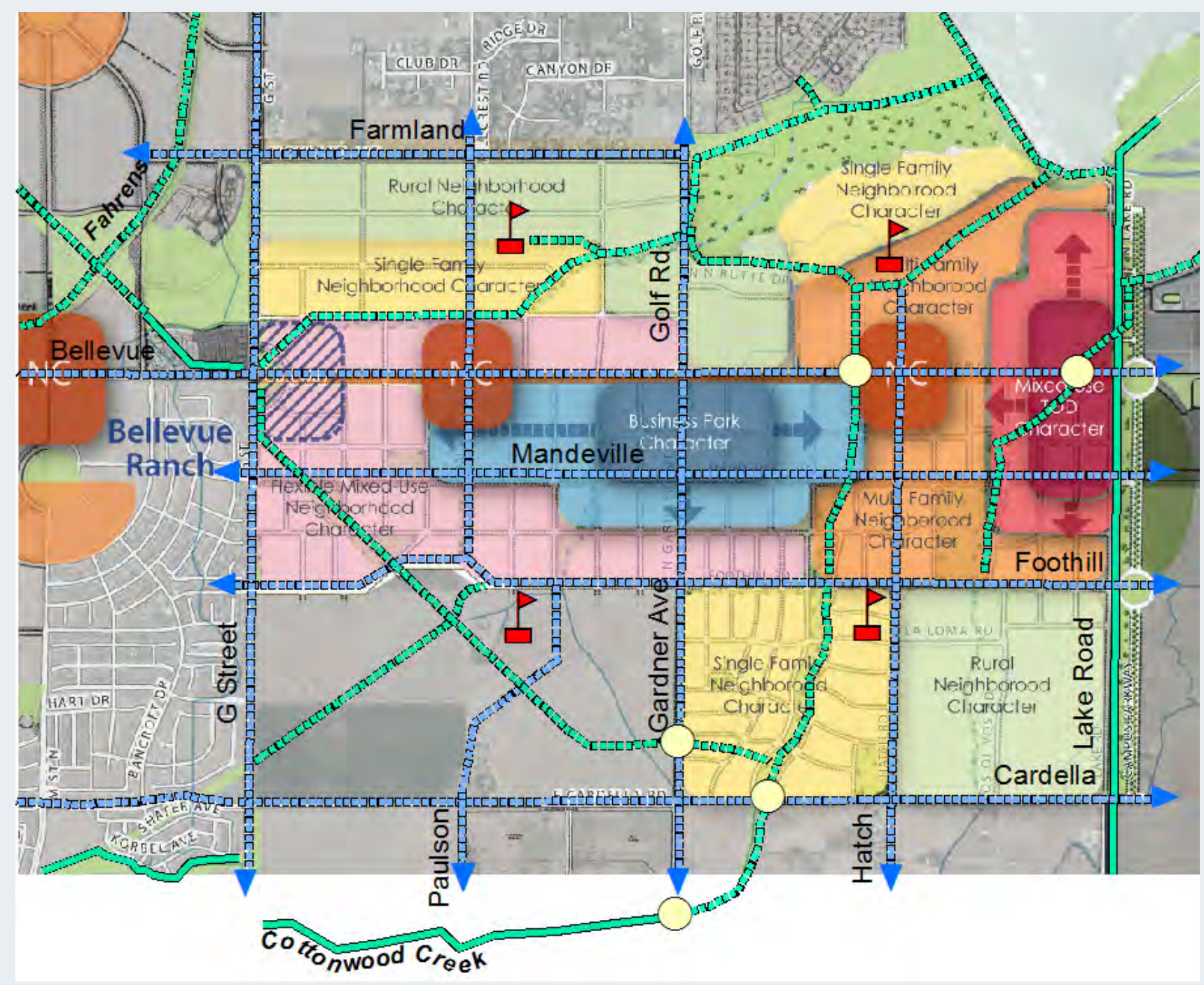




\section{PEDESTRIAN-ORIENIED COMPONENT}

Merced has many senior citizens, young people, and other residents who have limited access to an automobile. The ability to access shopping, community activities, and work within safe, easy walking distances to home is essential to support the needs of the local population. People who utilize cars and trucks can go anywhere, but students, youth and seniors must walk, bike, or use transit to go places they may need or want to go.

The street classification system and grid network of the BCP is designed to promote and increase walkability of the BCP area. Walkability is not only determined by close proximity between destinations, but also the pedestrian experience while moving between locations. Creating pedestrian scale environments that encourage walking over driving, is accomplished with the following basic design principles which are depicted in the BCP Pedestrian Transportation Map (Figure 27):

\section{Figure 27. Pedestrian Transportation Map}

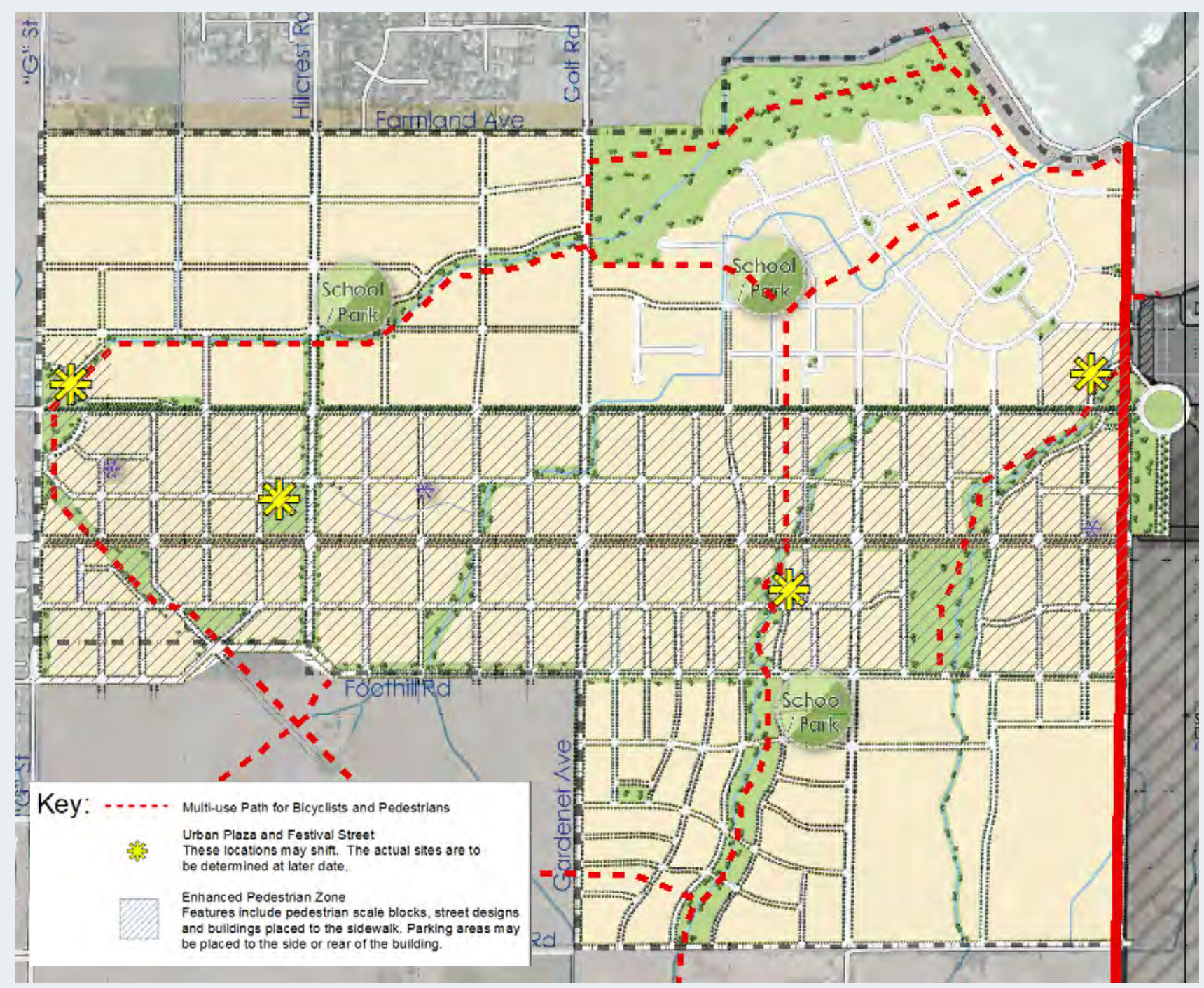




\section{Figure 28. Examples of Street \\ Landscape Features}

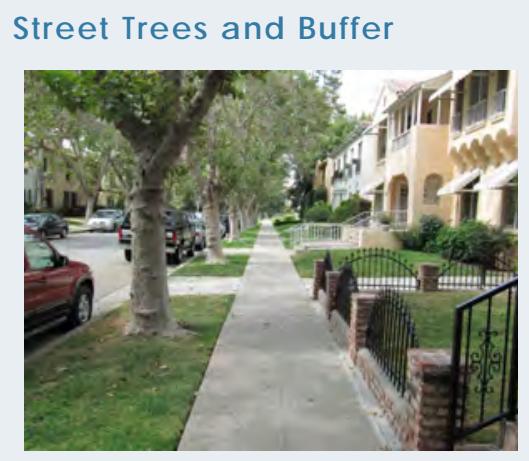

\section{Sto mwater Swale}

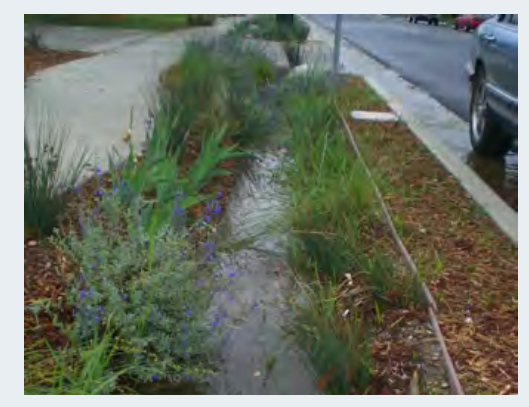

Figure 29. Example of an Urban Plaza and Festival Streets

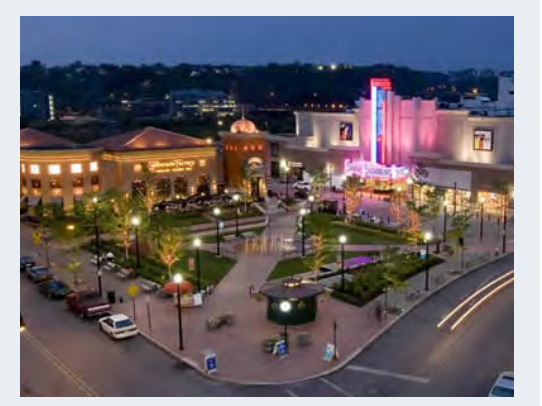

- A street block structure of closely spaced and interconnected streets with slow vehicular speed;

- Pedestrian scale development including open space, parks, and festival streets which increase pedestrian activity

- Visible cross walks, bulb outs, and other pedestrian and traffic calming designs to improve safety during street crossings;

- Appropriate walk-zone and planting/amenity zones, including sidewalks, trees, benches, and lighting; and

- Parking facilities that encourage shoppers to 'stop and walk'.

\section{OPEN SPACE, PARKS, AND FESTIVAL STREETS}

Public rights- of-way can be designed with features that support and enhance walking. These features include street trees, parkways, street furniture areas, stormwater drainage swales, and festival streets. Open-space features combined with enhanced architectural designs and urban plazas can create memorable community gathering places and gateways in the community.

\section{Open Space}

Street landscape features bring many benefits to a community including storm-water management, lower ambient air temperature, a comfortable and visually interesting environment for all users, and traffic-calming. Spaces for these open space features are provided through placement of street trees, islands, curb extensions, etc., in the right-of-way. Figure 28 shows examples of some of these features.

\section{Parks}

The urban nature of the BCP along the Mandeville Transit Corridor warrants the consideration of urban plazas. The City's 2000 Merced Park and Openspace Master Plan defines an urban plaza as a small park, usually passive, that provides an opportunity for the public to gather in urban locations. The BCP proposes at least three urban plazas (see Figure 29) to be located within or near neighborhood commercial centers, and connected to the area's openspace and bikeway network.

\section{Festival Streets}

Streets are a huge part of any community's public space network, and historically served as meeting places, playgrounds for children, marketplaces, and more. As populations spread out from city centers, most American cities have come to view streets primarily as conduits for moving vehicles from one place to another. While moving vehicles is one of their purposes, streets are spaces, even destinations in and of themselves. By approaching streets as public spaces, cities redirect their attention from creating merely traffic conduits to designing a place that offers greater value to pedestrians, bicyclists, and transit riders. This comprehensive approach requires intentional positioning of urban features to create these public spaces. The BCP identifies several urban plazas in land use and roadway settings to enable future public events using City streets. Festival Streets should contain traffic calming, flush curbs, and streetscape features that allow for easy conversion to public uses such as farmers' markets and music events (Other ideas can be found at the Los Angeles County Model Design Manual for Living Streets, Chapter 12). 


\section{Pedestrian Crossings/Traffic Calming}

There are several methods to ensure safe and convenient pedestrian crossing, including providing crosswalks spaced at appropriate intervals, reducing crossing distance, and managing speed and flow of vehicular traffic. The following tools are options to use within the BCP to improve pedestrian safety (see Figure 30 \& Figure 31 ):

- High visibility cross walks

- Pedestrian crossing warning signs

- Medians

- Bulb-outs and curb-extensions

- Pedestrian refuge islands

\section{Figure 30. Crosswalks}

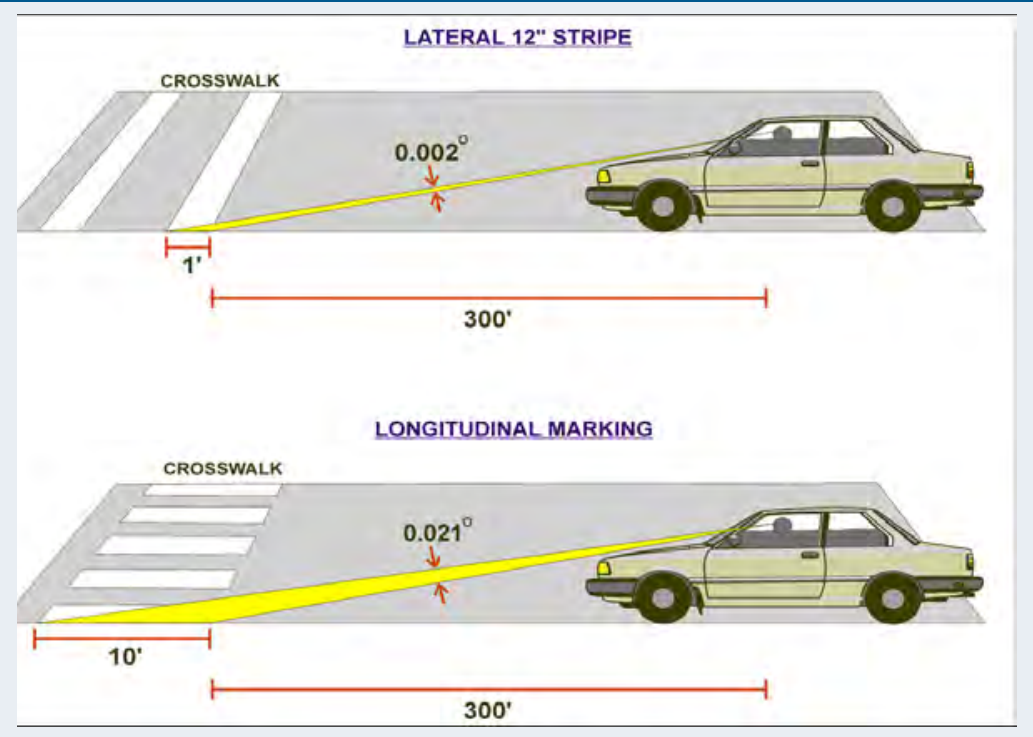

Crosswalk striping pattems with lines longitudinal to the roadway are more visible to approaching motorists than the two transverse lines used on many crosswa lks. High visibility pattems a re especia lly beneficial at uncontrolled crossing locations (i.e., where there are no stops signs or traffic signals requiring vehicles to stop).

\section{Walk, Planting, and Amenity Zones}

Sidewalk width is a key component of providing safe routes for pedestrian travel. Wider sidewalks within mixed-use or heavy traffic areas act as a physical buffer from vehicular traffic and provide a sense of safety and security for pedestrians. Additionally, wider sidewalks can accommodate more foot traffic and are most appropriate in commercial areas. Sidewalk characteristics, including addition of tree wells, planting strips, or street furniture varies depending on street classification and community character area. The parkway use type can be either a fully landscaped zone (L), or a furniture zone (F). There are character areas where no street furniture or

\section{Figure 31. Bulb-outs}
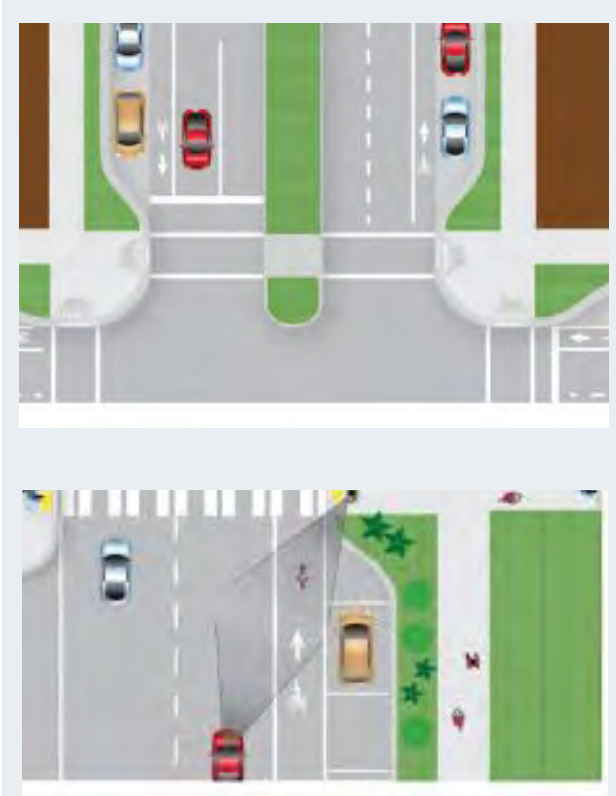

Curb extensions, or bulb-outs, can reduce the distance for pedestrian crossing while still accommodating bikepaths and on-street parking. Additionally, bulb-outs reduce vehicular speed and inc rea se visibility at busy intersections, increasing ped estria n sa fety.

Source: Bikepedsafe.org 
landscaping may be required in order to maintain consistency with existing neighborhoods. Figure 32 shows the location of different zones in the public realm. The sidewalk is made up of three main zones: amenity zone for landscaping and street furniture, the walk zone to allow pedestrian travel, and the frontage/setback zone which allows transition between the sidewalk and the building without blocking moving pedestrian (see Table 5 for exact standards).

While in some cases it may be appropriate to locate furniture or other landscaping amenities in places outside of the planting/amenity zone, the intent is to keep the walk zone free from obstacles to ensure easy pedestrian flow.

\section{Figure 32. Pedestrian Realm}

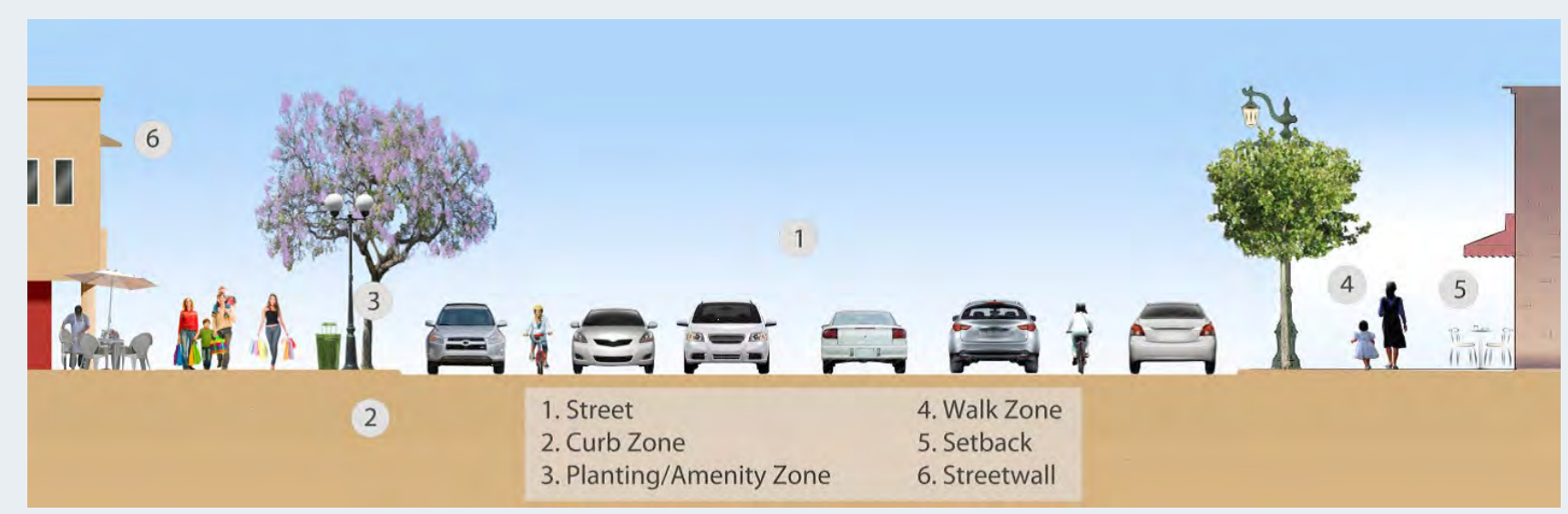

Táble 5 Pedestrian Way Standards

\begin{tabular}{|c|c|c|c|c|c|}
\hline Place Type & $\begin{array}{l}\text { Planting/Amenity } \\
\text { Zone Use Type }\end{array}$ & $\begin{array}{l}\text { Planting/Amenity } \\
\text { Zone Width }\end{array}$ & $\begin{array}{l}\text { Minimum } \\
\text { Walk Zone } \\
\text { Width }\end{array}$ & $\begin{array}{l}\text { Frontage/ } \\
\text { Setback } \\
\text { Zone Width }\end{array}$ & $\begin{array}{l}\text { Total } \\
\text { Sidewalk } \\
\text { Width }\end{array}$ \\
\hline Mixed-Use TOD & $\mathrm{F}$ & $4 \mathrm{ft}$ & $8 \mathrm{ft}$ & $2 \mathrm{ft}$ & $14 \mathrm{ft}$ \\
\hline R\&D Employment District & $\mathrm{L}$ & $4 \mathrm{ft}$ & $6 \mathrm{ft}$ & $2 \mathrm{ft}$ & $12 \mathrm{ft}$ \\
\hline Neighborhood Centers (NC) & $\mathrm{F}$ & $4 \mathrm{ft}$ & $6 \mathrm{ft}$ & $2 \mathrm{ft}$ & $12 \mathrm{ft}$ \\
\hline Flex-Mixed Use Neighborhood & F/Lor $L$ & $4 \mathrm{ft}$ & $6 \mathrm{ft}$ & $2 \mathrm{ft}$ & $12 \mathrm{ft}$ \\
\hline Multi-Fa mily Neighborhood & $\mathrm{L}$ & $3 \mathrm{ft}$ & $6 \mathrm{ft}$ & $1 \mathrm{ft}$ & $10 \mathrm{ft}$ \\
\hline Single Family Neighborhood & $\mathrm{L}$ & $7 \mathrm{ft}$ & $5 \mathrm{ft}$ & per setback & $\mathrm{N} / \mathrm{A}$ \\
\hline Rural Residential Neighborhood & $\mathrm{L}$ & $7 \mathrm{ft}$ & $4 \mathrm{ft}$ & per setback & $\mathrm{N} / \mathrm{A}$ \\
\hline
\end{tabular}




\section{BELLEVUE COMMUNITY PLAN G OALS AND POLICIES}

The goal headings of this BCP chapter are grouped into the same policy topics as the Merced Vision 2030 General Plan. This approach fosters consistency and builds on the City's broader General Plan guidance. In furtherance of consistency with the City's General Plan, Appendix C, policies specific to the BCP planning area are described in greater detail and grouped with the goals and policies it shares in common with the City's General Plan. In additions to the goals and policies below, Master Plans/projects/permit applications need to take into account the BCP in its entirety and be consistent with the language herein.

Table 6 Mobility Goals and Policies Specific to the Bellevue Corridor Community Plan Consistent with the City's General Plan

Goal Area M-1: Streets and Roads

\section{Policy M-1.1: Pursue the completion of the City's arterial grid network.}

All proposed arterial streets within and adjacent to the BCP a re essential roadways that need to be completed. Bellevue to serve as an urban a rterial in the loop road system; Gard ner Road south of Bellevue Road to connect the BCP, UCP and UCM with the Merced Community; Campus Parkway as part of the urban fabric to the east; and Cardella Road and Yosemite Avenue providing important east-west oriented linka ges knitting the long-term growth a rea s of the City of Merced.

Policy M-1.2: Examine the possibility to reduce the number of lanes on Gardner Avenue, Bellevue Road and Golf Road.

Inclusion of a broad range of transportation-related factors may result in a finding that would support fewer travel lanes on plan area arterial roadways. Complete a traffic impact analysis that considers the function of all transportation modes, land use pattems and both collector and arterial street designs to examine the potential to reduce the number of la nes from 6 to 4 on Bellevue Road, from 4 to 3 on Gardner Avenue (between Bellevue Road and Foothill Drive), and from 4 to 2 on Golf Road (north of Bellevue Road).

Policy M-1.3: Update the City's Standard Designs to incorporate the special cross-sections for collec tor roads within the BCP.

The BCP includes several special collector-street cross-sections that were designed to rec oncile the competing functions of streets, and include: Lake Road (Figure 22 \& Figure 23); Mandeville Avenue (Figure 20); Hatch Road (Figure 18); and Paulson/Hillcrest Avenue (Figure 17).

Policy M-1.4: Work with Merced County to identify future right-of-way locations for plan area arterial and collector streets and intersections.

Collaboration between the City and County to define arterial street locations within the BCP should occur soon after its adoption to avoid development within these important community rights of way. The location of these roadways should be designed flexibly to avoid or minimize impacts to existing uses while (1) assuring adequate width will be provided in the long-term; and (2) minimizing impacts to natural resources such as topography, sensitive habitats and water features. Of particular note a re the a lignments of Bellevue Road, Gardner Road, Foothill Avenue, Hatch Road, and the intersections involving (a) Bellevue Road, Campus Parkway and Lake Road; and (b) Bellevue Road with Paulson/Hillcrest (extended).

Policy M-1.5: Develop Bellevue Road to enhance the value of adjacent properties in an urban setting, while secondarily also serving as a route for regional traffic as a link in the City's Loop Road System.

While Bellevue Road is a link in the regional loop road, and will accommodate regional traffic, it is foremost an urban arterial with important land uses that will face it. Bellevue Road is also a gateway to and from UC Merced.

Policy M-1.6: Explore the use of Traffic Circles and Roundabouts.

Fully examine the value of placing roundabouts along the BCP's various roadways, considering such factors as infrastructure and operating costs, and compatibility with transit services, and pedestrian and bic ycle movements. 


\section{Policy M-1.7: Include side roads in the design of Bellevue Road.}

Use of a side access road adjacent to Bellevue Road brings several benefits, including, allows buildings to face or address a street, c reating a more visually pleasing setting and gateway environment, ascompared to sound walls or loading docks; creates a space for other modes of mobility (transit, bike lanes, sidewalks) to access buildings; provides for on-street parking; and maximizes access to uses without substa ntial slowing of through traffic on Bellevue Road. Additionally, side roads create a setting that provides more site design options for a dja cent build ings, a llows for very different la nd uses to loc ate on opposite sides of the road; and for build ing sites, overtime, to change.

Policy M-1.8: Synchronize traffic signals along Bellevue Road.

Heavy traffic loads, including through traffic are anticipated on Bellevue Road. To facilitate good vehicular flow and to avoid congestion at intersections, the traffic signals along Bellevue Road should be synchronized.

\section{Policy M-1.9: Seek to implement an interconnected street grid.}

An interconnected street pattern is foundational to the achievement of many goals of the BCP, including: 1) development of a successful transit system; 2) enabling functional sites for transit priority projects; 3) increased travel by pedestrians and bicyclists; 4) formation of an innovation hub and associated population; and 5) attracting research and development offices. Figure 12 of the BCP, an important illustrative diagram, should be utilized in the design of future development projects.

\section{Goal Area M-2: Bikes, Pedestrians, and Public Transit}

Policy M-2.1: Establish Mandeville Road as the extension of the City's "M" Street Transit Coridor to UC Merced.

During the BCP planning process, there were extensive discussions about the placement of the transit comidor, either on Bellevue Road or Mandeville Road. For many reasons described in the BCP, Mandeville Road was selected as the appropriate roadway to develop the transit comidor. The Mandeville Road Transit Comidor provides for multiple options to connect to or extend it as needed.

\section{Policy M-2.2: Seek to develop an interc onnected street grid on both sides of Mandeville Road.}

The interconnected roadway grid is a n essential foundational component of the urban fabric to support a succ essful transit system. A street network with a clear block struc ture and relatively closely spaced cross streets, whether curved, straight or otherwise, and having slower traffic than roads built to accommodate through-traffic, enables high-levels of access to transit and nearby uses and neighborhoods.

Policy M-2.3: Update the City's Bicycle Transportation Plan by incorporating the bikeway facilities planned in the BCP.

Figure 26 depicts the bike lanes, paths, and sharrows planned in the BCP. Placing these in the City's official bike plan will maximize the community's a wareness of how bikeways will connect with UC Merced and to County areas outside the City's Sphere of Influence.

Policy M-2.4: Identify a suitable location for a bicycle boulevard.

As the community plan develops and traffic patterns are formed, monitor circulation patterns and take steps to install a bicycle boulevard in the area bounded by Bellevue Road, Foothill Avenue, G Street and UC Merced. 
This page intentionally left blank. 


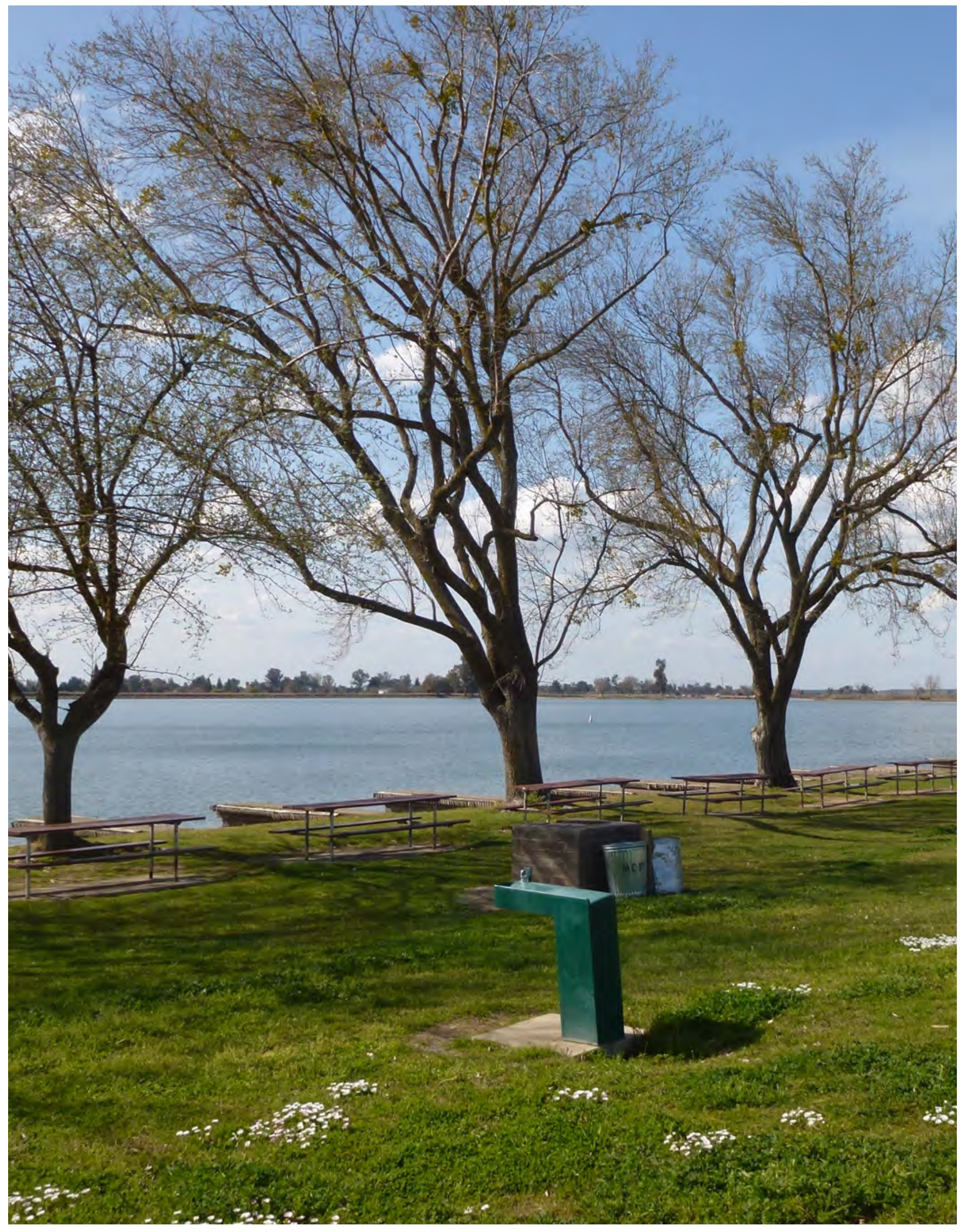




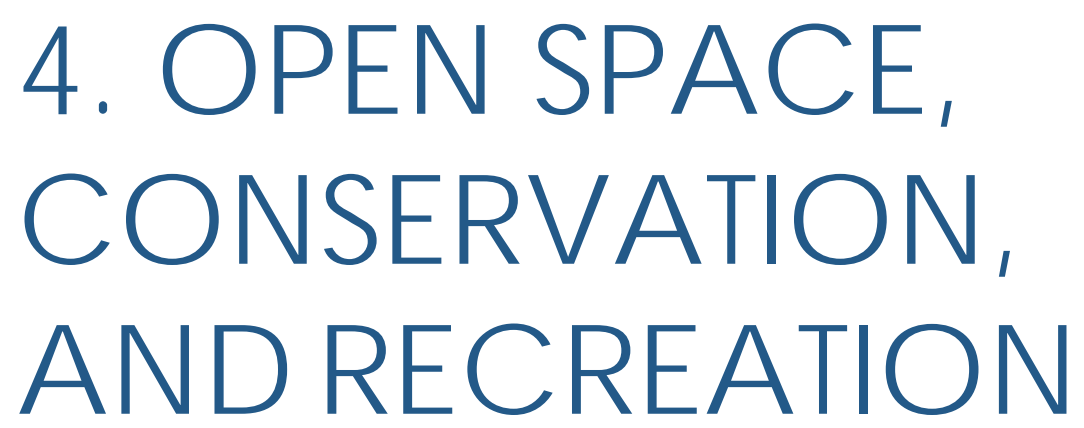

Similar to the Merced Vision 2030 General Plan, the Bellevue Community Plan (BCP) takes an integrated approach to managing and planning for openspace resources. The goal of the Open-space, Conservation, and Recreation Chapter of the $\mathrm{BCP}$ is to provide an interconnected network of open-space land while still allowing for new development in appropriate areas. This Chapter outlines the varied types of open-space land and provides examples of how additional land for open-space, conservation, and recreation can be integrated with the City's existing and planned network of trails, drainage basins, and urban plazas.

An integrated design with a focus on the connectivity of open-space will help further the City's goals of not only protecting natural and man-made resources, reducing impact on wildlife habitat, and managing water and agricultural resources, but also providing an expanded network of on- and off-street bike paths, preserving Merced's unique character, and planning for a sustainable future. Also, by providing a range of open-space types, the BCP allows flexibility for design depending on the surrounding environment and intended role of the open-space land for resource preservation, recreation, health and safety, or conservation. This strategy avoids the potential for adhoc and haphazard placement of inaccessible and ultimately, ineffective, open-space land.
Open-space takes many forms, and integrates a wide variety of needs including recreation, resource conservation, public health and safety, natural beauty, and wildlife protection. 


\section{Open-space is one of the} essential elements contributing to the high quality of life in the

City of Merced. It provides a multitude of functions that are beneficial to the community.

\section{View of Agric ulture Land \\ Near Plan Area}

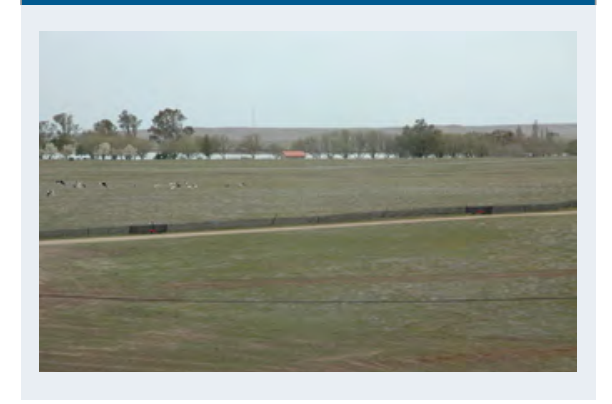

Lake Road Scenic Comidor

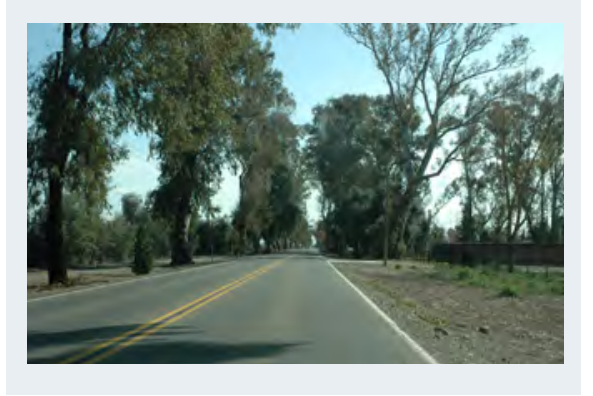

\section{SETTNG}

Open-space is one of the essential elements contributing to the high quality of life in the City of Merced. It provides a multitude of functions that are beneficial to the community. The BCP recognizes that the urban form of the planning area will be shaped in a positive manner through retention of openspace elements, including sensitive species habitat, creek and/or irrigation channels, street design, and recreation-based parks. Providing a well designed open-space network will attract residents, future employers, and investment.

This section provides an overview of the setting and environmental factors most significant to the open space, conservation, and recreation system.

\section{AGRICULTURE}

Agricultural lands provide a valued aesthetic and lifestyle contrast to the more urbanized areas. Agriculture open space is seen as an intermediary use until such areas are needed for urban expansion, however.

\section{SCENIC CORRIDORS}

Bellevue Road and Lake Road are listed as Scenic Corridors in the Merced Vision 2030 General Plan and are also identified in the BCP as Gateways. The scenic character of Lake Road is proposed to be maintained and enhanced, where possible. Lake Road forms the eastern boundary of the BCP planning area and acts as an important element of the large rural residential character area, buffering this area from future urbanization anticipated to occur to the east. More information can be found on the Gateway design principle in Chapter 2 of this document.

\section{TRANSPORTATION CORRIDORS}

Streets, bike paths, and transit facilities can include linear or nodal open-space features for the use and enjoyment by the public. These features include street trees, parkways, street furniture areas, storm water drainage swales, and public art. Open-space features combined with enhanced architectural designs and urban plazas can create memorable community gathering places and gateways in the community.

\section{BIOLOGICALRESOURCES}

The BCP seeks to continue the tradition of preserving and protecting openspace corridors along natural drainages in the plan area, and to enhance or create open-space corridors in appropriate environmentally sensitive areas. Open-space Land Use, Urban Expansion, and Sustainability policies of the Merced Vision 2030 General Plan, which are also applicable to future development in the $\mathrm{BCP}$, ensure that sensitive habitat areas, and the plants and animals found in them, are adequately considered and managed to reduce any adverse effects from development. In an effort to avoid significant future amendments to the BCP, a conceptual open-space network has been crafted to take into consideration the long-term protection of habitat and riparian areas. At the same time, the BCP recognizes that the BCP Open-space Map (Figure 37) may need to be adjusted to account for increases or decreases in 
Figure 33. Sensitive Habitats and Conservation Lands within and nearthe Plan Area

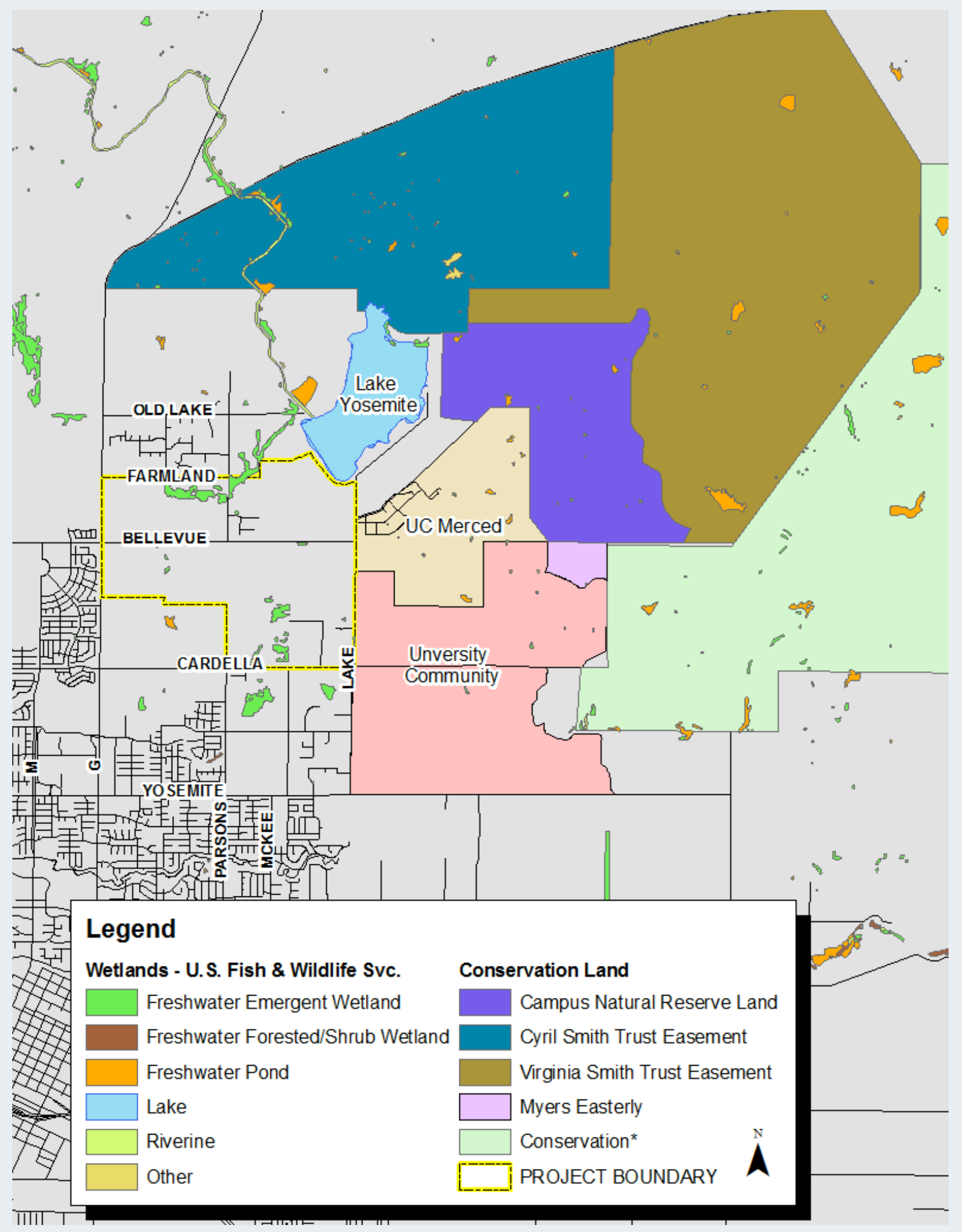


the amount of lands to be conserved, depending on how future development projects provide for conservation and protection of sensitive habitat and species. It is important to note that while the size of an open-space corridor or area may be reduced, it should not be removed altogether.

Figure 33 from the Merced Vision 2030 General Plan depicts the location of conservation areas and sensitive lands within and near the BCP area. Table 7.2 in the City's General Plan contains a list of Special Status plants and animal species, which are likely to be found in the City's Sphere of Influence, including the BCP area.

\section{CONSERVATION LANDS}

North and east of the BCP, many acres of land have been set-aside to protect sensitive species and habitats located in the region (see Figure 33). These sites act as a natural boundary to urbanization in Northeast Merced. The size and location of future additional conservation areas, whether adjacent to these sites or within the BCP, is unknown at this time. Consistent with the mitigation measures for the Merced Vision 2030 General Plan, these determinations will occur either prior to or concurrent with annexation proposals. The timing of this determination aligns with the Memorandum of Understanding between the City of Merced and the United States Fish and Wildlife Service (USFWS), which sets forth development permit review procedures related to the identification and protection of sensitive species and habitats in North Merced.

\section{POTENTIAL SENSITIVE HABITATAREAS}

The BCP planning area contains several water features, ranging from ephemeral streams, irrigation channels, wetlands, and vernal pools that may provide habitat for several sensitive species. These features are distributed throughout the BCP area and are depicted in the Merced Vision 2030 General Plan. Prior to development on public or private lands, detailed biotic assessments will be conducted. The results of these assessments, the determinations and requirements made by resource agencies, and any applicable mitigation measures, can play a major role in the future design of development projects.

\section{CRITICAL HABITAT DESIGNATIONS}

Portions of the BCP are designated critical habitat for various sensitive species. While such designation does not preclude development, it does raise the level of resource agency review and possible conservation-related requirements. 


\section{WATER RESOURCES}

The water resources of the Merced area are derived from two sources: local rainfall and runoff from the Sierra Nevada Mountains. Both sources contribute to groundwater and surface water resources of the BCP area. The Merced Irrigation District (MID) irrigation reservoir and canal system captures and distributes surface water resources.

Figure 34 depicts the locations of existing natural drainages, irrigation channels and existing storm-water drainage facilities.

\section{Figure 34. Ste Topography and Drainage Features Within and Near the Planning Area}

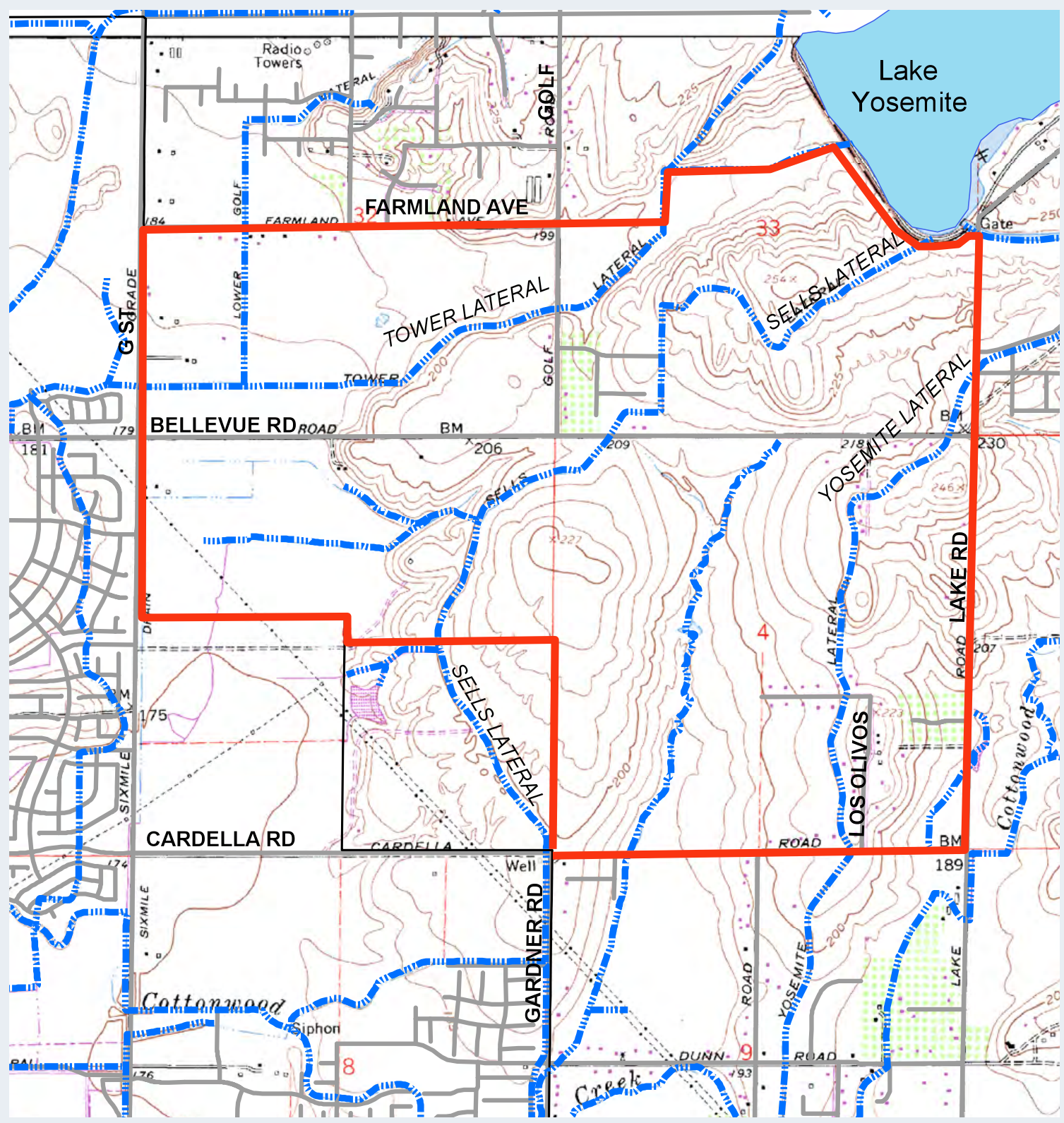


Example of a Stormwater Detention Basin

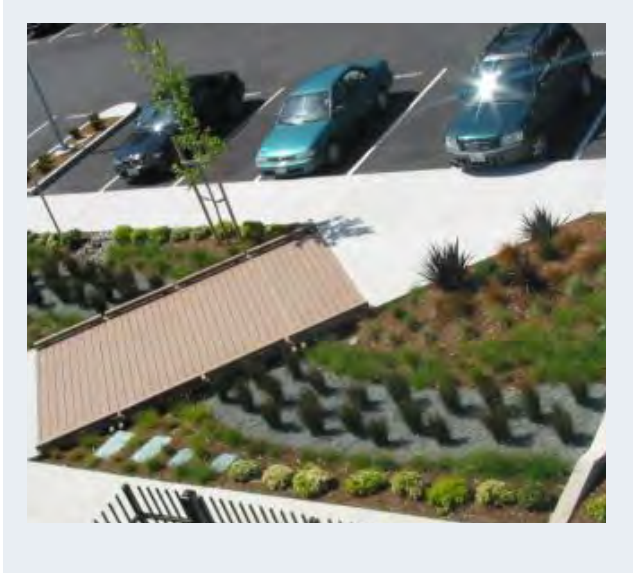

\section{SURFACE WATER}

The City of Merced contains a rich and varied surface water system which includes a natural creek and drainage system, the MID irrigation canal system and Lake Yosemite in the northeastern portion of the City's planning area. Surface water features within the BCP include the following, and are depicted in Figure 34 and Figure 35:

- $\quad$ Tower Lateral

- Settlers Lateral

- Yosemite Lateral

- $\quad$ Lower Golf Lateral

Water flow in these laterals are less than 100 cubic feet per second (cfs), which is the threshold used by the Merced Irrigation District (MID) to bury open laterals as development occuring adjacent or over them.

Irrigation-related laterals could be piped and placed in an easement containing public open-space with or without an off-street bike path. This design option currently exists along the Buhach Lateral in the City of Atwater and could have application to irrigation laterals in the plan area. Alternatively, a collaborative approach between the City, MID and property owners to create open space corridors in the BCP with surface water should also be explored further. For example, the Merced Vision 2030 General Plan (Figure 7.1) depicts a well-defined open-space recreational land use area between Lake Yosemite and Golf Road, and the Tower Lateral extends through this area as well, providing an opportunity for an open-space corridor and/or bike path.

Natural drainages that are not managed for irrigation purposes can be designed as open-space corridors that maintain natural surface water and riparian features. A tributary to Cottonwood Creek, located between the Sells Lateral and the Yosemite Lateral provides an opportunity to develop an uninterrupted bikeway between Cardella Road and Bellevue Road. Figure 34 depicts natural drainage features and site topography within the $\mathrm{BCP}$ area.

\section{STORM-DRAINAGE}

The City of Merced Storm Drainage Master Plan (2002) requires the retention of stormwater to regulate the flow into drainage channels. Storm water retention and/or detention basins are primarily used for flood control, with a secondary purpose of providing ground water recharge where soil conditions allow. These basins can also be utilized for open-space and limited recreational uses, where practical. Additionally, while the BCP area does not include sites for deep groundwater recharge, stormwater basins have the potential to recharge shallow aquifers. While joint use is encouraged, parkrelated uses in storm-drainage basins only partially satisfy City requirements for amounts of parkland needed to serve local populations. Opportunities to create storm-water related open-space features are discussed in the Public Facility Chapter of the BCP. 
Figure 35. Wetland Features with and near the Plan Area

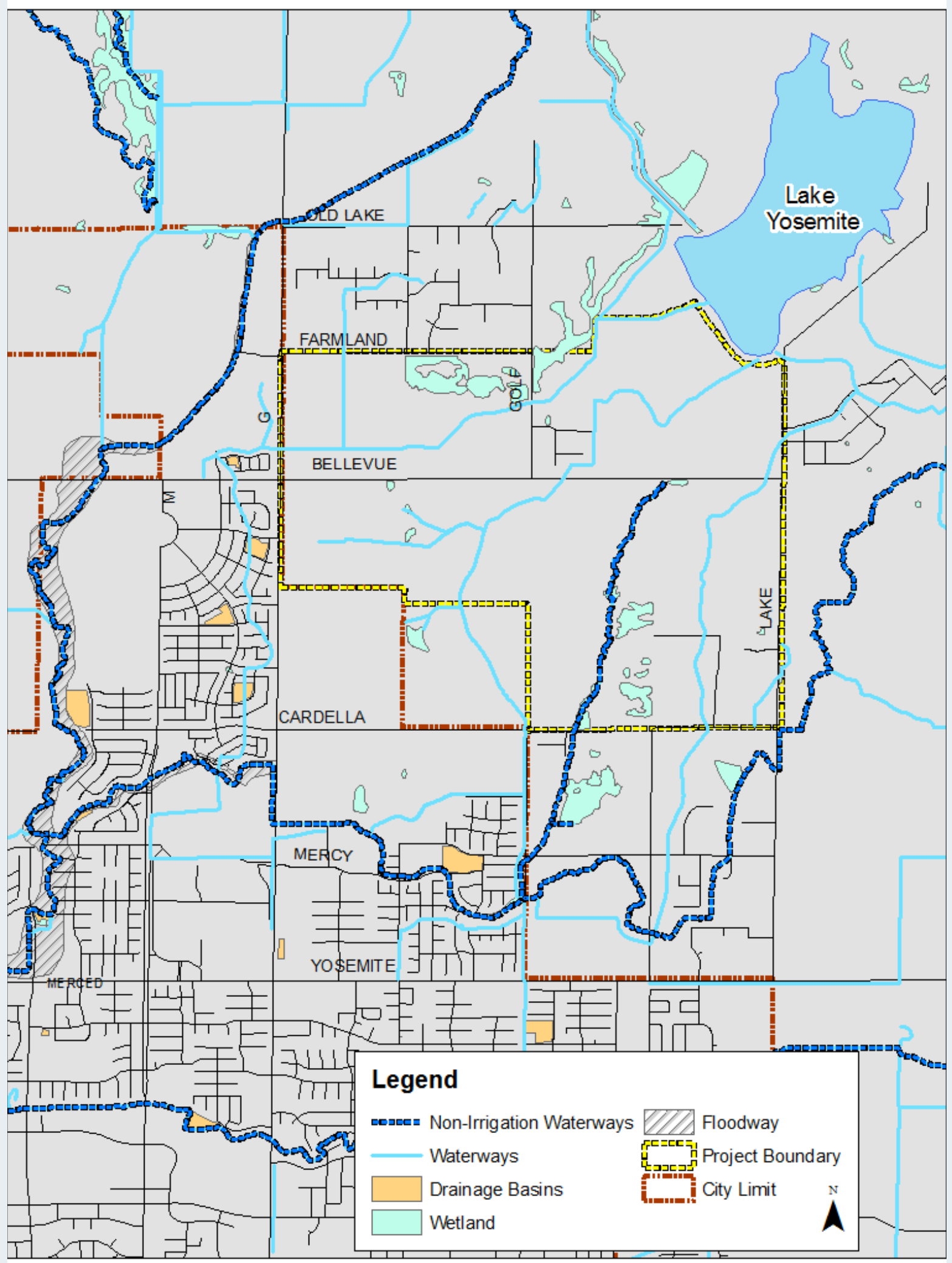




\section{A general underlying goal of}

the $B C P$ is to provide adequate

services and amenities to

current and future populations.

\section{OPEN-SPACE SERVIC E STANDARD}

A general underlying goal of the BCP is to provide adequate services and amenities to current and future populations. This is achieved by knowing the nature and amount of increased demand for recreational facilities resulting from increased population of the $\mathrm{BCP}$, and assuring the $\mathrm{BCP}$ provides recreational facilities or resources sufficient to meet potential demand. The City of Merced has historically used the standard of five acres of City park land for every thousand residents. Figure 36 on the following page details the existing and planned recreational facilities.

School grounds, church grounds, and Lake Yosemite are not included in the park standard; these supplement the network of the City's park lands. The City and local school districts have worked closely in the past to share facilities and programs. Similarly, lands required to be set-aside to conserve sensitive habitat are not counted when determining the amount of City park land. 
Figure 36. Existing and Planned Recreational Facilities Within and Near the Plan Area

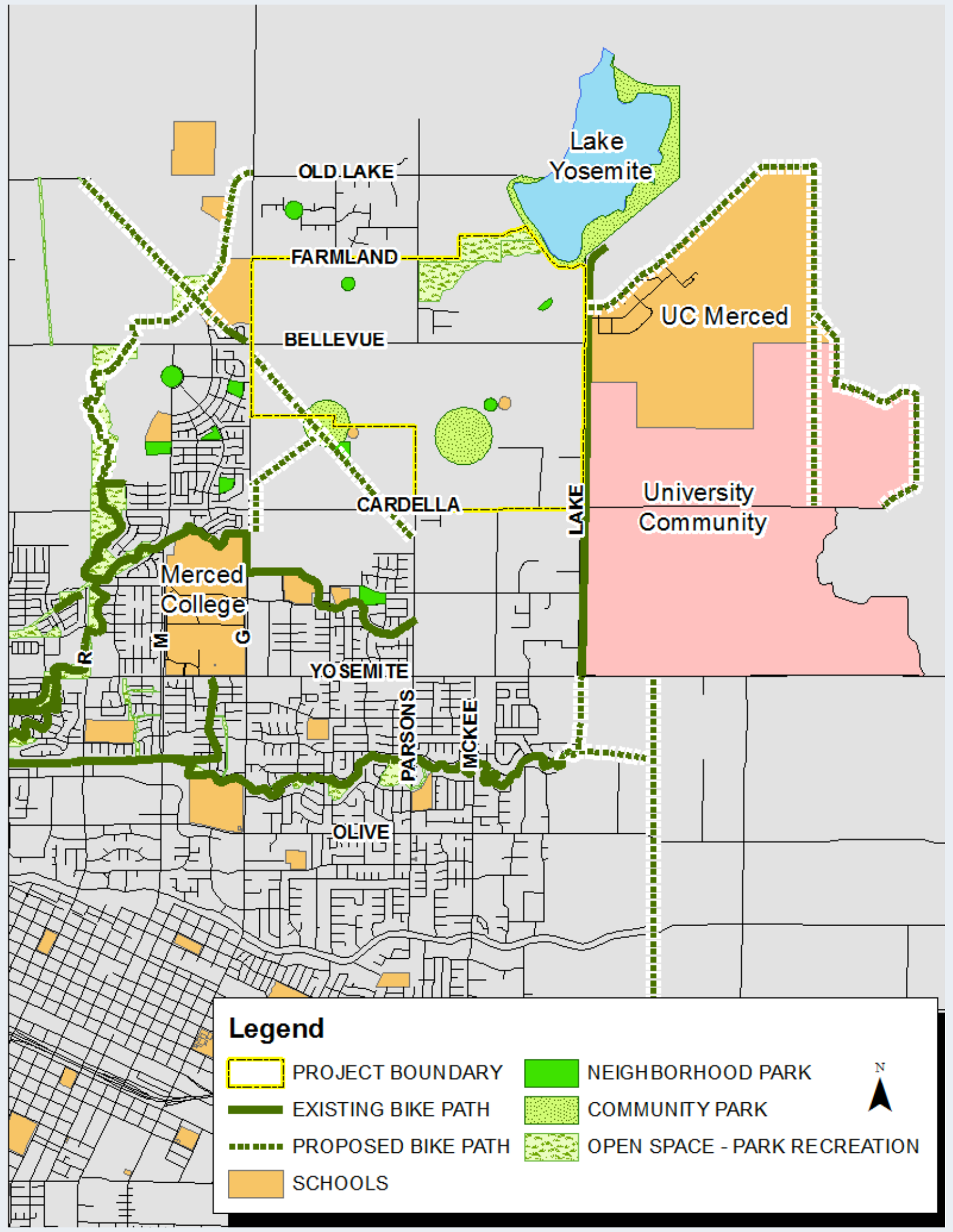




\section{PARK TYPES}

Parks in Merced are classified into the following types: Regional Parks, Community Parks, Neighborhood Parks, Mini-parks, linear parks, school parks, special use areas, urban plazas, and athletic parks. The following describes the types of recreation and park facilities which can most likely be used to meet the increase in park demand within or near the BCP area.

\section{REGIONALPARK}

Lake Yosemite Regional Park is located northeast of the City and operated by Merced County. Lake Yosemite Regional Park is of special interest to the broader Merced community because of its water recreation opportunities and open-space qualities. It is also within bicycle commute range for many residents. It is the intent of the BCP to provide options for open-space and trail linkages to Lake Yosemite Regional Park.

\section{COMMUNTTY PARK}

The Merced Vision 2030 General Plan (Figure 7.1 of the Merced Vision 2030 General Plan, showing conceptual park locations) depicts a large "floating" open-space recreational land use area in the area bounded by Bellevue Road, Lake Road, Cardella Road and Gardner (extended). This land use corresponds with proposed Community Park CP-43.

\section{Examples of Community Parks}

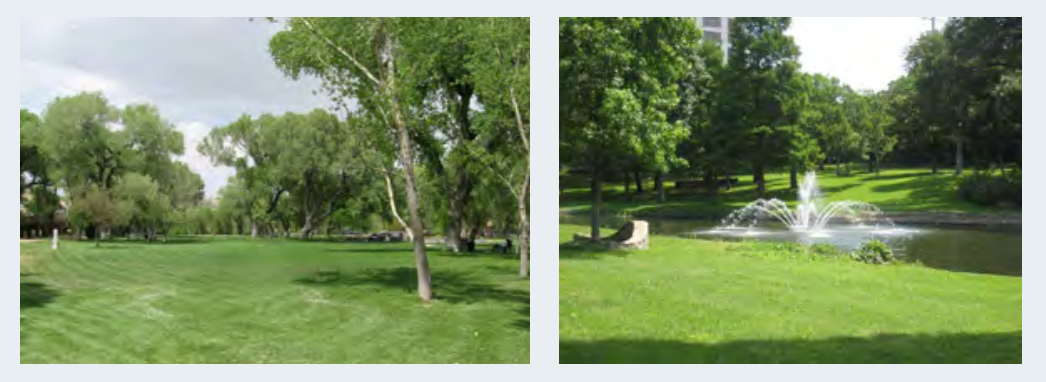

\section{NEIG HBORHOOD PARKS}

The Merced Vision 2030 General Plan (Figure 7.1 of the Merced Vision 2030 General Plan, showing conceptual park locations) depicts four neighborhood parks distributed throughout the BCP planning area.

\section{Examples of Neighborhood Parks}
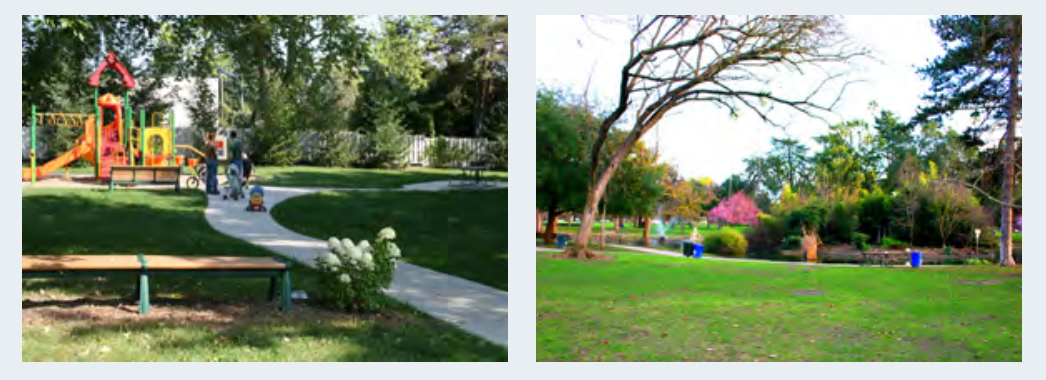


\section{MINI-PARK AND URBAN PLAZAS}

In addition to the provision of neighborhood and community parks, the urban nature of the BCP along the Mandeville Transit Corridor warrants the consideration of urban plazas. The City's 2000 Merced Park and Open-space Master Plan defines an urban plaza as a small park, usually passive, that provides an opportunity for the public to gather in urban locations, such as "Bob Hart Square". The BCP proposes at least three urban plazas to be located within or near neighborhood commercial centers, and connected to the area's open-space and bikeway network.

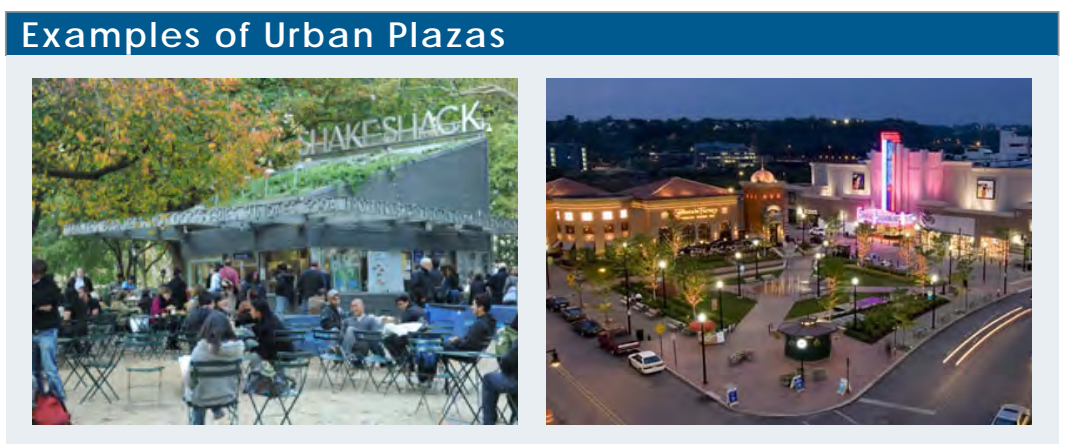

\section{UNEAR PARKS AND OPEN SPACE CORRIDORS}

In addition to provisions for park and recreational facilities, the BCP also emphasizes connectivity between open-space and encourages joint-use of existing open-space corridors. The BCP acknowledges that the connections within and between existing and planned open space is equally important to the total amount of open-space.

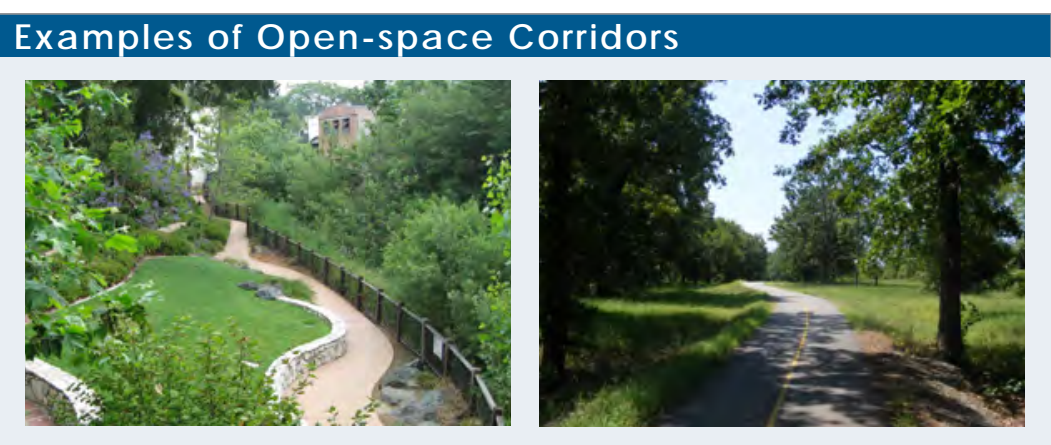

In Merced's built urban environment, many off-street bike paths run parallel with the numerous creeks that traverse the City. At UC Merced, bike paths are planned with campus expansion. The BCP presents opportunities to create important transportation and recreation corridors by connecting the off-street bike paths in the City and County with those of UC Merced.

Within the BCP, continuing emphasis should be placed on locating new park sites adjacent to existing open-space corridors such as wetlands, riparian areas, and irrigation canals and ditches. Placement of off-street bike paths within these linear parks and open-space areas should be considered, especially when able to connect to local and regional destinations and other bike paths. There are several opportunities for adding open space corridors to the existing bike network, including the Tower Lateral Bikeway, the Cottonwood Creek Tributary Bikeway, and the extension of bikeways from the PG\&E open-space corridors located to the southwest of the BCP planning area. 


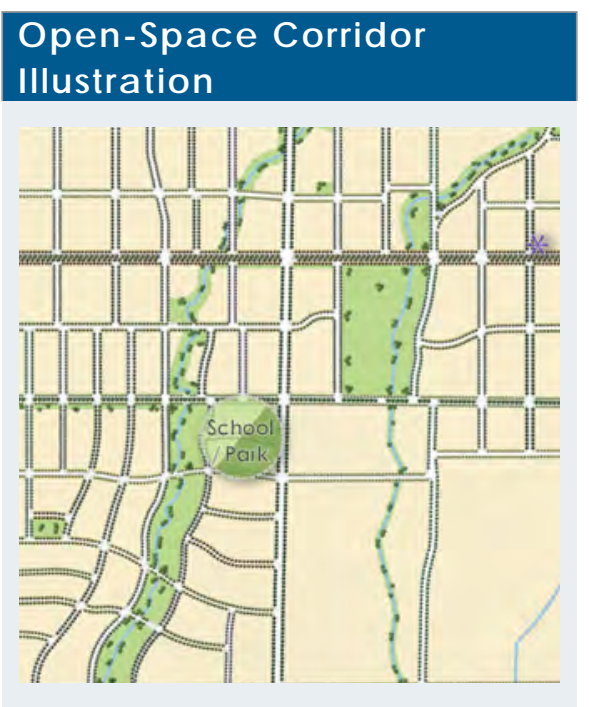

Examples of Off-Street Mult-Use Paths
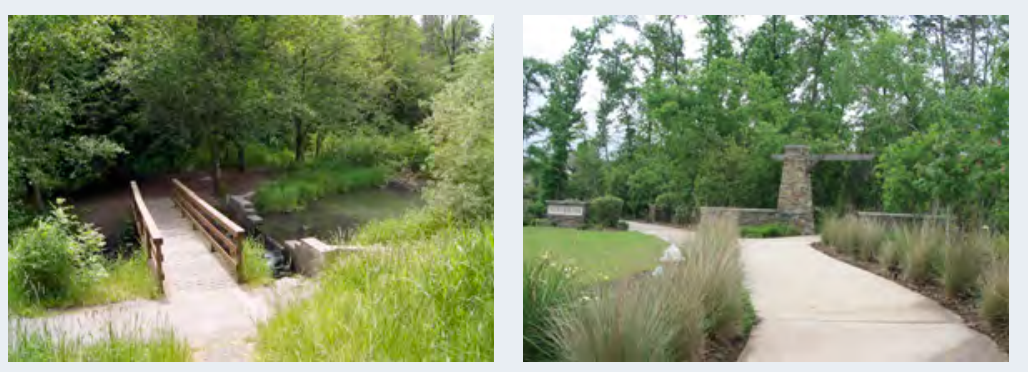

Merced is familiar with off-street pathways alongside natural watercourses and through parks, but has little experience with off-street pathways that extend through urban cores, campuses, or institutional sites. The BCP abuts UC Merced and will contain many Research and Development (R\&D) employment centers, providing an opportunity to create a continuous offstreet bikeway. The features of this bikeway will change depending upon the surrounding environment. For example, part of the bikeway may traverse through an urban plaza, a R\&D campus, alongside an active linear park, or as Merced's first cycle-track (a bike path parallel but physically and spacially separated from vehicle traffic).

\section{Examples of Bike Paths near or through R\&D Centers}
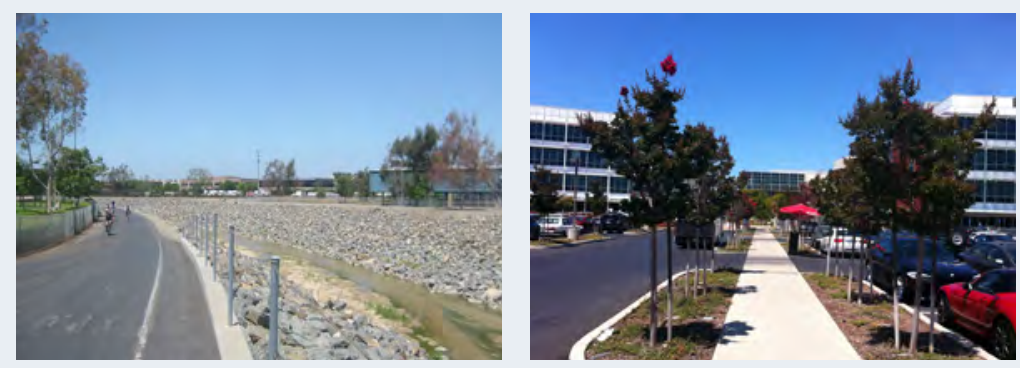

Creekside Greenway Illustration

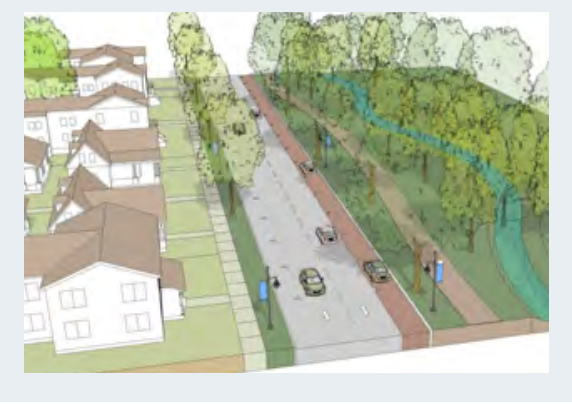

Safe environments for cycling facilities are essential. The application of five principles during the design process for bike paths and other human environments can reduce the incidence of crime, and include: natural surveillance, territoriality activity, access control and maintenance. For example, the principle of natural surveillance is directed primarily at discouraging criminal activity by ensuring that public spaces are easily observable. Designing for natural surveillance involves providing ample opportunity for legitimate users, engaged in their normal activities, to observe the space around them. The "eyes on the street" principle keeps more lines of sight open for normal users and potential witnesses. The overall sense of safety improves when people can easily see others and be seen. 


\section{CONCEPTUAL OPEN-SPACE DIAG RAM}

The conceptual BCP open-space diagram (Figure 37) is a composite of the open-space characteristics described in this chapter, and includes the following elements:

\section{Open Space Map Key Eements}

1

Open-space

Network of

Sensitive

Habitat and

Wild life Lands and Comidors

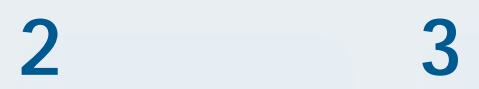

Imigation

Channels

and Natural

Drainages
3

Passive

and Active

Recreational

Sites
4

Conceptual

Locations

of Storm-

Drainage

Facilities

The BCP open-space diagram is meant to be a guiding and dynamic tool. The map establishes a network of City park land with corridors connected to important destinations and maintains acreage consistent with the City's park standard. The intent of the illustrative open-space plan for the BCP area is to establish an open-space framework consistent with community needs, but flexible enough to accommodate new information and approaches which could shift alignments and the amount of park and natural open-space lands to accommodate new information provide a better or more effective network. The open-space diagram provides the large, generally flat BCP area the opportunity to highlight and emphasize the subtle, existing natural terrain. By incorporating the existing topography, the BCP area celebrates the unique, natural qualities already present in Merced.

As with park-sites, these corridors are mapped so that future development can be designed in harmony with them, and not break or develop disconnected parks or detention basins that then become the default open-space features of the area. Rather, individual development in the BCP would help create its part of the larger interconnected open-space network. 


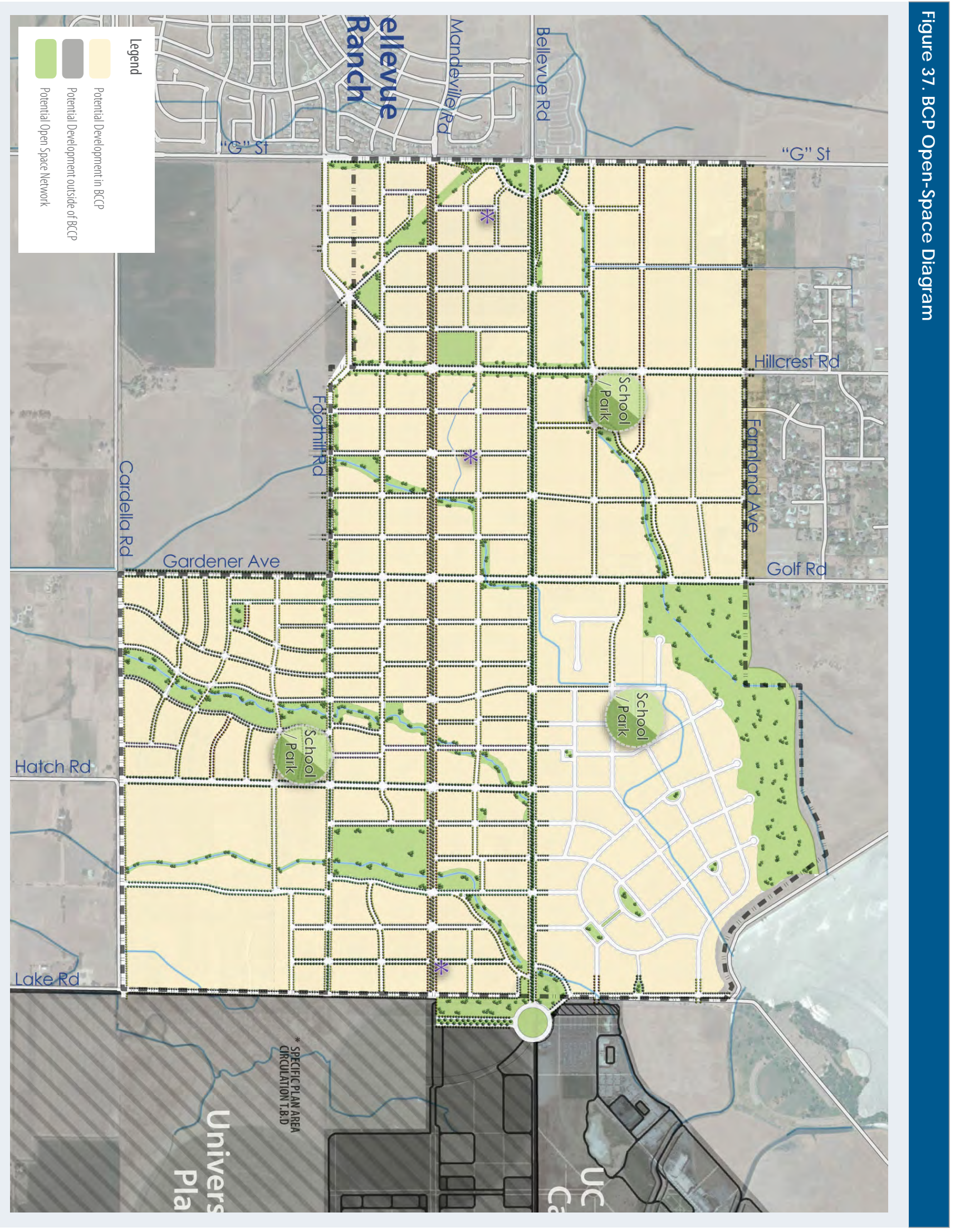




\section{BELLEVUE COMMUNITY PLAN GOALS AND POLICIES}

The goal headings of this BCP chapter are grouped into the same policy topics as the Merced Vision 2030 General Plan. This approach fosters consistency and builds on the City's broader General Plan guidance. In furtherance of consistency with the City's General Plan, Appendix C, policies specific to the BCP planning area are described in greater detail and grouped with the goals and policies it shares in common with the City's General Plan. In additions to the goals and policies below, Master Plans/projects/permit applications need to take into account the BCP in its entirety and be consistent with the language herein.

Table 7 Open Space, Conservation, and Recreation Goals and Policies Specific to the Bellevue Corridor Community Plan consistent with the City's General Plan

Goal Area OS-1: Open-space for the Presenvation of Natural Resources

Policy OS-1.1: Identify sensitive habitats and species early in the development process.

Prior to or concurrent with all annexation proposals, a biological study shall be prepared to identify the presence of sensitive habitats (including vernal pools) and species. Where appropriate, a delineation of the Waters of the U.S. and wetlands shall also be performed and submitted to the U.S. Amy Corp of Engineers prior to a nnexation of lands within the BCP.

Policy OS-1.2: Utilize the BCPOpen Space Map as both a guiding framework and an adjustable dynamic planning tool.

The BCP Open Space Map, which emphasizes avoidance of sensitive habitats, may be adjusted upon annexation if supported by biologic al studies, and comments by state and federal resource agencies, and if altemative mitigation supported by them, and is implemented by the property owner. The BCP Open Space Map inc ludes potential long-term habitat and ripa ria $n$ a reas, and shifts essential la nd uses such as research and development parks and land uses within one-quarter mile of Mandeville a way from these areas. While this approach avoids the potential loss of these significant uses due to a state or federal requirement to scaleback development, the BCP allows development to occur within the open space corridor in the event that no mitigation or alternative mitigation is applied. Pending final determinations about the extent of actual habitat area needs, the map may be amended by either increasing, decreasing or relocating the amounts of open-space lands, and meeting minimum land amount requirements by the City.

Policy OS-1.3: Encourage property owners to collaborate their planning and habitat protection and consenvation responsibilities.

A collaborative approach to planning and habitat protection and conservation can allow forgreater flexibility in locating development in the BCP area. Regardless of the method, steps to involve review of development proposa ls by resource agencies should occur early in process.

Policy OS-1.4: Encourage the formation of continuous open-space coridors.

Open-space comidors, whether developed, natural or a combination of both, should be formed with multiple use pathways within or immediately adjacent to these a reas. The BCP Open Space Map includestwo potential c ontinuous open-space comidors that will offer habitat a nd bikewa y connections to Lake Yosemite and UC Merced. The "Tower Lateral Bikeway" comidor located north and generally parallel to Bellevue Road connects to Lake Yosemite. The "Cottonwood Creek Tributary Bikeway" comidor located so uth of Bellevue Road connects to UC Merced. Work with the Merced Imigation District to crea te approaches to permit the Tower Lateral to continue to flow along the surface and not be under-grounded.

Policy OS-1.5: Plan forthe construction and use of an off-street bike path within an open space conidoralong the tributary to Cottonwood Creek (The "Cottonwood Creek Tibutary Bikeway).

The "Cottonwood Creek Tributary Bikeway islocated within the area bounded by Cardella Road, Lake Road, Bellevue Road and Gardner Road extended. Optionsfor the actual location of the pathway, as well as the size and extent of the open space drainage coridor, will need to be explored aspart of a masterdrainage study by the property owner prior to or as part of any future plans. The size and extent may also be affected by actions to conserve any proximate sensitive lands. 
Policy OS-1.6: Seek to maintain the rural character of Lake Road, and shift community and regional traffic to the Campus Parkway in the long-term.

The C ity's General Plan lists Lake Road as a scenic corridor. Its current design features include a two-lane road, natural dra inages, a separate off-street multi-use pathway and street trees; these should be maintained and enhanced. Generally, improvements to reduce vehicular traffic congestion or to increase vehicular traffic capacity should not be made unless it is consistent with and enhances the current design features described above. Sub-standard traffic level of service may occur in order to satisfy this policy.

Policy OS-1.7: Encourage designs that enhance the view of UC Merced from Lake Road and multi-purpose path on its east side.

Whether the current view of agricultural fields and the Sierra Nevada, or future views of UC Merced and the adjacent University Community, the natural elevation of Lake Road and accompanying bike path provide a unique opportunity to create an attractive eastem view. The alignment of the campus parkway immediately east and below the bluff will create space between these areas, further establishing the opportunity for a unique visual experience.

Policy OS-1.8: Coordinate Urban Forestry Projects with other community goals.

It is possible to advance many community goals through urban forest projects. Whether the goal is to improve energy efficiency, to enhance aesthetics, to encourage walking or bike riding, to enhance property values or to prepare for increased temperatures, trees a re the common solution. Urban forestry projects in the City currently include street and parking lot trees. Explore opportunities, supported by community, to expand and enhance the function of trees in the Bellevue Community Plan.

\section{Goal Area OS 2: Open-space for Outdoor Recreation}

\section{Policy OS-2.1: Plan forand construct the "Cottonwood Creek Tributary Bikeway."}

A tributary to Cottonwood Creek extends from UC Merced to Cottonwood Creek (located south of Cardella Road) through the BCP planning area. Prior to any subdivision along either side of this watercourse, a plan that describes the location and design of how this C lass I Bike Path will cross or extend under streets between UC Merced and Cottonwood Creek needs to be developed.

\section{Policy OS-2.2: Plan for and construct the "Tower Lateral Multipurpose Pathway."}

The Tower Lateral is an existing canal that extends from Lake Yosemite to "G" Street. Prior to any subdivision along either side of this canal, a plan that describes the location and design of how this Pathway will cross or extend under streets between Lake Yosemite and "G" Street needs to be developed.

Policy OS-2.3: Seek to develop Community Park CP-43 in the BCP.

Consistent with the 2004 Park and Open Space Master Plan, C P-43 should be located on arterial or collector streets, be highly visible from a djo ining streets, and should be a minimum of 20-acres in size, with the optimum being about 30-acres. Provided active recreation facilities can be provided, the community park may be sited a longside any natural open-space lands in this area.

Policy OS-2.4: Consider the utility and designation of the land immediately south and west of Lake Yosemite (between the earthen dam and Golf Road) for public park use.

This c onsideration could occur as part of the next update to the City's Recreation and Parks Master Plan, or as a separate action. This site is currently designated as Park and Open Space/Recreation on the City's Land Use Map. The site is proximate to Lake Yosemite Regional Parkand has limited development potential. Significant City park resources will be located south of Bellevue Road closer to the highest population density on the BCP, however. Justification for public use and availability of funding need to be further explored prior to any expansion of the City's planned recreation and parks open-space system.

\section{Goal Area OS-3: Open-space for Public Health and Safety}

Policy OS-3.1: Maintain the current Open Space/Parks-Recreation Land Use Designation that is located south and west of Lake Yosemite (between the earthen dam and Golf Road). Consider expanding the area as appropriate.

Proposa ls from property owners of land located adjacent to the site to expand the Open Space/ParksRecreation Land Use Designation onto their properties will be considered. There may be interest by these property owners to transfer any density rights to a nother property within the BCP. 
This page intentionally left blank. 


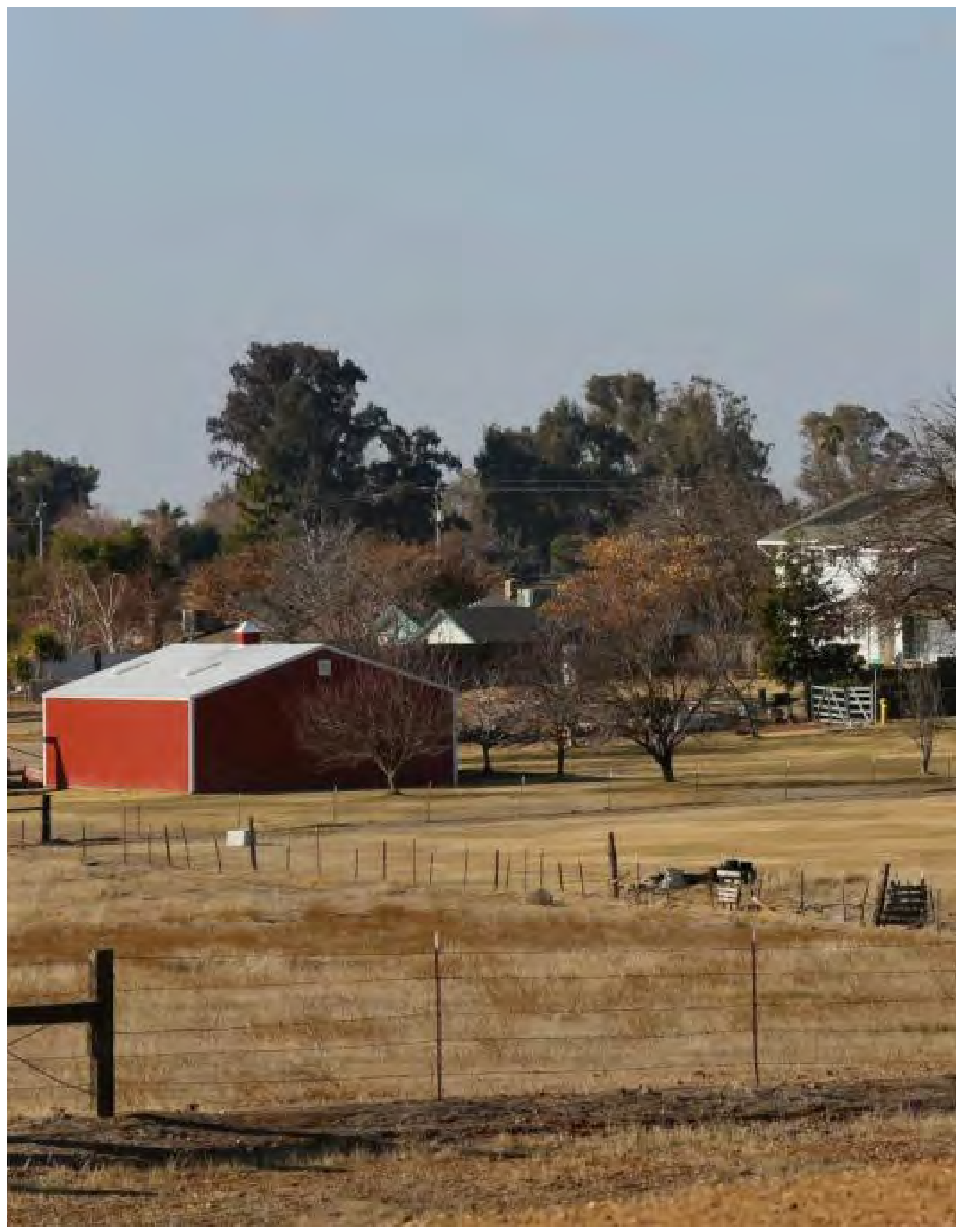




\section{COMMUNITY CHARACTER}

The impetus for the Merced Vision 2030 General Plan, and the focus of several General Plan policies, is the eventual expansion of the City toward and adjacent to UC Merced. The BCP covers land between the City boundary and west of UC Merced and establishes a high-level planning framework that strikes a balance between certainty and flexibility by anchoring key land uses while recognizing that their size may wish to adapt to changing market conditions in response to economic growth and the expansion of UC Merced. The BCP also protects the character of existing rural neighborhoods in the Plan area

The Community Character Chapter sets the foundation for how land uses are organized in the Plan Area. As described in Chapter 2 (Vision and Urban Design), the Core Principles from which the Plan was created include providing a "gateway" for UC Merced; making a network of "complete streets"; and creating neighborhoods and districts oriented to pedestrians and transit that are compatible with existing neighborhoods. Moreover, the community clearly expressed a desire for the Plan to be able to respond to market demands and leverage investment in UC Merced. Business growth is supported in the BCP through the creation of a flexible Research and Development employment corridor that is infused with innovation hub design elements in order to attract new firms and industry wishing to locate near the campus. Similarly, land use along Bellevue Road will be influenced by its character as a regional traffic conduit. To accomplish these objectives, the BCP establishes several "Place Types". Place Types are generally mixed-use environments, but may be dominated by a particular land use (for example residential uses or employment centers). Because the BCP focuses on urban form and a mixed-use environment, the term Place Type is used instead of the more conventional "land use", which is the Merced Vision 2030 General Plan nomenclature. The Place Types are defined by their location in the Plan, distinct physical characteristics (Table 9), and proximity to the circulation network set forth in the Mobility and Open Space Chapters.

The Community Character Chapter, together with mobility and opens space elements, establishes a platform from which infrastructure and phasing planning can be undertaken (see "Next Steps" in the Urban Expansion Chapter), and upon which Neighborhood Master Planning (as described in this chapter) can occur prior to actual development within the BCP.

\author{
The Bellevue Community Plan \\ sets the foundation for how \\ land uses connect along the \\ proposed c irculation networks.
}




\section{SEITING}

The Plan area is surrounded on all sides by existing or proposed future urban development. However, while there are a few rural residential areas to the north and southeast corners of the Plan area, it is largely vacant. The area is generally well positioned to accommodate regional and UC-related growth, but local decision makers and property owners need to work together to overcome annexation, infrastructure, environmental, and other potential obstacles to development.

\section{EXISTING LAND USE ENTITLMENTS}

Please refer to Technical Appendix B (Development Projects and Plans) for land use entitlements near the Plan area. 


\section{GENERAL PLAN CONSISTENCY}

While most of the BCP area is outside the City limits, it is within the proposed Sphere of Influence and Area of Interest, and therefore governed by the policies outlined in the City's General Plan. The Merced Vision 2030 General Plan Land Use Chapter provides key guidance in establishing land use goals and policies that can be implemented in the Bellevue Community Plan. These goals and policies provide direction for where new development will occur and how existing uses should be preserved. While the General Plan regulates land use and approximate land use distribution, the Bellevue Community Plan builds upon this vision, and based on community input, provides more specific policies and implementation recommendations.

The General Plan Land Use Chapter covers four major issue areas including: Residential Neighborhoods, Economic Environment, Urban Growth and Design, and Community Plans. The guidance provided by the General Plan requires that Community Plans follow the "village concept" design when possible. The urban village concept is meant to establish a cohesive mix of land uses with primarily higher densities. The urban village concept allows the Bellevue Community Plan to provide for mixed-use areas within the planning area. Thus, allowing higher density uses next to the UC Merced campus and within close proximity to proposed transit locations. Additionally, the Bellevue Community Plan aims to protect the character of and provide adequate transitions to the Rural Residential communities in and near the project area. This is accomplished by determining appropriate locations for various densities of residential development and compatible commercial and professional development.

The BCP establishes a range of land use amounts and intensities that are consistent with those assumed in the City's General Plan. The Merced Vision 2030 General Plan includes a illustrative land use plan (Figure 3 in the Introduction Chapter) as a guide to craft the Bellevue Community Plan. The illustrative plan designates large stretches of Bellevue Road within the project area as "Mixed-Use" and a "Business Park" to support a dynamic assortment of future employment generating uses, housing options and commercial and office uses. Surrounding Bellevue Road are areas of Low Density Residential (LD) and Rural Residential (RR). Closer to the UC Merced campus land uses transition from Low to Medium Density Residential (LMD), High to Medium Density Residential (HMD), and then to High Density Residential (HD). The southern portion of the project area contains an established Rural Residential (RR) center.

Intermixed with the varying residential land uses near UC Merced, at the intersection of Bellevue Road and Lake Road, are areas designated as Business Park (BP), Thoroughfare Commercial (CT) and Neighborhood Commercial (CN). The table depicting the Merced Vision 2030 General Plan land use designations and densities which the BCP community character areas are derived from can be found in the Introduction of this plan (Table 1).
While the General Plan

regulates land use and

approximate land use

distribution, the Bellevue

Community Plan builds upon

this vision, and based on

community input, provides

more specific policies

and implementation

recommendations. 
The Merced Vision 2030 General Plan depicts a large area of Open Space - Park Recreation (OS-PK) at the southern end of Lake Yosemite. This creates a natural flow from the existing recreational areas near Lake Yosemite to the proposed nearby residential areas. There is also an Open Space - Park Recreation designation in the southern portion of the Bellevue Community Plan area within a Low Density Residential area. The BCP Open Space corridors allow for additional pedestrian and bicycle facilities within the neighborhoods to act as connectors to other nearby areas and provide outdoor amenities to residents directly adjacent to homes and neighborhood conveniences.

More information about how the Merced Vision 2030 General Plan supplies the foundation for the Bellevue Community Plan can be found in Appendix A. 


\section{CORE ELEMENTS FOR COMMUNITY CHARACTER AREAS}

\section{TRANSTTPRIORTY PROJ ECTCOMPATIBIE DEVELOPMENTS}

The foundation of the BCP is set up by the interconnected street network discussed in the Mobility Chapter of this Plan. The grid patterned street structure promotes walkable connections to transit, bicycle infrastructure, and other pedestrian amenities. A multi-modal street network is a vital component to encouraging increased and efficient use of public transit and transit oriented development. The grid structure of the street system also promotes the benefit for residents and visitors to park once and walk to multiple destinations or "Place Types" within the BCP.

A key feature of most of the Place Types located within a quarter-mile of Mandeville Avenue is the ability to meet the requirements of Transit Priority Projects (TPP). TPPs were introduced in California's Senate Bill 375 (SB 375) and are intended to align regional transportation, land use, housing, and greenhouse gas emissions planning. One main requirement of TPPs is that it be located within one-half mile of either a major transit stop or highquality transit corridor included in a regional transportation plan, with service intervals of not less than 15 minutes during peak hours (see Figure 25). This criteria reinforced the need for a basic, connected block structure (see Figure 7) which forms the basic structure of the mobility framework and the community character designations.

Transit Priority Projects which meet the requirements of SB 375 can invoke significant California Environmental Quality Act (CEQA) regulatory streamlining. The BCP allows for densities and intensities to meet TPP requirements along the Mandeville transit route. However, since TPPs will be implemented at the project level, the exact size and locations have no been determined.

\section{COMPATIBLE DEVELOPMENTWTH EXISTING \& PLANNED NEIGHBORHOODS}

It is a priority of the BCP to protect the character of existing neighborhoods within the Plan area. There are two Rural Residential neighborhoods within the northern and southern portions of the Plan area. Through the proposed interconnected street network, these neighborhoods will be afforded the same pedestrian and transit amenities as the rest of the area. By establishing where key features and land uses should be located and how they interface with existing homes, the existing neighborhoods can be integrated into the overall framework of the planning area while retaining their current character.

In addition, connections with street networks adjacent to the $\mathrm{BCP}$ will provide for greater overall connectivity from the UC Merced campus to other parts of the City along transit routes. This structure will position the BCP as a central connection between downtown Merced and UC Merced. The walkable block structure of the BCP allows infrastructure to easily connect with adjacent plan
Requirements of Transit Priority Project (TPP)

TPPs must meet the requirements of SB 375 whic $h$ include the following:

- $\quad$ TPPs must be located within 1/2 mile of either a major transit stop or high-qua lity transit comidor

- $\quad$ Service intervals of tra nsit must not be greater 15 minutes during peak operating hours

- $\quad 50 \%$ of a TPP must be residential use by square footage

- Minimum of 20 dwelling units per acre (20 du/ac)

- Commercial uses within a TPP are not required to meet a Floor Area Ratio (FAR) if the use accounts for less than $25 \%$ of the project area by square footage.

- Commercial uses which account for 26 - $49 \%$ of a TPP a rea by square footage, must meet a required FAR of no less than 0.75 . 
areas. This will support natural transitions from the BCP to other plan areas such as the Bellevue Ranch Master Plan and the University Community Plan.

\section{COMPATIBLE DEVEOPMENTWTH UC MERCED}

The BCP includes an appropriate mix of compatible uses that are anticipated to occur in close proximity to UC Merced. The Plan's Place Types respond to UC Merced's campus 'Gateway District,' while providing an attractive location for businesses to convert new ideas into functional technologies which can provide many social, economic, and environmental benefits to Merced.

\section{GATEWAY DISTRICT}

The UC Merced Long Range Development Plan describes the 'Gateway District' as the campus entrance and public face of the University. The Gateway is located immediately east of Lake Road, south of Bellevue Road, placing it adjacent to the BCP's Mixed-Use TOD Center. The Gateway District is the link between UC Merced and Central Valley communities; serving UC Merced's core mission of focused education, research, and public service on the one hand, and the private sector on the other. The characteristics make it a resource for public-private ventures and a means for expression of the growing entrepreneurial culture at UC Merced. The Gateway District is planned to include visitor and conference facilities as well as associated support services for those engaged with the campus in joint research, education, and public service initiatives. ${ }^{18}$ Administrative offices and continuing education or extension programs can also be located in this district. Within the context of the Gateway District, the City should allow public and government offices and service centers in the Mixed-Use TOD to enhance, support, or complement uses that may occur in UC Merced's "Gateway District" area. The formation of public-private partnerships in or adjacent to this area could form a strong economic-driver for the local and regional economy.

\section{RESEARCH AND DEVELOPMENT USES}

The placement of UC Merced within the growth boundary of the City presents an opportunity for the BCP to create a setting for entrepreneurs, businesses, and social enterprises to benefit from the research activity and competencies of innovations at the University. To capitalize on this opportunity and create an innovation hub, the Plan includes a research and development (R\&D) employment area geared to attract and foster talent in the 21st century.

While the uncertainty surrounding UCM's future research programs and their potential for technology transfer coupled with the lack of an established real estate market for R\&D space in Merced make it difficult to establish an estimate of long-run demand for such space, a review of market areas with a UC campus provide a basis for a potential range. For example, Yolo County, near Sacramento and home to the UC Davis campus (established more than 50 years ago), supports about 500,000 square feet of R\&D/flex space. Meanwhile, Orange County, where UC Irvine is located, supports roughly 18 million square feet of such space. However, employment in scientific industries in Orange County is dramatically higher than in both Yolo and Merced Counties. 
Overall, given consideration of real estate market factors, employment characteristics, UC programs, and the City's desire for employmentsupporting uses, planning for 2.5 to 5 million square feet of R\&D/flex space in the BCP area would be reasonable albeit slightly aggressive, provide sufficient capacity to satisfy near-term R\&D demand, and allow for long-term upside potential for new development and job growth. As such, the BCP provides for nearly 3 million square feet of R\&D space in about 100 acres. In addition, the Plan provides for expansion of this R\&D area (see light blue area in Figure 38) with additional CEQA review.

\section{COMPATIBLE DEVELOPMENTSIRATEGIES}

The BCP encourages a mix of land uses, whether in a multi-story building or spread horizontally throughout a project or neighborhood. To overcome potential conflicts between adjacent uses and their occupants, the BCP advances several proven strategies and includes provisions for urban form, design, and performance standards, and incorporates a master planning process. Refer to the "Neighborhood Master Planning" section at the end of this chapter for more information.

\section{RETAIL DEVELOPMENT}

As stated earlier, based on General Plan guidance, the BCP must ensure that development within the $\mathrm{BCP}$ complements rather than competes with existing development and community focal points, including Downtown Merced and other regional retail areas. Given this, the retail component of the Plan was developed to primarily serve potential retail demand generated from workers and households in the Plan area. Based on estimates of aggregate spending by new workers and persons in the Plan Area, new residential and nonresidential development could support between 450,000 and 500,000 square feet of retail. While retail uses may be permitted in a wide range of BCP character areas (see Table 9), retail is allowed as a primary use in the Neighborhood Center TOD character areas. Placement of large retail uses, particularly in the Flexible Mixed-Use character area, should only be done in a manner that protects the viability of existing and/or future retail within the Neighborhood Centers and TODs and may require further market analysis.

\author{
Place Types provide flexible \\ land uses and are designed to \\ adapt to future growth within \\ the BCP. Several areas are \\ designed to be Transit Prionity \\ Project compatible.
}




\section{PLACE TYPES/ CHARAC TER AREAS:}

The BCP builds upon the Merced Vision 2030 General Plan land uses by establishing specific Place Types. These Place Types provide flexible land uses and are designed to adapt to future growth within the BCP. Figure 38, on the following page, illustrates the recommended general distribution of Place Types, each of which is characterized by a range of land uses and a range of development types, scales, and intensities (See also Table 8). The Mixed-Use TOD, Research and Development (R\&D) Employment District, and Neighborhood Centers are intended to be flexible in size to respond to future market conditions, but should generally be centered where shown below, and could even grow into the Flexible Mixed-Use Neighborhood area. The Multi-Family Neighborhood is intended to have flexible and variable residential density, including single-family types. The quantified physical characteristics of these place types are as summarized in Table 9. Although, real zoning regulations should be developed to implement the Plan.

The descriptions in this section focus on their physical design and basic land use characteristics. The general location of joint-use school and park sites, while not a Place Type, are depicted on the Place Type Map. Similarly, the Bellevue Gateway is not a Place Type, but a special design area which is described in the Urban Design Chapter. The BCP recognizes the potential to expand some Place Types. This increased development potential is based on future development patterns and additional CEQA review would be required. See Appendix A for further discussion of development capacity.

\section{Table 8 Place Type Characteristics}

\begin{tabular}{|c|c|}
\hline Place Type & $\begin{array}{l}\text { Approximate Acreage } \\
\text { in the BCP (Gross) }\end{array}$ \\
\hline Rural Residential Neighborhood & 192 \\
\hline Single Fa mily Neighborhood & 417 \\
\hline Multi-Fa mily Neighborhood & 120 \\
\hline Flex-Mixed Use Neighborhood & 147 \\
\hline Neighborhood Centers (NC) & 25 \\
\hline Mixed-Use TOD & 74 \\
\hline R\&D Employment District & 103 \\
\hline Potential Expansion Area ${ }^{2}$ & 335 \\
\hline Other ${ }^{1}$ & 182 \\
\hline Total: & 1,595 \\
\hline \multicolumn{2}{|c|}{$\begin{array}{l}\text { 1. Including ROW (except local roads) and open space. } \\
\text { 2. Requires additional CEQA review. } \\
\text { 3. J oint use school and park sites are anticipated to be } 10-13 \text { acres and } \\
\text { would primarily be located in the Single-Family Neighborhood }\end{array}$} \\
\hline
\end{tabular}




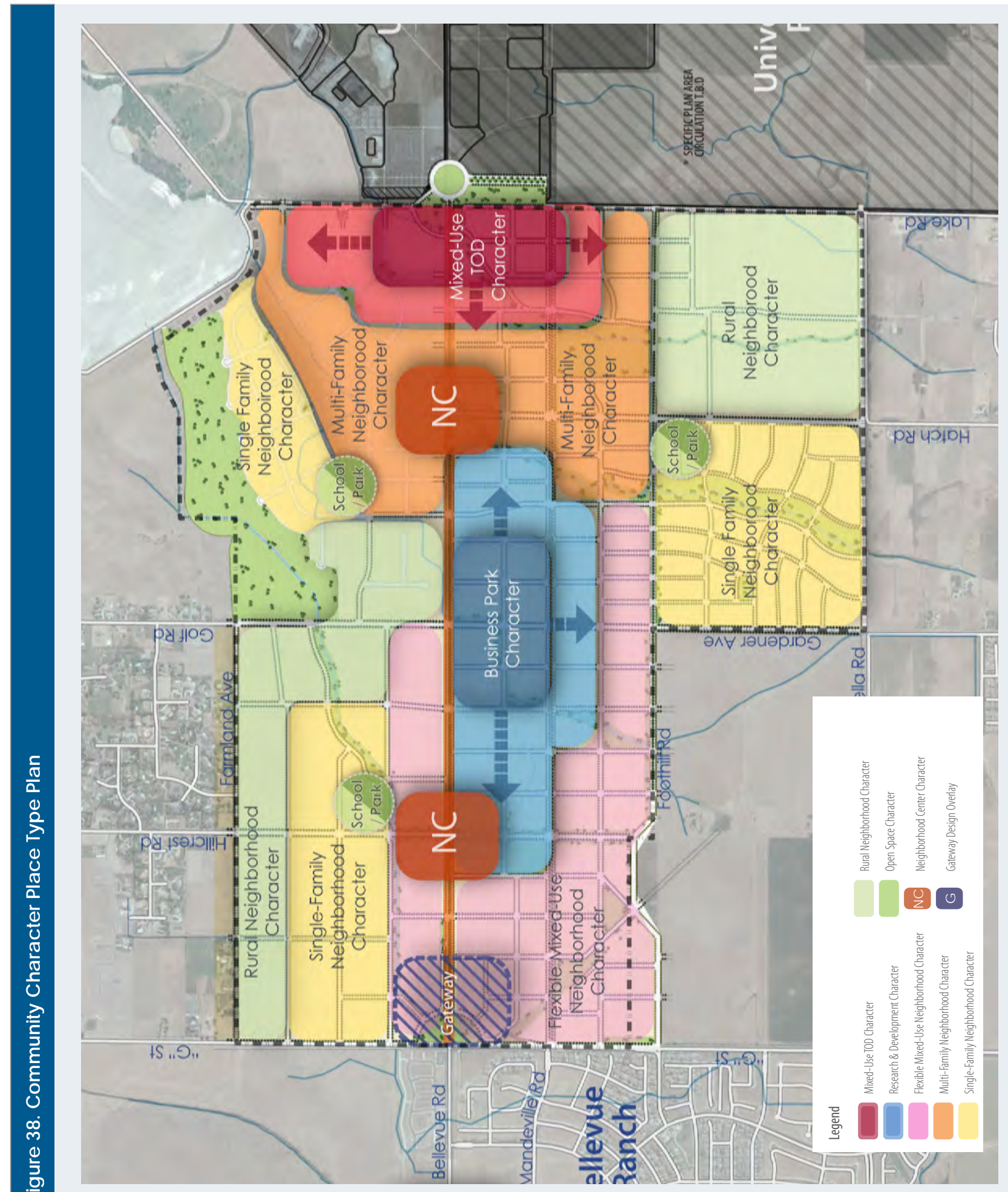




\section{BLOCK CONFIG URATION}

The conceptual land use and block structure diagrams below illustrate two of the many variations that may evolve as each property owner pursues development opportunities based on economic conditions at the time of development. In both diagrams the general location and street orientation of buildings is illustrated by the heavy black lines and rust colored areas, and the general land use and development intensity of each block - or in some cases each frontage of a block - are color coded per the legend. R\&D employment district uses (blue and purple) are prioritized along the south side of Bellevue Road to the east and west of Gardner Road.

Also, in both diagrams, mixed density neighborhoods with significant amounts of multi-family housing (orange) abut the R\&D blocks, generally back to back rather than face to face. Mixed-use neighborhood centers (red) are located at key transit nodes, and may be either small retail centers or mixed-used development that includes multi-family residential and neighborhood-serving commercial uses. And in both diagrams, blocks to the south transition to single-family neighborhood character, which may include small-scale multi-family uses in the form of duplexes or triplexes or quadplexes, and perhaps townhomes.

The first diagram illustrates more blocks of $R \& D$ development than the second diagram, and also illustrates that in some areas R\&D development may aggregate multiple blocks into larger "R\&D campus" environments. Within such campuses pedestrian and bicycle connectivity is maintained along with internal vehicular circulations and shared parking arrangements - but public streets are not extend through.

Diagram 2 illustrates a more modest amount of R\&D development, which although not currently the preferred scenario could nonetheless be dictated by future demand for such products. In this case, mixed-density neighborhoods multi-family neighborhood development and single-family neighborhood development could expand northward to fill in.

Note that in each case the transition from $R \& D$ to mixed-density to singlefamily neighborhood character occurs systematically across multiple blocks to avoid an incompatible patchwork of R\&D development and low-intensity housing. Note also that these transitions are accomplished by changing development character at major streets, greenways and back to back within blocks, so that all development can be oriented to the streets. As opposed to backing up to streets with sound walls and screen walls, which would be contrary to the core Plan goals of walkability and transit-orientation. 


\section{Sample Block Configuration- Diagram 1}

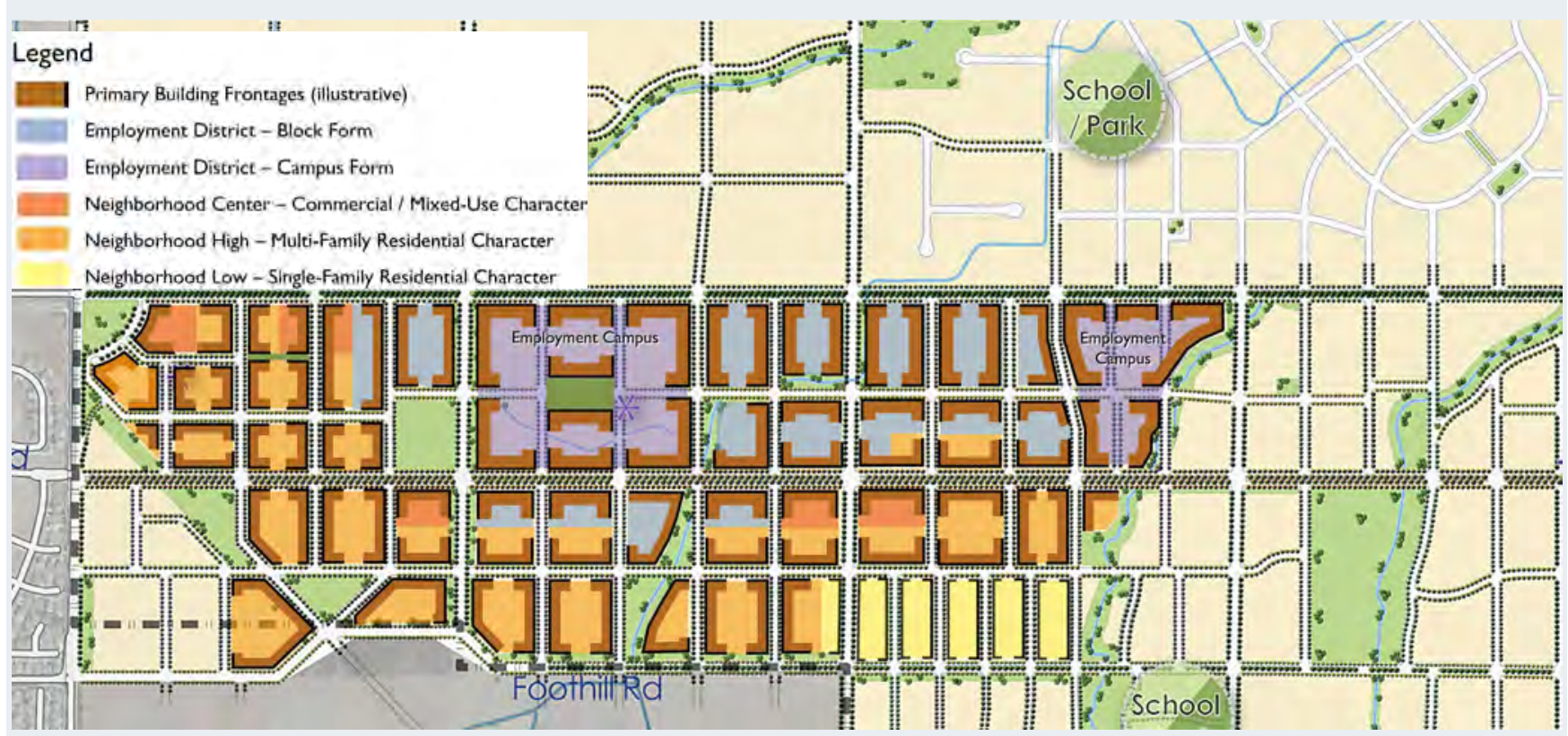

\section{Sample Block Configuration- Diagram 2}

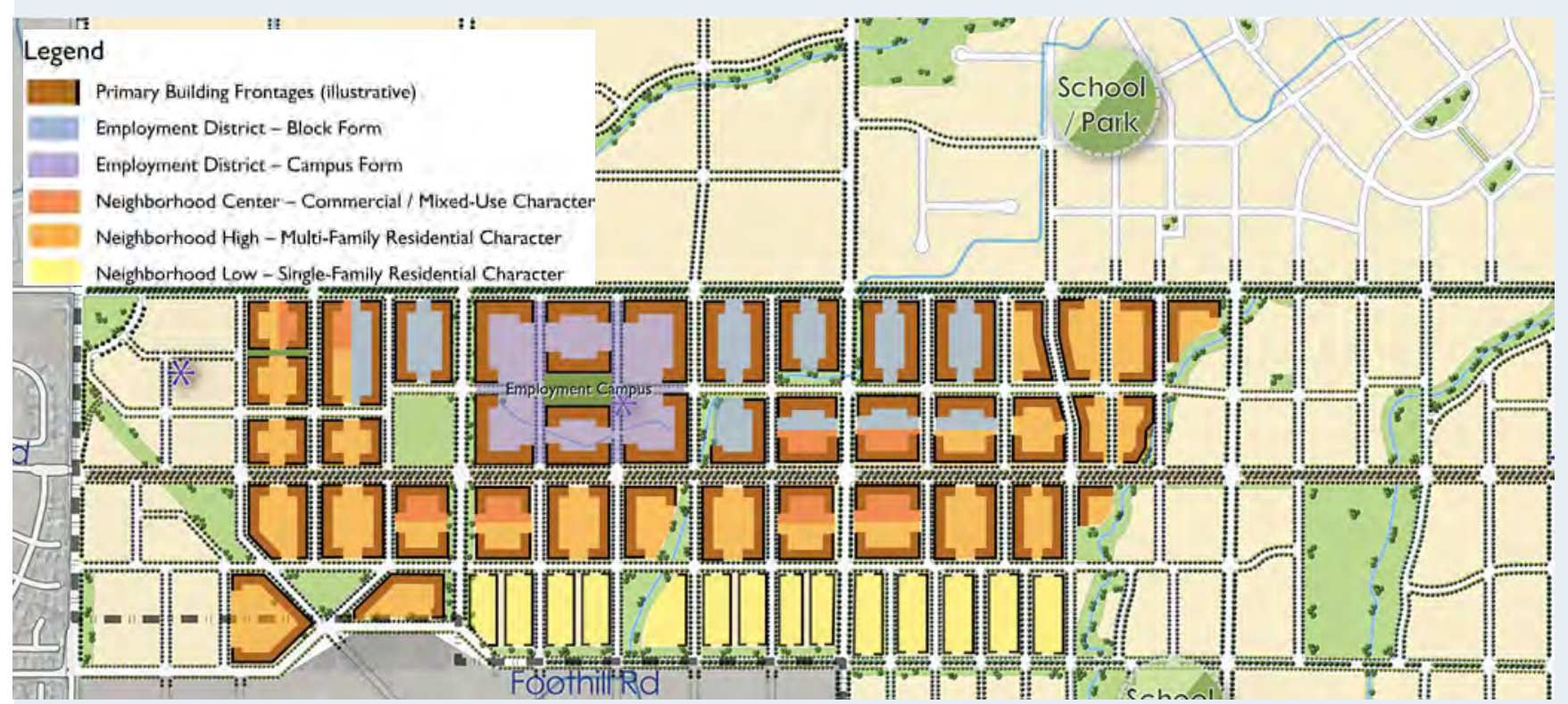


Mixed-Use T.O.D. development

is characterized by a mix

of uses in generally equal

proportions ranging from

multi-family residential to

community retail to office and

R\&D, with some elements of

entertainment and assembly.

\section{MIXED-USE TRANSITORIENTED DEVELOPMENT}

The Mixed-use Transit Oriented Development (T.O.D.) is the most intense urban environment anticipated in the BCP. By placing a T.O.D. directly next to the UC Merced campus, it will serve a variety of needs for students, professors, other UC employees, and campus visitors. Mixed-Use T.O.D. development is characterized by a mix of uses, generally in equal proportion, ranging from multi-family residential to community retail to office, and small to moderate scale $R \& D$, with some elements of entertainment and assembly. Buildings generally range between 3 and 5 stories in height, are set close to the street with shallow front yards at residential or office ground floors and shopfronts set right on the sidewalk for retail and entertainment uses. Initially, an identity distinct from Downtown Merced will need to be fostered by the City to develop a separate and non-competing center in the Mixed-Use T.O.D.

Initially parking is expected to be surface parking with shared parking encouraged. A minimal number of spaces should be dedicated for residential uses, typically one per dwelling. Curbside parking is provided on all streets in Mixed-use T.O.D. areas, in some cases angled in at retail frontages. Over time, parking could transition to structured facilities and should be managed to generate revenue for the City (or a parking district) and to reduce development costs. Another benefit of a compact, transit-oriented environment is a lower car ownership rate and lower household costs.

\section{Examples of Mixed-Use / T.O.D. Centers}

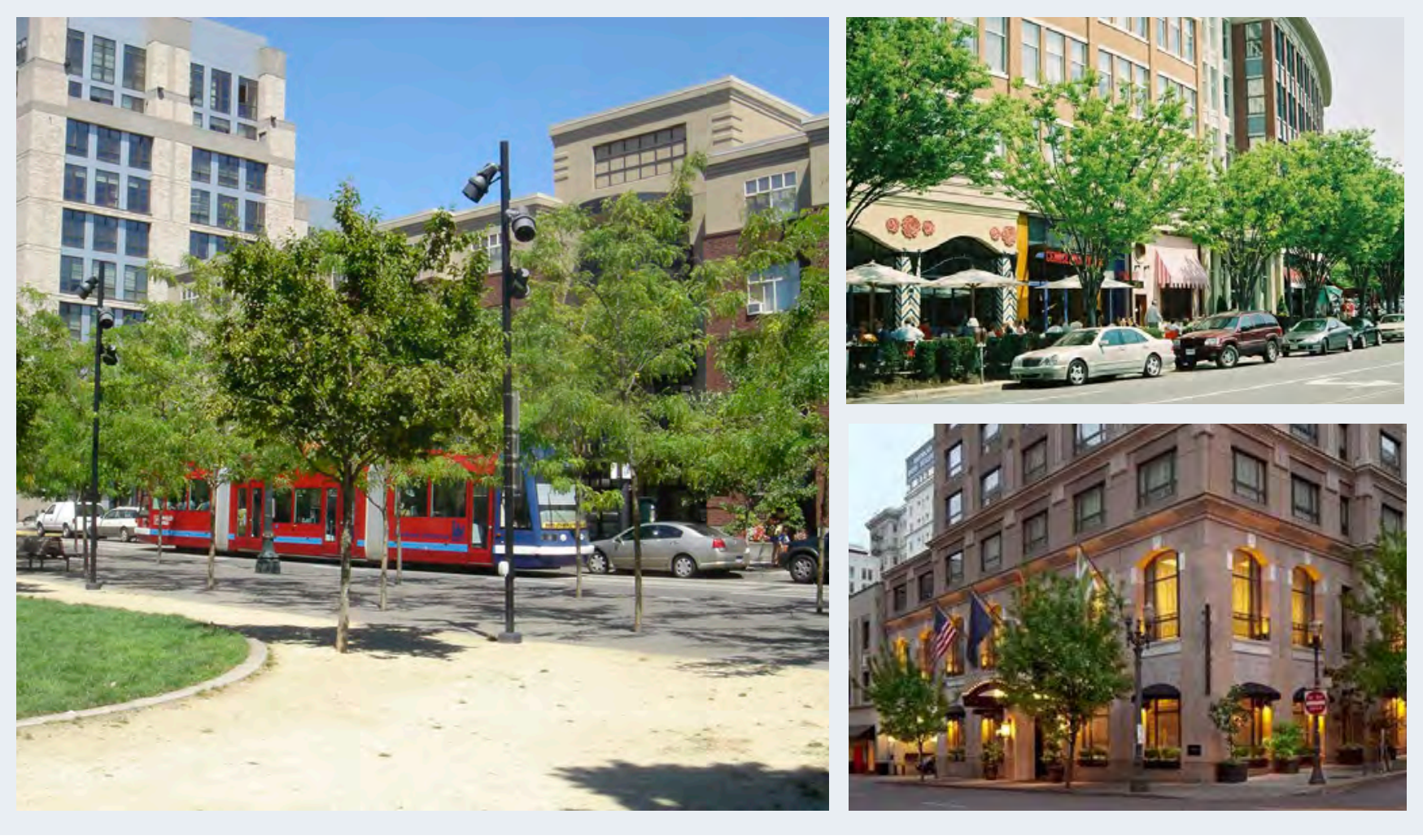


Examples of Pedestrian Features in Mixed-Use / T.O.D. Centers
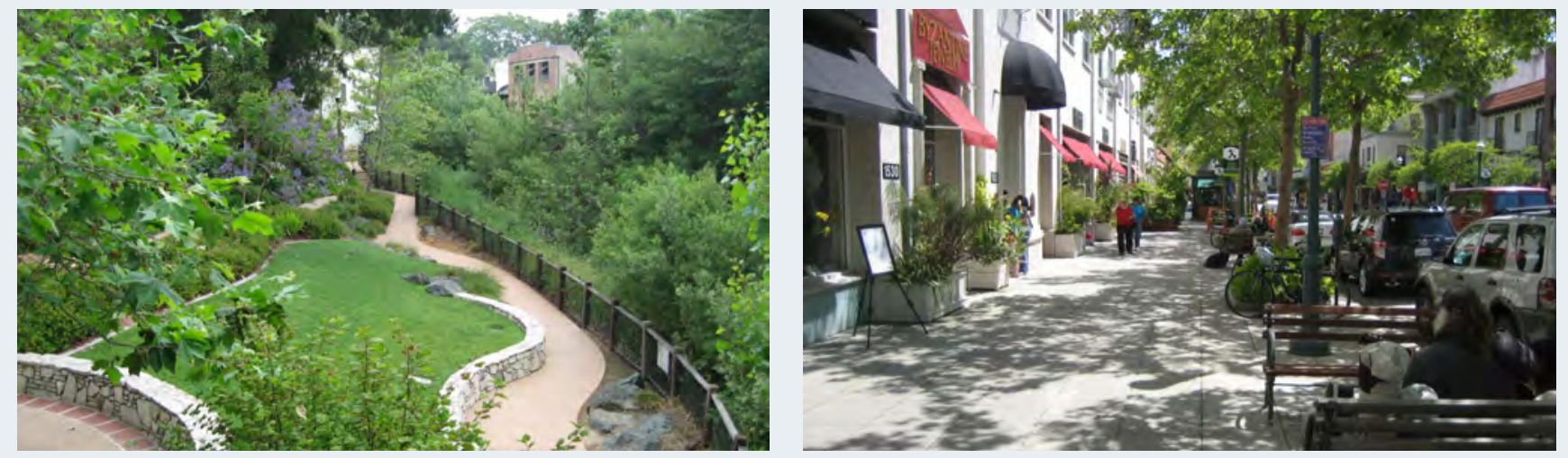

\section{R\&D EMPLOYMENTDISTRICT}

The R\&D Employment District provides an opportunity to attract and incubate new businesses that will benefit from the presence of the intellectual capital and research of UC Merced while providing job opportunities for local residents. Offices and light manufacturing are the primary uses envisioned in this Place Type. This Place Type is similar in character and scale to business and research "parks", characterized by one and two (or three) story larger office buildings, each usually with its own parking lot. This Place Type is inherently automobile-oriented, as it was developed for places like the Silicon Valley and Irvine, CA that are designed for auto access almost exclusively. The variation intended for the $\mathrm{BCP}$ provides large blocks (comparable to those in Irvine and the Silicon Valley) but framed by complete streets for use by pedestrians, bicyclists and transit. Typical R\&D site plans should include street facing buildings with on-street front entries, major parking lots located beside or behind buildings, and limited visitor parking near front entries. Some amount of commercial and office uses associated with the Research and Development Employment District and its workforce population are encouraged to locate within this character area, for example, along Gardner
Typical R\&D site plans should place buildings facing streets with front entries, and major parking lots typically beside or behind buildings, and limited visitor parking in front near entries.

\section{Figure 39. Illustration of a RSD Employment District}

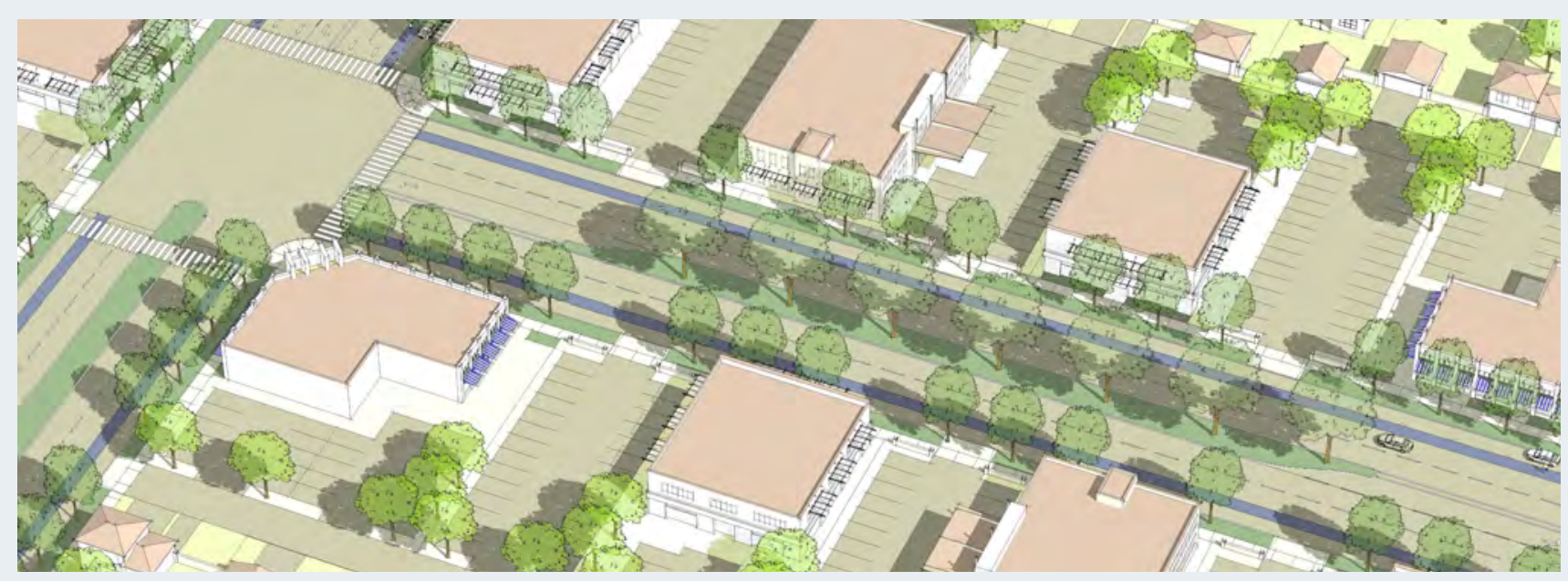


Road between Bellevue Road and Mandeville Avenue, or other nearby urban setting. Limited retail, financial, personal service, dining, entertainment, recreation, and similar uses in mixed-use buildings that support the research and light manufacturing functions of this Place Type should be encouraged between other place types to the east, south and west.

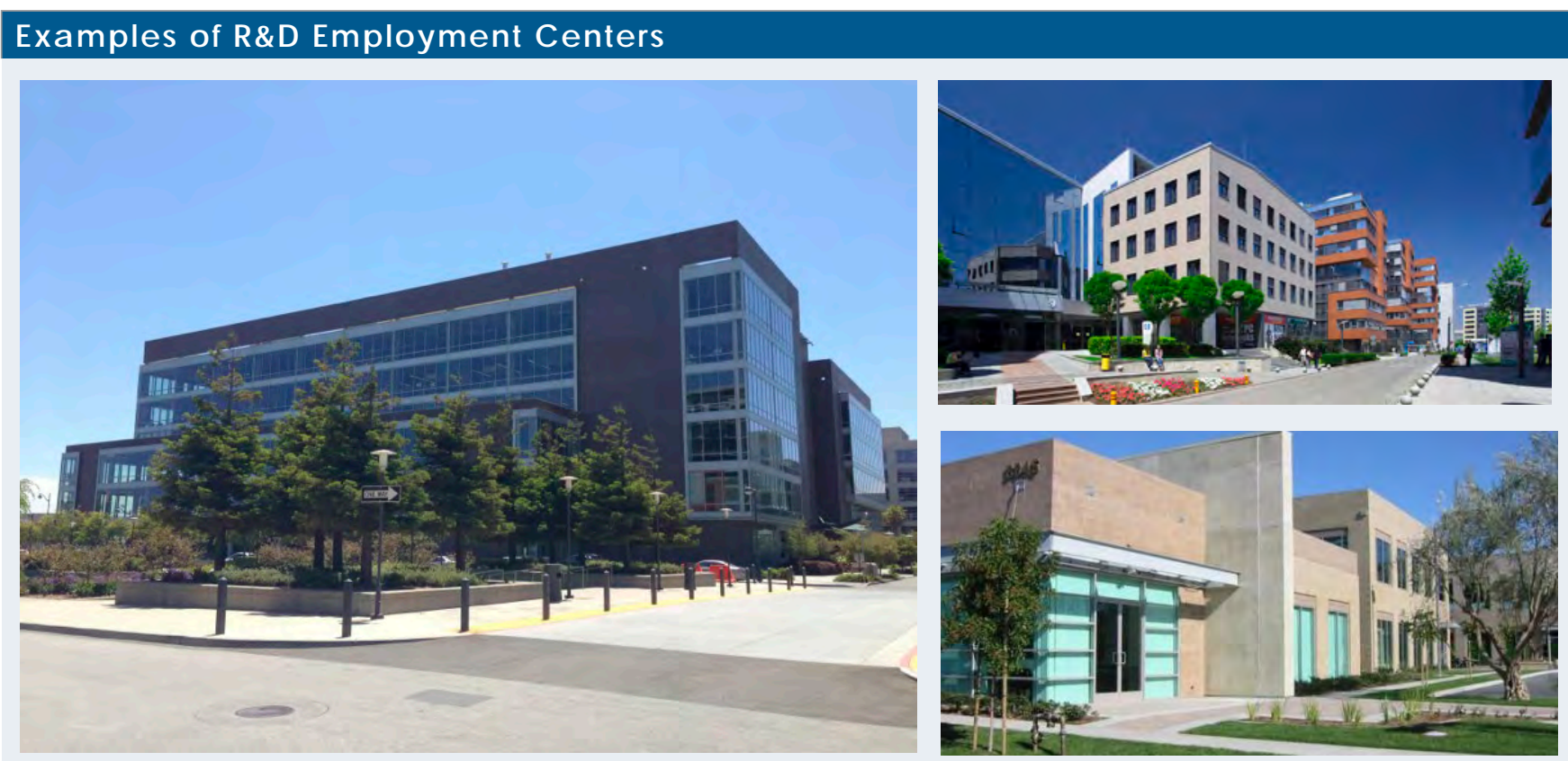

\section{R\&D Centers with Bike Access and Sustainable Parking Lots}
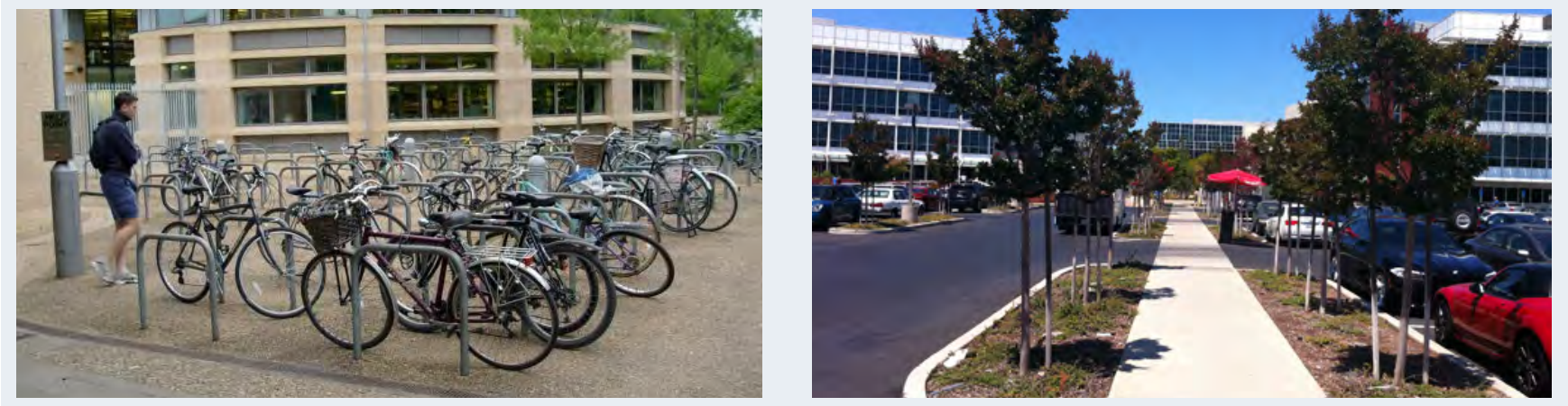

Neighborhood Centers are the

places that can provide certain

daily necessities and amenities

within comfortable walking

or biking distance of many

residences. 


\section{NEG HBORHOOD CENTERS}

Neighborhood Centers are the places that can provide certain daily necessities and amenities within comfortable walking or biking distance of many residences. Neighborhood Centers should be designed to primarily serve adjacent neighborhoods and the north east corner of the City. The scale and program of such centers must be calibrated to the location, the intensity of surrounding neighborhoods, the presence of other nearby options for such goods or services, and generally to the market. Neighborhood centers are typically located at the edge of a neighborhood, preferably at the junction of multiple neighborhoods, on a street with relatively high traffic volumes to help support the businesses. Minor arterials or major collector roads are suitable locations for neighborhood centers and should be configured for convenient access from major as well as smaller local neighborhood streets. In addition to providing local access to goods and services, neighborhood centers also act as social gathering places and provide opportunity for new businesses. Such centers are also ideal locations for important transit stops, allowing transit riders access to a range of good and services, easily incorporated into their daily activity and travel patterns. The BCP anticipates three types of neighborhood centers: Major Neighborhood Center, Mixed-use Neighborhood Center, and Rural/Small Neighborhood Center. Mixed-use Neighborhood Centers are identified on Figure 38, however exact locations for the Major Neighborhood Center and Rural/Small Neighborhood Centers are not provided and locations may vary.

\section{Figure 40. Illustration of a Typical Neighborhood Center}

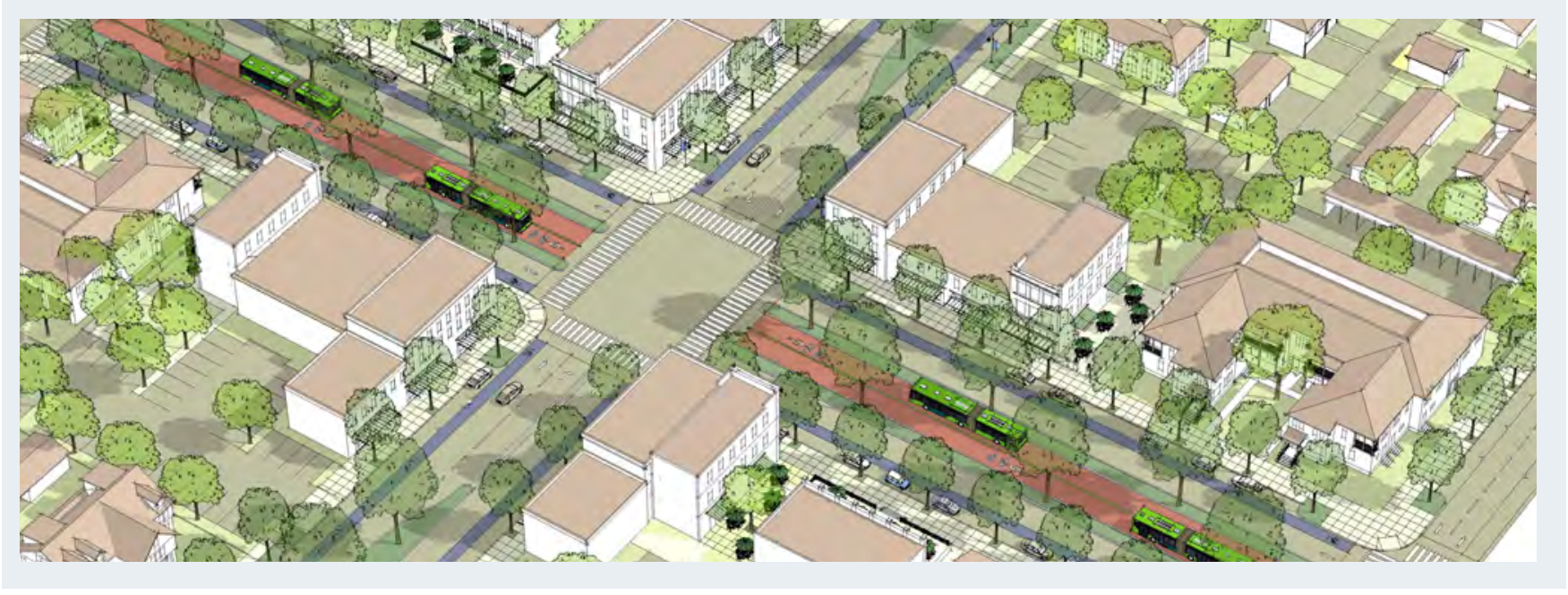

\section{MAJ OR NEIG HBORHOOD CENTER}

Depending on market analysis at the time of development, a Community Center at Bellevue Road east of G Street might function as the neighborhood center for rural residential neighborhoods to the north and east, and for mixeddensity neighborhoods to the south of Bellevue Road. These larger centers would have a more auto-oriented character than the other Neighborhood Center types. 


\section{Examples of Major Neighborhood Centers}
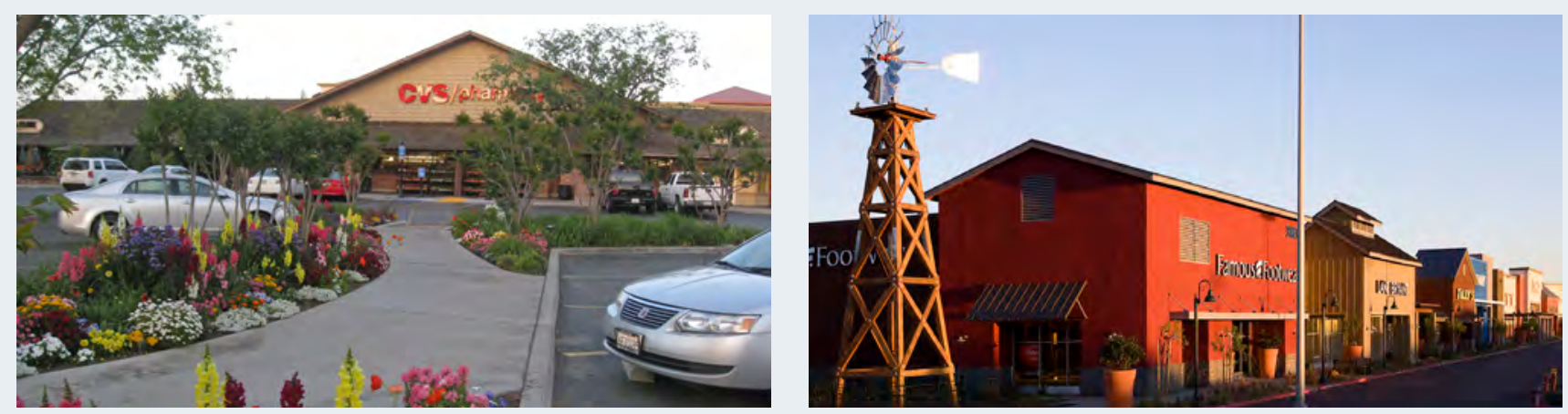

While the Merced Vision 2030 General Plan encourages commercial sites to be located at the corner of an arterial and collector street, there is flexibility in the General Plan (Land Use Policy 2.7.a) to consider high-quality projects commercial development at the corners of two arterials. According to the policy, such projects would follow these criteria:

- Strict access and land use restrictions in proximity to the intersection;

- Strong connectivity from the adjacent neighborhood;

- No freestanding pads with multiple curb cuts to arterial streets;

- A mix of uses and residential densities throughout the project;

- Access to a wide range of mobility options including transit, bikeways, and sidewalks;

- High-quality architecture, landscaping, site design, and signage; and

- $\quad$ Significant public improvements.

\section{MIXED-USE NEIGHBORHOOD CENTER}

This type of center has shops and service businesses that are oriented to a major multi-modal street, such that customers arrive on foot, by bike, by car, and by transit. Retail shops, restaurants, and service businesses in this type of neighborhood centers are usually less than 5,000 square feet in size, although with careful design - and the market supporting - could include a small supermarket up to 20,000 square feet. The BCP envisions such a mixeduse neighborhood center transitioning to multi-family residential and finally single family residential several blocks away.

While some of the buildings are likely one-story retail buildings, multi-story mixed- use office and residential buildings are allowed and encouraged. Shared parking arrangements are also encouraged, as provided in the larger neighborhood centers described above. 


\section{Examples of Mixed-use Neighborhood Centers}
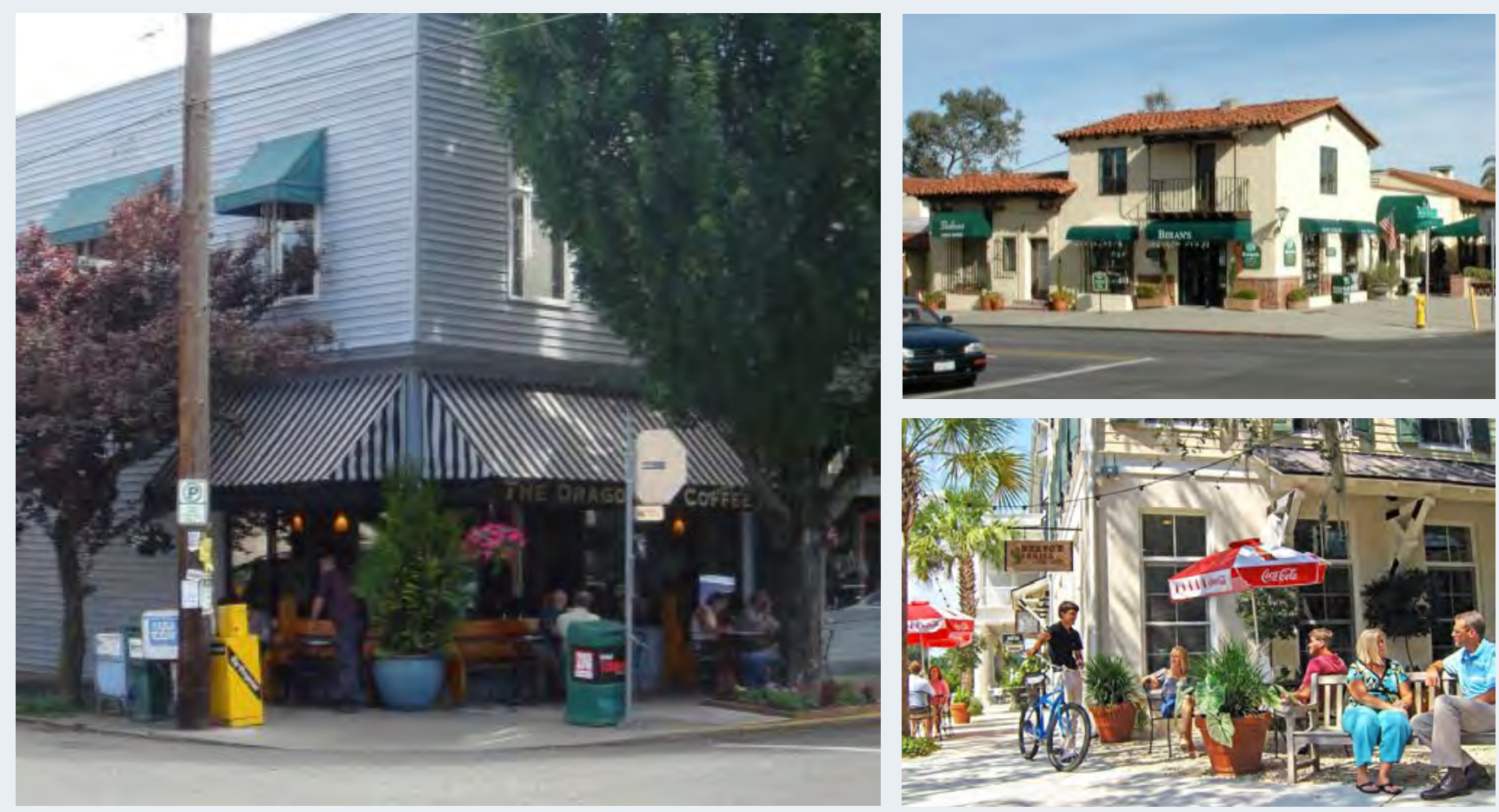

\section{RURAL/ SMAШ NEIG HBORHOOD C ENTER}

In some of the lower density rural residential neighborhoods along Lake Road or north of Bellevue Road, small neighborhood centers are still an option and can act as valued meeting places. Small neighborhood centers are compatible in scale and in character with their surroundings. In the context of the BCP, this would likely take the form of a single building such as a country store or roadside restaurant at a crossroads. Outdoor dining areas, hitching posts, big shade trees, and other rural design elements can make a small commercial business a very welcome neighbor and unique amenity.

\section{Examples of Rural Neighborhood Center}
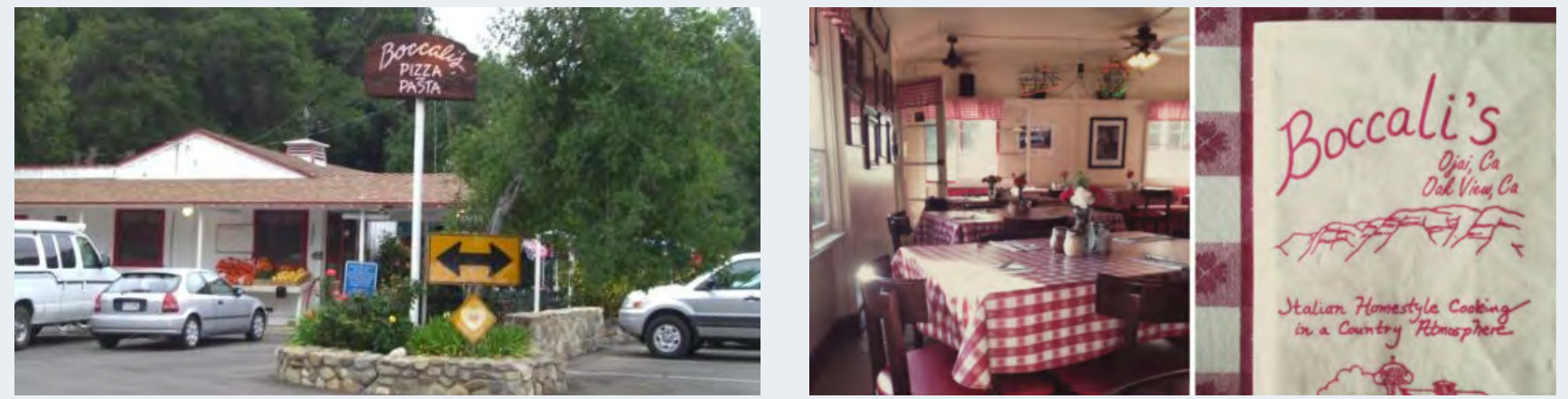


\section{Multi-family neighborhoods are predominantly residential in use and that inc lude multi-family housing at a range of densities mixed with smaller amounts of single family housing.}

\section{MULTI-FAMILY NEIGHBORHOOD}

Adjoining the "Mixed Use T.O.D." and allowed in the "Flexible Mixed Use Neighborhood" area, Multi-Family Neighborhoods are predominantly residential and include multi-family housing at a range of densities combined with some single family housing. Commercial uses are generally limited to one or two buildings scaled to serve the surrounding neighborhoods and customers passing by on adjacent arterial or collector streets, not including mixed-use neighborhood centers or major neighborhood centers. The residential and commercial composition is expected to shift from street-tostreet and block to block. Facing buildings within a block will be similar in scale and character; however, scale and use may change for non-facing buildings, particularly those separated by an alleyway (See Figure 41).

This traditional pattern for mixing various uses and densities allows, for instance, apartment buildings and neighborhood-serving shops to face each other at a key intersection, while allowing houses and duplexes behind or a block away. It will be critically important in implementing such patterns that each neighborhood area (quarter section) be master planned at one time, rather than allowing an apartment builder to build "an apartment project" in one quadrant, a "patio-home builder" to fill up another quadrant with that product, and then fill the rest with houses. As evidenced by a great deal of local, regional, and national experience in recent decades, that invariably generates places that are not connected, walkable, or transit-ready.

\section{Figure 41. Illustration of Multi-Family Neighborhood Character Area}

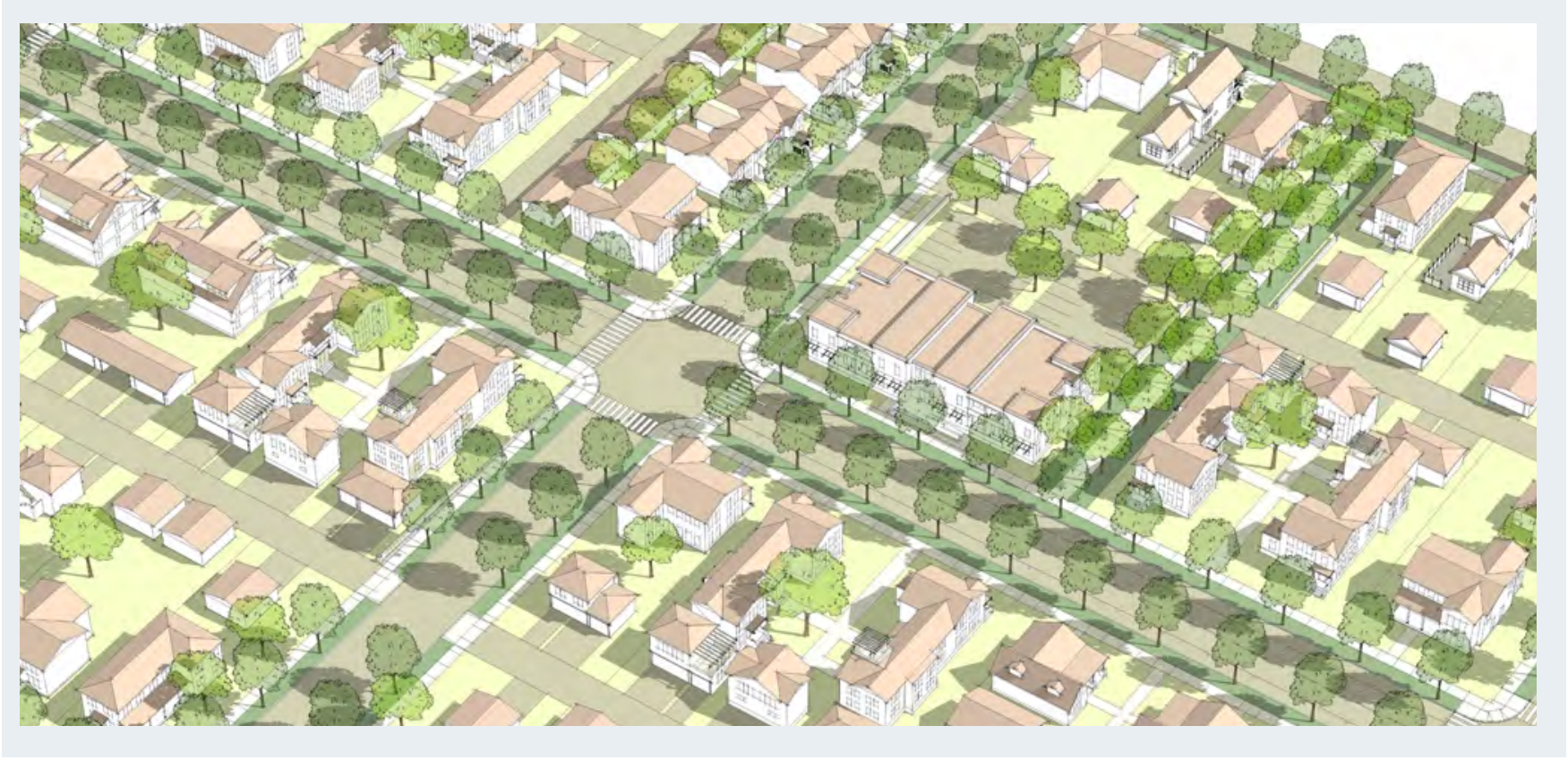


Examples of Multi-Family Residential
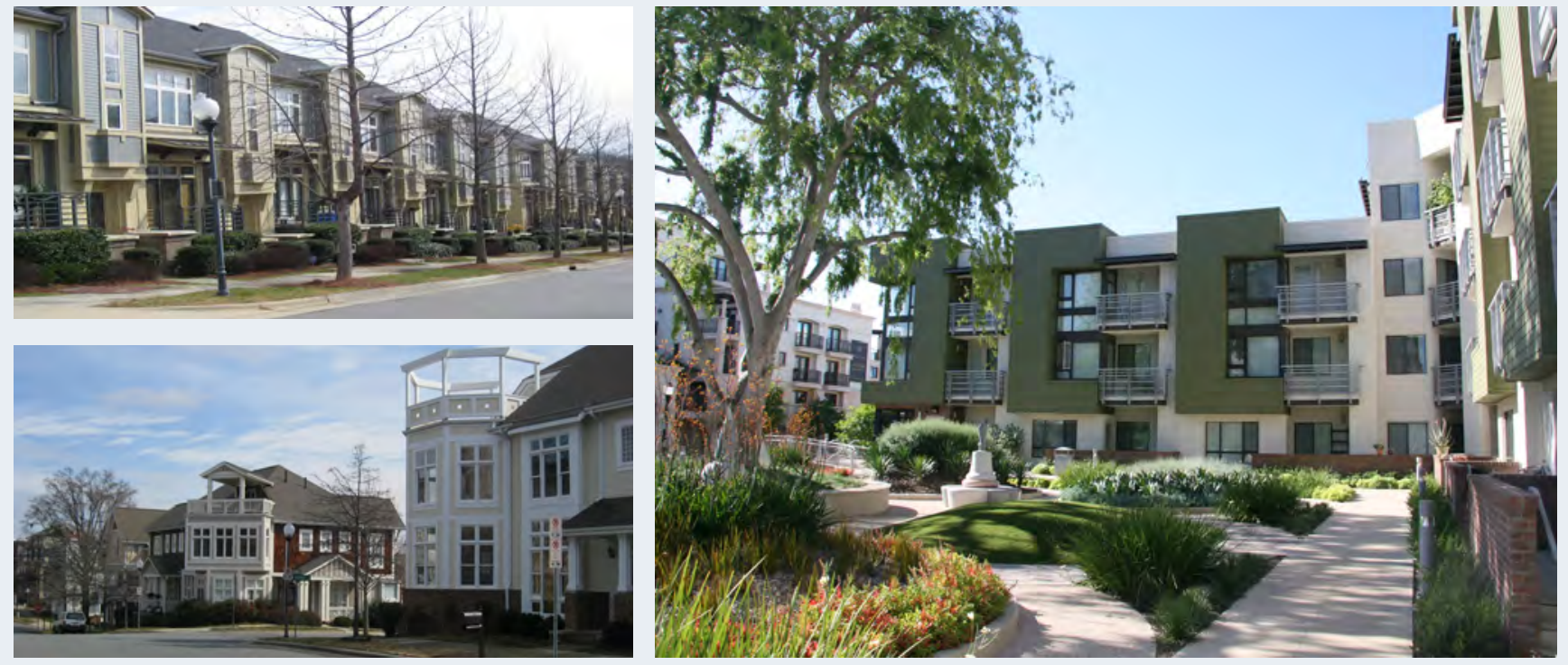

\section{RURAL RESDENTIALAND SINGIE FAMILY NEGHBORHOODS}

A great deal of the $\mathrm{BCP}$ area is expected to be made up of low-density residences, which typically means single-family homes with or without accessory dwellings and duplexes. Triplexes and four-plexes, designed to be compatible in scale and appearance with single-family homes can be located along collector roads or along the single-loaded roads delineated in the plan. Pedestrian-oriented, walkable blocks can form a seamless part of a transitready community. Neighborhood streets of the type illustrated in Figure 42 can connect directly to the streets of any of the other place types, allowing residents to live in a quiet residential environment that is a convenient and safe 2, 5, or 10 minute walk or bike ride from a bus stop, a shop, a job, a park, or a school.

\section{Figure 42. Illustation of Single Family Residential}

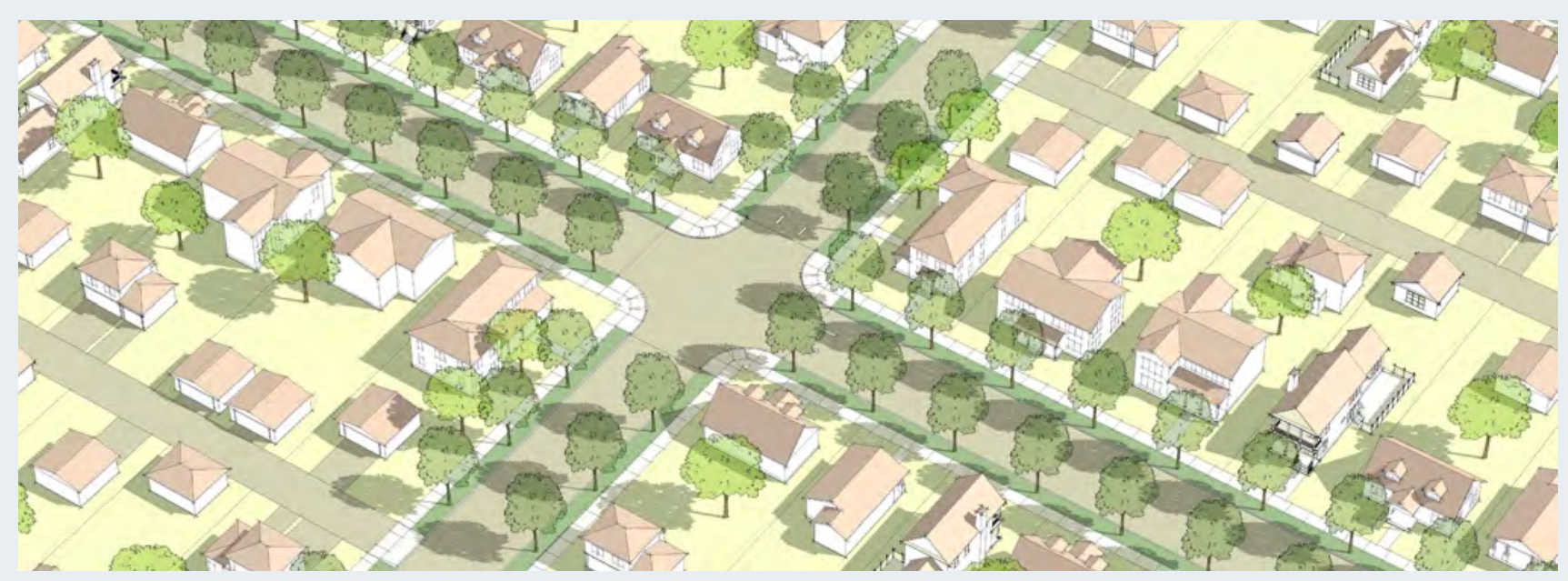


Some blocks would not have alleys, and in such cases driveways would connect to the street. In this case, residential lots should be wide with narrow paved driveways to prevent visual domination of the front yard, the sidewalk, and the parkway strip by pavement and cars. Homes that front major arterials or collectors should be equipped with alleys. A small amount of locally serving retail should be encouraged within or near these neighborhoods, provided they are designed at a compatible scale with residential heights, setbacks, building materials and operation.

\section{REX-MIXED USE NEIGHBORHOOD:}

Because the BCP is expected to be developed over the course of many decades, it is not reasonable to expect that the ultimate mix of uses within each area can be predicted at this time. Accordingly, this designation will allow neighborhood planning areas (typically quarter mile square areas) to be developed as any one of the other Place Types above. Neighborhood Master Planning outlines procedures for assigning one or a combination of the Place Types when development is timely, providing for appropriate transitions between each Place Type.

\section{Examples of Neighborhood Development and Street Types}

Rural Residential
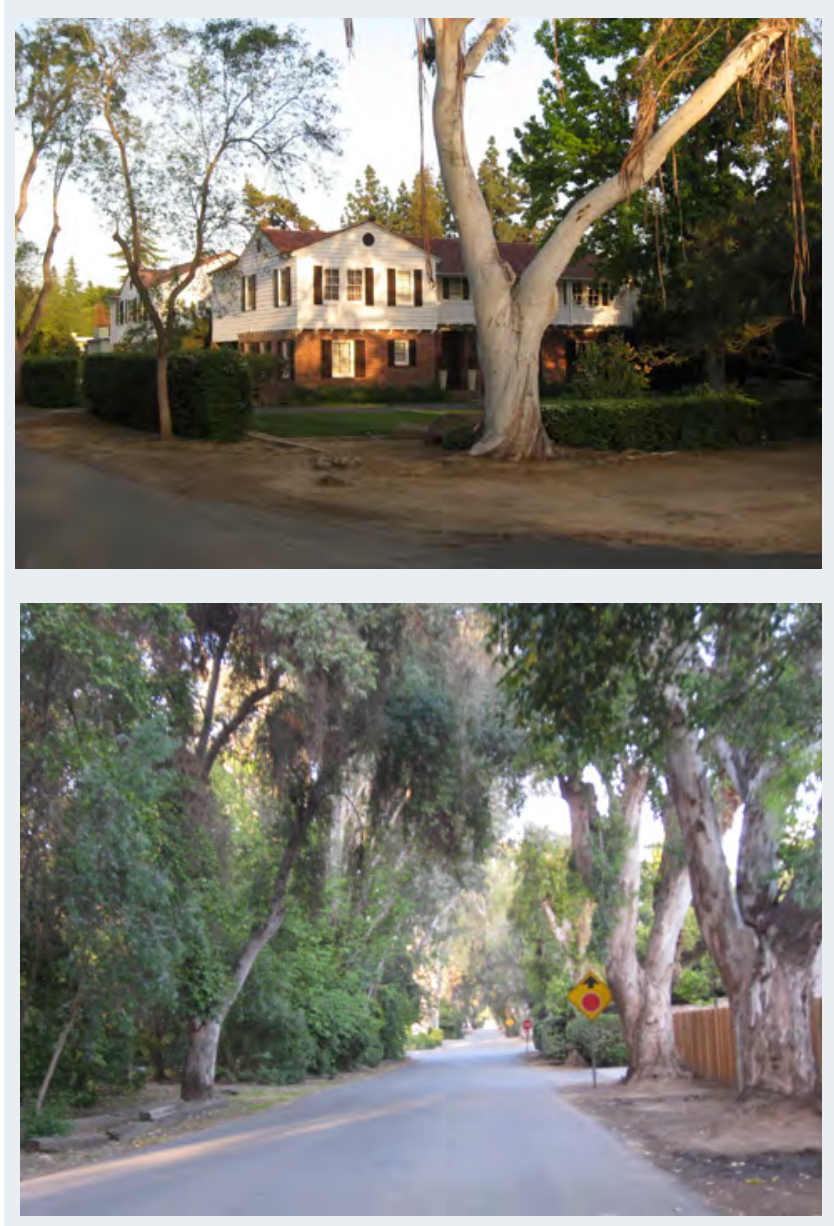

\section{Single-Family Residential}
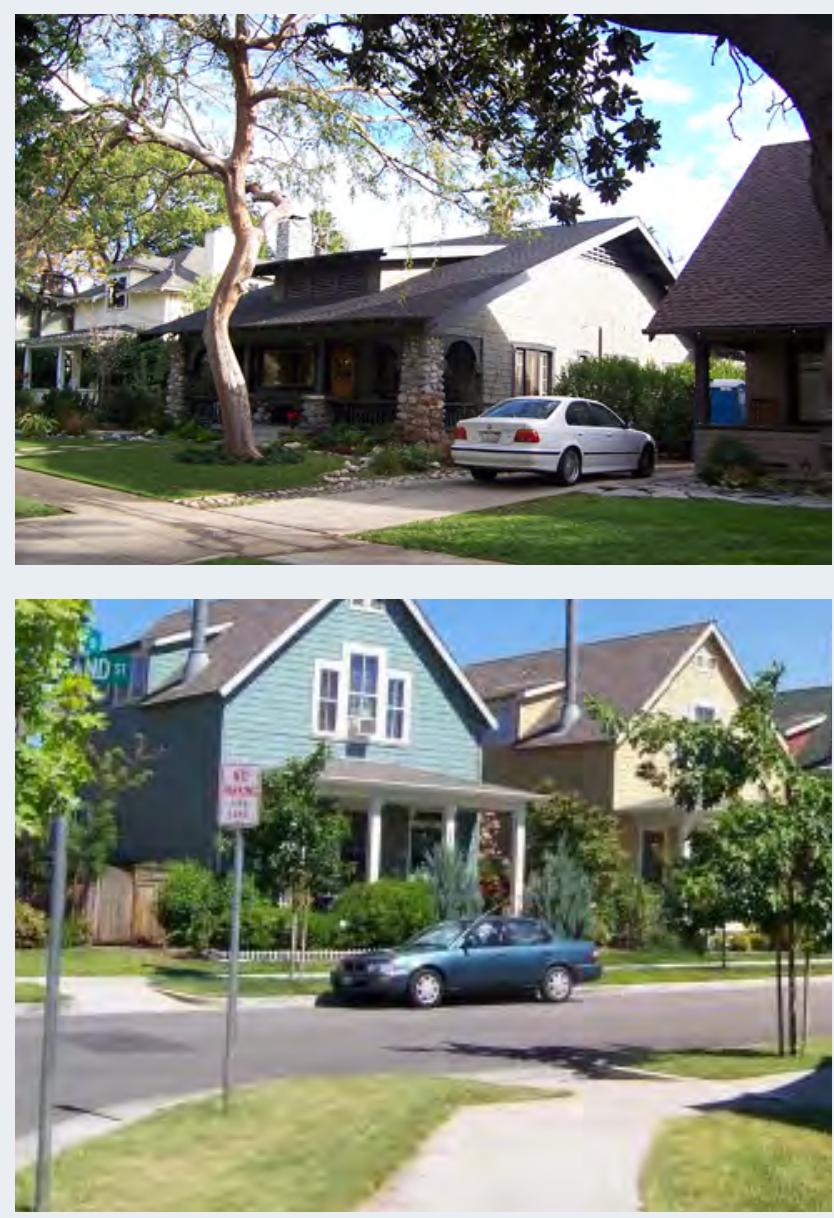


\section{NEIG HBO RHOOD MASTER PLANNING}

In order to create compatible adjacent land uses, the BCP encourages Neighborhood Master Plans to be prepared prior to subdividing any land and that no zone changes be approved without a concurrent neighborhood subdivision and block structure. This process acts as the fundamental tool to ensure that the overall physical community structure meets the requirements of Transit Priority Projects and connects adequately with any adjacent subdivisions. Subdivisions proposed within the BCP should also have block structures that connect adequately to adjacent subdivisions outside of the plan area to promote future transit routes. Neighborhood Master Plans create the manner in which the community character Place Types interact and establish how the BCP functions. The Neighborhood Master Plans will incorporate the broad set of parameters identified in this Chapter to carry forward the vision of the $\mathrm{BCP}$ and inform zoning decisions which implement this vision on a daily basis. Neighborhood Master Plans should also include appropriate performance standards in order to further encourage compatibility of adjacent uses.

After the adoption of the BCP the City will need to establish a Neighborhood Master Plan review process. The BCP recommends the use of the following key review parameters to guide this process. Even though development projects may be smaller, the minimum size of a Neighborhood Master Plan should be 160 acres. The objectives of the master planning process are to:

- Create a dynamic "Neighborhood Master Plan" process to ensure that each new increment of development is well-connected to existing and future adjacent development, while responding to market.

- Focus near-term investments in transit and utility infrastructure to support the development of complete centers, districts and neighborhoods.

- Collaborate with the University and other nearby growth areas to ensure the orderly and fiscally sustainable expansion of urban infrastructure.

- Ensure that development standards deliver the performance of an interconnected transit-oriented development pattern, clarity of urban character and flexibility of use to respond to changing markets.

- Organize new development in the form of complete neighborhoods and districts, oriented to pedestrians and transit.

- Establish a clear and interconnected - yet flexible - network of complete, green streets and community open spaces as the framework for new development.

- $\quad$ Provide for a mix of uses within each neighborhood and district, with flexibility to respond to future market conditions.

- Concentrate higher intensity development and activities near planned BRT stops.

- Define the general scale and urban character of key centers, flexible in size, with appropriate transitions to adjoining neighborhoods.

The review should occur as part of annexation applications and prior to subdivision, and be acted on by the City Council with a recommendation from the Planning Commission.

\section{Urban Design Framework}

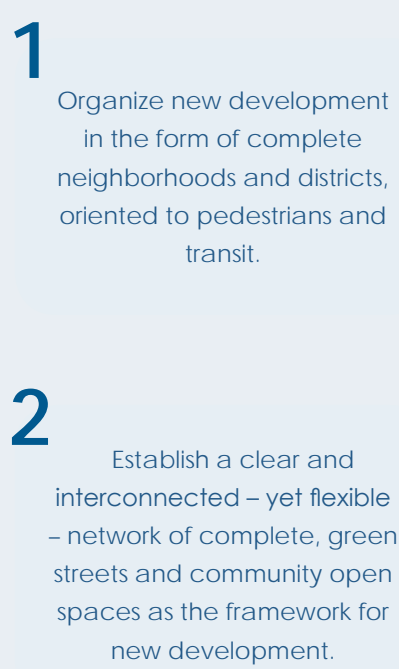

3

Provide for a mix of uses within each neighborhood and district, with fexibility

to respond to future market conditions.

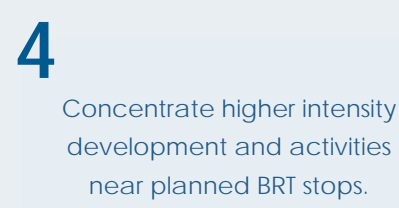

5

Define the general scale and urban character of key centers, flexible in size, with appropriate transitions to adjoining neighborhoods. 


\section{BC P REG ULATO RY FRA MEWO RK}

The following Table details the physical characteristics of the character areas. More detailed zoning regulations should be developed to implement the plan

\section{Table 9 BCPCharacter Area Descriptions and Regulatory Framework}

\begin{tabular}{|c|c|c|}
\hline & TOD Center & R\&D Employment District \\
\hline $\begin{array}{l}\text { General } \\
\text { Descriptions }\end{array}$ & $\begin{array}{l}\text { Regional node with a } \\
\text { walkable design and } \\
\text { high density, high quality } \\
\text { development within a } \\
\text { 10-minute walk of a transit } \\
\text { station and a wide mixture } \\
\text { of uses in close proximity, } \\
\text { including residential, office, } \\
\text { services, retail, and civic. The } \\
\text { transit station should be a } \\
\text { prominent feature and the } \\
\text { pedestrian is the top priority. } \\
\text { Designed to support feeder } \\
\text { transit systemsand easy use } \\
\text { of othernon-auto modes } \\
\text { of transit. Reduced and/ or } \\
\text { managed parking programs. }\end{array}$ & $\begin{array}{l}\text { R\&D/business park } \\
\text { districts would } \\
\text { be research and } \\
\text { employment centers that } \\
\text { have strong ties to UCM } \\
\text { and attract workers from } \\
\text { throughout the region. } \\
\text { Distric ts a re a reas that } \\
\text { because of their size } \\
\text { or function need to be } \\
\text { regulated differently } \\
\text { than other centers. These } \\
\text { districts a re typically } \\
\text { located a long or near } \\
\text { major comidors. }\end{array}$ \\
\hline
\end{tabular}

\begin{tabular}{|c|c|c|}
\hline \multicolumn{3}{|c|}{ Neighborhood Centers } \\
\hline Mixed-Use & Major & Rural/Small \\
\hline \multicolumn{3}{|c|}{$\begin{array}{l}\text { Centers are located to serve adjacent } \\
\text { neighborhoods and districts and a re typically } \\
\text { located a long a Comidor. One of three types of } \\
\text { Centers is applied to a location a long a Comidor } \\
\text { or along the edges of a District or Neighborhood. } \\
\text { Streets and streetscapes are the most urban of all } \\
\text { in the BCP. Three types of centers provide for the } \\
\text { expected range of land use activity. }\end{array}$} \\
\hline
\end{tabular}

\begin{tabular}{|c|c|c|}
\hline $\begin{array}{l}\text { Conta ins reta il } \\
\text { and service } \\
\text { businesses } \\
\text { a imed at the } \\
\text { greater BCP } \\
\text { and City. }\end{array}$ & $\begin{array}{l}\text { Conta ins retail } \\
\text { and service } \\
\text { businesses } \\
\text { aimed at the } \\
\text { greater BCP } \\
\text { and residents. }\end{array}$ & $\begin{array}{l}\text { Contains retail } \\
\text { and services to } \\
\text { serve nearby } \\
\text { neighborhoods } \\
\text { or businesses. }\end{array}$ \\
\hline
\end{tabular}

\section{Physical Description}

\begin{tabular}{|c|c|c|c|c|c|}
\hline Residential Density & $12-36 d u / a c$ & $24-36 d u / a c$ & $12-36 d u / a c$ & $12-24 \mathrm{du} / \mathrm{ac}$ & $6-24 d u / a c$ \\
\hline $\begin{array}{l}\text { Non-Residential } \\
\text { Intensity }\end{array}$ & $0.35-.75$ FAR & $0.35-0.75$ FAR & $0.35-0.50$ FAR & $0.35-0.50$ FAR & 0.35 FAR \\
\hline Height & 3 - 5 stories & 1 - 3 stories & 1 - 4 stories & 1 - 3 stories & 1 - 3 stories \\
\hline $\begin{array}{l}\text { Typical Block Size } \\
\text { (Perimeter) }\end{array}$ & $400 \mathrm{ft} \times 325 \mathrm{ft}(1,600 \mathrm{ft})$ & $400 \mathrm{ft} \times 600 \mathrm{ft}(2000 \mathrm{ft})$ & \multicolumn{3}{|c|}{$1,600-2,400$ sf perimeter } \\
\hline Other Features & $\begin{array}{c}\text { Streetsc a pes mostly with } \\
\text { tree wells but parkway strips } \\
\text { in residential a reas allowed. } \\
\text { Pedestrian a menities, } \\
\text { such as wide sidewalks, } \\
\text { small parks, and plazas, } \\
\text { incorporated. }\end{array}$ & $\begin{array}{l}\text { Streetsc a pes would be } \\
\text { treelined streets with } \\
\text { onstreet parking. }\end{array}$ & \multicolumn{3}{|c|}{$\begin{array}{c}\text { Streetsc a pe mostly with tree wells but parkway } \\
\text { strips in residential a reas allowed. Pedestrian } \\
\text { a menities, such as wide sidewalks, small parks, } \\
\text { and plazas, incorporated. }\end{array}$} \\
\hline
\end{tabular}

\begin{tabular}{|c|c|c|c|c|}
\hline \multicolumn{5}{|l|}{ Residential } \\
\hline \multicolumn{5}{|l|}{ Office } \\
\hline \multicolumn{5}{|l|}{ Retail } \\
\hline \multicolumn{5}{|l|}{$\begin{array}{l}\text { Restaurants/ } \\
\text { Coffee shops }\end{array}$} \\
\hline \multicolumn{5}{|c|}{$\begin{array}{l}\text { Services- personal } \\
\text { and business }\end{array}$} \\
\hline \multicolumn{5}{|l|}{$\begin{array}{l}\text { Hotel/Meeting } \\
\text { facilities }\end{array}$} \\
\hline \multicolumn{5}{|l|}{$\begin{array}{l}\text { Theater/ } \\
\text { Enterta inment }\end{array}$} \\
\hline \multicolumn{5}{|l|}{ Light Industrial } \\
\hline TPP Compatible & Potential & Potential & Potential & Potential \\
\hline
\end{tabular}

Primary $O$ Secondary $O$ Limited Pet Permitted




\begin{tabular}{|c|c|c|c|c|}
\hline & \multicolumn{3}{|c|}{ Neighborhoods } & \multirow{2}{*}{ Fex Neighborhood } \\
\hline & Multi-Family & Single-Family & Rural & \\
\hline & \multicolumn{3}{|c|}{$\begin{array}{l}\text { Neighborhoods are located between comidors and } \\
\text { accommodate a wide range of housing choices with the } \\
\text { most intense housing nearer comidors, centers, and Districts. } \\
\text { Depending upon location, neighborhoods are composed } \\
\text { of at least two and up to three neighborhood residential } \\
\text { environments. }\end{array}$} & \multirow{2}{*}{$\begin{array}{l}\text { This designation will allow } \\
\text { neighborhood planning areas } \\
\text { (quarter mile square areas, } \\
\text { typically) to be developed as } \\
\text { a mix of the other place types } \\
\text { above. The development } \\
\text { code will provide procedures } \\
\text { for assigning a combination } \\
\text { of these designations to each } \\
\text { neighborhood planning a rea } \\
\text { when development is timely, } \\
\text { providing for a ppropriate } \\
\text { transitions between each place } \\
\text { type. }\end{array}$} \\
\hline & $\begin{array}{l}\text { Consists of the } \\
\text { most intense } \\
\text { housing in the } \\
\text { neighborhood } \\
\text { and between } 30 \\
\text { and } 62 \% \text { of the } \\
\text { total housing area } \\
\text { depending upon } \\
\text { location. }\end{array}$ & $\begin{array}{l}\text { Consists prima rily } \\
\text { of single-family } \\
\text { housing and, on } \\
\text { a verage,55 \% of } \\
\text { the total housing } \\
\text { a rea depending } \\
\text { upon location. }\end{array}$ & $\begin{array}{l}\text { Consists prima rily } \\
\text { of single-fa mily } \\
\text { housing on large } \\
\text { lots and makes } \\
\text { up } 13-35 \% \text { of the } \\
\text { neighborhood, } \\
\text { depending upon } \\
\text { location. }\end{array}$ & \\
\hline \multicolumn{5}{|l|}{ Physical Description } \\
\hline Residential Density & $12-36 \mathrm{du} / \mathrm{ac}$ & $6-12 \mathrm{du} / \mathrm{ac}$ & $2-6 d u / a c$ & $6-24 d u / a c$ \\
\hline $\begin{array}{l}\text { Non-Residential } \\
\text { Intensity }\end{array}$ & $0.35-0.50$ FAR & $0.35-0.50$ FAR & 0.35 FAR & $0.35-0.75$ FAR \\
\hline Height & 1 - 4 stories & 1 - 2 stories & 1 - 2 stories & 1 - 4 stories \\
\hline $\begin{array}{l}\text { Typical Block Size } \\
\text { (Perimeter) }\end{array}$ & \multicolumn{2}{|c|}{$1,600-2,400$ sf perimeter } & $\mathrm{TBD}$ & Varies \\
\hline Other Features & \multicolumn{3}{|c|}{$\begin{array}{l}\text { Streetscape mostly with tree wells but parkway strips in } \\
\text { residential a reas a llowed. Ped estrian amenities, such as } \\
\text { wide sidewa lks, small parks, and plazas, incorporated. }\end{array}$} & Varies \\
\hline \multicolumn{5}{|c|}{ Permitted Uses (SupplementaI Retail and Service could be allowed where appropriate) } \\
\hline \multicolumn{5}{|l|}{ Residential } \\
\hline \multicolumn{5}{|l|}{ Office } \\
\hline \multicolumn{5}{|l|}{ Retail } \\
\hline \multicolumn{5}{|l|}{$\begin{array}{l}\text { Restaurants/ } \\
\text { Coffee shops }\end{array}$} \\
\hline \multicolumn{5}{|l|}{$\begin{array}{l}\text { Services- personal } \\
\text { and business }\end{array}$} \\
\hline \multicolumn{5}{|l|}{$\begin{array}{l}\text { Hotel/Meeting } \\
\text { facilities }\end{array}$} \\
\hline \multicolumn{5}{|l|}{$\begin{array}{l}\text { Theater/ } \\
\text { Enterta inment }\end{array}$} \\
\hline \multicolumn{5}{|l|}{ Light Industrial } \\
\hline TPP Compatible & Potential & & Potential & \\
\hline
\end{tabular}




\section{BELLEVUE COMMUNITY PLAN G OALS AND POLICIES}

The goal headings of this BCP chapter are grouped into the same policy topics as the Merced Vision 2030 General Plan. This approach fosters consistency and builds on the City's broader General Plan guidance. In furtherance of consistency with the City's General Plan, Appendix C, policies specific to the BCP planning area are described in greater detail and grouped with the goals and policies it shares in common with the City's General Plan. In additions to the goals and policies below, Master Plans/projects/permit applications need to take into account the BCP in its entirety and be consistent with the language herein.

Table 10 Community Character Goals and Policies Specific to the Bellevue Community Plan consistent with the City's General Plan

\section{Goal Area CC-1: Residential \& Neighborhood Design}

Policy CC-1.1: Follow Table 9 as a guide to prepare and assess future zoning regulations, master plans, or specific plans within the BCP.

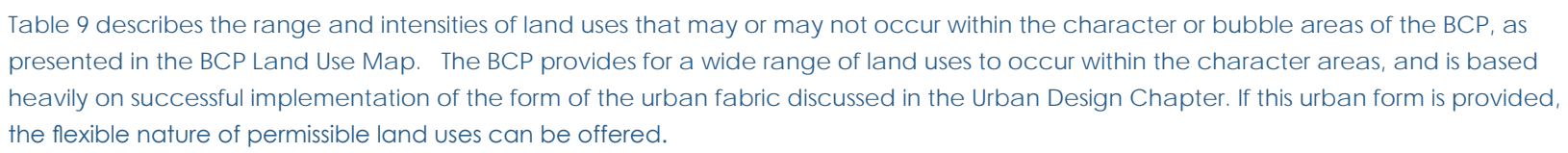

Table 9 describes the range and intensities of land uses that may or may not occur within the character or bubble areas of the $B C P$, as presented in the BCP Land Use Map. The BCP providesfor a wide range of land uses to occur within the character areas, and is based heavily on successful implementation of the form of the urban fabric disc ussed in the Urban Design Chapter. If this urban form is provided, the flexible nature of permissible land uses can be offered.

Policy CC-1.2: Encourage and support the development of Transit Prionity Projects within the Mandeville Transit Conidor.

The Mandeville Transit Comidor, bounded by Bellevue Road, Foothill Road, G Street and Lake Road, should include high-density residential, research and development, and retail land uses within a transportation fabric that emphasizes a pedestrian-scale streetscape. This structure is intended to support a functional transit service, and to create opportunities for qualified transit priority projects.

Policy CC-1.3: Seek to create compatible developments adjacent to existing Rural Residential neighborhoods. When designing new neighborhoodsadjacent to existing rural residential neighborhoods, the new development should incorporate compatibility stra tegies to minimize impacts on existing neighborhoods, such as: 1) when backing up to existing lots, use similar rear-setbacks, minimum lot area and height standards as the existing neighborhood; (2) when fronting new lots across a street from existing lots, use similar front setba cks, lot width, height standards and road standards a s the existing neighborhood.

Policy CC-1.4: Enc ourage multi-family development to oc c ur within $1 / 4$ mile of the Mandeville Transit Comidor. Multifamily housing is emphasized to oc cur in the Multi-Family Neighborhood Character Area. Moderate amounts may occur in the Mixed Use TOD Character Area, and the Flexible Mixed Use Neighborhood Character Area. Refer to Table 1 (BCP Character Area Descriptions and Regulatory Framework) for details of relative a mounts antic ipated to occur throughout the BCP planning area.

Policy CC-1.5: Provide opportunities for the development of housing types to meet the special needs of students and others attracted to a University environment

Housing types related to the needs of a university may include co-housing, higher density units, group quarters, etc. This may include a reas set a side for the development of experimental or housing prototypes provided they are compatible with adjacent uses.

\section{Goal Area CC-2: Economic and Business Development}

Policy CC-2.1: Emphasize the key role of the BCP as a tool to identify and set-aside lands for future opportunities for research and development sites near UC Merced.

The designation of sites for future research and development land uses need to be highlighted in the community and fixed at specific locations but flexible to grow and shift. Fixed R\&D sites are essential to both anc hor the BCP and to reserve a reas as other land uses develop around the R\&D sites. 
Policy CC-2.2: Emphasize commerc ial development within the plan's Neighborhood Commercial centers.

The Plan's neighborhood commercial centers within the Mandeville Corridor contribute significant value to the liva bility of the future community. The variety of land-uses provided in close proximity to housing and employment supports the function of the transit corrid or, the complete-street infra struc ture improvements and the level of pedestrian and bicycle travel.

Policy CC-2.3: Consider the development of commercial center, appropriately-scaled to the adjacent neighborhood and consistent with the design parameters of General Plan Policy L-2.7.a, at the comer of G and Bellevue Road.

A market study to determine the impact to existing and planned commercial sites in the area shall be required, and be a significant part of the City Council's decision to zone the property for commercial uses. If permitted, design of the center will need to be based on minimizing traffic congestion; developing a center that is sc aled to the surrounding neighborhoods and to avoid big-box stores.

Policy CC-2.4: Work to implement the mobility chapter of the plan, especially its bikeway and transit comidor features.

The BC P provides importa nt bikeway and transit links between Downtown, Merced College and UC Merced. Mandeville Avenue is the extension of the main transit comidor to downtown. G Street and Gardner/Parsons are important roadway linka ges. Bikewa ys will extend from Cottonwood Creek and the PG \&E transmission line corridor. This integrated system will help to ensure Downtown is connected to the City as it expands toward UC Merced.

Policy CC-2.5: Foc us a Research and Development center in the vic inity of Bellevue Road and Gardner Road, and allow it to expand with market demand.

Research and Development uses should be developed asan integrated campusconnected by public spaces with an urban pedestrian-oriented scale. Surface parking lots may be permitted in the near-term, but the site should be designed to allow conversion to parking structures in the long-tem. R\&D uses should be supported by nearby compatible land uses to create a live, work, play environment, and may include varied uses including restaurants, reta il, dayca res and gyms in a dense urban setting that emphasizes mobility by transit, bikes and pedestrians.

\section{Goal Area CC-3: Urban Growth and Design}

Policy CC-3.1: Create a mixed-use, transit ready comidoralong Mandeville Road.

A carefully designed urban environment with appropriate paired land uses and circulation options can well serve a large population and associated commercial service market. The Mandeville Comidor is such a place. The synergy created by the paring of mixed-use with transit and other mobility options will help to attract research and development firms to the BCP.

Policy CC-3.2: Balance the ability to permit a range of land uses with the need to emphasize partic ular types in specific areas of the BCP.

While the BCP enables a variety of land uses to occur in the most of the Character Areas (see Table 1), this should not be interpreted as any use can go anywhere in any a mount. The following tools have been crafted to explain the function of the character areas, and should be used to guide land use decisions in the BCP: 1) written narrative of Character Areas; 2) Table 9; and 3) the assumed land use amounts in the BCP traffic assessment.

\section{Policy CC-3.3: Implement the Pedestrian Plan as an essential component of the BCP's Circ ulation Plan.}

The City's standard designs for roadways a llow for pedestrian and bic ycle use. Such use can be enhanced through a variety of otherfeatures, as noted in Implementing Action L-3.3.b, however. The BCP's use of an interconnected grid street, mainly occuming along the Mandeville Avenue transit-comidorand the MixedUse TOD is one such feature. Figure 12 of the BCP depicts where other mobility-enhancing features are encouraged to occur. 


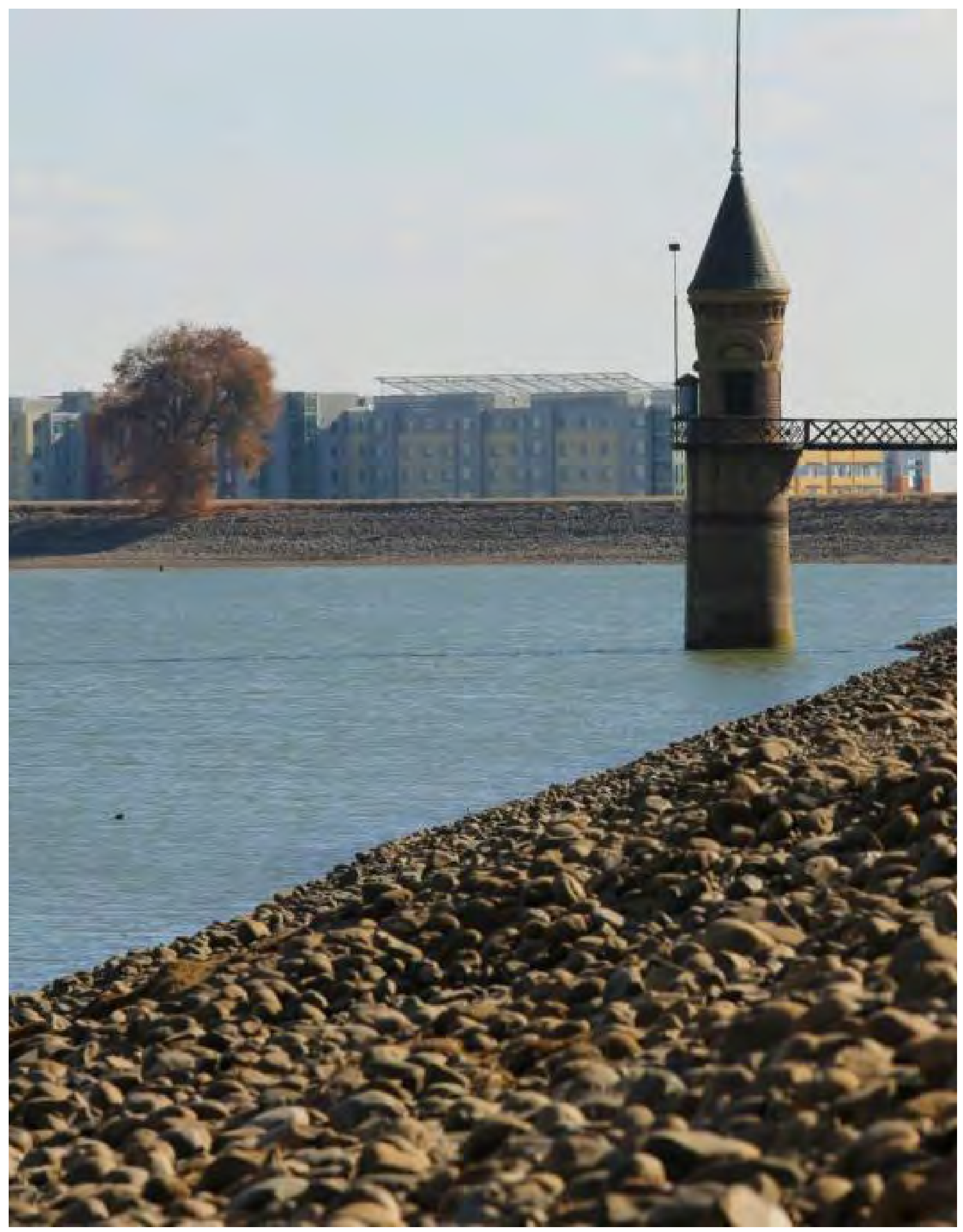




\section{URBAN EXPANSION}

The Urban Expansion Chapter discusses topics associated with the urbanization of the $\mathrm{BCP}$ area including a comprehensive approach to governance and identifying factors affecting growth. In turn, these influence future growth scenarios for the BCP planning area. The Urban Expansion Chapter emphasizes the need for a regional and collaborative approach to long range planning for the area surrounding UC Merced. Such an approach can help resolve complex infrastructure and governance issues, whereas a divided approach could result in fragmented development without adequate infrastructure or public services. Without coordination, these deficiencies could hinder the growth of UC Merced and surrounding lands.

\section{Governance and Terminology}

In addition to forming a foundation in understanding urban expansion challenges and opportunities, this section helps the community to understand governance issues related to urbanization of unincorporated lands. Issues include long-term growth boundaries, fringe development, and annexation.

\section{Comprehensive Approach}

The Bellevue Community Plan (BCP) area is located in close proximity to UC Merced, the City of Merced and lies within the City of Merced's Sphere of Influence (see Figure 44). As an area where future growth is encouraged, the BCP builds upon and integrates concepts from current and past planning efforts, as appropriate. This section describes how the BCP implements the goals of the Merced Vision 2030 General Plan and integrates with other planning efforts in the community. For example, the BCP recognizes and supports the development of the Merced Loop, with Bellevue Road acting as a functional roadway link between the Atwater-Merced Expressway and the Campus Parkway Expressway.

\section{Growth Factors}

Demand for services, housing, and employment exert pressure for growth and development in the BCP and surrounding areas. However, internal and external factors can inhibit or prevent orderly growth. It is important to understand how these growth factors, such as availability of services and infrastructure, can directly affect the form, pattern, and cost of urban expansion. Many of these decisions are made locally, and can be informed by this plan. 
Figure 43. Bellevue Community Plan Area

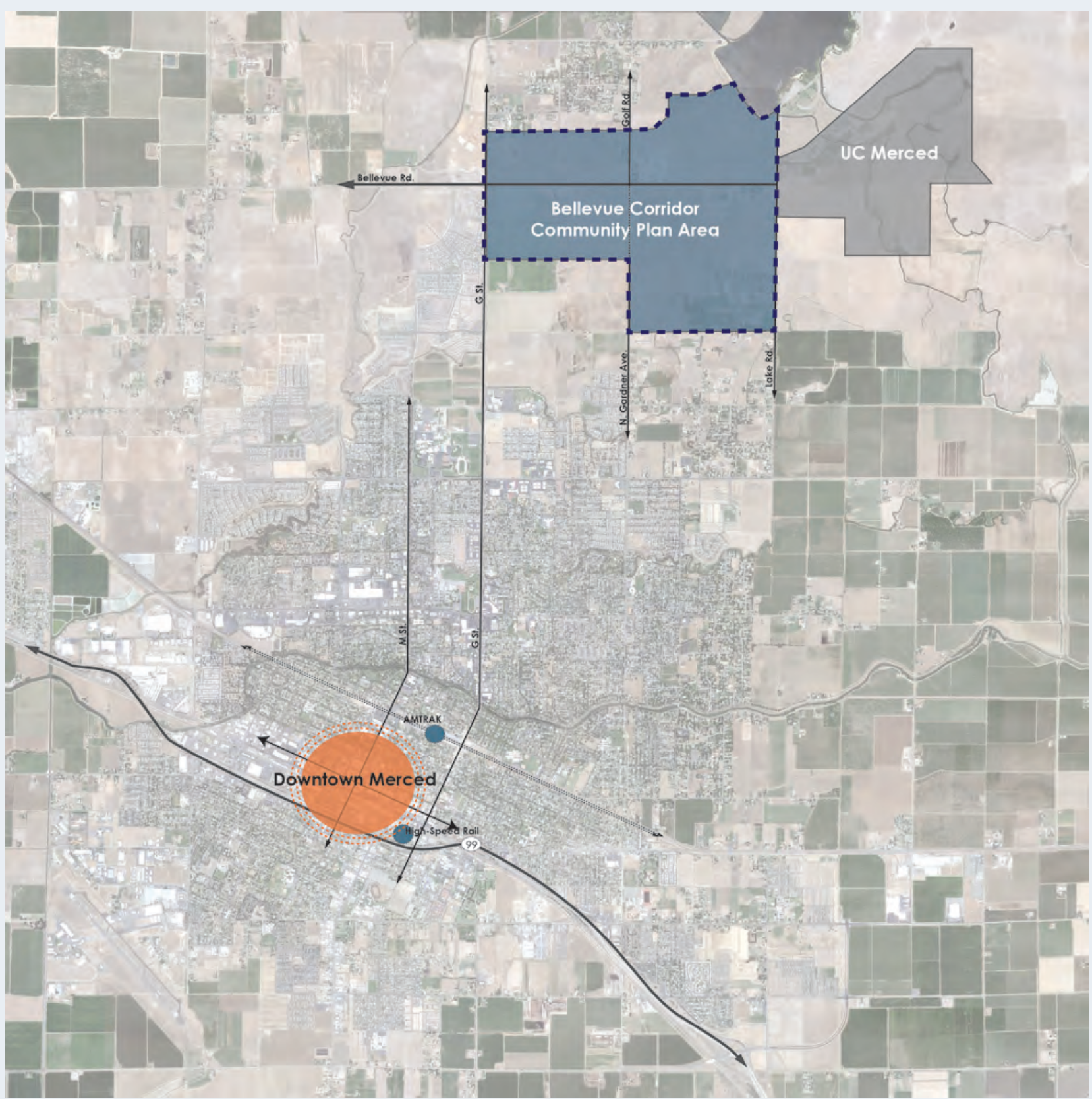

\section{Growth Scenarios}

As introduced above, the expansion of the $\mathrm{BCP}$ area is heavily reliant on collaboration between decision makers. With many infrastructure-related decisions yet to be made, there are several possible growth scenarios for the Bellevue Community Plan area. The growth scenarios presented in this section set the stage for further community discussion regarding future expansion. 


\section{GOVERNANCE AND TERMINOLOGY}

The BCP area lies within unincorporated Merced County with future growth and development related decisions guided by the County of Merced General Plan. The General Plan for the County of Merced focuses its discussions and policies on the unincorporated areas of the County, as incorporated cities have their own general plan goals and policies separate from, but not inconsistent with, the County. In addition, cities within the county have their own set of urban expansion boundaries that include portions of unincorporated lands to be urbanized and incorporated in the future. Urban expansion boundaries extend beyond a city's corporate limits and must be appropriately planned for and included in any long range development plan or policy. The Area of Influence (AOI), Sphere of Influence (SOI), and Specific Urban Development Plan (SUDP) all help to describe a city's long-term boundary for urban expansion into unincorporated lands.

\section{URBAN EXPANSION AND THE MERCED VISION 2030 GENERALPLAN}

The Bellevue Community Plan, though located outside Merced's corporate city limits, lays completely within the City's urban expansion boundaries. Therefore, the City of Merced has interest and influence over development within the BCP area. While Merced County has zoning and development authority over unincorporated land within a City's SOI, there are mechanisms for cities and counties to coordinate growth and development efforts. (See discussion under Fringe Development later in this chapter). This collaboration is important for successful long-term planning, as a city must prove it is capable of providing infrastructure and services to land within its SOI before it can be annexed. Similarly, the Urban Expansion chapter of the City's General Plan includes several planning tools to guide well-planned growth into unincorporated lands, including a list of annexation criteria.

It is important to note that urban expansion occurs in response to the market, is initiated by property owners, and is regulated in large part by a Local Agency Formation Commission (LAFCO).

\section{URBAN EXPANSION BOUNDARIES}

While City limit boundaries are commonly understood, there are a variety of other governance-related boundaries. These include the Area of Interest (AOI), the Sphere of Influence (SOI) and the Specific Urban Development Plan (SUDP). These growth-related boundaries are utilized by cities and counties to manage urban expansion. While the Bellevue Community Plan (BCP) is located outside Merced's current municipal boundary, it is located within all three of the above listed boundaries. Figure 44 depicts the relationship of the BCP to the City corporate limits, the AOI, SOI, and SUDP.

\section{AREA OF INTEREST - AOI}

The AOI describes lands for which a City has a long-term development interest, but which are unlikely to urbanize within the 20-year plan horizon of the Merced Vision 2030 General Plan (See Figure 44). Though originally
In addition to a City's

comorate limits, the Area of

Influence (AOI), Sphere of

Influence (SOI), and Specific

Urban Development Plan

(SUDP) all help to describe a

City's long-term plan for urban

expansion into uninc orporated

lands. 
Figure 44. Merced City Limit, Sphere of Influence (SOI), Sphere of Specific Urban Development (SUDP), and Area of Interest (AOI)

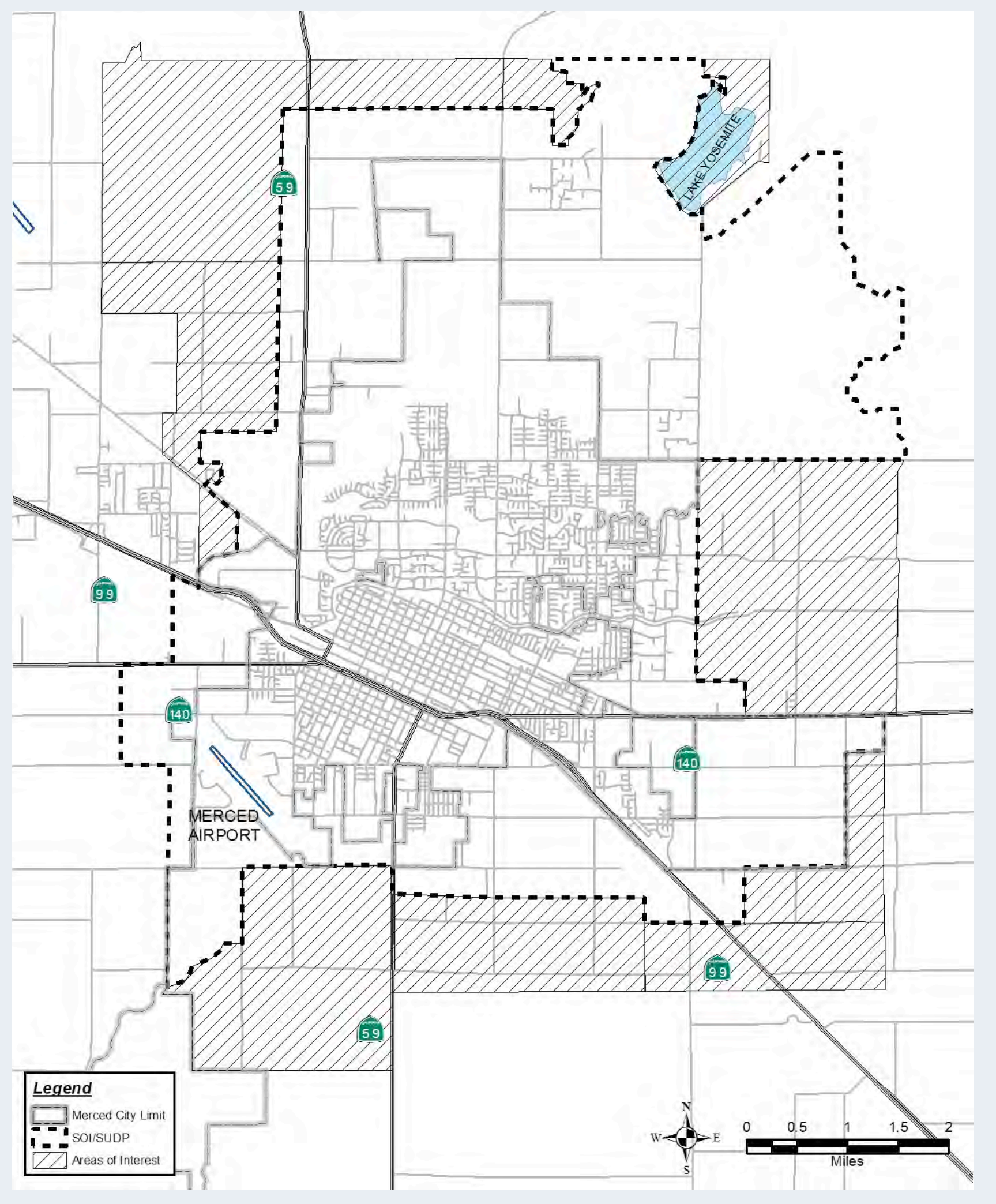


considered to be placed in the City's SOI, the Castle Farms and Mission Lakes development plans eventually became a part of the City's AOI instead. Lands near UC Merced were retained within the City's proposed SOI/SUDP. As discussed below, lands in the City's SOI/SUDP are anticipated to develop prior to those in its AOI.

\section{SPHERE OF INFLUENCE - SOI}

The Sphere of Influence defines the primary area within which urban expansion is to be encouraged. The entirety of the BCP planning area was enclosed within the SOI established in 1997. In 2012, with adoption of the Merced Vision 2030 General Plan, the City included the University Community Plan area within its proposed SOI. LAFCO officials and local decision-makers recognize the logical assumption that the lands lying within the SOI are those that the City may someday propose to annex. See Figure 45 for the City's 2015 and 2030 SOI boundaries.

\section{SPECIFIC URBAN DEVELOPMENT PLAN - SUDP}

With adoption of the Merced Vision 2030 General Plan in January 2012, the Merced City Council placed the entirety of the BCP within the City's SUDP. Whenever land is added to an SUDP, the decision is made that it will ultimately be converted to an urban use. An SUDP has a boundary line which is recognized as the ultimate growth boundary of the community over the life of the Plan, and all land within the SUDP is planned for eventual development in a mixture of urban and urban-related uses.

\section{ANNEXATION}

Once the Local Agency Formation Commission (LAFCO) has approved the City's Sphere of Influence (SOI), annexation requests from the City for areas inside the SOI require only limited review by LAFCO. This review deals with the appropriateness and efficiency of the boundary and conformance with the City's General Plan, including relevant phasing policies and public service availability. LAFCO's were created by the State to oversee changes in jurisdictional boundaries. Locally, Merced County LAFCO is composed of two members of the Board of Supervisors, two members that represent the six incorporated cities in Merced County, and one independent public member.

When a property is located within all three urban expansion boundaries (AOI, SOI and SUDP), and is located adjacent to a city limit boundary, it becomes eligible for annexation to that City. The BCP planning effort does not involve an annexation request by the City of Merced. Rather, the purpose of the BCP planning effort is to establish a conceptual land use framework and set of policies in preparation to respond to private property owner requests for annexation. Annexation requests are usually initiated by a property owner that has an interest to urbanize their property.

\section{CRITERIA}

The Merced Vision 2030 General Plan includes updated policy language that is used to evaluate future annexation requests (Implementing Action UE-1.3g). Building upon the 5-point list of annexation criteria is a sixth criteria which
The Area of Influence describes lands for which a City has a longterm development interest

The Sphere of Influence defines the primary area within which urban development is to be encouraged.

The BCP is located within Merced's Specific Urban Development Plan whic $h$ contains land to be converted to urban use.

The purpose of the BCP planning effort is to establish a conceptual land use framework and policy set in order to be ready to respond to private property owner requests for annexation. 


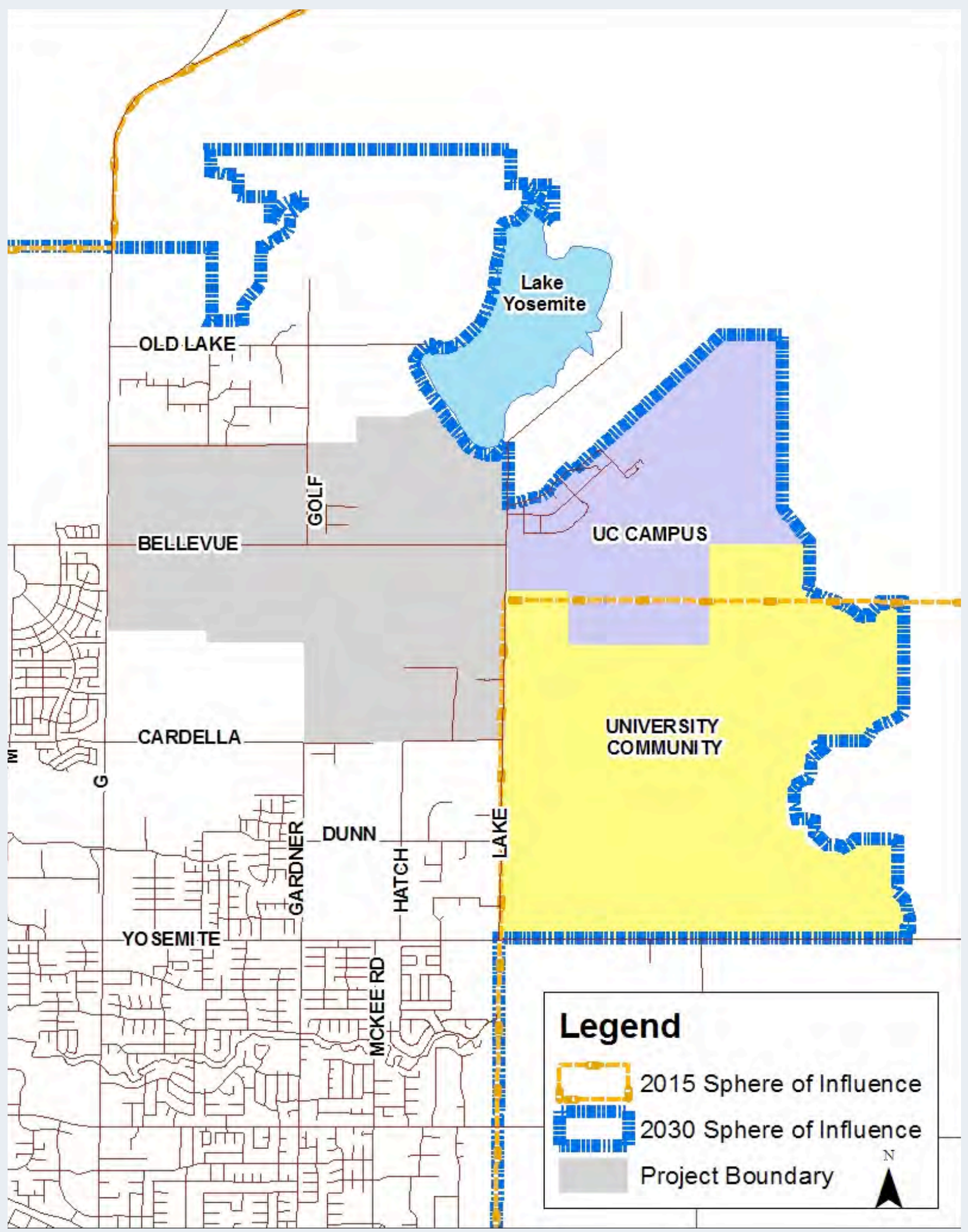


supports annexations that help the City reach one of the following goals. The sixth criteria emphasizes the following three conditions:

- Does annexation of the area bring the City closer to annexation of the UC Merced campus and University Community?

- Does the area contain significant amounts of job-generating land uses, such as industrial, commercial, office, and business/research \& development parks?

- $\quad$ Does the project provide key infrastructure facilities or other desirable amenities, such as the extension of major roads, utility trunk lines, parks and recreational facilities, etc.?"

Taken as a set, these policies support the future annexation of the BCP planning area or parts thereof.

\section{CITY/ COUNTY TAX SHARING AGREEMENT}

In February 1997, the Merced City Council and Merced County Board of Supervisors adopted the "Property Tax Sharing Agreement between the City of Merced and the County of Merced" which included various land use provisions. By adopting the Agreement, the County agreed to amend the General Plan to accommodate future growth of the City of Merced. The agreement includes project review procedures, the circumstances when City development standards apply to development, and terms for payment of development impact fees for new construction. This agreement was a critical landmark in City/County cooperation and granted the City some control over development within its SOI and SUDP.
Planning the Bellevue Comidor

"The City should begin the

process of planning for the

eventual annexation of the

Campus to the City, including

evaluating various corridors for

possible annexation in order

to bridge the gap between

the current City limits and the

Campus boundary. Planning

of the land uses along those

comidors should also begin

as well, including possible

loc ations for researc $h$ and

development parks."

--Implementing Action UE

1.4.a, Merced Vision 2030

\section{General Plan.}


Figure 46. Key Growth Factors for the Bellevue Community Plan

1

Physical

Constraints

2

UC Merced

3

Population

Growth

4

Public

Infrastruc ture

and Services

5

The

Regulatory

Environment

6

Coordinated

Development

\section{GROWTH FACTORS}

Urban Expansion in the BCP area will be strongly influenced by certain growth factors. Understanding these growth factors will help the community anticipate growth-related needs and to predict probable growth patterns (discussed in the next section). The key growth factors for the BCP include:

- Physical Constraints

- UC Merced

- Population Growth

- Public Infrastructure and Services

- The Regulatory Environment

- Coordinated Development

Taken as a whole, a combination of growth factors could dramatically limit the development potential of any given site near UC Merced. Thus, a strategy to assure the ability to respond to growth pressure being generated from UC Merced is to prepare several nearby development sites and form a community-wide development phasing plan. The phasing plan is defined, in part, by understanding the reality of how different growth factors affect the timing and location of new development.

\section{PHYSICALCONSTRAINTS}

The Merced Vision 2030 General Plan identified several physical growth constraints that restricted or severely limited the growth potential of areas other than the BCP. These constraints included proximity to airports, flooding potential, high water tables, presence of prime agricultural soils, lack of roads and public services, and sensitive habitats. While the $\mathrm{BCP}$ planning area does not contain all of these growth constraints, there are some that need to be considered, including agricultural lands, sensitive species and habitats, and flooding.

\section{AGRIC ULTURAL LAND}

Urban expansion into the $\mathrm{BCP}$ is not constrained by the presence of significant agricultural resources. As such, it offers a potentially reasonable alternative location for urban growth rather than sites that do provide valuable agricultural resources, especially given the $\mathrm{BCP}^{\prime} \mathrm{s}$ ability to provide key circulation infrastructure (Bellevue Road) and economic opportunities (Research and Development sites) for the community.

\section{SENSITIVE SPECIES AND HABITATS}

Natural resource agency requirements to protect and conserve sensitive species and habitats have affected the location and intensity of development near the BCP planning area. For a variety of reasons described in the Open Space, Conservation, and Recreation Chapter, it is reasonable to assume that future development within the BCP would be affected as well. To avoid dramatic changes to key land uses and circulation components, the BCP includes an Official Open Space Map that includes likely resource lands. It is important to note that this map is flexible, allowing for increased 
development should impacts to resources be addressed through other means. However, growth may be constrained by the presence of sensitive habitats, such as vernal pools. Consistent with the City's General Plan EIR, private property owners are required to resolve these issues prior to or concurrent with annexation proposals, and have the option to do this individually or as a group in a programmatic manner.

\section{FLOODING}

There are no floodways in the planning area and lands affected by a regulatory floodplain. A large portion of the BCP planning area is located within the flood-inundation area of Lake Yosemite, however. This potential constraint was evaluated as part of the Merced Vision 2030 General Plan, which concluded the threat low enough to allow urban land use designations within this area. Nevertheless, shallow seasonal flooding occurs in the planning (see discussion on stormwater drainage in Chapter 2).

\section{UC MERCED}

UC Merced is a significant growth node that will strongly influence the rate and opportunity for nearby development. UC Merced is anticipated to have a campus population of 10,000 students by the year 2020, with ultimately a capacity of 25,000 students and 6,500 employees at full buildout.

\section{POPULATION GROWIH}

The Great Recession has had a profound impact on the San Joaquin Valley; most of the Valley's counties have been affected substantially worse than the national or State average in terms of employment losses, reductions in growth and development, and general weakening of the local economy. Merced County has been one of the most affected counties and has impacted the City's economy and growth rates. While conditions have stabilized somewhat during 2012, housing supply and demand relationships remain weak and pricing is such that little to no new development can occur. Growth projections used in the preparation of the Merced Vision 2030 General Plan, however, remain optimistic in order assure adequate infrastructure can be planned for build out.

\section{REG IONAL INFLUENC ES}

By 2030 the Central Valley is anticipated to exceed 6.5 million people, a $60 \%$ increase over the 2009 Central Valley population estimate of nearly 4 million people provided by the California Department of Finance. Increases in population will result from new births and from new residents moving to the area. In addition, at build out, UC Merced anticipates having a student population of 25,000, a faculty and staff population of 6,500, and a daily population of about 600 others. This population cluster, located approximately 5 miles from downtown Merced, has and will now demand new residential, employment and commercial services. In addition to the UC Merced campus, the proposed high-speed rail (HSR) station in Merced is another population generator. The general population increase in the Central Valley, together with locally generated populations of UCM and the HSR, as well as normal

\section{UC Merced is a significant growth node that will strongly influence the rate and opportunity for nearby \\ development}

\section{Images of the UC Merced \\ Campus}

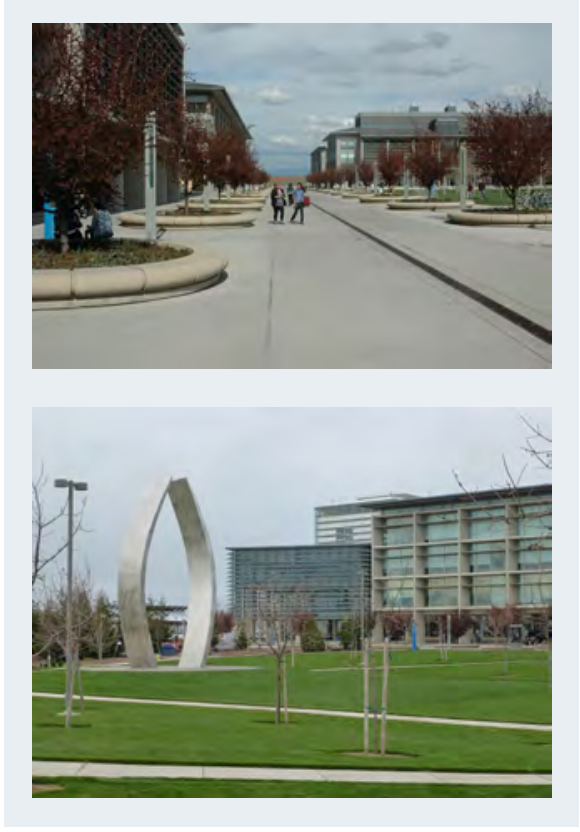


growth locally, is forecasted to dramatically increase the population of the City of Merced to 137,400 people by the year 2030 according to projections from the California Department of Finance.

\section{POPULATION FORECASTS}

Merced currently has a population of 79,328 and 27,412 households. A large number of new housing developments were built in the City during the economic boom of the mid-2000s. Since the onset of the national economic recession, development and annexation activity, which was significant during the preparation of the 2004 Municipal Service Rreview (MSR), is largely on hold. The Merced Vision 2030 General Plan projects a City population of approximately 137,400 by 2030 , an increase of 58,442 , or 74 percent, not including UC Merced. The population of the City will continue to be largely influenced by the growth of UC Merced, which, since its opening in 2005, has steadily increased its student body, faculty, and staff.

Assuming an average household of size of 3.2 persons per dwelling unit, by 2030 Merced will need to accommodate roughly 43,000 new housing units (compared to 27,400 in 2010) and 35,000 new employment opportunities (compared to approximately 22,000 in 2010). However, these projections may be revised due to remaining uncertainty regarding local housing and job markets.

\section{PUBUC INRASTRUCTURE AND SERVICES}

While most growth factors generally affect development potential, it will most likely be the decisions regarding public infrastructure and services that define the timing and location of urban expansion. This in turn will determine whether UC-based growth impacts on the City will be positive or negative. The value of infrastructure-based decisions will be determined by the success of collaboration between the City, Merced County, and UC Merced. This is the reason the ULI Report emphasized the formation of a "collaborative working group" comprised of these entities. It is not the goal or role of the $\mathrm{BCP}$ to formulate this group or to define a common purpose and approach. Rather, following the lead of the City's recently adopted General Plan, the BCP expands the platform upon which future development can occur, and provides a complete vision for urban expansion in the area near UC Merced. This information can then be used to comprehensively plan for the future rollout of public infrastructure and services in a manner that achieves the best interest of the community.

\section{THE REG ULATORY ENVIRONMENT}

The regulatory environment includes the policies, laws, standards and procedures used by various government entities to comply with state or local directives. These can limit where, when and the form of development. For example, LAFCO regulations would not allow the City to incorporate land next to UC Merced if in a form separate or disjoined from the rest of the City; though demand for housing and services could be best served in this manner. Thus, instead of a small annexation, LAFCO rules in this case could lead to annexation of a large swath of properties in order for housing and commercial services to locate next to the campus. 
However, as it applies to development near UC Merced, large portions of lands have been included in either a SUDP or SOI, laying the foundation for future near-term development options. Regulations regarding formation of service districts, city limits, and ability to install infrastructure will help define the project-readiness of various areas near UC Merced. For example, tapping into the City's wastewater treatment plant which is planned to operate at 20 million gallons per day would be easier than attempting to receive State of California permits for a new wastewater treatment plant.

Annexation is a precursor to urban expansion. If the City agrees to annex a property, it is agreeing to provide City services (i.e. sewer, water, police, fire, garbage, etc.). The City and the County have a "master property tax exchange agreement" in place that may constrain annexation because under the agreement the County retains its share of property taxes following annexation. Under these circumstances it is more challenging for the City to fund needed municipal services to the annexed area. It is likely that some revision of this agreement will be necessary before substantial annexations within the SUDP/SOI will occur.

\section{COORDINATED DEVELOPMENT}

The preparation of long-range planning documents, such as the Merced Vision 2030 General Plan, the UC Merced Long Range Development Plan, the University Community Plan (UCP), and the Bellevue Community Plan (BCP) are important first steps in establishing a shared vision for the future. These, and other development plans, help set the foundation upon which infrastructure, service and phasing plans will be developed. This section broadly describes the numerous planning and development efforts underway near UC Merced, setting the stage for a discussion of recommended next steps at the end of this chapter.

A detailed description of development plans and projects occurring within and near the Bellevue Community Plan area is provided in Technical Memorandum B (Appendix B) of the BCP. The "Development Plans and Projects" document identifies and describes recent and anticipated growth patterns. Figure 4 shows approved and planned developments in the northwest growth area of the City of Merced.

\section{UC MERCED}

The form in which the campus grows has and will continue to affect adjacent development and public infrastructure and service needs. For example, in 2013, the Long Range Development Plan concept was adjusted based on recommendations from the Urban Land Institute (ULI), resulting in a smaller and contracted development site, increased land use densities, and shifting of non-academic uses (such as offices) to off-site locations. The ULI Report strongly recommended strengthened partnerships with the City of Merced, stating that the fates of UC Merced and the City of Merced are inextricably linked. ${ }^{16}$
The preparation of long-range planning doc uments, such as the Merced Vision 2030 General Plan, the UC Merced Long Range Development Plan, the University Community Plan (UCP), and the Bellevue Community Plan (BCP) are important first steps in establishing a shared vision for the future. 


\section{CITY UMITS}

Lands within the City Limits have completed the annexation process, and are developed, used for agriculture purposes, vacant or partially constructed and occupied. These lands are generally ready to develop as they are usually immediately adjacent to development, city services and infrastructure, and require relatively few permits. Lands to the south and west of the Bellevue Community Plan are within the City Limits.

Many public comments received at the BCP public workshops pointed out the unfinished nature of the Bellevue Ranch Development and their support to complete that development prior to opening new lands for development. Lands within, adjacent to, and near the Bellevue Community Plan (BCP) planning area are in various stages of development entitlements such as formation of Specific Urban Development Plans and subdivisions. Narrative descriptions, maps, and tables presented in Appendix B depict current and future land uses.

The Merced Vision 2030 General Plan also includes many policies that encourage a compact urban form and logical growth, and to avoid leapfrog development. At the same time, it encourages sites to be ready for industrial development and to extend services to sites proposed for significant employment-related uses.

\section{FRINGE DEVELOPMENT}

Fringe development occurs outside a City but within its Sphere of Influence (SOI) or Specific Urban Development Plan (SUDP). Counties possess zoning jurisdiction over this unincorporated territory. However, the State legislature recognized (in passing $A B$ 2838) that as the future service provider of such unincorporated lands in the City's SOI, the City should have an opportunity to address how land in the SOI is planned for and developed in anticipation of future annexations. In the BCP planning area, these mechanism for input on SOI development can be described in the context of Rural Residential Centers and the City-County Tax Sharing Agreement.

Rural Residential Centers (RRC's) contain concentrations of suburban housing on a minimum of one-acre lots without commercial services. RRC's typically lack municipal sewer, water, and emergency services; curbs, gutters, and sidewalks; street-lights; and fire hydrants. There are five RRC's in Merced County; one is located adjacent to the City of Merced, with a portion located within the eastern half of the BCP.

\section{Challenges of Rural Residential Centers}

Although RRC's provide a unique semi-rural character that is prized by residents, governance challenges with Rural Residential Centers include: 1) extremely inefficient land use in terms of agricultural land conversion and service delivery costs to the County; 2) potential for ground water contamination from the concentration of septic tanks on one-acre lots; and 3) the increasing difficulty in obtaining potable drinking water from individual wells due to stricter state-wide standards. The County General Plan recognizes that the challenges with the increasing number of RRCs, stating no new RRCs 
are needed and expansion of RRC boundaries should be strictly scrutinized by reviewing the development alternative options in established urban centers. For example, draft policy LU-10.7 in the Draft 2030 Merced County General Plan states, "Evaluate, during the update of the county's community plans, the alternative of redesignating undeveloped rural-residential areas to the Urban Reserve designation to support the effort of the affected city to achieve more efficient use of land within its existing sphere of influence."

Some of the RRC's within or adjacent to the BCP are already developed and subdivided into one- to two-acre lots which makes redevelopment or redesignation of these properties unlikely. The City's General Plan supports the maintenance of existing RRC's, but no new ones. However, in the area along the Bellevue Road corridor the City's Land Use Diagram indicates this area as Mixed-Use. The presence of major water and sewer lines; large vacant parcels; and the potential to develop job-generating uses in proximity to UC Merced support higher intensity uses along the Bellevue Corridor, in lieu of the neighboring RRC designation.

\section{SOI PROJ ECTS}

In addition to the above growth areas, several large planned communities are being staged for future development within the City's SUDP/SOI, and include the Yosemite Lake Estates, the University Community Plan (UCP), and the Bellevue Community Plan (BCP).

\section{Examples of a Rural} Residential Centers
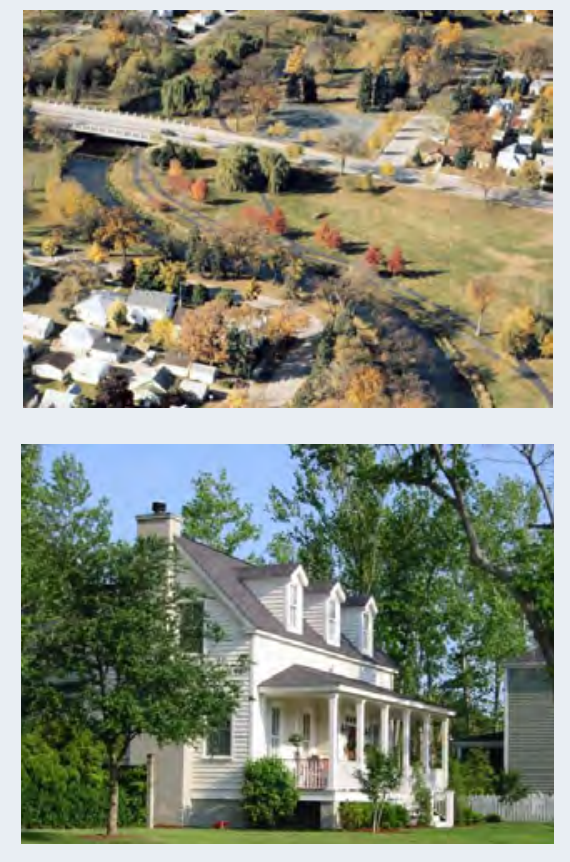


\section{Figure 47. Bellevue Community Plan Project Index}

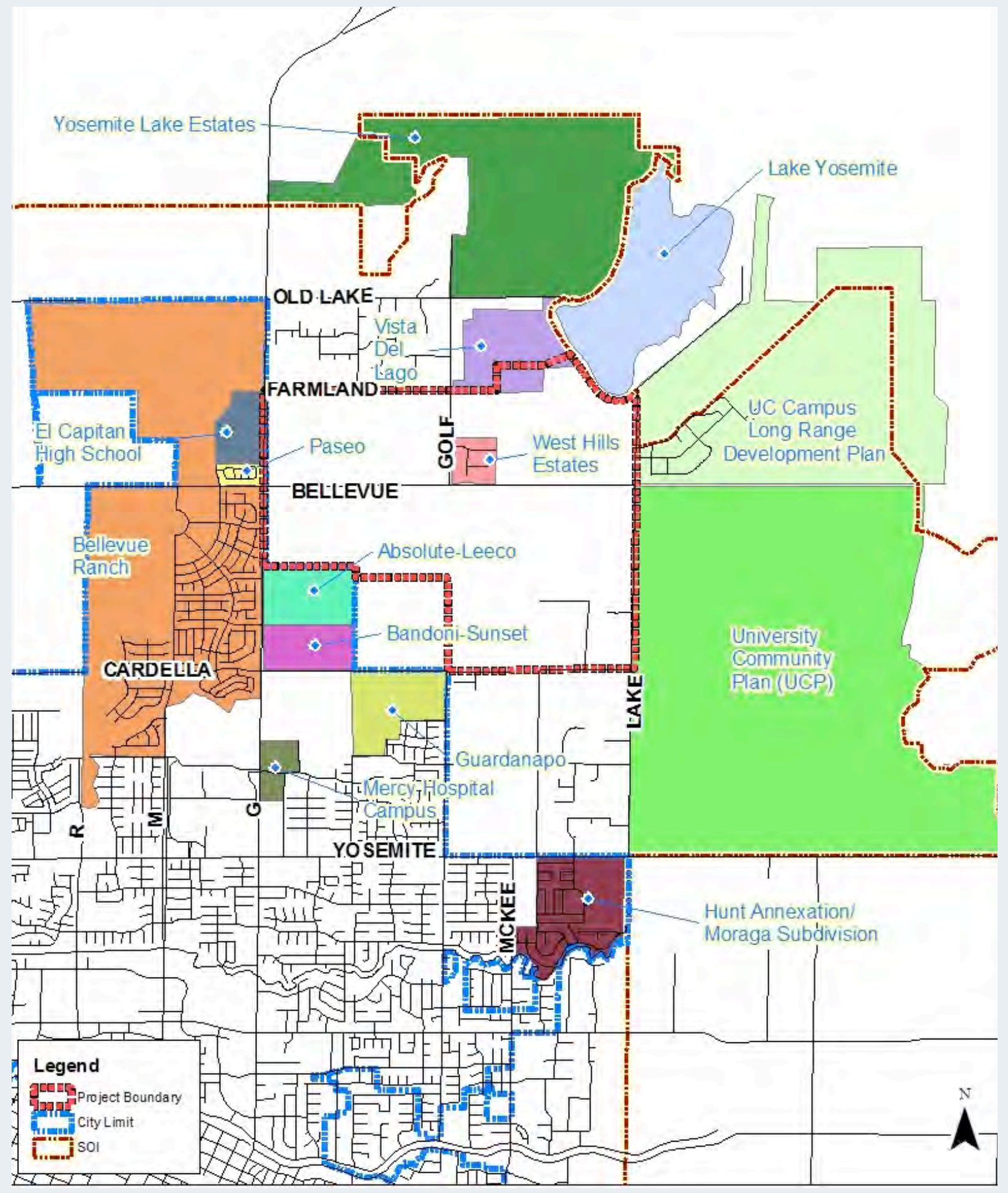




\section{COMMUNITY PLAN GROWTH SCENARIOS}

The Bellevue Community Plan (BCP) describes the endpoint of a development vision. The scenarios of how this vision may be constructed over time in the plan area are varied, however. Growth could occur adjacent to the University of California at Merced, in multiple locations adjacent to the City of Merced, as programmed growth within a large annexed area, or any combination of the above. As with the City's General Plan, it is not the place of the BCP to determine which growth scenario will be implemented. Rather, this section of the $\mathrm{BCP}$ describes various urban expansion options, their likely infrastructure roll-out outcomes, and identifies supportive factors of future annexation proposals.

\section{ORDERLY DEVELOPMENT- OVERVIEW}

The Cortese-Knox-Hertzberg Local Government Reorganization Act of 2000 (CKH) encourages collaboration among LAFCO's, cities, counties, landowners, and other local agencies to balance the timing and location of development within Spheres of Influence (SOI). This is consistent with the legislative intent of the $\mathrm{CKH}$ to promote:

- Orderly development;

- Discourage urban sprawl;

- Preserve open space and prime agricultural lands;

- Provide housing for persons and families of all incomes; and

- Encourage the efficient extension of governmental services. ${ }^{4}$

Though with varying degrees, all growth scenarios presented herein are aimed to be consistent with the intent of the CKH.

\section{SCENARIO 1: GROWTH WTHIN THE CITY}

For two key reasons, vacant lands within the City are more likely to be developed than lands outside the City. 1) These vacant lands have already been through the annexation process, and 2) are either immediately adjacent to public services or contain some, many or all of the required public services and infrastructure. Provided the markets created by UC Merced and the general market in Merced are not particular as to location, these sites will develop first. These sites will absorb market pressures and reduce growth pressure outside the City Limits.

\section{SCENARIO 2: GROWTH CONTIG UOUS TO THE CITY}

This option describes the business-as-usual model of urban expansion whereby development occurs immediately adjacent to the City of Merced, expanding the City generally from the southwest to the northeast within the City's SUDP/SOI. There are several variations of this scenario ranging from development directly from the west or south of UC Merced. Since it includes a relatively large area, the availability of public services and infrastructure will be a limiting factor. Unless there is a deliberate effort to focus public 
infrastructure and services in a specific geographic area, connecting the urban fabric to UC Merced will take many years and potentially result in a hodge-podge development pattern. Development could be frustrated by limiting availability of financial resources that are used for improvements in a haphazard uncoordinated fashion.

\section{SCENARIO 3: DIRECTED GROWTH}

This scenario is based on selection of a preferred growth area within which development is more certain to benefit from a coordinated deployment of public services and infrastructure. A geographic area would need to be selected before any annexations occur in the northeast region of the City's SOI, and to minimize the creation of peninsular form. Absent these actions, this scenario would be very unlikely to occur.

\section{SCENARIO 4: NODAL DEVELOPMENTADJ ACENTTO UC MERCED}

This scenario places private development immediately adjacent to UC Merced. Phasing within both approaches described below would be geared to: 1) prevent the premature conversion of agricultural land; 2) assure efficient and cost effective extension of services; 3 ) work with the ability of the City to provide infrastructure and municipal services; and 4) designate certain areas for development relative to other phases. Complementing the flexible nature of the $\mathrm{BCP}^{\prime}$ s land use element, this urban expansion model also provides for the greatest degree of responsiveness to the market.

Though the later approach has significant challenges, the nodal growth scenario could happen through two approaches, specifically by:

- $\quad$ Programmed or phased growth within a large annexation area extending between the City of Merced to and including UC Merced. This approach involves the annexation of a large land area between UC Merced and the City of Merced. Submitted with the annexation would be master utility and service plans that define the circumstances under which the various phases would be developed, emphasizing growth next to UC Merced. This approach could be limited by the need for a large block of land owners to agree to the annexation.

- Ability to develop adjacent to the UC Merced campus without a contiguous annexation with the City. Though unlikely, this could occur in two ways: 1) if the State of California were to allow an exemption to LAFCO policies and allow annexation immediately adjacent to UCM as a separate and second growth node in the City's SOI; or 2) through some form of extraterritorial service agreement between the City and County. 


\section{PUBLIC FACILITIES FINANCING AND NEXT STEPS}

A common vision and approach to urban expansion creates certainty, and certainty attracts investments, and investments create jobs. Yet, as evidenced in the growth scenarios above, along with concerns raised by the BCP Ad-hoc Advisory Committee, there is an unstable investment climate. A collaborative effort to create a multi-jurisdictional infrastructure and service plan could sort through these challenges and result in decisions that direct growth in a manner that serves the interest of the community as a whole in a fiscally sound manner.

\section{CHAUENGES}

During the preparation of the BCP that involved input from area property owners and representatives of UC Merced, Merced County and the Virginia Smith Trust, there was a strong concern expressed about the need to 1) coordinate development; 2) advance fiscally sound plans; and 3) to plan for the adequate provision of public services and infrastructure. While each planning area in northeast Merced strives for such goals, implementing them is challenged due to conflicting growth policies or interpretations thereof; support for competing plan areas; and a "wait-and-see" approach to public infrastructure and services. These do not create an atmosphere of certainty, but instead creates an unstable investment climate.

\section{INFRASTRUCTURE}

- What is the ratio of use between future developments and UC Merced of the remaining capacity in existing sewer collection facilities? For example, is new development favored, or should a large share of it be reserved for the growth of the campus?

- What is the ratio of road fund expenditure between Bellevue Road and Campus Parkway? For example, should the City's expend its funds to improve Bellevue Road, or Campus Parkway? If the later, then should it be spent on constructing the northern section to serve nearby developments including UC Merced?

\section{FINANCING}

- $\quad$ Are new financing mechanisms needed to address growth?

- Absent an updated tax-sharing agreement, will growth be limited to lands within the existing City Limits?

- What is the total cost to serve the planned growth in Merced's northeast growth area?

\section{PHASING:}

- How much growth is directed to lands within the current City Limits versus new annexations?

- Where should initial annexation efforts be supported?

- Is growth next to UC Merced, whether in the County or City or not, considered "compact," and if so, what is the best method to enable growth next to UC Merced? 


\section{COORDINATED DEVEOPMENT}

Key to coordinated development is the formation of a collaborative effort to create a multi-jurisdictional infrastructure and service plan to sort through these challenges. Such discussion and decisions would involve the University of California, the City of Merced, Merced County, as well as the Merced Irrigation District, local schools and the Merced County Association of Governments. The UC Merced Long Range Development Plan (LRDP), the University Community Plan (UCP), and the Bellevue Community Plan $(\mathrm{BCP})$, among other plans, provide the necessary information and options from which a unified development phasing plan could be crafted. Figure 54 illustrates the relationship between the BCP and surrounding plans.

\section{NEXTSTEPS}

The City of Merced, Merced County and UC Merced, and other affected agencies, should form a collaborative working group to establish a shared vision for growth in Merced's northeast SOI, and addressing unresolved infrastructure, financing and phasing issues. Three outcomes from this effort should be:

1. Select a growth scenario, or combination thereof;

2. Develop a strategic phasing plan and plan for services that coordinate expenditure of resources, provides certainty in the marketplace; and leads to an efficient use of public infrastructure and services.

3. Update the City's Tax-Sharing Agreement to align with the broad decisions concerning financing, infrastructure and phasing in the northeast Merced SOI. 


\section{BELLEVUE COMMUNITY PLAN GOALS AND POLICIES}

The goal headings of this BCP chapter are grouped into the same policy topics as the Merced Vision 2030 General Plan. This approach fosters consistency and builds on the City's broader General Plan guidance. In furtherance of consistency with the City's General Plan, Appendix C, policies specific to the BCP planning area are described in greater detail and grouped with the goals and policies it shares in common with the City's General Plan. In additions to the goals and policies below, Master Plans/projects/permit applications need to take into account the $\mathrm{BCP}$ in its entirety and be consistent with the language herein.

Table 11 Urban Expansion Goals and Policies Specific to the Bellevue Corridor Community Plan consistent with the City's General Plan Regarding Urban Expansion

\section{Goal Area UE-1: A Compact Urban Form/ Effic ient Urban Expansion}

Policy UE-1.1: : In cooperation with Merced County, seek to designate undeveloped parcels within the RRC as "Urban Reserve," a Merced County General Plan Land Use Designation.

Policy UE-1.3: Promote high residential densities along the Mandeville Transit Coridor within the Bellevue Community Plan.

The population near UC Merced will consist of a higher percentage of students, teachers, and employees than in other part of Merced. This population will need opportunities for a range of housing opportunities ranging from apartments, condominiums, rooming homes, among others.

\section{Goal Area UE-2: J oint Planning Efforts}

\section{Policy UE-2.1: Seek to form a collaborative approach to planning and implementing future growth near UC} Merced.

A broad discussion of how best to utilize limited financial resources, to devise an intra-government infrastructure plan for roads and sewer, etc ., and to decide govemance issues should occur prior to development within or near the BCP. These efforts would be aimed to result in decisions that direct growth in a manner that serves the interest of the community as a whole. Such discussion an decisions would involve the University of Califomia, the C ity of Merced and Merced County, as well as the Merced Imigation District, local sc hools and the Merced County Association of Govemments.

Policy UE-2.2: In conjunction with the collaborative approach above, assess annexation options, and where appropriate, consistent with these efforts, encourage annexation of lands between the City and UC Merced.

Annexation of lands between UC Merced and the City need to be consistent with a community-based strategic approach to infrastructure improvement and property development in order to avoid: 1) an uncoordinated dispersal of infrastructure; 2) uncertainty in the marketplace; and 3) inefficient use of public infrastructure, servic es and funds.

\section{Goal Area UE-3: Timing, Density and Location of New G rowth}

Policy UE-3.1: Development of Research and Development Parks that are not contiguous to existing urban areas may be considered.

Implementation Action UE-1.3a of the Merced Vision 2030 G eneral Plan emphasizes that new urban development and annexations be contiguous to existing urban areas and have reasonable access to public services and facilities. Given that the City also seeks to provide significant job-based land uses, flexibility on the proximity of these land uses may be permitted. Important considerations include: reasonable provision and access to public services and facilities; extent of new jobscompared to community needs; impact costs of servic es and infrastructure and sources to compensate and mitigate. 
Policy UE-3.2: In the context of Implementing Action UE-1.3.a, growth adjacent to or in close proximity to UC Merced is considered one that is contiguous to an existing urban area.

The siting of UC Merced has created a second growth node within the City's Sphere of Influence. The City's model to form a compact urban form can be applied to a community with more than one center. Development adjacent to UC Merced, concurrent with growth adjacent to the City's traditional form, should be considered.

Policy UE-3.3: Support efforts that permit campus serving housing, office and commercial development adjacent to UC Merced.

Under circumstances that a re compatible with logical provision of C ity public infrastructure and services, development adjacent to UC Merced could be supported. The development should be related to proven market demands that originate predominately from UC Merced, and may include housing, office and commercial development.

Policy UE-3.4: Annexation proposals in the BCP shall be accompanied by a phasing plan.

In order to assure efficient and cost-effective extension of services, a phasing plan that matches infrastructure needs with a ntic ipated development will need to be submitted with applications to a nnex lands within the Bellevue Community Plan area. The Phasing Plan will need to be consistent with City mecha nisms and tools to finance and install public infrastructure and services. 
This page intentionally left blank. 


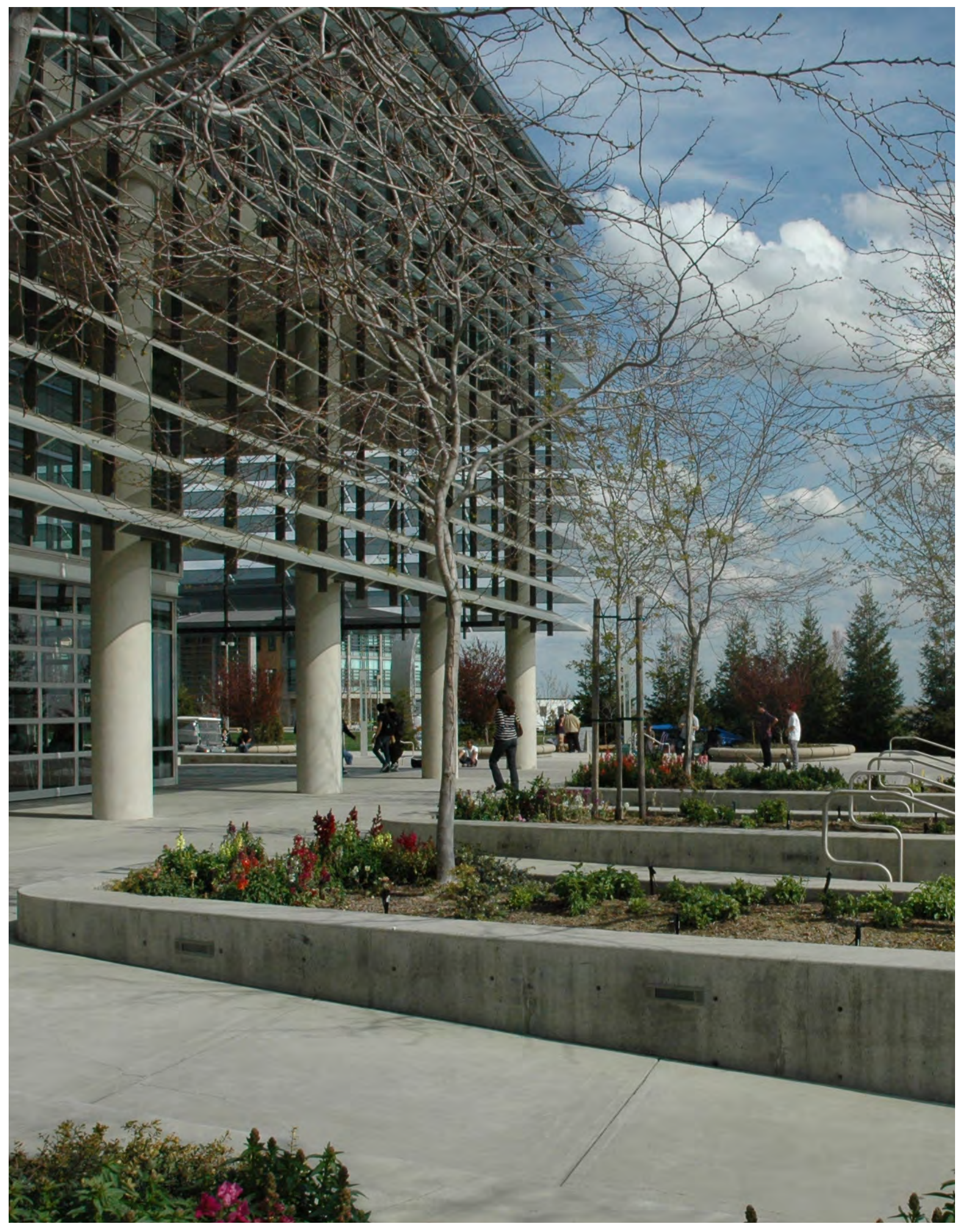




\section{PUBLC SERVIC ES AND FAC ILTIES}

The City's Municipal Service Review (MSR), approved by LAFCO on May 23, 2013, provides information about public services for future applications and LAFCO actions. The MSR addresses fire and police emergency services, stormdrainage, wastewater and water in the context of several determinations: population growth; disadvantaged unincorporated communities; infrastructure capacity, needs and deficiencies; financial ability of agencies to provide services; shared facility opportunities; and accountability.

This Chapter addresses the availability of public infrastructure and services, the challenges of providing these, and the steps necessary to overcome these challenges. For example, there is a need to: 1) craft infrastructure Master Plans (sewer, water and storm drainage) that address the needs of development areas within the City's Sphere of Influence; and 2) coordinate efforts concerning short-term and long-term infrastructure needs, expenditures, and improvements to the roadways which serve the northeast area of the SOI, namely Bellevue Road, Mandeville Avenue and Campus Parkway. Where appropriate, these actions should consider new approaches to design, operations, and financing. These efforts will also create the tools needed to select and implement infrastructure phasing plans, which in turn provide certainty and direction for development to proceed in a manner that serves the interests of the community. 


\section{Currently, there are no fixed} services suc $h$ as fire stations or fire-hydrants operated and maintained by the City in the BCP planning area. Through a mutual-aid agreement with Merced County, the City may provide limited senices to the planning area until such time as it is annexed to the City, however.

\section{Merced Fire Station 55}

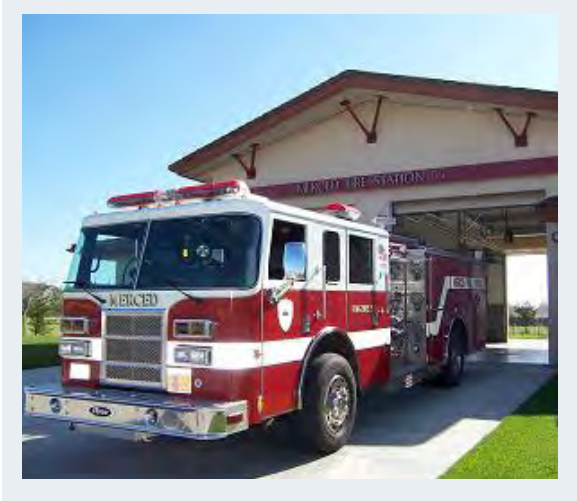

Image courtesy of City of Merced

\section{SEITING AND ISSUES}

\section{FRE AND POUCE PROTECTION}

\section{FIRE PROTEC TION}

Currently, there are no fixed services, such as fire stations or fire-hydrants, operated and maintained by the City in the BCP planning area. However, through a mutual-aid agreement with Merced County, the City may provide limited services to the planning area until such time as it is annexed to the City. Various fire coverage and protection strategies will be needed to provide adequate service levels for urbanization of the BCP area. Strategies include station service, site access, piped water, and mitigating building and site designs (see Figure 5.1 of the City's General Plan). While the General Plan does not specifically include a fire station in the BCP planning area, the General Plan anticipates needing up to four additional fire stations in the City's SOI by the year 2030, with three of the four proposed sites near the BCP area. As with other infrastructure improvements, the location and timing of the construction of the City's next fire station can strongly influence the location of future development.

Development will need to meet the City's fire protection standards; including, but not limited to, street width and connectivity, building siting and construction, and water pressure.

\section{POUCE PROTECTION}

Similar to the City's Fire Department, the Merced Police Department provides limited service to the BCP area until such time as it is annexed to the City. Additional officers, equipment, and facilities will need to be added to the City's Police Protection System in order to serve substantial growth in the $\mathrm{BCP}$ area. However, due to the mobile nature of the police force, construction of a new station may not be essential. (Note: Consistent with the City's General Plan, the BCP does not include a proposed police station site; but at the same time, the $\mathrm{BCP}$ does not preclude the placement of a station in the planning area.)

\section{WATER}

The City of Merced pumps, treats, and delivers potable water exclusively from the Merced Groundwater Basin. Water is pumped at 17 active well sites and routed through approximately 500 miles of pipe. In 2009, the City supplied 20.8 million gallons per day to approximately 86,000 users. This equates to about one well site per 5,000 users. With a population of approximately 17,00 or more residents planned in the $\mathrm{BCP}$, additional well sites would be needed at a rate of about one well per square-mile. A water line currently runs underneath $\mathrm{G}$ Street and Bellevue Road, and terminates at an active well site serving UC Merced.

\section{GROUNDWATER REC HARG E}

Long-term hydrographs in the Merced sub-basin show that most groundwater levels are declining. Beginning in 2010, the sub-basin entered into a state of emergency due to overdrafting. Using the growth rate of the City's 2010 
Urban Water Management Plan, total water use in Merced will increase by 188 percent by 2030. To stop the decline of groundwater resources, groundwater recharge programs by the Merced Irrigation District are necessary.

TheBCPsupports severalopportunitiesforgroundwater recharge, encouraging surface water flows along existing natural drainages and irrigation laterals; a multi-use distributed storm-water system; and development of multiuse storm drainage basins.

While recharge is the primary tool to ensure an adequate water supply, the City seeks to attain a twenty percent reduction in water use per capita by 2020. Since 1979, likely due to the City's conservation efforts, per capita water demand has steadily decreased despite the continued increase in total demand. Future reductions can be achieved by implementing reclaimed water projects, which take many forms. Private distributed reclaimed water systems should be encouraged provided that water quality issues can be adequately addressed. These systems may involve the collection of rainwater, the use of gray-water, or other similar reclaimed technologies. Secondly, large portions of the BCP Park and Open Space network is planned to be located adjacent to Merced Irrigation District surface waters, that can be used for landscape irrigation, thereby reserving clean groundwater for potable uses. Finally, innovative uses of storm water could supplement groundwater sources.

\section{WASIEWATER COUECTION AND DISPOSAL}

Wastewater, generated from a combination of residential, commercial, and industrial sources within the City and Phase I of the UC Merced campus is conveyed to the City's waste water treatment plant. The waste water treatment plant has a current design capacity to treat an average annual flow of 12 million gallons per day (mgd). The City has environmental clearance to treat $20 \mathrm{mgd}$; additional improvements to the waste water treatment plant are needed for this to occur, however.

A capacity of $20 \mathrm{mgd}$ would be able to serve a population of approximately 174,000, which is more than 12 percent higher than the 2030 projected population within the 2030 Specific Urban Development Plan (SUDP) and SOI of 155,000 (which includes UC Merced and the University Community).

Wastewater generated within Merced is collected by a series of pipelines that are owned, operated, and maintained by the City. The City's pipelines include over 400 miles of gravity sewers ranging in size from 6 to 48 inches in diameter. A 48-inch sewer trunk line collects waste from areas north of Bear Creek and conveys it to the wastewater treatment plant. The update to the City's Sewer Master Plan will need to examine alternative locations for installation of an additional sewer trunk line to serve the expanded SUDP to the northeast of the City.

In addition, Rural Residential land uses in the northern and southern portions of the BCP currently rely on septic systems that could either fail or become illegal due to the State of California concern with groundwater contamination. The update to the City's Sewer Master Plan should include a strategy that accommodates development in the Rural Residential areas of the City's SOI (including those in the BCP planning area) while providing opportunities to minimize ground-water contamination.

\section{While recharge is the primary \\ tool to ensure an adequate \\ water supply, the City seeks to}

attain a $\mathbf{2 0 \%}$ reduction in water

use per capita by 2020. Part of

this reduction can be achieved

by implementing reclaimed

water projects, whic $h$ take

many forms.
Rural Residential land uses

in the northem and southem

portions of the BCP c urrenty

rely of septic systems that

could fail or be required to be

phased-out by the State due

to concems of groundwater

contamination. 
The BCP planning area

is generally free of large

flood prone areas bec ause

it contains: 1) several low

hilltops, 2) the headwaters of

small drainages; and 3) no

creeks or nivers.

\section{EXTRA-TERRITORIAL SERVIC E TO UC MERCED}

Through an extra-territorial service agreement with the City of Merced, Phase I of the UC Merced campus was granted use of the City's wastewater collection and treatment infrastructure. In 2004, sewer collection line was installed in G Street and Bellevue Road connecting Phase I of the campus with a 48-inch sewer trunk line in the City. The 27-inch line extends through lands presently within the City's SOI and SUDP. At least one other major sewer line will be needed in northeast Merced to serve development within the City's SOI/SUDP.

An assessment of capacity constrictions downstream of the G Street/Bellevue Road sewer line will need to be performed to determine the presence of other growth constraints. It will also be important to coordinate wastewater planning activities with UC Merced and Merced County, such as including the land use plans for UC Merced, the University Community Plan, and BCP and other development plans within the City's Sphere of Influence, in any updates to the City's Sewer Master Plan.

\section{STORM WATER DRAINAGE AND ROOD CONTROL}

The topography in the BCP planning area sheds storm-water in three areas. The primary drainage area is located southwest of Lake Yosemite and aligns proximate to the Tower Lateral. The second drainage area is generally bounded by Bellevue Road, G Street, Mandeville Avenue (future), and Gardner Road (future). Portions of the Sells Lateral approximate the ephemeral watercourses in this small drainage area. Water from these two drainages flow in a westerly direction. The third drainage is roughly bounded by the Sells Lateral to the north and west and by the Yosemite Lateral to the east. Water from this drainage flows south out of the BCP. A natural drainage swale has formed in this area (See Figure 49).

The $\mathrm{BCP}$ proposes that master planning for storm water drainage be done in coordination with other community goals, such as the desire to: 1) develop groundwater recharge; 2) protect sensitive species and their habitats; and 3) create attractive public spaces along transportation and recreation corridors.

The BCP planning area is generally free of large flood prone areas because it contains: 1) several low hilltops, 2) the headwaters of small drainages; and 3) no creeks or rivers. The 100-year floodplain waters from Fahrens Creek occur in the BCP planning area between G Street, Farmland Avenue, the Lower Golf Lateral, and the Tower Lateral. While there are no regulatory floodways, the flood inundation area of Lake Yosemite cover a portion of the far north and far west portions of the BCP planning area. The inundation areas of Lake Yosemite and Bear Creek covers most of Merced north of Highway 99 (see Figure 11.3 of the Merced Vision 2030 General Plan). Earthen dams could fail due to the erosion of the breach if over-topped. Flood waters would build gradually to a peak and then decline. Finally, the natural drainage area located west of the Yosemite Lateral is unregulated (see Figure 48). The BCP proposes that this area be a natural open space corridor linking to area schools and parks and fitted with recreational pedestrian and bicycle trails. 
Figure 48. Image of Lake Yosemite and Area Stom Water Runoff

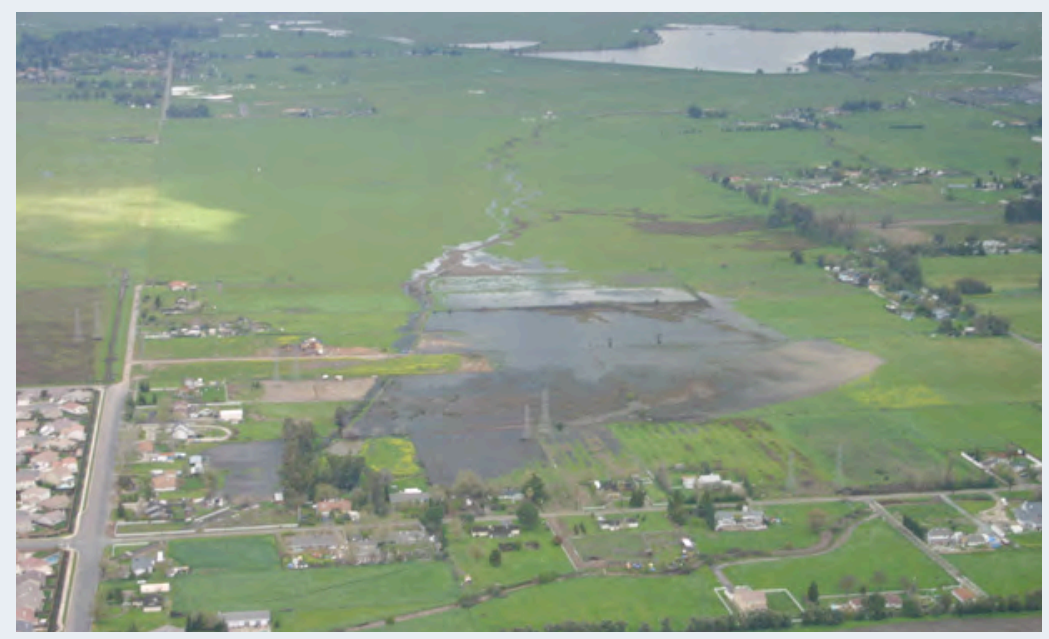

Image is looking north with Dunn Road in the foreground and

Parsons Avenue on the left; Lake Yosemite appears at the upper right comer of the image.

\section{MERCED IRRIGATION DISTRICTIRRIGATION LATERALS}

Several Merced Irrigation District (MID) laterals trace through the BCP conveying Merced River surface water in the spring and summer (May to October) to agricultural fields both inside and outside of the BCP planning area. To the east of the BCP planning area is Yosemite Lake Regional Park and UC Merced including the campus' canal-based open space features, the Lake Road bike-path, and future bikeways within and around UC Merced. The BCP planning area is void of any notable creeks that can connect Merced to these features. The MID laterals in the BCP provide a unique opportunity to link these features and address a range of community needs including groundwater recharge, storm-water management, and recreational open space corridors. A collaborative effort between the City, Merced County, and MID should be initiated to create a long-term multiple-use strategy for the future use of MID laterals in the BCP.

\section{STREET DESIGN}

The BCP encourages a multiple use approach to storm-water management by examining the value and feasibility of using a variety of multi-purpose storm-water capture strategies to minimize the extent of the traditional curband-gutter system. Instead of following the current practice of capturing and transporting water immediately into basins, a multi-use distributed system that captures and slows the flow of water can offer multiple benefits to the City and residents. The capture and use of rainwater on private properties, the siting of street planters, curb extensions, and green strips in medians can implement several City objectives including the ability to:

- Provide cost-effective peak flood reduction;

- Filter pollutants;

- Provide a source of groundwater recharge;

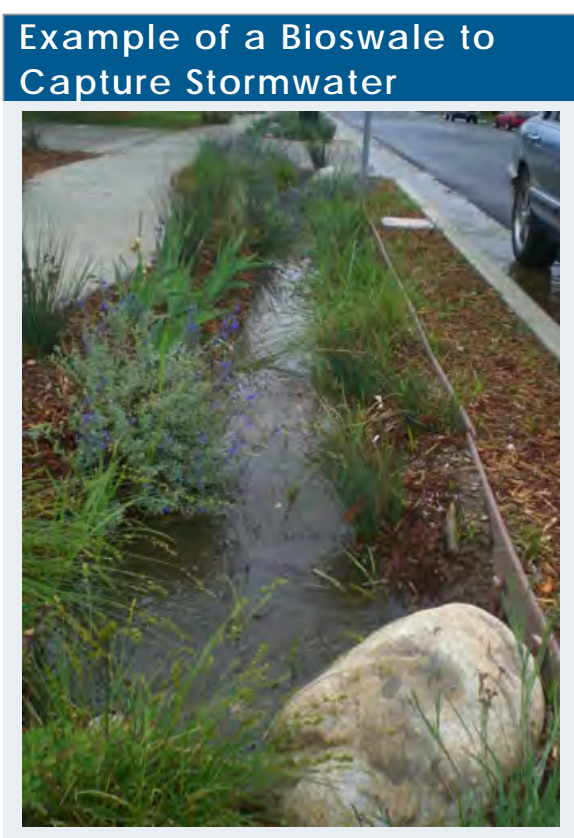




\section{Figure 49. Site Topography and Water Features within and Nearthe Plan Area}

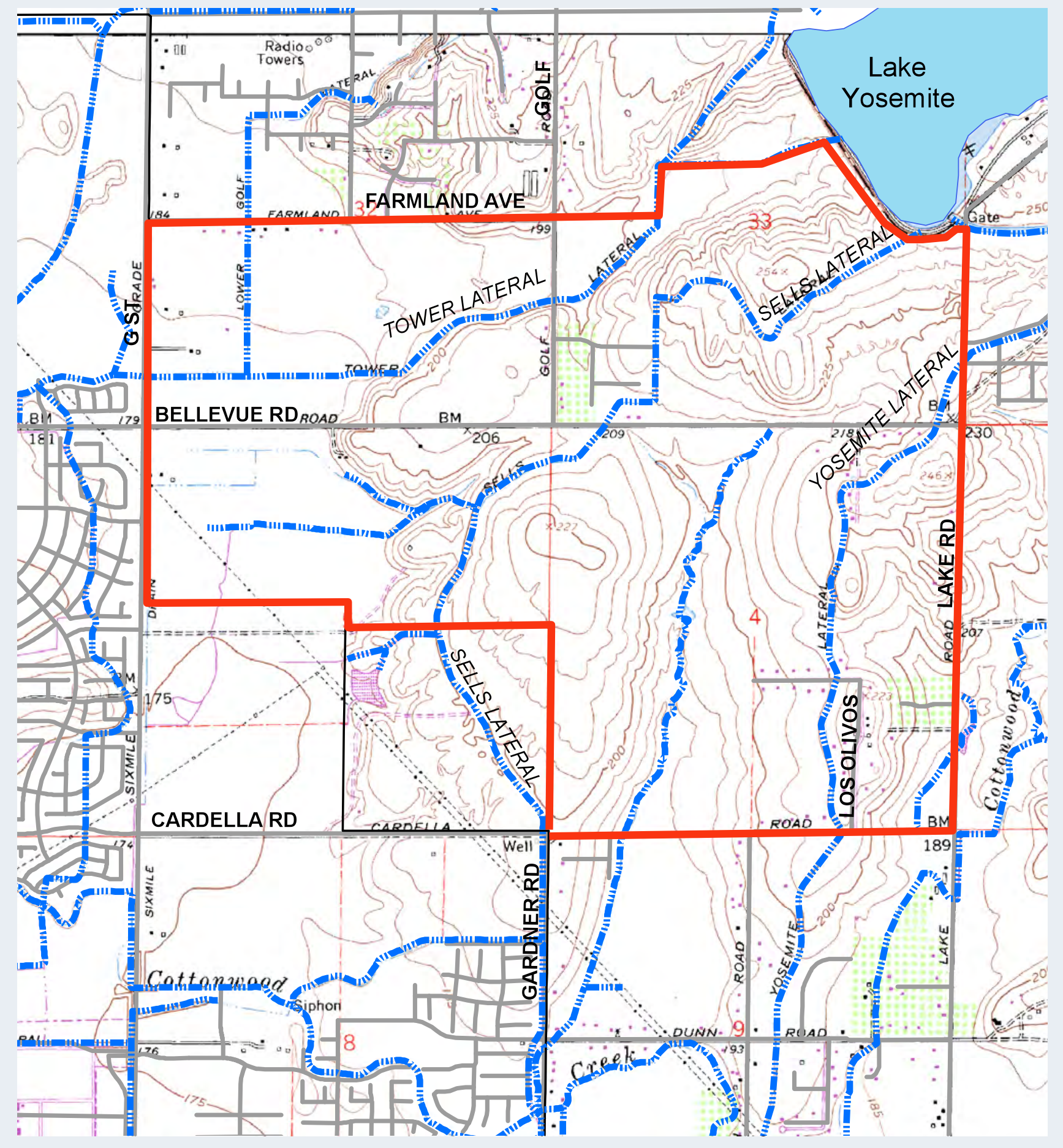


- Improve pedestrian safety;

- Beautify neighborhoods;

- Help to alleviate the urban "heat-island" effect; and

- Conserve the City's potable water source.

The strategy to capture storm-water before entering a regional collection and storage system can reduce infrastructure costs of the regional system.

\section{STORM DRAINAGE SYSTEM}

The City's Storm-water Master Plan will need to be updated to cover the City's expanded SUDP. The plan will need to assure that storm-water flow from and through the BCP is addressed on a regional scale, taking into consideration the important opportunities and constraints of the Lake Yosemite Reservoir. The plan will need to identify conveyance channels and stormwater basins, whether inside or outside the BCP, in anticipation of future flood waters and need to divert water from urbanized areas, including UC Merced. As part of this assessment, the plan should include methods to create a multi-use distributed storm water management system with co-beneficial features (in lieu of the simple curb and gutter system).

\section{SOUD WASTE}

The City of Merced provides services for all refuse pick-up within the City limits, including green waste and recycling. The City implements recycling efforts and public education programs to minimize the waste stream. Additionally, the City requires that adequate solid waste collection is provided for commercial, industrial, and residential uses in accordance with state law. In 2007, the University of California adopted a Policy on Sustainable Practices, which sets waste diversion goals of 75 percent by June 2012 and zero waste by 2020. This presents an opportunity for the City of Merced to collaborate with UC Merced to identify and implement new programs to reduce the wastestream in the City. Collected wastes are disposed of at the State Route 59 Landfill located several miles to the northwest outside the planning area.

\section{SCHOOLS}

Several long-range planning efforts in the City's Sphere of Influence (see Appendix B), including this $\mathrm{BCP}$, have set the stage for the Merced Union High School District and the Merced City School District to begin the process of updating school-siting plans. City Staff and representatives from these school districts estimated the need for 3 primary and possibly 1 secondary public school sites to be located in the BCP. Consistent with the approach of the City's General Plan, these "floating school sites" represent the general location of future schools needed in the BCP and are anticipated to be 1013 acre joint-use school and neighborhood park sites with 8-10 acres for the school (see Figure 38 on page 91).

During future annexation reviews, City Staff will work with property owners and school districts to more definitively site potential schools in appropriate areas. Due to their singular-use and non-residential or commercial nature, these school sites should be located outside the Mandeville transit-corridor
Roating school sites are loc ated near future high population areas, share planned active recreational facilities managed by the City, and will be connected to neighborhood bikeways and sidewalks.

El Capitan High School Near the BCP Area

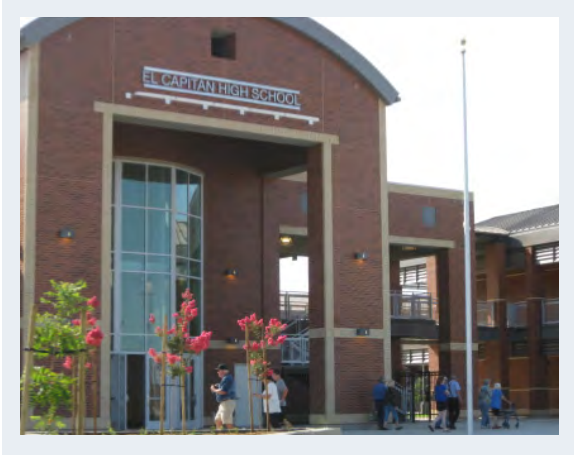


and the Mixed-Use Transit-Oriented Development place-types. The floating school sites are located near future high population areas, share planned active recreational facilities managed by the City, and will be connected to neighborhood bikeways and sidewalks.

\section{GOVERNMENT, HEALTH, UBRARY, AND C ULTURAL FACIUTES}

While the population of the BCP will need to be served by government, health, library, and cultural facilities, the Plan does not identify a need for a significant concentration of these uses as occurs in other areas of the City. For example, Downtown Merced will continue to be the center of government, library, and cultural facilities, and Mercy Medical Center has expansion plans at its current location. Nevertheless, satellite uses to serve the local population could occur in the BCP. For example, the City should allow public and government offices and service centers in the Mixed-Use TOD character area to enhance, support, or complement uses that may occur in UC Merced's campus "Gateway District" area. The City will need to balance the allowance of these uses without negatively affecting downtown Merced as the center of multi-cultural and performing arts programs and facilities, and public and government facilities in the City (e.g., County and City government centers, civic center, post office, department of motor vehicles, federal and state offices, etc.). 


\section{PUBLIC FACILITIES FINANCING}

Public Facilities Financing is a key ingredient to realization of land use plans. Public facilities need to be aligned with the community's ability to construct and operate them.

Capital facilities and services are financed from various sources:

- $\quad$ The City's General Fund;

- Grants from State and federal governments;

- Developer Infrastructure Improvements;

- $\quad$ Sewer and Water Funds / accumulated from user fees;

- Public Facilities Impact Fees / determined by the City's Public Facilities Financing Plan. By State law, these fees can only be spent on capital facilities and cannot be used for operations or maintenance:

- $\quad$ Regional Transportation Impact Fee to pay for regional transportation improvement; and,

- $\quad$ Community Facilities District (CFD) - Services. The Services CFD imposes an annual assessment on new homes and businesses to pay for their impacts on City services, including police and fire protection, parks maintenance, storm drainage, street trees, street lights, etc

\section{CITY OF MERC ED PUBUC FACIUTIES FINANCING PLAN}

In 2012, the City of Merced adopted a comprehensive update to its Public Facilities Financing Plan (PFF) for public improvements that will be required through 2030 (the 2012 PFFP does not include sewer, water, flooding/ drainage, public works, and airport projects). The PFFP identifies resources to ensure that adequate public facilities will be available to meet the projected needs of the City as it grows, and to further ensure that the facilities planned are consistent with the City's General Plan. The Merced Vision 2030 General Plan serves as the basis for the PFFP. The consistency of the BCP with the City's General Plan ensures that adequate public facilities will be available in the plan area.

\section{MASTER UTIUTY PLANS}

The BCP does not include improvement standards for sewer, water, and storm-drainage utilities. The $\mathrm{BCP}$, along with other long-range planning efforts within the City's Sphere of Influence, identify desired arrangement and density of land uses that can be used to determine the design needs of these utility improvements. To ensure that infrastructure will be adequately sized to serve proposed development within the $\mathrm{BCP}$, as with other lands within the City's Sphere of Influence, further studies are needed. Infrastructure Master Plans for sewer, water, and storm-drainage are needed to describe the system needed to serve the land use plans, and should be conducted in a collaborative manner with UC Merced, the Merced Irrigation District, and Merced County. Along with such determination, it is important to reassess the adequacy of
The BCP, along with other long-range planning efforts within the City's Sphere of Influence, identify desired arrangement and density of land uses that c an be used to determine the design needs of these utility improvements. 
funding sources for such improvements, and to make necessary adjustments to funding sources or to amend the long-range planning documents to align with funding resources for these utilities. This describes a continuous iterative process that occurs between planning and engineering.

\section{Relevant Financing Tools from the Infrastructure Financing Options for Transit-Oriented Development Report Provided by the US Environmental Protec tion Agency, J a nuary 2013}

Direct fees: Charges paid by the users of the infrastructure.

1. User fees and transportation utility fees

2. Congestion Pricing

Debt tools: Mechanisms for borrowing money to finance infrastructure.

1. Industrial loa companies and ind ustrial banks

2. General obligation bonds

3. Revenue bonds

4. Private activity bonds

5. Certificates of participation and lease revenue

bonds

6. Revolving loan funds

7. State infrastructure banks

8. Grant antic ipation revenue vehic le bonds

9. Railroad Rehabilitation and Improvement

Fina ncing

Credit assistance: Mechanisms that improve the creditworthiness of the bonower issuing a bond or requesting a loan and thus provide access to better bonowing terms.

1. C redit a ssistance tools

2. Transportation Infra structure Fina nce and Innovation Act

Equity sources: Tools that allow private entities to invest (i.e., take an ownership stake) in infrastructure in expectation of a retum.

1. Public-private partnerships

\section{Infrastructure investment funds}

Value capture mechanisms: Tools that capture the increased value or savings resulting from the public provision of new infrastructure.

1. Developerfees and exactions

2. Special districts

3. Tax increment financing

4. J oint development

Grants: Funds that do not need to be paid back.

1. Congestion Mitigation and Air Quality

Improvement Program

2. Transp orta tion Altema tives Program

3. Urbanized Area Formula Funding Program

4. Community Development Blo ck Grant Program

5. Economic Development Administration grants

6. Foundation grants

7. Program-related investments

Emerging tools: New concepts for making TOD-related infrastructure possible. Most of the tools in this category do not fit neatly into any of the other categories.

1. Structured funds

2. Land banks

3. Redfields to greenfields

4. National infrastructure bank 


\section{BELLEVUE COMMUNITY PLAN GOALS AND POLICIES}

The BCP goal headings below are the same as those listed in the Merced Vision 2030 General Plan. This approach fosters consistency with the City's General Plan. Policies specific to the BCP are listed beneath each goal. In furtherance of consistency with the City's General Plan, Appendix C is arranged such that BCP policies are "nested" within the broader goals, policies and implementation actions of the Merced Vision 2030 General Plan. In additions to the goals and policies below, Master Plans/projects/permit applications need to take into account the BCP in its entirety and be consistent with the language herein.

Table 12 Public Services and Facilities Goals and Policies Specific to the Bellevue Corridor Community Plan consistent with the City's General Plan

\section{Goal Area P-1: Public Facilities and Services}

Policy P-1.1: Ensure that utilities are adequately sized to serve proposed development within the BCP and other lands within the City's Sphere of Influence.

The BCP does not include improvement standards for utilities. It along with other long-range planning efforts within the City's Sphere of Influence identify desired arrangement and density of land uses, which can be used to determine improvement needs. Infrastructure Master Plansfor sewer, water, stom-dra inage a re needed to describe the system needed to serve the land use plans. Along with such detemination, it is important to identify feasible funding for such improvements, and to make necessary adjustments to the long-range planning documents to align with fiscal constraints or opportunities. The study should include the urban expansion area in northeast Merced, and be developed collaboratively with UCM and Merced County.

Policy P-1.2: Development within the BCP should be based on "Plans for Senvice", which will be prepared at the time of annexation of the project site.

As part of the dec ision-making process, "Plansfor Service" will be prepared and considered by the City and Merced County LAFCO to assure that infrastruc ture development and public facilitiesand munic ipal servic es are consistent with overall local public agency plans. These public agency plans include Master Infrastructure Plans that need to be prepared using the BCP and otherlong-range land use plans asa basis for assessment and provision of service.

\section{Goal Area P-2: Police and Fire Protection}

Policy P-2.1: Ensure adequate service levels for police and fire protection in order to service substantial growth in the BCParea.

Consistent with the City's General Plan, the BCP does not include a proposed police of fire station site; but at the same time, the BCP does not preclude the placement of a station in the planning area.

\section{Goal Area P-3: Water}

Policy P-3.1: Examine the value and feasibility of using a variety of multi-purpose stom-water capture features compared with the traditional c urb-and-gutter system.

In lieu of current practice of capturing and transporting water immediately into basins, a multi-use distributed system of features can offer multiple benefits to the City and residents. Along with encouraging the capture and use of rainwater on private properties, the siting of street planters, curb extensions, and green strips in the medians can provide cost-effective peak flood reduction, filter pollutants, be a source of groundwater recharge, improve pedestrian safety, beautify neighborhoods, help alleviate the urban "heat-island" effect, and conserve the City's potable water source. This altemate system could blend well with the rural character of the plan's residential neighborhoods. 
Policy P-3.2: Initiate a program to imigate public parks with MID surface water supplies.

Large portions of the BCP park and open space network is planned to be located adjacent to MID surface waters, that can be used for landscape imigation, thereby reserving clean groundwaterfor potable uses.

Policy P-3.3: Coordinate with the Merced Inigation District (MID) to design and operate laterals as sites for recharge, stom-water management and recreational open space corridors while protecting its primary function as conveyance of water to agric ultural pursuits.

SeveraI MID laterals trace through the BCP conveying Merced River surface water in the spring and summer (May to October) to agricultural fields both inside and out of the BCP planning area. To the east of the BCP planning area is UCM including its canal-based open space features, the Lake Road bike-path, future bikeways within and around UC Merced, and Yosemite Lake Regional Park. The planning a rea is void of any notable creek that can connect Merced to these features. The MID latera Is in the BCP provide a unique opportunity to link these features and addressa range of community needs including groundwater recharge, stom-water mana gement and recreational open space coridors. A collaborative effort between the City, Merced County and MID should be initiated to create a long-tem multiple-use strategy for the future use of the MID laterals.

\section{Goal Area P-4: Wastewater}

Policy P-4.1: Coordinate wastewater planning activities with UCM and Merced County.

Include the Bellevue Community Plan, the University Community Plan and UCM's Long-Range Development Plan, as well as other development plans within the City's Sphere of Influence in any update to the City's wastewa ter planning activities. Such studies should include an assessment of potential strategies to minimize groundwater contamination from septic tank systems in Rural Residential areas.

Policy P-4.2: Encourage innovative distributed reclaimed water improvements for buildings.

Priva te on-site systems should be encouraged provided that water quality issuescan be adequately addressed. These systems may involve the collection of rainwater, the use of gray-water, or other similar recla imed technologies. For example, build ings can incorporate wastewater reuse systems, encouraging onsite water recycling for cooling systems and landscaping needs.

\section{Goal Area P-5: Storm Drainage and Flood Control}

\section{Policy P-5.1: Craft a Stom-water Master Plan that emphasizes multiple use objec tives of the community.}

Assure that storm-water flow from and through the BCP is addressed on a regional scale, taking into consideration the important opportunities and constraints of the Lake Yosemite Reservoir. The plan will need to identify conveyance channels and stormwater basins, whether inside or outside the BC $\mathrm{P}$, in a nticipation of future flood waters and need to divert water from urbanized areas, including UC Merced. As part of this assessment, the plan should include methods to create a multi-use distributed system of features (in lieu of the simple curb and gutter system). Such features can include the capture and use of rainwater on private properties, the siting of street planters, curb extensions, and green strips in street medians. These features can provide cost-effective peak-flood reduction, filter pollutants, be a source of groundwater recharge, improve pedestrian safety, beautify neighborhoods, help alleviate the urban "heat-island" effect, and conserve the City's potable water source.

Policy P-5.2: Examine the value and feasibility of using a variety of multi-purpose stom-water capture features compared with the traditional c urb-and-gutter system.

In lieu of current practice of capturing and transporting water immediately into basins, a multi-use distributed system of features can offer multiple benefits to the City and residents. Along with encouraging the capture and use of ra inwater on private properties, the siting of street planters, curb extensions, and green strips in the medians can provide cost-effective peak flood reduction, filter pollutants, be a source of groundwater recharge, improve pedestrian safety, beautify neighborhoods, help alleviate the urban "heat-island" effect, and conserve the City's potable water source. This altemate system could blend well with the rural character of the plan's residential neighborhoods. 


\section{Goal Area P-6: Solid Waste}

\section{Policy P-6.1: Collaborate with UC Merced to implement new recycling, composting, and source reduction} programs.

In 2007, the University of Ca lifo mia a dopted a Polic y on Susta inable Practices, whic h sets wa ste diversion goals of 75 percent by J une 2012 and zero waste by 2020. This presents an opportunity for the C ity of Merced to collaborate with UC Merced to identify and implement new programs to reduce the waste-stream in the City.

\section{Goal Area P-7: Schools}

Policy P-7.1: During the annexation process of any of any portion of the BCP, work with property owners and the school district to more definitively site potential schools in appropriate areas.

Due to their singular use and non-residential or employment nature, school sites should not be located within one-qua rter mile of Mandeville Avenue, or within the Mixed-Use Transit-Oriented Development placetype. Outside these areas, schools should be located nearhigh population areas, share active recreational facilities; and be well connected to bikewaysand sidewalks.

Schools that are designed with limited outdoor open space, dense populations and a small footprint may be appropriate within transit-oriented development place-types, especially the mixed-use flex place-type. While these may take the form of private technical schools, the BCP would not preclude a public school with such design.

\section{Goal Area P-8: Govemment, Health, Library, Cultural Facilities}

Policy P-8.1: Encourage senior centers, satellite libraries, adult education, recreation and/or other public facilities to locate near each other in neighborhood centers.

Policy P-8.2: Allow public and government offices and service centers in the Mixed-Use TOD place-type to enhance and support a community-related use within UCM's “Gateway" area.

Policy P-8.3: Encourage child care centers to locate near schools and high-employment areas. 


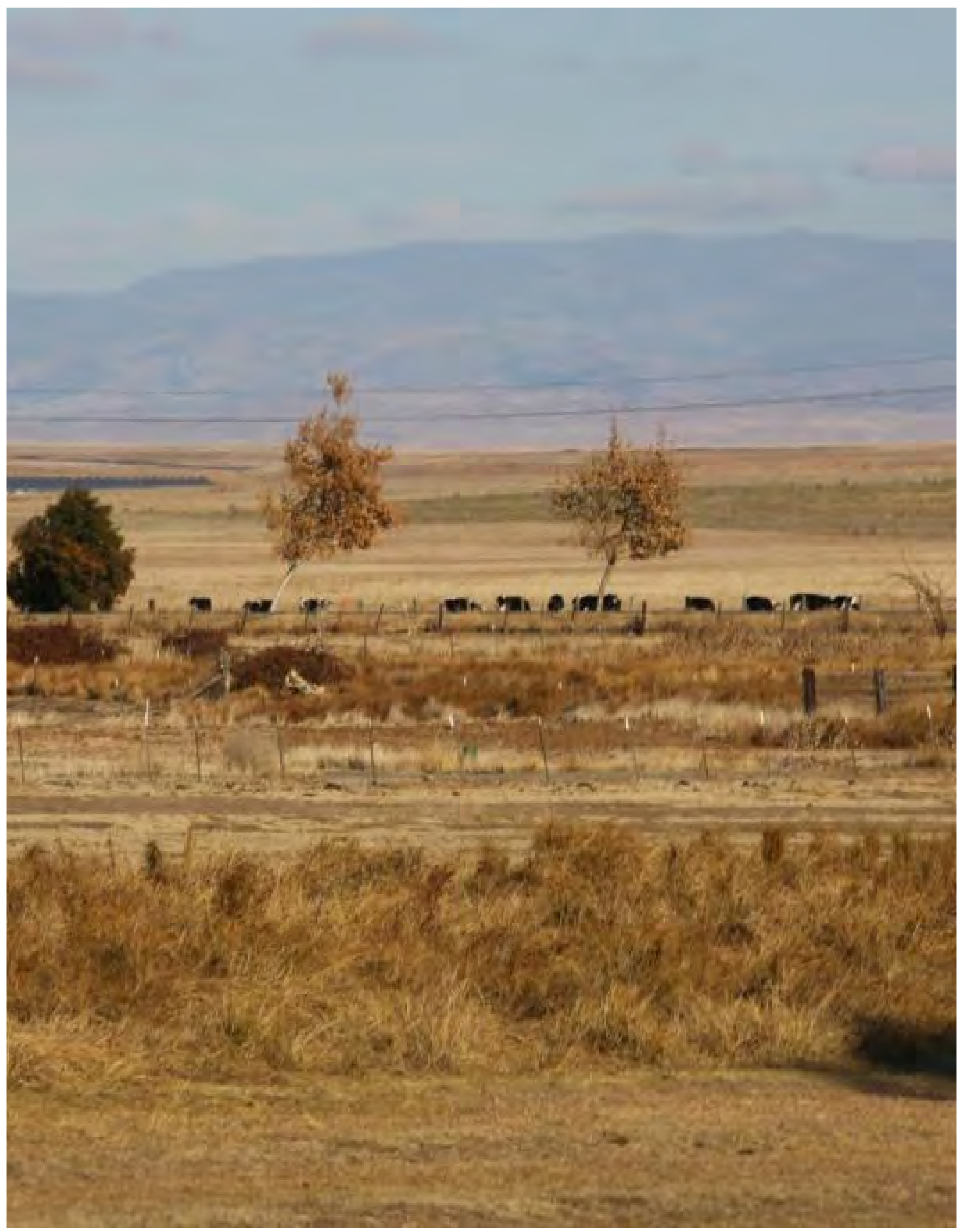




\section{PLAN MAINTENANCE}

The Bellevue Community Plan (BCP) includes a Plan Maintenance Program to insure that it remains an active and relevant document, assuring an ongoing effort to implement, monitor and assess the utility of Plan. It's the follow-through component of the planning process, and involves five key characteristics (Figure 50):

\section{Figure 50. Plan Maintenance Key Characteristics}

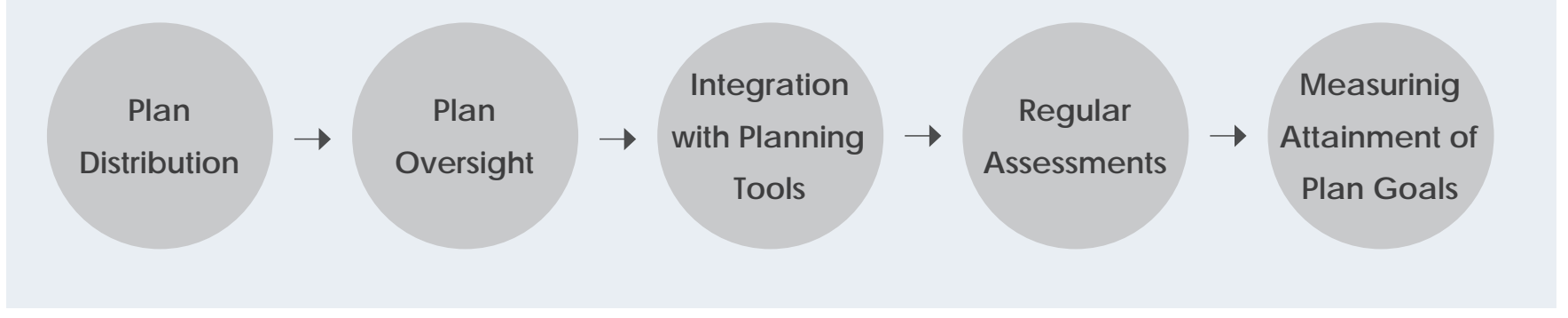

\section{PLAN DISTRIBUIION AND OVERSIGHT}

After adoption of the BCP, the City Planning Division assumes two key roles: (1) to distribute the plan to City Departments, partner agencies involved in Plan Maintenance activities; and to the general public; and (2) to provide Plan Maintenance oversight. This later step includes keeping the BCP at the forefront of community decision making by prioritizing and tracking plan recommendations and ensuring that other City plans and programs reflect the vision and goals of the BCP (see also Plan Integration below).

Continued involvement by affected individuals and groups is imperative for the success of the BCP. Copies of the Plan will be provided to Merced County, the University of California at Merced, and other local jurisdictions. A public review copy of the BCP will be available at the City Planning Division and local libraries. The BCP will also be posted on the City's Planning Division website. The availability of the $\mathrm{BCP}$ will be publicized in the City newsletter which reaches every utility customer in the City, and will be made known to the City's development community by the City Planning Department. 
The Bellevue Conidor

\section{Community Plan integrates}

existing planning-related

doc uments and processes

inc luding, but not limited to the

following:

- Merced Vision 2030 General

Plan

- City of Merced 2013 Bic ycle Transportation Plan

- 2003 Parks and Recreation Master Plan

- Capital Improvement Plans

- Public Utility Master Plan

- Transit Plans

\section{INTEGRATION}

Upon adoption of the BCP by the Merced City Council, the Planning Division will begin the process to integrate it with existing planning-related documents and processes, including but not limited to the following:

- $\quad$ Merced Vision 2030 General Plan

- City of Merced 2013 Bicycle Transportation Plan

- 2003 Parks and Recreation Master Plan

- Capital Improvement Planning

- Public Utility Master Plans

- Transit Planning Documents

\section{PLAN ASSESSMENT}

Planning is an ongoing process and as such, the Bellevue Community Plan should be treated as a living document that will grow and adapt to keep pace with changes. Some changes that could affect the BCP include:

- New General Plan policies, or interpretations of existing ones

- Changes to nearby area plans, for example the University Community Plan or the UCM Long Range Development Plan;

- Influences of various State of California and/or Federal actions;

- Changes in foundational BCP assumptions and/or findings of the BCP Background Report.

The Planning Department will monitor and assess how changes may affect the $\mathrm{BCP}$. When a corresponding change to the $\mathrm{BCP}$ is warranted, the City will follow General Plan Amendment process.

Plan assessment also includes continued public and stakeholder involvement and input through public meetings, web postings, and press releases to local media.

\section{MEASURING PROGRESSTO IMPLEMENTTHE GOALS OF THE PLAN}

As a guiding document, the BCP will be used by the community as a tool to attain long-range urban growth-related goals. Whether or not the community actually attains these goals, however, won't be revealed for several decades. Near-term development of the plan area presents opportunities to measure the direction and pace the community is making toward its stated goals, and with this knowledge, adjustments may be made so that long-term goals are more likely to be reached. This process generally includes the identification of a starting point (baseline), an end-point (goals and objectives), and measurable aspects of development (indicators) that reflect attainment of goals and objectives. Technical Memorandum M (Appendix M) assembles these components into a tool that the City will use to assess the progress to implement the BCP. 
This page intentionally left blank. 


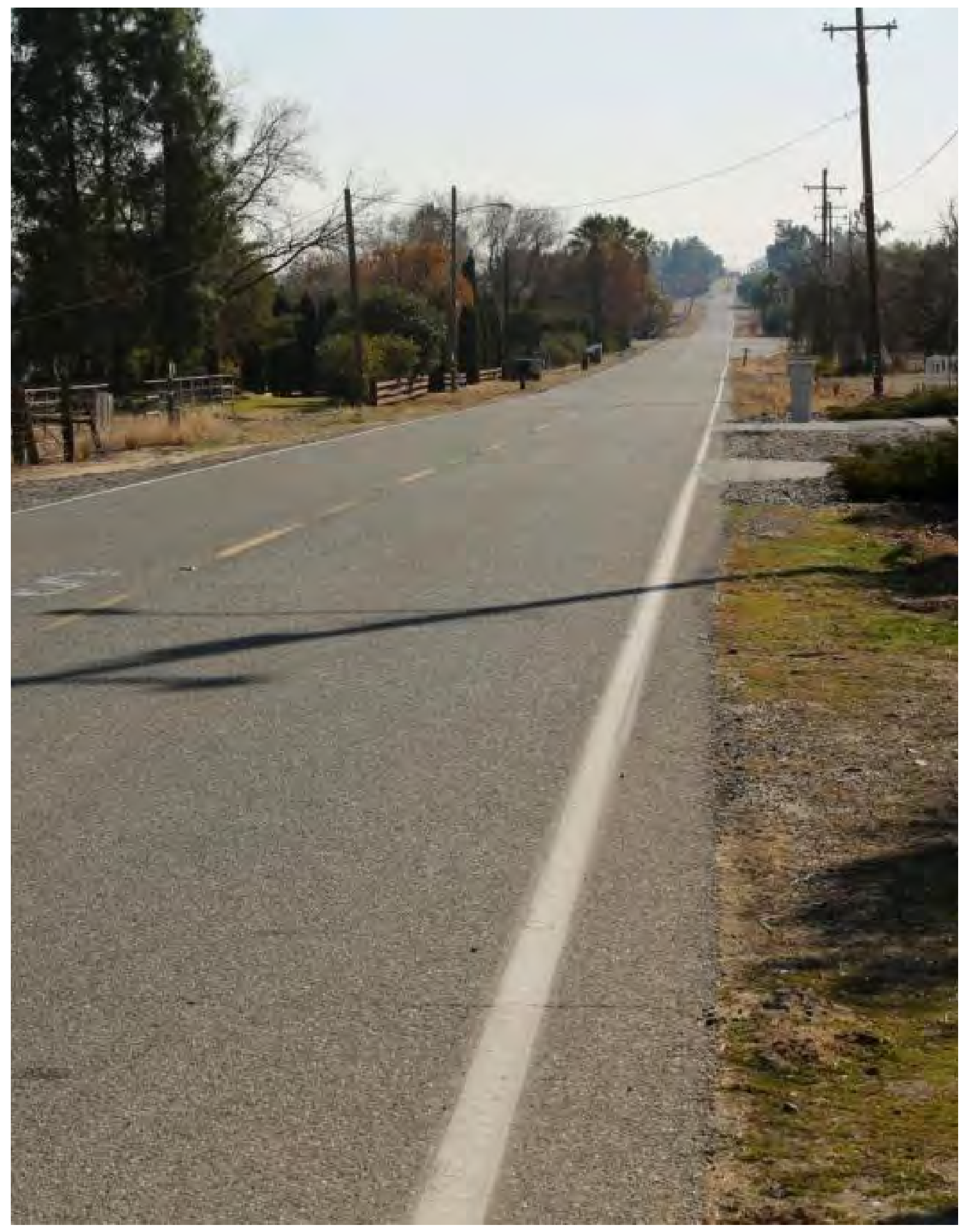




\section{WORKS C ITED}

1. California Planning Guide: An Introduction to Planning in California, December 2005.

2. A Planner's Guide to Specific Plans, January 2001.

3. A Planners Guide to Specific Plans, April 1998.

4. California Department of Finance, California Added more than a quarter million in 2011; Total Sate Population Nearly 37.7 million. May 1, 2012. Population Estimate for January 1, 2012.

5. Merced Vision 2030 General Plan, Implementation Action 3.6.a, page 3-62, and Section 3.7.2 "Proposed Community Plans," page 3-68.

6. Merced Vision 2030 General Plan, Section 3.7.3 “University Community Plan," page 3-70.

7. Merced Vision 2030 General Plan, Section 3.7.4 "Bellevue Corridor Community Plan," page 3-71.

8. Merced Vision 2030 General Plan, Section 3.10.1 “Conceptual Land Use Plans for Proposed Community Plans," beginning on page 3-86.

9. 2004 Merced Park and Open-space Master Plan.

10. Merced Vision 2030 General Plan.

11. Merced Vision 2030 General Plan.

12. Draft 2030 Merced County General Plan, November 30, 2012.

13. City of Merced Municipal Service Review (April 2013).

14. LAFCOs' General Plans, and City Annexations. Governor's Office of Planning and Research. February 7, 2012

15. Merced County Year 2000 General Plan. Adopted by Board of Supervisors on 12-4-1990.

16. Urban Land Institute Advisory Panel Report, Fall 2012.

17. City of Merced 2013 Bicycle Transportation Plan

18. UC Merced Tomorrow, Long Range Development Plan, UC Merced 2009

19. UC Merced, Long Range Development Plan, UC Merced 2013 
This page intentionally left blank. 


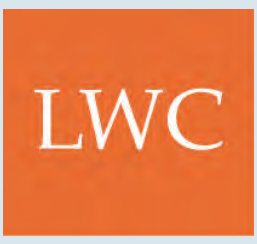


Appendix II. City of Merced Staff Report 


\section{Novus AGENDA}

Agenda Item: $\underline{\mathrm{I} .3}$

Meeting Date: $\underline{7 / 16 / 2012}$

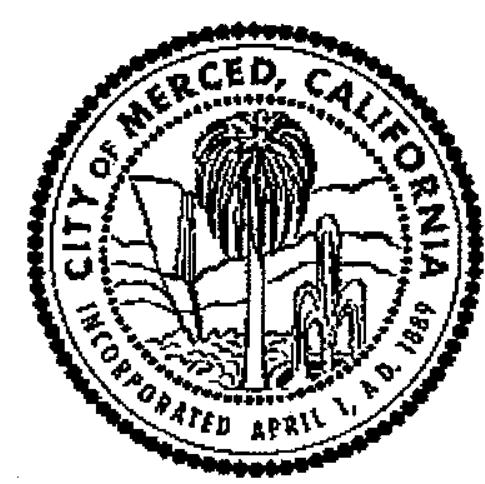

ADMINISTRATIVE REPORT

TO:

FROM:

DATE:

SUBJECT:
City Manager

Bill King, Principal Planner

$06 / 26 / 2012$

Appointments - Bellevue Corridor Community Plan Ad-Hoc Advisory Committee

\section{REPORT IN BRIEF}

Accept nominations and appoint individuals to the temporary committee for the Bellevue Corridor

Community Plan.

\section{RECOMMENDATION:}

City Council - Adopt a motion accepting nominations and appointing individuals to the Bellevue Corridor Community Plan Ad-Hoc Advisory Committee.

\section{ALTERNATIVES:}

1. Accept nominations, and appoint individuals to serve as members of the Bellevue Corridor Community Plan Ad-Hoc Citizen's Advisory Committee; or,

2. Refer to staff for further recruitment of applicants; or,

3. Continue to a future meeting (date and time to be specified in the motion).

\section{AUTHORITY:}

Charter of the City of Merced, Sections 700 and 702.

\section{History and Past Actions:}

On June 7, 2010, the City Council adopted Resolution No. 2010-43, approving the application for grant funds from the Sustainable Communities Planning Grant and Incentives Program to cover costs to prepare the Bellevue Corridor Community Plan. A grant award was made in January 2011 and a contract with the State became effective in August 2011. In February 2012, the City Council approved the professional firm of Lisa Wise Consulting. Inc. (LWC) to assist staff in crafting the 
plan and to provide a recommendation to the City of Merced Planning Commission, who then makes a recommendation to the City Council. In February 2012, City Council direction was given to staff to form a citizen's advisory committee for this project.The recently adopted Merced Vision 2030 General Plan specifies the need for the Bellevue Corridor Community Plan, and provides guiding language for development of the plan. Preparation of the community plan is the next step in the process leading to eventual development of the area. Plan adoption is anticipated to occur by fall 2013. Depending on market conditions, subsequent land use entitlements such as annexation, subdivision, etc., will need to occur prior to development of the area.

The planning area is generally located between "G" Street (City limits) and Lake Road (UC Merced's western border), and generally $1 / 2$ to 1 mile on either side of the Bellevue Road corridor. With exception of a few pockets of rural residential homes, the planning area is a combination of rangeland, grassland and row crops (Attachment 1).

\section{Description:}

\section{Key Topics of the Bellevue Corridor Community Plan}

The Bellevue Corridor Community Plan (BCCP) encompasses an area of 2.42 square-miles , and will establish a land-use map, a mobility plan, and tackle questions such as: 1) the location and amounts of student housing, research and development parks; and 2) the design of Bellevue Road. The mobility plan will assure that all forms of transportation are provided for in the planning area. Based on public outreach events held to date, emerging topics include: 1) infrastructure and development phasing with regard to the UC Merced and University Community and the BCCP area;2) competition with existing commercial sites, for example, downtown Merced; 3) location and amount of research and development lands; and, 4) location and type of future transit service.

\section{Project Partners and Stakeholders}

The planning work will continue the efforts accomplished to date with area stakeholders, which include UC Merced, the Merced County Association of Governments (MCAG), Merced County, property owners, and development interests. Other groups that support and will participate in the planning effort include: the Merced/Mariposa County Asthma Coalition, Merced Bicycle Coalition, and the Merced County Department of Public Health, all of whom provided letters of support for the grant application.

City Staff has also arranged an opportunity for UC Merced students to contribute to the Plan through UC Merced's Community Engaged Scholarship (CES) program. Their topic of research is aimed at describing potential university spin-off growth, and attracting entrepreneurs through site design and other methods.

\section{Recruitment for Citizen's Advisory Committee}

Following public outreach events in May and June 2012, a Notice of Vacancy was posted on June 6, 2012, in accordance with Section 54.970, et seq., of the Government Code, for recruitment of a Citizen's Advisory Committee for the Bellevue Corridor Community Plan. The notice indicated that committee meetings will be held at least once every two months beginning August 2012 through April 2014, and that the meetings would occur in the daytime, last approximately 3 hours each, and be located at the City of Merced Civic Center. On June 20, 2012, Staff presented an overview of the Bellevue Corridor Community Planning effort to the City of Merced Planning Commission, and requested the Commission select a member to sit on the Citizen's Advisory Committee for this project. Planning Commissioner Mary Ward was selected. Staff also presented an overview of the Plan to the Economic Development Advisory Committee on June 26, 2012, and Jeff Pennington was selected as their representative. 


\section{$\underline{\text { Roles and Duties }}$}

In its advisory capacity to City Staff, the Committee will hold public meetings and make recommendations to Staff on specific issues concerning the Bellevue Corridor Community Plan, which will be a comprehensive effort to address the following objectives:

- Size and Location of Research and Development Parks and/or Business Parks

- Street Design and Mobility Options (auto, transit, pedestrian, bicycles)

- Building Design and Development Codes

- Open Space and Recreation

- Project Phasing and Infrastructure

The Committee shall be purely advisory and for purposes of the Political Reform Act (California Government Code Section 81000 et seq.):

1. Shall not have the authority to make a final decision on any issue on behalf of the City;

2. Shall not have exclusive authority to initiate or veto a decision on behalf of the City in order to compel or prevent a decision on behalf of the City;

3. Shall have its recommendations carefully reviewed by City staff and/or the City Council and amended or modified as deemed appropriate; and,

4. Shall not have the authority to make recommendations directly to City Council.

In general, the activities of the Committee will be guided by the City's Handbook for City Advisory Bodies (to be distributed by the City Clerk's Office during their swearing in process), which discusses such items as election of a chairperson, meeting schedules, the Committee's relationship with City Staff, and conflict of interest considerations.

\section{Application Information}

The City Clerk's Office has 19 applications on file plus a representative from the Planning Commission, Mary Ward, and a representative from Economic Development Advisory Committee, Jeff Pennington. A list of the applicants, together with their respective applications (Attachment 3) and relevant background information, has been attached.

\section{Selection of Committee Members}

The membership of a Committee needs to reflect a fair representation of different interests and skills that will be used to accomplish the Committee's role. In addition, due to the high public and private interest level in this project, Staff recommends that a broad representation of stakeholders be appointed to the Committee. Please note that some members of the Committee may have direct economic interests in the project area. In order to balance these varying interests, Staff recommends representation from these three groups:

I. Residents and/or property owners within or near the plan area;

2. Citizens who have previously served on City Commissions or Committees; and,

3. Advocates who represent community organizations (non-profit, non-government, etc.) with an interest in the project.

Staff has assembled data for each candidate to assist the City Council in the appointment process (Attachment 4).

\section{Appointment Consideration}

Balancing representation and size of the Committee with functionality should be considered. The Committee will hear public testimony, ask questions of the public and Staff, and deliberate and vote on recommendations. Larger committees generally equate to longer meetings, more staff time, and 
longer project timelines which should be considered as Council appoints the committee. Size can be reduced without a large negative effect on representation, if one limits the number of individuals that represent similar issues or properties, should Council decide to limit the size of the Committee. Public participation and outreach will be emphasized throughout the process, which will also allow different viewpoints to be heard.

Respectfully Submitted,

Bill King, AICP, Principal Planner

Approved By,

John M. Bramble
Reviewed,

David B. Gonzalves Director of Development Services

\section{ATTACHMENTS:}

Attachment 1-Project Boundary

[] Attachment 2 - Notice of Vacancies - BCCP

$\square$ Attachment 3-CAC Applications

[.] Attachment 4-Committee Application Traits

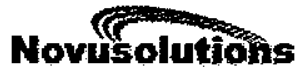

Copyright 2001-2012 


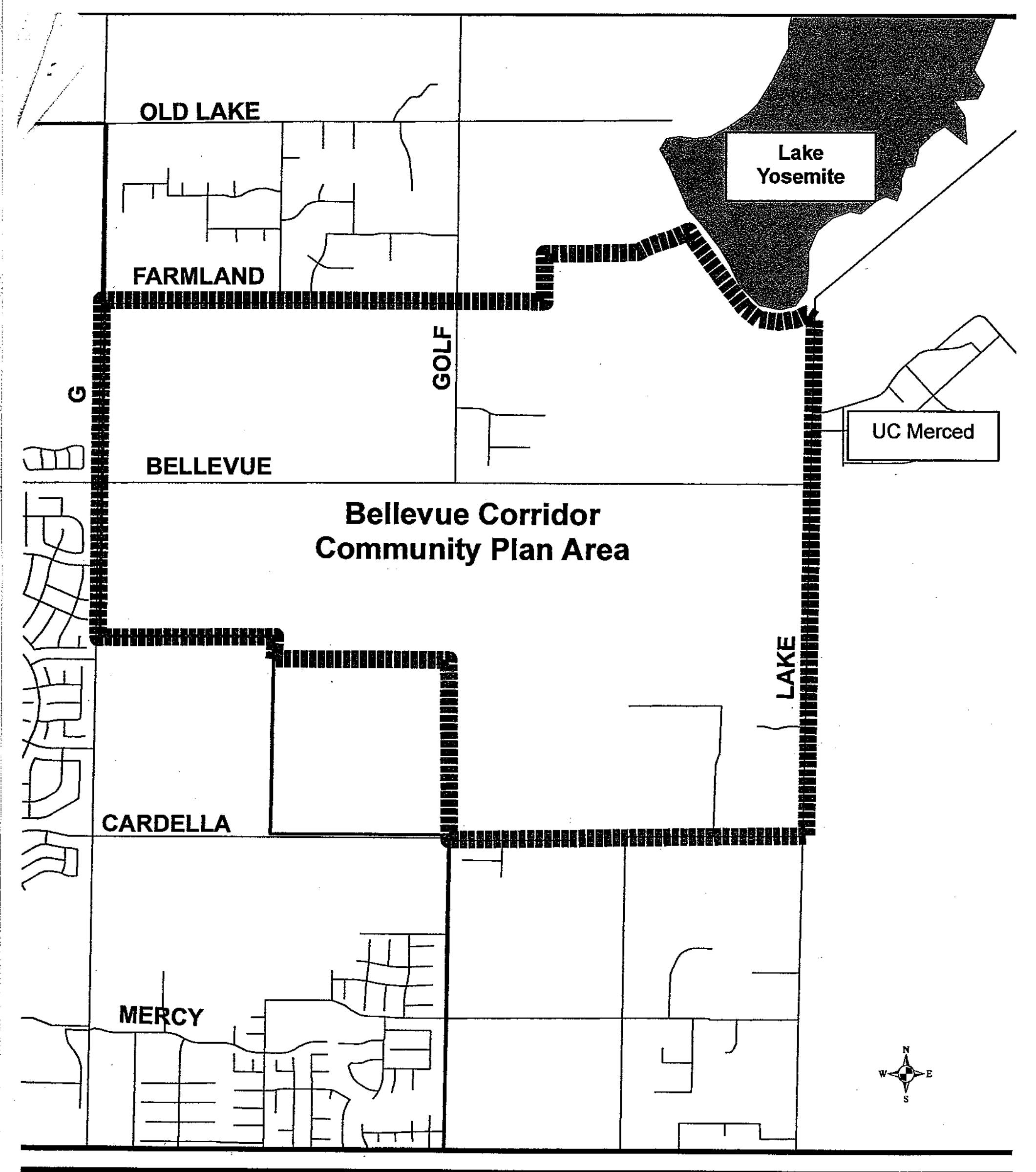

\section{ATTACHMENT 1 \\ Bellevue Corridor Community Plan Project Boundary}




\section{CITY OF MERCED}

\section{NOTICE OF VACANCIES}

The City of Merced is accepting applications for vacancies on the Bellevue Corridor Community Plan Ad-hoc Advisory Committee.

The Committee will make recommendations to the Plan Leadership Team (PLT) concerning aspects of the Bellevue Corridor Community Plan. These aspects include, but are not limited to the following:

- Size and Location of Research and Development Parks and/or Business Parks

- Street Design and Mobility Options (auto, transit, pedestrian, bicycles)

- Building Design and Form-Based Development Codes

- Open Space and Recreation

- Project Phasing and Infrastructure

Plan Leadership Team (PLT) consists of the City of Merced Planning Division and the professional planning firm of Lisa Wise Consulting. The PLT's role is to craft the plan and to provide a recommendation to the City of Merced Planning Commission, who then makes a recommendation to the City Council.

Committee meetings will be held at least once every two months, beginning in August 2012 through April 2014. Meetings will generally last 3 hours and occur in the daytime at the City of Merced Civic Center.

Applications and additional information are available on-line at www.cityofmerced.org or at the City Clerk's Office, $678 \mathrm{~W} .18^{\text {th }}$ Street, Merced, \#388-7100. FILING DEADLINE: 5:00 p.m., Thursday, June 21, 2012.

Dated: June 7, 2012

BY: Dana J. Davidson, Assistant City Clerk 


\section{City of Merced \\ Application for Appointment to the \\ Bellevue Corridor Community Plan Ad-Hoc Advisory Committee}

Name: Jerry E. Callister

Date: 6-8-2012

Home Address:

(street)

Mailing Address:

(street) $\quad$ Merced
95340

Merced

(street) (city) 95340

E-mail Address:

Home Phone:

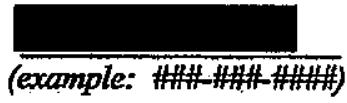

Cell Phone: (example: \#\#-\#\#-\#)

Work Phone:

(example: \#\#-\#\#-\#\#)

Place of Employment: Callister and Hendricks Occupation: Attorney

Work Address:

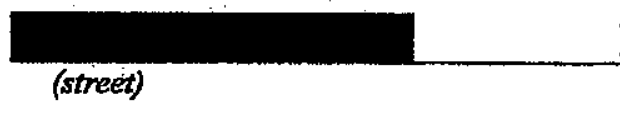

$\begin{array}{cc}\text { Merced } & 95340 \\ \text { (city) } & \text { (2ip) }\end{array}$

1. The City Council seeks committee representation from the following groups: citizens, property owners within or nearby the Plan area, and representatives of: local schools, colleges and universities; community advocacy groups; public health officials or advocates; development community, and local chambers of commerce representatives or other business interests.

Which organization do you represent? Property owner within the Plan area

2. List past or present involvement in community-related activities (i.e. volunteer work, committees, commissions, boards, etc.)

Merced College Foundation secretary (previously) Merced County Bar Association President (previously), Merced Rotary Club President (previously), volunteer work through church and other local organizations

3. State your understanding of the purposes, responsibilities, and services offered by the board/commission for which you are applying.

To assist in the planning of the streets, land uses, transportation for the area described as the "Bellevue Corridor" to determine what the area should be like in the future with particular attention to its physical relationship to the UC campus and the City of Merced 
4. List any training, education, or experience that you feel would be advantageous to the board/commission for which you are applying. Legal work for special districts and in the area of real estate developinert Have worked with specialists relative to our property in land use planning, future grö with studies for the area, etc.

5. State your reasons for submitting this application and what you expect to accomplish on this board/commission. Because we have an interest in land within the Plan area, we are of course anxious to be part of the planning process and would like focus on the long term results of the ultimate plan as the UC and the City of Merced grow.

6. This space may be used for any other information you feel is pertinent.

7. List two references who can attest to your suitability for appointment to the board/commission.

Name: Dr. L Thomas Fife
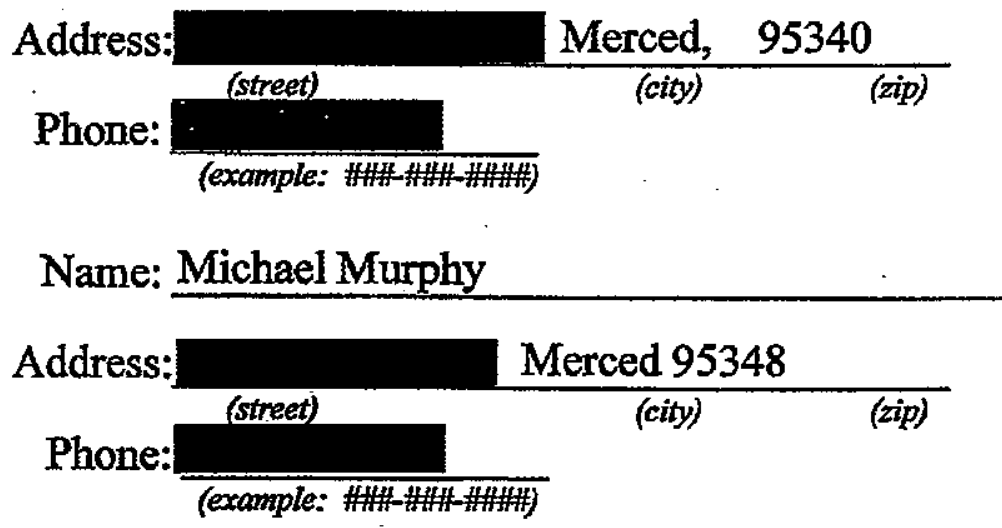


\section{City of Merced \\ Application for Appointment to the \\ Bellevue Corridor Community Plan Ad-Hoc Advisory Committee}

Name: Susan Gerhardt

Home Address:

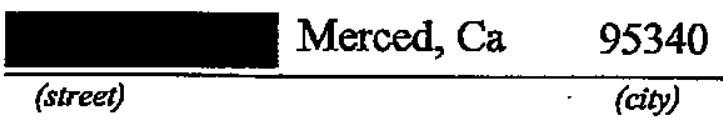

Date: $6 / 25 / 2012$

$\therefore \quad$ (street) (city) (zip)

Mailing Address:

(street) (city)

(zip)

E-mail Address:

Home Phone:

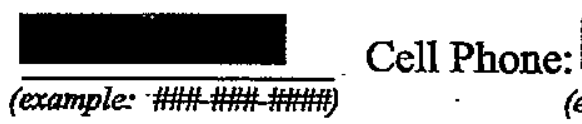

(example: \#\#\#\#-\#\#)

Work Phone:

(example: \#\#\#\#)

Place of Employment: Touch of Heaven Occupation: Massage Therapist

Work Address: Haven't found office yet

(street) (city) (zip)

I. The City Council seeks committee representation from the following groups: citizens, property owners within or nearby the Plan area, and representatives of: local schools, colleges and universities; community advocacy groups; public health officials or advocates; development community, and local chambers of commerce representatives or other business interests.

Which organization do you represent? Merced Bicycle Coalition

2. List past or present involvement in community-related activities (i.e. volunteer work, committees, commissions, boards, etc.)

Merced Bicycle Coalition member

Sat on steering cotmmittees for State of California Public Health issues including reporting of Vital Statistics.

Community food bank volunteer

3. State your understanding of the purposes, responsibilities, and services offered by the board/commission for which you are applying.

Make recomendations on the design of The Bellevue Corridor Community Plan to the Leadership Team 
4. List any training, education, or experience that you feel would be advantageous to the board/commission for which you are applying.

Working with the Bicycle Coalition as a member to promote a healthier community, with cleaner air, safer alternative commuting and a healthier population.

5. State your reasons for submitting this application and what you expect to accomplish on this board/commission.

I am famliar with commuting by bike as it is my only form of transportation. I'd like to
encourage more people to commute by alternative means by making it a safe \& viable
form of transportation.
I would also like Merced to become an excellent example of a bicycle friendly
community, with cleaner air and healthier people.

6. This space may be used for any other information you feel is pertinent.

I have been looking for a way to give back to the community and this would fit me perfectly.

7. List two references who can attest to your suitability for appointment to the board/commission.

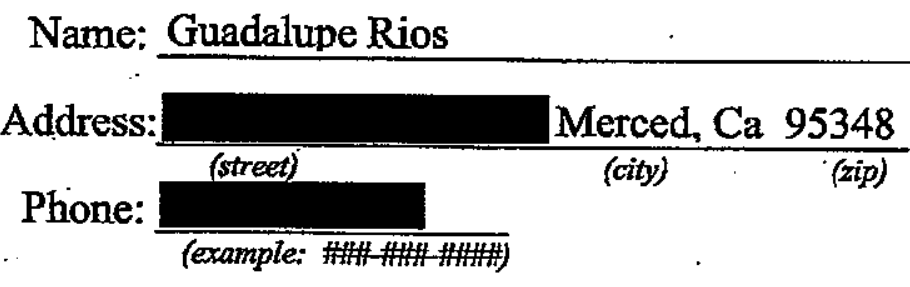

Name: Renee Jones

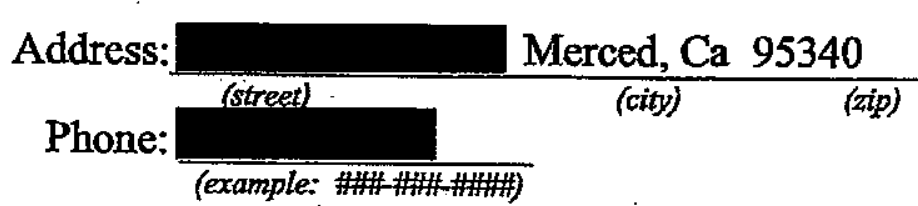




\section{Application for Appointment to the Bellevue Corridor Community Plan Ad-Hoc Advisory Committee}

Name: MELBOURNE N. GWIN, JR.

Date: 6-7-12

Home Address:

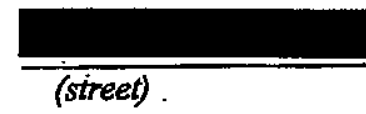

$\begin{array}{cc}\text { MERCED, CA } & 95340 \\ \text { (city) } & \text { (zip) }\end{array}$

Mailing Address:

$$
\text { (street) }
$$

MERCED

95344

E-mail Address:

Home Phone:

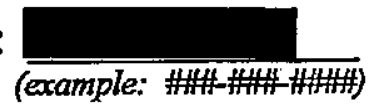

Place of Employment: SELF

Work Address:

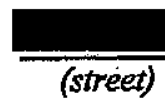

Cell Phone: (exainple: \#\#-\#\#)

Work Phone: (example: \#\#\#)

1. The City Council seeks committee representation from the following groups: citizens, property owners within or nearby the Plan area, and representatives of: local schools, colleges and universities; community advocacy groups; public health officials or advocates, development community, and local chambers of commerce representatives or other bưsinés interests.

Which organization do you represent? PROPERTY OWNER WITHIN THE PLAN

2. List past or present involvement in community-related activities (i.e. volunteer work, committees, commissions, boards, etc.)

SYMPHONY BOARD, ROTARY CLUB PRESWENT, BAR ASSN PRESIDENT, ATTORNEY ALTERNATE ASSESSMENT APPEALS BOARD, PRESIDENT INTERNATIONALL ASS OF EDUCATIONAL, NEGOTIATORS (MUCH TRAINING IN CONSENSUS AND.COOPERATIVE PROBLEM SOLVING)

3. State your understanding of the purposes, responsibilities, and services offered by the board/commission for which you are applying.

PROVIDE INPUT OF IMPACTED INDIVIDUALS ON THE PLAN --BRING EXPERIENCE OF 30 YEARS CONTINUOUS RESIDENCY IN SAME HOME TO THE COMMISSION--BRING̈ EXPERIENCE OF 20+ YEARS ADVISING GOVERNMENTAL AGENCIES 
4. List any training, education, or experience that you feel would be advantageous to the board/commission for which you are applying.

EXTENSIVE TRAINING IN NEGOTIATION AND CONSENSUS BUILDINGJURIS DOCTOR-MEMORY OF OTHER PROPOSALS SWHILE LIVING IN PLAN AREA--EXPERIENCING THE IMPACT OF OTHER EVENTS IN PLAN AREA

5. State your reasons for submitting this application and what you expect to accomplish on this board/commission.

I WANT TO BE INVOLVED IN WHATEVER IS PLANNED FOR MY NEIGHBORHOOOD. I EXPECT TO BRING BALANCE AND COMMON SENSE TO THE EFFORT-- I WANT TO PROTECT THE WNVESTMENT OF THE HOME OWNERS AND AVOID SOME OF THE DESATEROUS MISTAKES MADE BY THE CITY PLANNING COMMISSION

6. This space may be used for any other information you feel is pertinent.

ITEM 7 IS LEFT EMPTY BECAUSE NO STANDARD IS GIVEN FOR "SUITABILITY." IT IMPLIES THE COMMISSION WILL ONLY TAKE LIKE MINDED APPLICATIONS.

IF THIS IS A DISQUALIFYING FACTOR, I WANT A HEARING BEFORE THE DECISION MAKER.

7. List two references who can attest to your suitability for appointment to the board/commission.

Name:

Address:

Phone: (street) (city) (zip)

(example: \#\#\#\#-\#\#)

Name:

Address:

$\begin{array}{lll}\text { (street) (city) } & \text { (zip) }\end{array}$

(example: \#\#\#\#\#) 


\section{City of Merced}

\section{Application for Appointment to the}

\section{Bellevue Corridor Community Plan Ad-Hoc Advisory Committee}

Name: Dan Holmes

Date: 6-18-12

Home Address:

$\frac{\text { Merced }}{\text { (street) }}$
95340 (zip)

Mailing Address: (same) (street)

(city)

(zip)

E-mail Address:

Home Phone: (example: \#\#\#-\#\#)

Place of Employment: $\underline{n} / \mathbf{a}$
Cell Phone: (example: \#\#\#\#)
Work Phone: $\mathrm{n} / \mathrm{a}$

(example: \#\#\#-\#)

Work Address: $\mathrm{n} / \mathrm{a}$ (street) (city)

(zip)

1. The City Council seeks committee representation from the following groups: citizens, property owners within or nearby the Plan area, and representatives of: local schools, colleges and universities; community advocacy groups; public health officials or advocates; development community, and local chambers of commerce representatives or other business interests.

Which organization do you represent? property owner

2. List past or present involvement in community-related activities (i.e. volunteer work, committees, commissions, boards, etc.)

Board Member Mercy Hospital Foundation, Board Member Merced Theatre Foundation; Member Board of Elders Christian Life Center

3. State your understanding of the purposes, responsibilities, and services offered by the board/commission for which you are applying.

We will meet with staff and the City's planning consultant on a regular basis to help formulate a proposed land use plan and policies to implement the proposed land use plan for the area North of Cardella Rd., South of Farmland Rd., East of G Street and West of Lake Rd. These will be presented to the Planning Commission and City Council for adoption of a Specific Plan for the area. 
4. List any training, education, or experience that you feel would be advantageous to the board/commission for which you are applying.

I am a licensed Civil Engineer with 36 years experience in preparing land use and engineering plans for land development in and around Merced. I am retired and have no clients influence my decisions.

5. State your reasons for submitting this application and what you expect to accomplish on this board/commission.

Merced has been my home for 39 years, I have a strong desire to make sure development continues in a well planned and managed way. Growth in the Bellevue Corridor Area needs to meet the needs of the current and future citizens of Merced without adversely affection the existing large lot development in the area. I believe my experience in planning coupled with my desire to minimize the effect on existing homes brings a unique perspective to the committee.

6. This space may be used for any other information you feel is pertinent.

7. List two references who can attest to your suitability for appointment to the board/commission.

Name: Kathleen Crookham

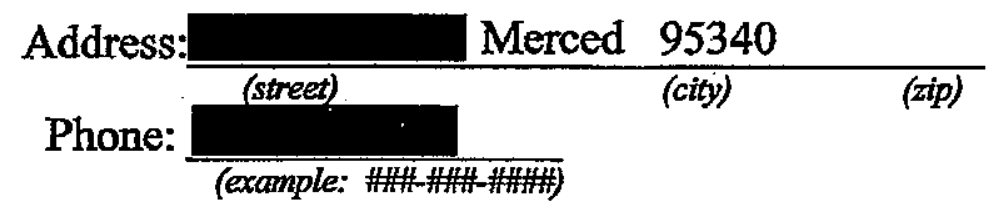

Name: Don Ohlinger

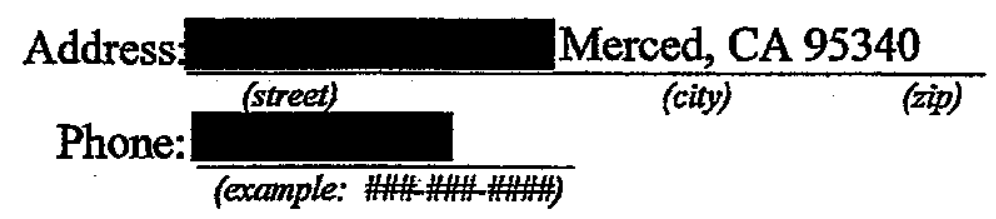




\section{City of Merced \\ Application for Appointment to the \\ GITY OF NERCED \\ Bellevue Corridor Community Plan Ad-Hoc Advisory Committee}

Name: Dan Hong

Date: $6 / 21 / 2012$

Home Address:

$$
\text { (street) }
$$

(cily)

(zip)

Mailing Address:

same as above

$$
\text { (street) }
$$

E-mail Address:

(city)

(zip)

Home Phone: (example: \#\#\#\#)

Cell Phone:

(example: \#\#)
Work Phone:

(excomple: \#-\#)

Place of Employment: Youbiquicast Occupation: Videographer

Work Address:

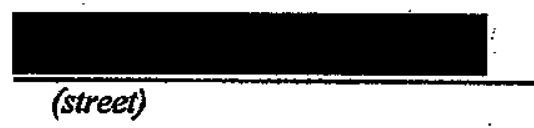

Merced

95340

(zip)

1. The City Council seeks committee representation from the following groups: citizens, property owners within or nearby the Plan area, and representatives of: local schools, colleges and universities; community advocacy groups; public health officials or advocates; development community, and local chambers of commerce representatives or other business interests.

Which organization do you represent? Other business interets

2. List past or present involvement in community-related activities (i.e. volunteer work, committees, commissions, boards, etc.)

President of Merced Business Xchange, Served on the boards of the Merced County Boys and Girls Club. Currently I am actively participating with Merced Ahead and working on the State Fair Exhibit for Merced County

3. State your understanding of the purposes, responsibilities, and services offered by the board/commission for which you are applying.

The city is looking into expanding the Bellevue corridor with commerce including but not limited to technology-based companies. 
4. List any training, education, or experience that you feel would be advantageous to the board/commission for which you are applying.

I have been a member of the Merced business community for many years. I have worked in both the private and public sectors. My diverse experiences as an entrepreneur will bring an interesting and useful perspective to the commission.

5. State your reasons for submitting this application and what you expect to accomplish on this board/commission.

I was born and raised in Merced. As a long time resident and member of the Merced business community, I would like to do my part to help Merced grow into its greatest potential.

6. This space may be used for any other information you feel is pertinent.

I look forward to a dynamic exchange to further Merced's walk into 21 st century.

7. List two references who can attest to your suitability for appointment to the board/commission.

Name: Frank Quintero

Address:

Phone:

(street) (city) (zip)

(example: \#\#-\#\#-\#)

Name: Flip Hassett

Address:

Phone:

(street) (city) (zip)

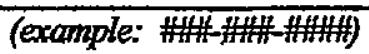




\section{Application for Appointment to the}

\section{Bellevue Corridor Community Plan Ad-Hoc Advisory Committee}

Name: SilRrai HUNT DKCKER

Home Address:

MERCED, CA $95340^{\text {Date: } 6 / 21 / 2012}$

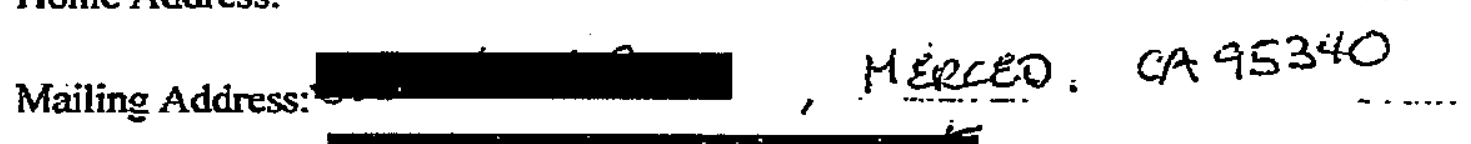

E mail Address:

Home Phone: --- -

Cell Phone.

Work Phone:

Place of Employment: LuiH 7NRMS LLC Occupation: Real Estate HanageR

Work Address: CA 95340

1. The City Council seeks committee representation from the following groups: citizens, property owners within or nearby the Plan area, and representatives of: local schools, colleges and universities; community advocacy groups; public health officials or advocates; development community, and local chambers of commerce representatives or other business interests.

Which organization do you represent? Protertycukef UCP

2. List past or present involvement in community related activities

Chair-PatronsofCysticFibrosis - medical research charity -

Board merniber - Merced Cousty Family Farmers Coalition

CPAC planning group-University Community Plan, Stakeholder

3. State your understanding of the purposes, responsibilities, and services offered by the board/commission for which you are applying.

Committee members will attend all meetings for duration of planning process, development suggestions to be presented to the Plan Leadership Team concerning land use, recreation opportunities, environmental issues, transportation. overall sustainability and reaction to market conditions as the area develops and is incorporated into the City of Merced. 
4. List any training, education, or experience that you feel would be advantageous to the board/commission for which you are applying.

26 years, VP CBRichardEllis Commercial Real Estate Co. = primary focus Investment properties, land development

CCIM designation, Commercial Real Estate designation

CPAC member,stakeholder, 10 year planning process University Community Plan 181 acre rezone, annexation to City of Merced,

5. State your reasons for submitting this application and what you expect to accomplish on this board/commission. I hope to assist in development of a plan for the Bellevue Corridor resulting in sustainable; environmentally sensitive, responsive to market conditions land uses which, when combined with other immediate area projects results in an exciting and innovative community area surrounding the University of California Merced campus.

6. This space may be used for any other information you feel is pertinent.

7. List two references who can attest to your suitability for appointment to the board/commission.
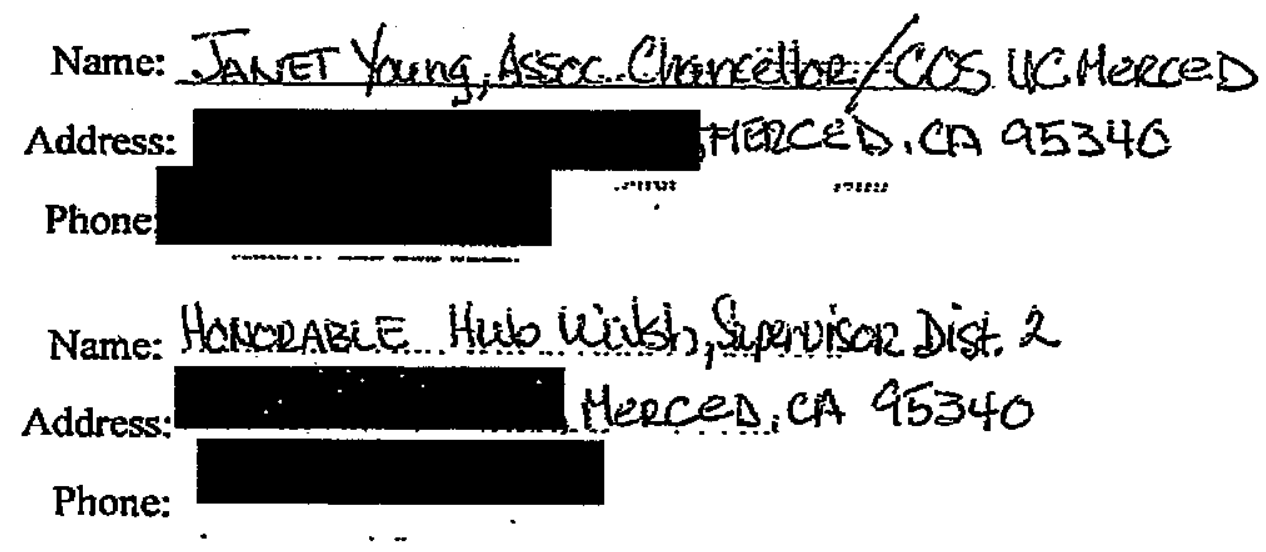


\section{City of Merced \\ Application for Appointment to the \\ Bellevue Corridor Community Plan Ad-Hoc Advisory Committee}

Name: Richard M. Kirby

Date: 6-18-2012

Home Address:

\begin{tabular}{ccc} 
& Merced & 95348 \\
\hline (street) & (clit) & (zip)
\end{tabular}

Mailing Address:

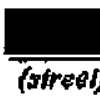

Merced

95341-0989

(streal)

(city)

$(z \mid p)$

E-mail Address:

Home Phone: (example: \#\#\#\#)

Cell Phone:

(example: \#HH\#\#\#)
Work Phone:

(example: H\#-\#-\#)

Place of Employment: Kirby Mfg., Inc. Occupation: President

Work Address:
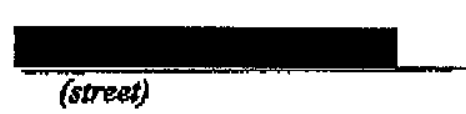

-

$\frac{\text { Merced }}{\text { (city) }}$ 95340

1. The City Council seeks committee representation from the following groups: citizens, property owners within or nearby the Plan area, and representatives of: local schoois, colleges and universities; community advocacy groups; public health officials or advocates; development community, and local chambers of commerce representatives or other business interests.

Which organization do you represent? Citizen, property owner

2. List past or present involvement in community-related activities (i.e. volunteer work, committees, commissions, boards, etc.)

Past President of the Merced County Historical Society, current member OLM School Board, current member Mercy Hospital Foundation Board, past member of City of Merced EDAC, current member of Children's Movement of Merced County.

3. State your understanding of the purposes, responsibilities, and services offered by the board/commission for which you are applying.

To help develop the plan by working with the community, property owners, neighbors and UC Merced. 
4. List any training, education, or experience that you feel would be advantageous to the board/commission for which you are applying.

Business owner

Property owner

Life long resident of Merced

Past EDAC member

5. State your reasons for submitting this application and what you expect to accomplish on this board/commission. I look forward to helping develop a plan for an opportunity in our community. This project has the potential to bring new businesses and jobs to Merced by tapping into the influence of UC Merced, while beautifying a gateway into our city.

6. This space may be used for any other information you feel is pertinent.

7. List two references who can attest to your suitability for appointment to the board/commission.

Name: Bob Carpenter

Address:

Phone:

(street)

Name: Elmer Lorenzi

Address:

Phone: $\frac{\text { (oli) }}{\text { (street) }}$




\section{City of Merced \\ Application for Appointment to the \\ Bellevue Corridor Community Plan Ad-Hoc Advisory Committee}

Name: Lee J. Kolligian

Date: 6-20-12

Home Address:

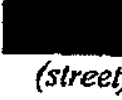

Pacific Palisades

90272

Mailing Address:

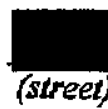

(city)

Santa Monica

(city)

90401

E-mail Address:

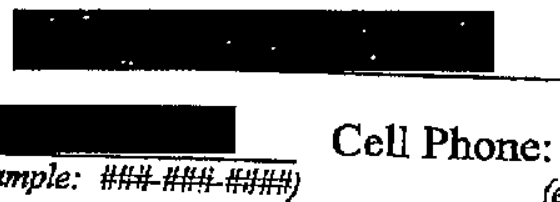
(example: HH)

(example: H\#)

Work Phone:

(example: \#\#)

Place of Employment: self employed Occupation: Attorney, Land Owner

Work Address:

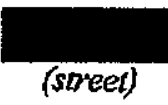

Santa Monica

90401

1. The City Council seeks committee representation from the following groups: citizens, property owners within or nearby the Plan area, and representatives of: local schools, colleges and universities; community advocacy groups; public health officials or advocates; development community, and local chambers of commerce representatives or other business interests.

Which organization do you represent? Property owner within the Plan area

2. List past or present involvement in community-related activities (i.e. volunteer work, committees, commissions, boards, etc.)

Participated in some general plan discussions with the City of Merced and other land owners concerning the subject study area.

3. State your understanding of the purposes, responsibilities, and services offered by the board/commission for which you are applying.

I will be responsible for providing candid opinions on a variety of issues pertaining to the future planning and development of the Bellevue Corridor including but not limited to issues involvement traffic, land use, noise, air quality, esthetics, etc. 
4. List any training, education, or experience that you feel would be advantageous to the board/commission for which you are applying. I am a graduate of Stanford Law School and have experience in land development, planing and entitlement issues.

5. State your reasons for submitting this application and what you expect to accomplish on this board/commission.

I am directly impacted by some of the recommendations regarding this study area in respect to many issues including but not limited to, land use, transportation, environmental concerns and architectural guidelines.

6. This space may be used for any other information you feel is pertinent.

I am an owner of significant land within the subject area and have been involved in discussions concerning the planning of this Corridor with members of the City staff since 2008.

7. List two references who can attest to your suitability for appointment to the board/commission.

Name: Janet Young

Address: UC Merced

Phone:

(street)

(city)

(zip)

Name: Ralph Temple

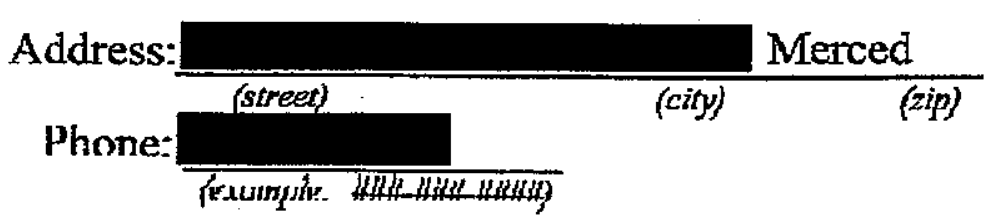




\section{City of Merced}

Application for Appointment to the

JUN18'12am11:89

Bellevue Corridor Community Plan Ad-Hoc Advisory Committee

Name:

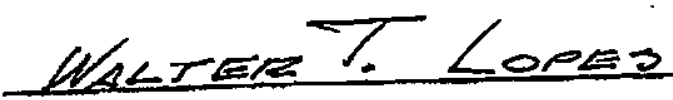

Date: $6 / 18 / 12$

Home Address:

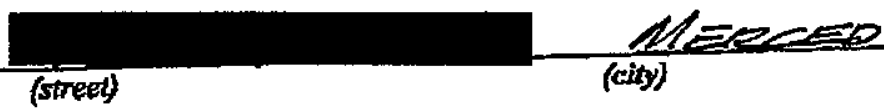

(xip)

95340

Mailing Address: (street)

(city)

(zip)

E-mail Address: Nene

Home Phone:

Cell Phone: (example:
Work Phone: $\mu$ oNe (exampie: \#\#-\#)

Place of Employment: Periese Arecurtser Occupation:

Work Address:

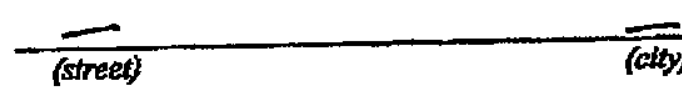

(city)

(zip)

1. The City Council seeks committee representation from the following groups: citizens, property owners within or nearby the Plan area, and representatives of: local schools, colleges and universities; community advocacy groups; public health officials or advocates; develogment community, and local chambers of commerce representatives or other business interests.

Which organization do you represent? CrIZENS, PRoparzTr ownere, ERE.

2. List past or present involvement in community-related activities (i.e. volunteer work, committees, commissions, boards, etc.)

JUST CONCLUDEO AROHTECTURAL RENTWW BOARDF

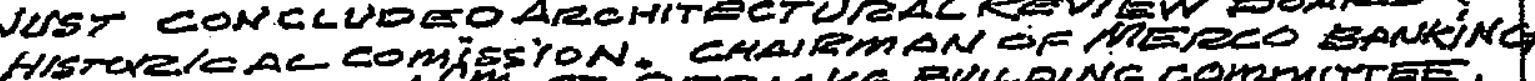

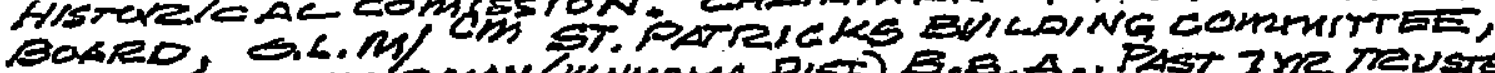
OAST DIST. CHWREMAN (WAWONA PIST) B.B.A., PAST 7 WR TRUSTE

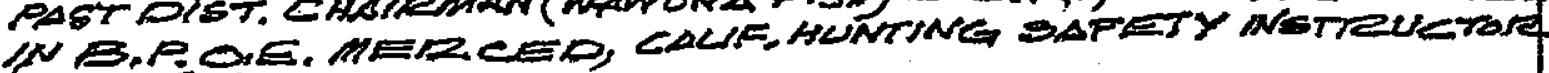
(5 Y)ans?

3. State your understanding of the purposes, responsibilities, and services offered by the board/commission for which you are applying.

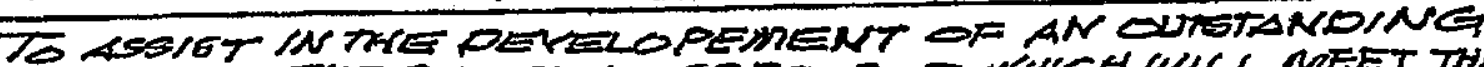
PLAN FUE THE BEWEVUE COREIDOR WHICH WILL MIEET THE FUTURE NEENS OF THE CITH AND THE UNIVERESTY. 
4. List any training, education, or experience that you feel would be advantageous to the board/commission for which you are applying.

1 WAS A LICENSED AECMTECT FOR OVER HOYEARS. I WAS

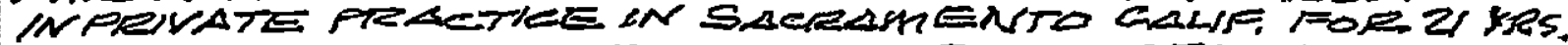
BEFUE MUUENAG TO MERCED 70 BSCONE THE LSSTANT

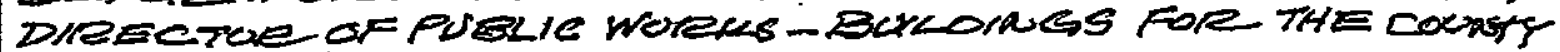

5. State your reasons for submitting this application and what you expect to accomplish on this board/commission.

TO HESP IN THE DEVELOPHENT OF ANEXE WWNT PLAN.

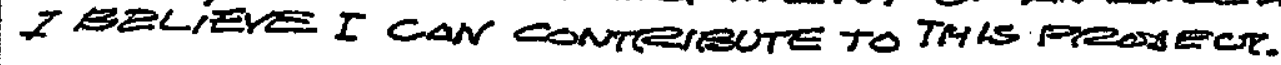

6. This space may be used for any other information you feel is pertinent.

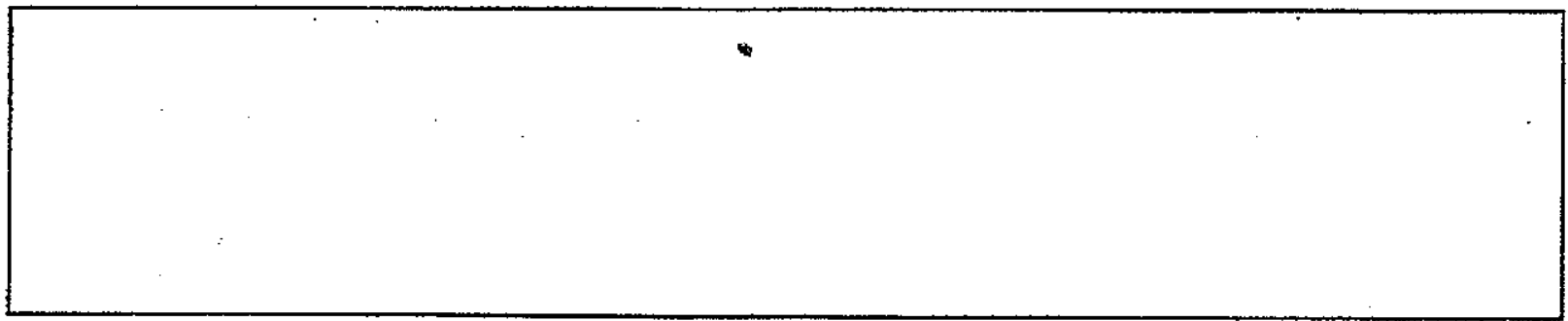

7. List two references who can attest to your suitability for appointment to the board/commission.

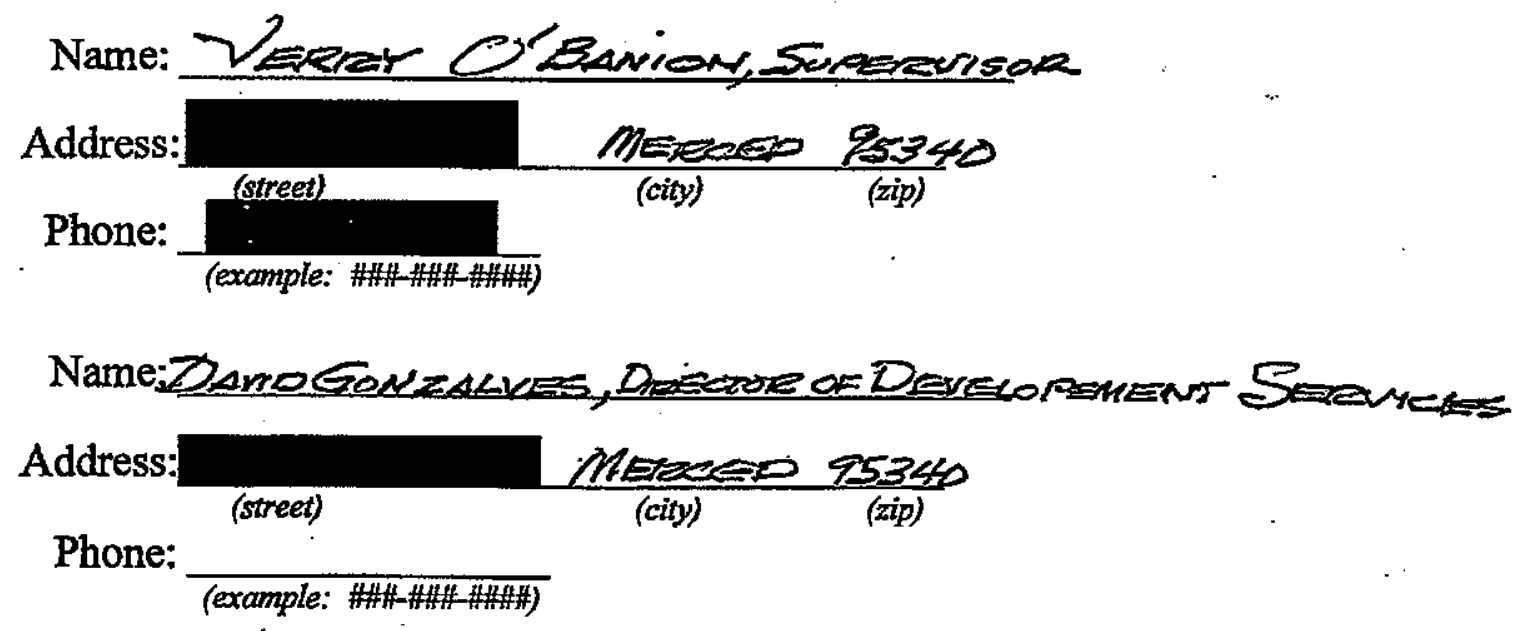




\section{City of Merced \\ Application for Appointment to the \\ Bellevue Corridor Community Plan Ad-Hoc Advisory Committee}

Name: Kenneth M. Robbins

Date: $6 / 8 / 2012$

Home Address:

(street)

Mailing Address:

(street)

1

$\frac{\text { Merced }}{\text { (city) }}$

Merced . 95340

(city)

(zip)

E-mail Address:

Home Phone:

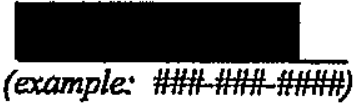

Cell Phone: (example: Won Phone: 95344 (zip)

Place of Employment: Mason Robbins Browning \& G Occupation: Attorney

Work Address:

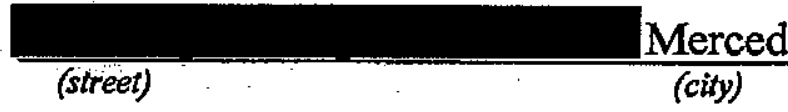

95348

(zip)

1. The City Council seeks committee representation from the following groups: citizens, property owners within or nearby the Plan area, and representatives of: local schools, colleges and universities; community advocacy groups; public health officials or advocates; development community, and local chambers of commerce representatives or other business interests.

Which organization do you represent? Virginia Smith Trust

2. List past or present involvement in community-related activities (i.e. volunteer work, committees, commissions, boards, etc.)

Member UC Merced Committee, Trustee UC Merced Foundation Chair Audit Committee, Chair Board of Directors for Central Presbyterian (session), Member Governor's Judicial Appointments Advisory Board, Mercy Hospital Foundation Board, Water Foundation Board, MID Foundation, Rotary, Merced Boosters, Chamber of Commerce, Local political campaign committees.

3. State your understanding of the purposes, responsibilities, and services offered by the board/commission for which you are applying.

This committee will explore and help inform the future planning process for establishment of development criteria and infrastructure plans for the designated area from $\mathrm{G}$ to Lake Road. 
4. List any training, education, or experience that you feel would be advantageous to the board/commission for which you are applying.

1 represent the Virginia Smith Trust which is a partner with UC Merced in the University Community Area which will be heavily impacted by this committee. I have back ground in land use, representation of public agencies, Brown Act, CEQA, specific development plans, public infrastructure financing.

5. State your reasons for submitting this application and what you expect to accomplish on this board/commission.

I am interested in the connectivity, esthetics, transportation and public services interface between the City, the University Community Plan area and the Bellevue Corridor. I expect to promote broad based decision making with regard to recommendations and to help coordinate this project with UC Community Plan Development and infrastructure.

6. This space may be used for any other information you feel is pertinent.

I would represent a large regional land owner as well as the County Board of Education which is the Trustee of the Virginia Smith Trust. They have forwarded a letter requesting my appointment.

7. List two references who can attest to your suitability for appointment to the board/commission.

Name: Bill Spriggs

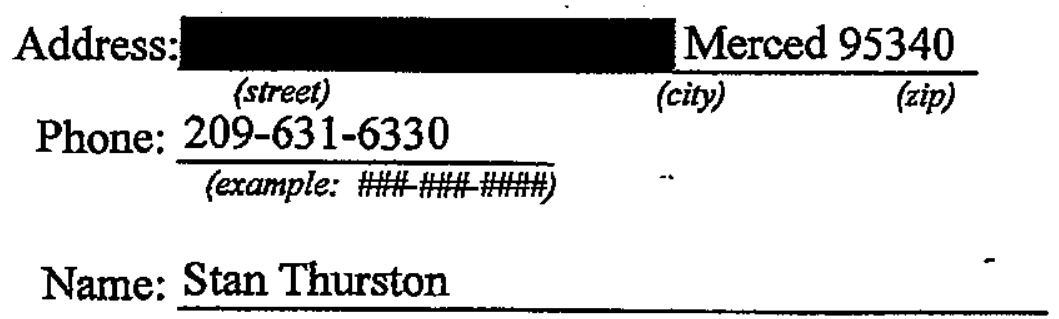

Address:

Phone:

(street) (city)

(example: \#\#\#\#) 


\section{MASON, ROBBINS, B̈ROWNING \& GODWIN}

MICHAEL L. MASON

KENLNETE M. BORBNS

CORBETT J.-BROWNING

ARTEUR F. CODWIN

RICTARD T. MARCHDN

BETH BEUSH

PARALEGAL

\author{
ATTORNEYS AT LAW \\ A LMTTED LIABILITY \\ PARTNERSHIP \\ TOO LOUGHBOROUGR DR. \\ SUITE D . \\ MERCED, CA 95348 \\ (209) 383-9334
}

JUA1212PW5:04

MALING ADDRESS

P.O. BOX 2057

MERCED, CA 95344-0067

FAX: (209) 363-9386

E-MAIl: mrgb@urghore WEBSTE: Ww'urgb,org

June 11, 2012

Julie Sterling, Associate Planner

City Clerk's Office

678 W. $18^{\text {th }}$ Street

Merced, CA 95340

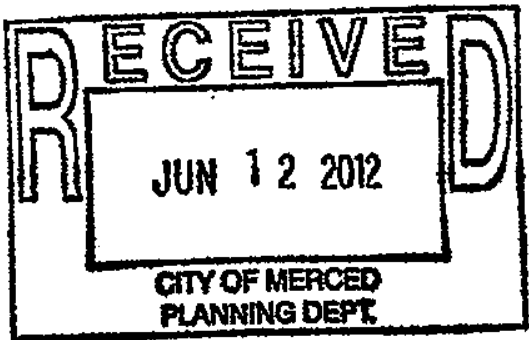

RE: Bellevue Corridor Community Plan Committee Application

Dear Julie:

Please find enclosed a completed application for appointment to the Bellevue Corridor Community Plan Ad-Hoc Advisory Committee. In addition to the application appended I have also attached a copy of the letter from the Virginia Smith Trust signed by Steve Gomes, the County Superintendent of Schools, requesting my appointment as well.

Your help in this matter is greatly appreciated.

Very truly yours,

MASON, ROBBINS, BROWNING \& GODWIN

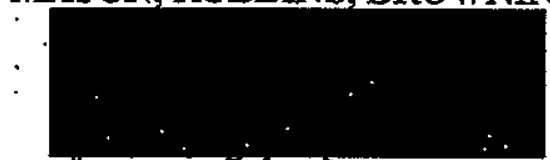

KENNETH M. ROBBINS

$\mathrm{KMR} / \mathrm{d} b$

Enclosures 


\section{SMITH FAMILY SCHOLARSHIP BOARD}

and

整

Bvelyn Eagieton

Trustee, Area One
Mary Ellen Chavez

Trustee, Area Two
Rudy Albritton Trustee, Area Three
Fred Fonoré Trustee, Area Four
In Memory of

Etmer Smith

Ursula Smith

Cynil E. Smith

Virgtria Smith

May 16, 2012

Bill King, AICP

Principal Planner

City of Merced

$678 \mathrm{~W} .18^{\text {th }}$ Street

Merced, CA 95340

RE: Representative for the Citizen's Advisory Committee

Dear Mr. King:

This letter is being sent to advise that the Virginia Smith Trust (VST) has an interest in the Bellevue Area Corridor Plan matter due to the land is UC Merced community area. Kenneth M. Robbins is VST's land agent and will be VST's representative to the committee. An application has been filed in that regard.

We would like to endorse Mr. Robbins's request for appointment to the Advisory Committee on our behalf. If you have any additional information or questions that you need from us please do not hesitate to contact us.

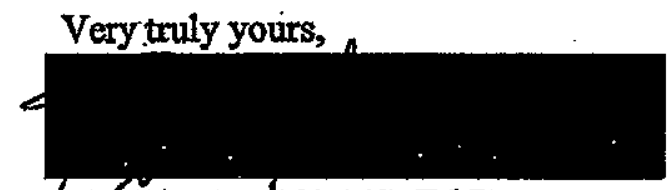

SFEVEN E. GOMES, Ed.D.

County Superintendent of Schools

Merced County Office of Education 


\section{Bellevue Corridor Community Plan Ad-Hoc Advisory Committee}

Name: Steve Simmons

Date: $6 / 21 / 2012$

Home Address:

$$
\text { (street) }
$$

(city)

(zip)

Mailing Address:

same as above (street)

(city)

(zip)

E-mail Address:

Home Phone: (example: \#\#\#-\#)
Cell Phone:

(example: \#\#\#\#\#)
Work Phone:

(example: \#\#-\#\#)

Place of Employment: NLBDG Occupation: Entrepreneur

Work Address:

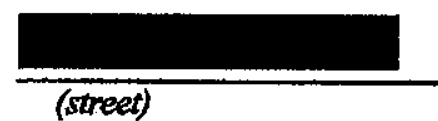

$\frac{\text { Merced . }}{\text { (city) }} \frac{95340}{\text { (zip) }}$

1. The City Council seeks committee representation from the following groups: citizens, property owners within or nearby the Plan area, and representatives of: local schools, colleges and universities; community advocacy groups; public health officials or advocates; development community, and local chambers of commerce representatives or other business interests.

Which organization do you represent? Other business interets

2. List past or present involvement in community-related activities (i.e. volunteer work, committees, commissions, boards, etc.)

President of Merced High QB Club, Served on the boards of the Greater Merced and Hispanic Chambers of Commerce. Currently serving on the CVCAH board and actively participating with Merced Ahead.

3. State your understanding of the purposes, responsibilities, and services offered by the board/commission for which you are applying.

The city is looking into expanding the Bellevue corridor with commerce including but not limited to technology-based companies. 
4. " List any training, education, or experience that you feel would be advantageous to the board/commission for which you are applying.

I have been a member of the Merced business community for many years. I have worked in all sectors. My diverse experiences as an entrepreneur should bring an interesting and useful perspective to the commission.

5. State your reasons for submitting this application and what you expect to accomplish on this board/commission.

As a long time resident and member of the Merced business community, I would like to do my part to help Merced grow into its greatest potential.

6. This space may be used for any other information you feel is pertinent. I look forward to a dynamic exchange to further Merced's walk into 21st century.

7. List two references who can attest to your suitability for appointment to the board/commission.

Name: Frank Quintero

Address:

Phone:

(street) (city) (zip)

(example: \#\#\#\#)

Name: Flip Hassett

Address:

Phone: 


\section{City of Merced}

\section{Application for Appointment to the}

JUN19'12P19:13

\section{Bellevue Corridor Community Plan Ad-Hoc Advisory Committee}

Name: Justi Smith

Date: $6 / 19 / 2012$

Home Address:

\begin{tabular}{lcc} 
& Merced & 95340 \\
\hline (street) & (oin) & (zip)
\end{tabular}

Mailing Address: Same as above

(street)

(cin)

$(z i p)$

E-mail Address:

Home Phone: (excmple: \#\#-\#)
Cell Phone:

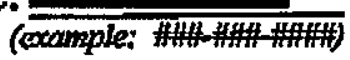

Work Phone:

(exmple: \#\#+\#)

Place of Employment: State Farm Occupation: Agent

Work Address:

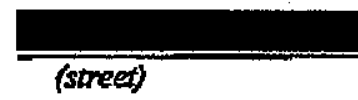

Merced

95340

(elig)

(zip)

1. The City Council seeks committee representation from the following groups: citizens, property owners within or nearby the Plan area, and representatives of: local schools, colleges and universities; community advocacy groups; public health officials or advocates; development community, and local chambers of commerce representatives or other business interests.

Which organization do you represent? Property owner

2. List past or present involvement in community-related activities (i.e. volunteer work, committees, commissions, boards, etc.)

Merced City Chamber of Commerce Merced County Chamber of Commerce

Soroptimists International

Habitat for Humanity

Relay for Life

Rebuilding following Hurricane Katrina in Mississippi

3. State your understanding of the purposes, responsibilities, and services offered by the board/commission for which you are applying.

To help advise and to provide input on the Bellevue Corridor Plan. To work with the Plan Leadership Team. Discussing all aspects of the Project Phasing, street design transportation options, development parks and all other aspects of the growth to extend to the most Northern part of Merced. 
4. List any training, education, or experience that you feel would be advantageous to the board/commission for which you are applying.

I have volunteered for Habitat for Humanity and also worked in Biloxi, Mississippi to help rebuild homes. It has been very rewarding for me to help planning and problem solve to complete projects alongside others.I have worked with many authorities in the past including the CSLB. I am enthusiastic to work with others in this exciting project. My experience as an insurance agent allows me to have a very objective view on many levels.

5. State your reasons for submitting this application and what you expect to accomplish on this board/commission.

I hope to be able to be the voice of my neighbors and to be able to keep them abreast of the growth in our area. I hope that I can also express any concerns of the residents so that our community can maintain a comfortable lifestyle while growth occurs.

6. This space may be used for any other information you feel is pertinent.

I thank you in advance for the opportunity to serve on this committee.

7. List two references who can attest to your suitability for appointment to the board/commission.

Name: Scott A. Smith

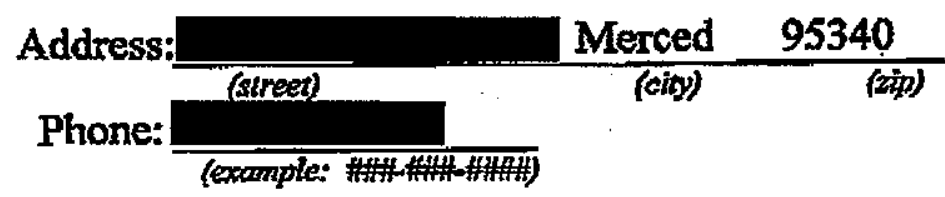

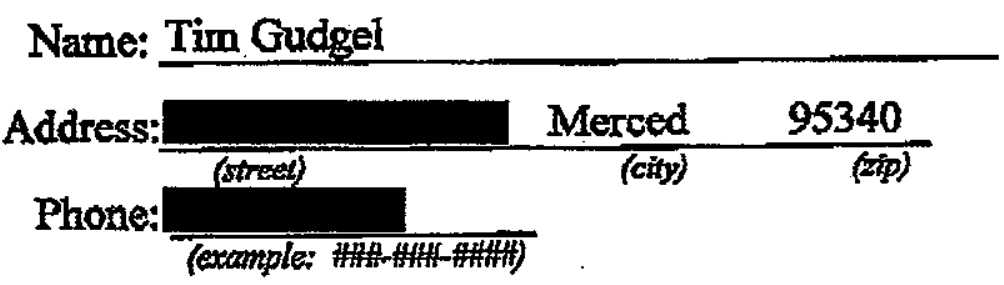


Bellevue Corridor Community Plan Ad-Hoc Advisory Committee

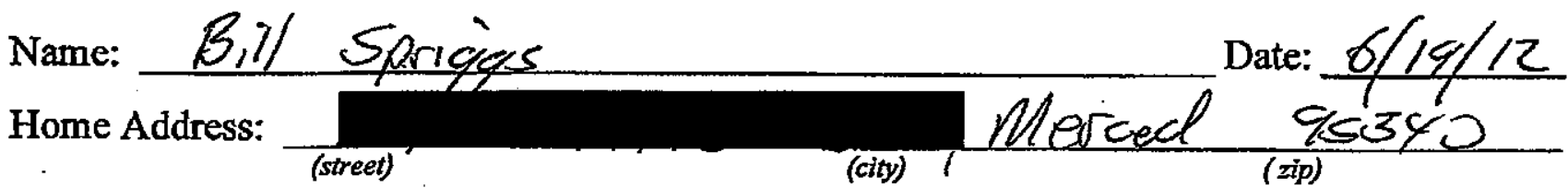

Mailing Address:

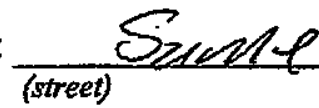

E-mail Address: 1 (street)

Place of Employment: Howns Collewis os

Work Address:

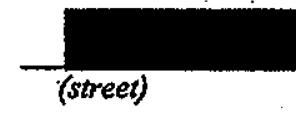
Occupation:

1. The City Council seeks committee representation from the following groups: citizens, property owners within or nearby the Plan area, and representatives of: local schools, colleges and universities; community advocacy groups; public health officials or advocates; development community, and local chambers of commerce representatives or other business interests.

Which organization do you represent? bubieres Leferest

2. List past or present involvement in community-related activities (i.e. volunteer work, committees, commissions, boards, etc.)

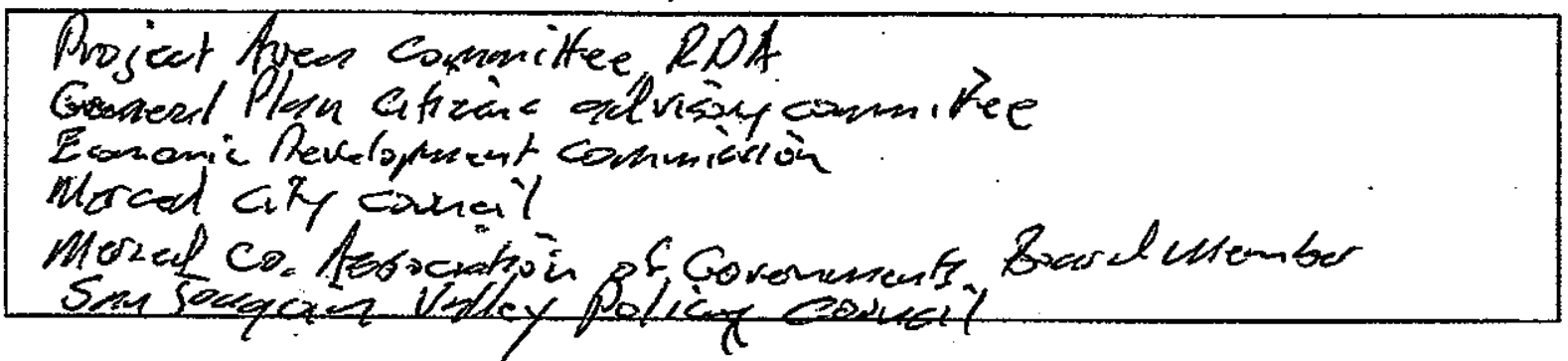

3. State your understanding of the purposes, responsibilities, and services offered by the board/commission for which you are applying.
Advie flaming commison ruel sfeff on

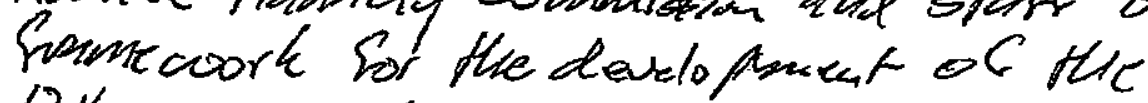
telkuve cosidor. 
4. List any training, education, or experience that you feel would be advantageous to the board/commission for which you are applying.

$$
\text { Cortibiel commocind real es fite apponter }
$$

5. State your reasons for submitting this application and what you expect to accomplish on this board/commission.

$$
\begin{aligned}
& \text { I have an interesf in cossurmy orderty development } \\
& \text { of ovor comonmixy }
\end{aligned}
$$

6. This space may be used for any other information you feel is pertinent.

7. List two references who can attest to your suitability for appointment to the board/commission.

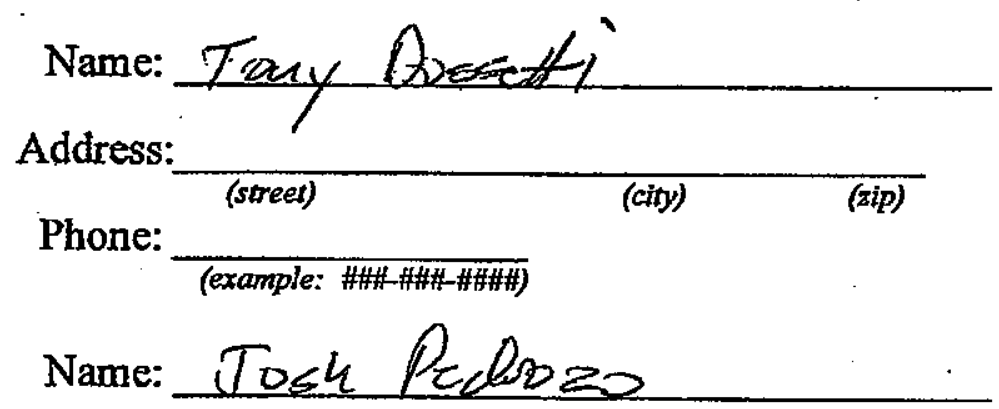

Address:

Phone:

$$
\text { (street) (city) (zip) }
$$

(example: \#\#-\#\#\#\#) 


\section{City of Merced \\ Application for Appointment to the Bellevue Corridor Community Plan Ad-Hoc Advisory Committee}

Name: Rick Telegan Date: $6 / 19 / 2012$

Home Address: (street) Fresno, CA 93720

Mailing Address: (street) (city) (zip) Fresno, CA 93720

E-mail Address:

Home Phone:

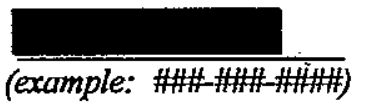

Place of Employment: Self
Cell Phone: (example: \#\#-\#\#\#\#)
Work Phone:

(example: \#\#-\#\#\#\#)

Work Address:

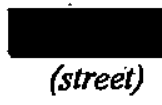
Occupation: Real Estate Dev. \& Invest

1. The City Council seeks committee representation from the following groups: citizens, property owners within or nearby the Plan area, and representatives of: local schools, colleges and universities; community advocacy groups; public health officials or advocates; development community, and local chambers of commerce representatives or other business interests.

Which organization do you represent? Property owner within the Plan area

2. List past or present involvement in community-related activities (i.e. volunteer work, committees, commissions, boards, etc.)

"CRIS" citizen's committee

UC Merced community plan planning committee

Wastewater Plant expansion task force

HCP/NCCP steering committee for Eastern Merced County

Regional Transportation Improvement Plan steering committee

South Merced Specific Plan Committee

3. State your understanding of the purposes, responsibilities, and services offered by the board/commission for which you are applying.

For purposes of establishing land use development patterns for the Bellevue Corridor Community Plan area,

1) Identify issues and constraints (i.e. circulation, infrastructure, environmental, et al) and,

2) Offer options or suggest alternatives that will reflect and respond to the issues identified above. 
4. List any training, education, or experience that you feel would be advantageous to the board/commission for which you are applying.

I have been a real estate broker and/or developer (hence, planner) for over four decades and have been actively involved in Merced real estate for nearly 35 years; In other words, as one former city council member put it, "Rick knows too much about the city".

5. State your reasons for submitting this application and what you expect to accomplish on this board/commission.

As a property owner, I expect to participate in real estate development and investment in this area of the city and hence, I would very much appreciate the opportunity to offer my expertise in this planning effort.

6. This space may be used for any other information you feel is pertinent.

I am currently involved in one pre-zoning, annexation and general plan amendment application within the Bellevue Corridor Community Plan area.

7. List two references who can attest to your suitability for appointment to the board/commission.

Name: Jesse Brown (Executive Director, MCAG)
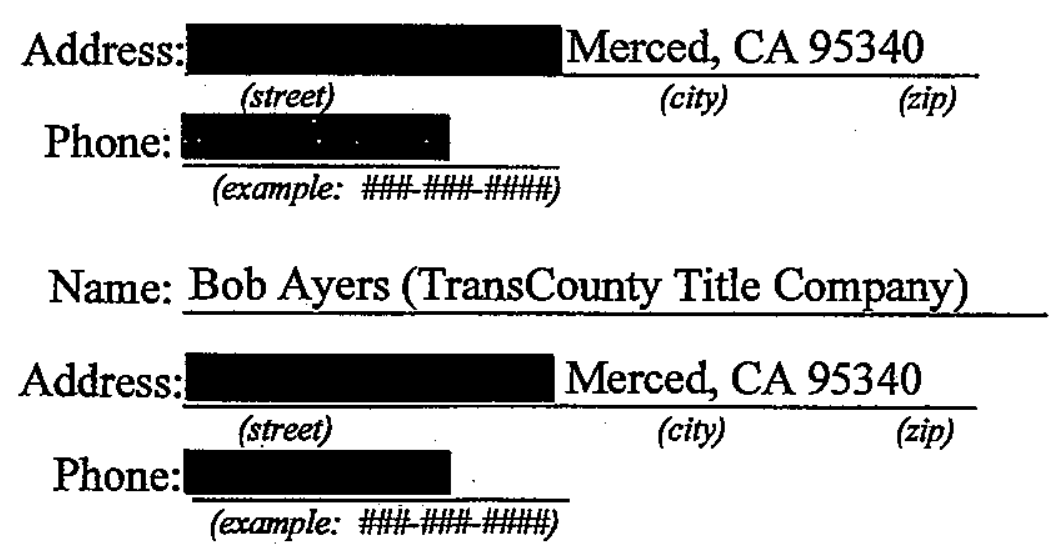


\section{City of Merced \\ Application for Appointment to the \\ Bellevue Corridor Community Plan Ad-Hoc Advisory Committee}

Name: Greg Thompson

Date: 06-14-12

Home Address:

(street)

$\begin{array}{cc}\text { Merced } & 95340 \\ \text { (city) } & \text { (zip) }\end{array}$

Mailing Address:

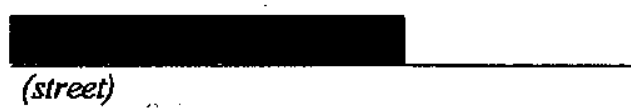

Merced

95340

E-mail Address:

Home Phone: (example: \#\#-\#\#-\#\#\#)

Cell Phone: (example: \#\#\#\#\#\#)

Work Phone: (example: \#\#-\#\#\#\#\#)

Place of Employment: Joseph Gallo Farms Occupation: Land Development Mngr

Work Address:

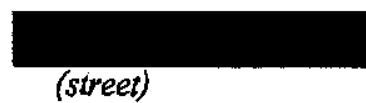

Atwater CA

(city) 95301

(zip)

1. The City Council seeks committee representation from the following groups: citizens, property owners within or nearby the Plan area, and representatives of: local schools, colleges and universities; community advocacy groups; public health officials or advocates; development community, and local chambers of commerce representatives or other business interests.

Which organization do you represent? Land Owner impacted by the Plan Area

2. List past or present involvement in community-related activities (i.e. volunteer work, committees, commissions, boards, etc.)

Former Director Merced County Chamber of Commerce

Current Planning Commissioner Dist 1 County of Merced

Former Member of the Technical Advisory Committee for the City of Merced General Plan Update (during former employment with the Merced Irrigation District)

3. State your understanding of the purposes, responsibilities, and services offered by the board/commission for which you are applying.

To provide guidance and local input during the planning and scope development for the Bellevue Corridor Community Plan. 
4. List any training, education, or experience that you feel would be advantageous to the board/commission for which you are applying.

Current work with the Merced County Planning Commission, Work as Development Manager at Joseph Gallo Farms, Extensive work and training with legal documents and the public record, extensive work experience with land title and real estate matters including mapping and the application process, experience with CEQA and regulatory compliance processes.

5. State your reasons for submitting this application and what you expect to accomplish on this board/commission:

To provide input and experience to this project and area. This project serves as a gateway to some of the most important assets in the Merced area, namely the U.C. Merced and the Yosemite Lake reservoir and will supply supporting infrastructure and access to most of the North Merced area.

6. This space may be used for any other information you feel is pertinent. $\mathrm{n} / \mathrm{a}$

7. List two references who can attest to your suitability for appointment to the board/commission.

Name: Mike Salvadori

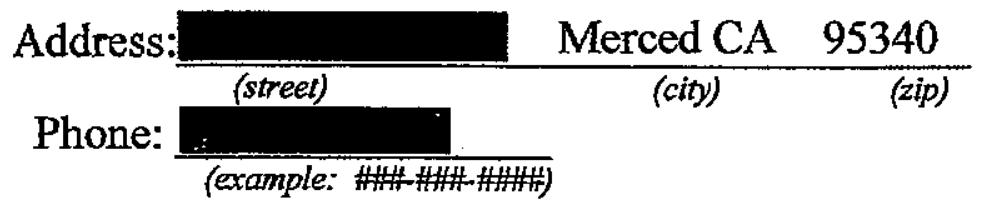

Name: Robert Haden

\begin{tabular}{llrr} 
Address: & \multicolumn{1}{c}{ Merced CA } & 95340 \\
Phone: (street) & & (city) & (zip) \\
\hline (example: & &
\end{tabular}




\section{City of Merced \\ Application for Appointment to the \\ Bellevue Corridor Community Plan Ad-Hoc Advisory Committee}

Name: Steve Tinetti

Date: $6-8-12$

Home Address

(street)

(streel)

Mailing Address:

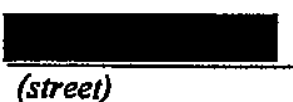

Merced

$\begin{array}{ll}\text { Merced } & 95340 \\ \text { (city) } & \text { (zip) }\end{array}$

E-mail Address:

Home Phone:

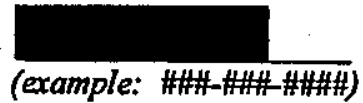

Cell Phone:

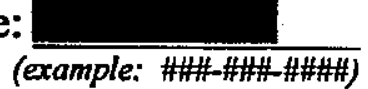

Work Phone:

95340

(sip)

Place of Employment: Tinetti Realty Group Occupation: Real Estate Brokerage

Work Address:
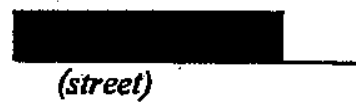

Merced 95340

(zip)

1. The City Council seeks committee representation from the following groups: citizens, property owners within or nearby the Plan area, and representatives of: local schools, colleges and universities; community advocacy groups; public health officials or advocates; development community, and local chambers of commerce representatives or other business interests.

Which organization do you represent? Property owner \& developer within Plan Area

2. List past or present involvement in community-related activities (i.e. volunteer work, committees, commissions, boards, etc.)

- Board Chairman of the Merced County Revolving Loan Fund Advisory Board

- Board Member of the Merced County Economic Development Corporation (MCEDCO)

- Board Member Challenger Learning Center Foundation of the San Joaquin Valley

- Board Member Merced County Office of Education Foundation

- Past President of the Merced Booster's Club

3. State your understanding of the purposes, responsibilities, and services offered by the board/commission for which you are applying.

Give input and advice to the Merced City Planning Department on the potential development of properties within the Bellevue corridor area between G Street and Lake Road with an eye toward making the area asthetically appealing (as the 'Gateway Entrance' to the UC Merced Campus), economically viable for multiple businesses / developments and without adversely impacting upon the existing property owners that reside in or adjacent to the Plan Area 
4. List any training, education, or experience that you feel would be advantageous to the board/commission for which you are applying.

I have been involved as either the developer and or investor/ owner in several real estate estate developments and have had the opportunity to market residential and commercial properties throughout the area over the past $38+$ years.

5. State your reasons for submitting this application and what you expect to accomplish on this board/commission.

I live within the Plan Area 5162 West Hills Avenue)and own a residential subdivision (West Hills Subdivision) within the Plan Area and therefore what happens within the Plan Area will have a direct economic impact on myself and my family. I would like to see the area developed in such a way as to be very attractive aesthetically as well as being economically viable for the development of several types of usages that will enhance the area and create job opportunities.

6. This space may be used for any other information you feel is pertinent.

7. List two references who can attest to your suitability for appointment to the board/commission.

Name: Lee Andersen

Address:

Phone:

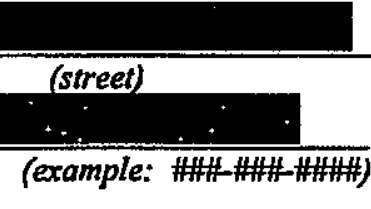

Name: Grey Roberts

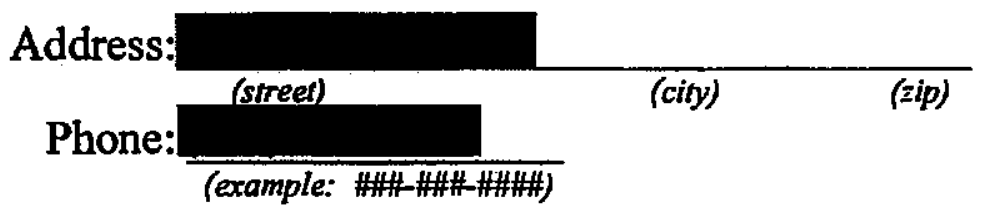




\section{City of Merced}

\section{Application for Appointment to the \\ Bellevue Corridor Community Plan Ad-Hoc Advisory Committee}

Name: Pas Ge Vang Date: $06 / 19 / 12$

Home Address:

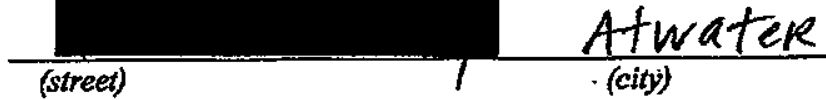
95361 .

Mailing Address: (street) (cify) (zip)

E-mail Address:

Home Phone: (example: \#\#\#\#)

Place of Employment: Cell Phone: (example: \#\#-\#\#-\#\#) Work Phone: (example: \#\#\#\#\#)

Work Address:

$$
\text { (street) }
$$

(city) Occupation:

1. The City Council seeks committee representation from the following groups: citizens, property owners within or nearby the Plan area, and representatives of: local schools, colleges and universities; community advocacy groups; public health officials or advocates; development community, and local chambers of commerce representatives or other business interests.

Which organization do you represerit? Citizan

2. List past or present involvement in community-related activities (i.e. volunteer work, committees, commissions, boards, etc.)

Have Been working on the Bellowne Corridere project since January 2012 .

3. State your understanding of the purposes, responsibilities, and services offered by the board/commission for which you are applying.
I understand my duties invelve
Sypporet is the creation of an innerative ecosystem into the city of merced. 
4. List any training, education, or experience that you feel would be advantageous to the board/commission for which you are applying.

Hare been pesearch the necessany material for
the project for ores half a yeak. Hfo possess a
s.sin management to over see projed if necessaing

5. State your reasons for submitting this application and what you expect to accomplish on this board/commission.

Twas ecquested by the city plannere bill king to
assibt him in his project to defelop the eity of
meeced into a self sustaining economy.

6. This space may be used for any other information you feel is pertinent. Beving meried. cesident all my life, 7 want to contribute to its growth and its realization of the potential of ace city.

7. List two references who can attest to your suitability for appointment to the board/commission.

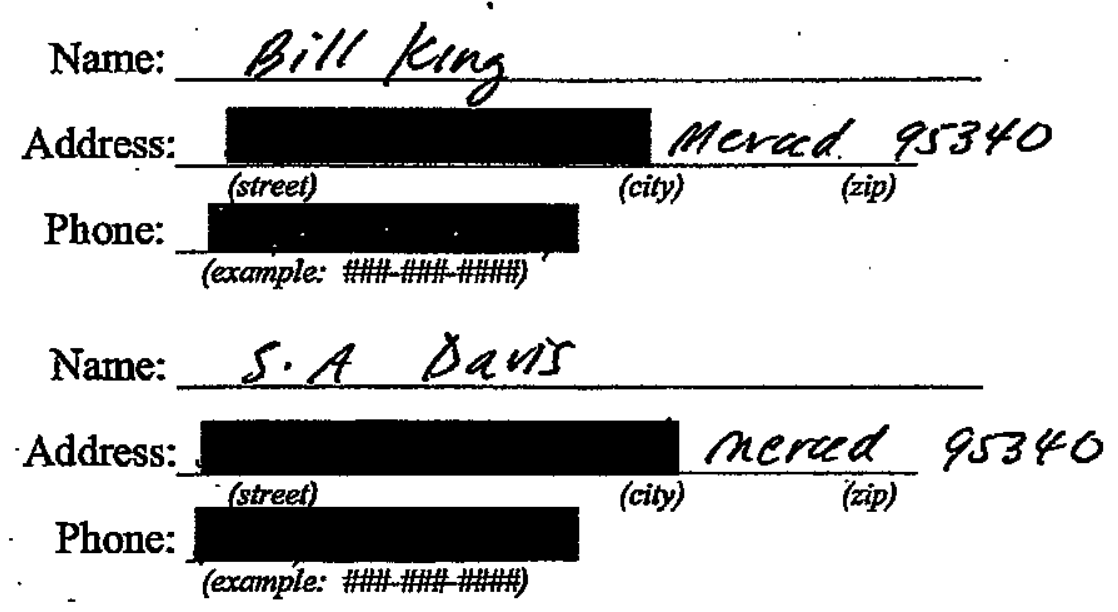




\section{City of Merced \\ Application for Appointment to the \\ Bellevue Corridor Community Plan Ad-Hoc Advisory Committee}

JUE11'12Pw1:31

Name: Diana Westmoreland

Date: 6-8-12

Home Address:

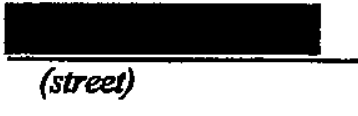

Merced

95340

Mailing Address:

$$
\text { (street) }
$$

(city)

(zip)

E-mail Address:

Home Phone:

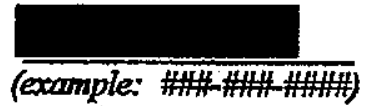

Cell Phone: (example: \#\#-\#\#-\#\#)

Work Phone:

(example: \#-\#)

Place of Employment: Occupation:

Work Address:

1. The City Council seeks committee representation from the following groups: citizens, property owners within or nearby the Plan area, and representatives of: local schools, colleges and universities; community advocacy groups; public health officials or advocates; development community, and local chambers of commerce representatives or other business interests.

Which organization do you represent? California Women for Agriculture

2. List past or present involvement in community-related activities (i.e. volunteer work, committees, commissions, boards, etc.)

San Joaquin Valley Partnership Land Use, Housing and Agriculture; Merced County Williamson Act; UC Merced Community Plan; Natural Communities Conservation Plan; Governor's Central Valley Task Force Agricultural; Merced City Chamber Tourism; Central Valley Tourism Committee; Central Valley Rural Farm Tour Committee; Merced Vision 2020; Yosemite Area Regional Transportation System (XARTS)

3. State your understanding of the purposes, responsibilities, and services offered by the board/commission for which you are applying.

The Committee will make recommendations to the Plan Leadership Team (PLT) concerning aspects of the Bellevue Corridor Community Plan. My responsibilities will be to review material, attend meetings, offer input and be part of a good working committee. 
4. List any training, education, or experience that you feel would be advantageous to the board/commission for which you are applying.

I currently serve on the Citizens Advisory Committee for MCAGias Representative. I have a good working knowledge of transpontatenta agriculture issues.

5. State your reasons for submitting this application and what you expect to accomplish on this board/commission. Planning for the Bellevue Cooridor is essential for the future of the City and County of Merced and I expect to be able to offer my knowledge and perspective to the process.

6. This space may be used for any other information you feel is pertinent.

7. List two references who can attest to your suitability for appointment to the board/commission.

Name: Deidre Kelsey

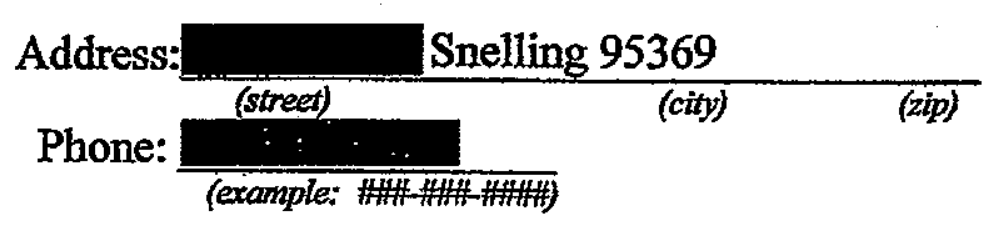

Name: Maria Azevedo, President Merced CWA

Address: $\frac{\text { Merced } 95340}{\text { (street) }}$ (city)




\section{City of Merced \\ Application for Appointment to the \\ Bellevue Corridor Community Plan Ad-Hoc Advisory Committee}

Name: Janet E. Young

Date: June 20, 2012

Home Address:

$$
\begin{aligned}
& \text { (street) } \\
& \text { Same } \\
& \text { (street) }
\end{aligned}
$$

Merced

95340

Mailing Address: $\frac{\text { Same }}{\text { (street) }}$

(city)

(zip)

E-mail Address:

Home Phone: (example: \#\#\#\#\#\#)

Cell Phone: (example: \#\#-\#\#\#)
Work Phone: (example: \#-\#\#-\#)

Place of Employment: Univ. of California, Merced Occupation: Associate Chancellor

Work Address:

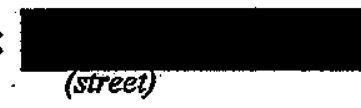

$\frac{\text { Merced }}{(\text { city })}$ 95340

(zip)

1. The City Council seeks committee representation from the following groups: citizens, property owners within or nearby the Plan area, and representatives of: local schools, colleges and universities; community advocacy groups; public health officials or advocates; development community, and local chambers of commerce representatives or other business interests.

Which organization do you represent? University of California, Merced

2. List past or present involvement in community-related activities (i.e. volunteer work, committees, commissions, boards, etc.)

Airport Authority for Merced Regional Airport, Economic Development Advisory Committee for City of Merced, Mercy Medical Center Merced Community Board, Merced Rotary Club, Merced Boosters

3. State your understanding of the purposes, responsibilities, and services offered by the board/commission for which you are applying.

It is my understanding that the role of the Ad-Hoc Advisory Committee is to offer recommendations to the Bellevue Corridor Community Plan Leadership Team related to the size and number of research or business parks in the Bellevue Corridor area, street design and transportation modality options, provision for open space and recreation areas, and for the phasing of the project, particularly as it relates to infrastructure. 
4. List any training, education, or experience that you feel would be advantageous to the board/commission for which you are applying.

My experience with research university administration and with development of large entities, such as UC Merced, will be valuable, along with knowledge of economic development work, and knowledge of Merced Medical Center which is located near the Bellevue Corridor area.

5. State your reasons for submitting this application and what you expect to accomplish on this board/commission.

$I$ believe that such as group can provide a service to the City leadership in exploring near and long- term opportunities to develop the Bellevue Corridor area in a way that is synergistic with the expansion of the UC Merced campus. It would be a privilege to serve and I would look forward to contributing to the work of the ad hoc Advisory Committee concerning the development of this area in a manner that will be beneficial to the City and the creation of new jobs and economic opportunity.

6. This space may be used for any other information you feel is pertinent. The City of Merced has an excellent future. It is important to for volunteer citizens to help position the City to take advantage of economic opportunities that will be available in the future when economic conditions are more favorable for business creation and expansion.

7. List two references who can attest to your suitability for appointment to the board/commission.

Name: Dorothy Leland, Chancellor UC Merced

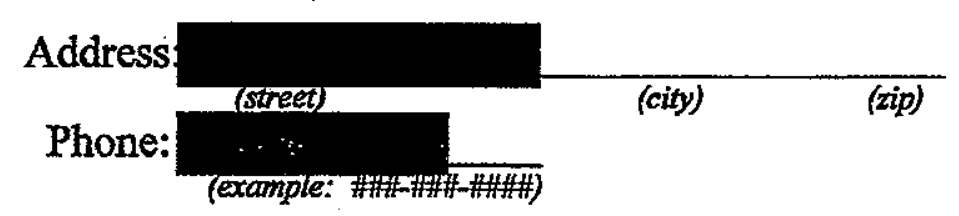

Name: David Dunham, President, Mercy Med. Ctr.

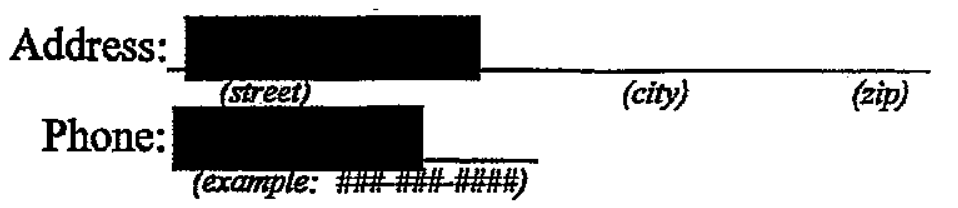




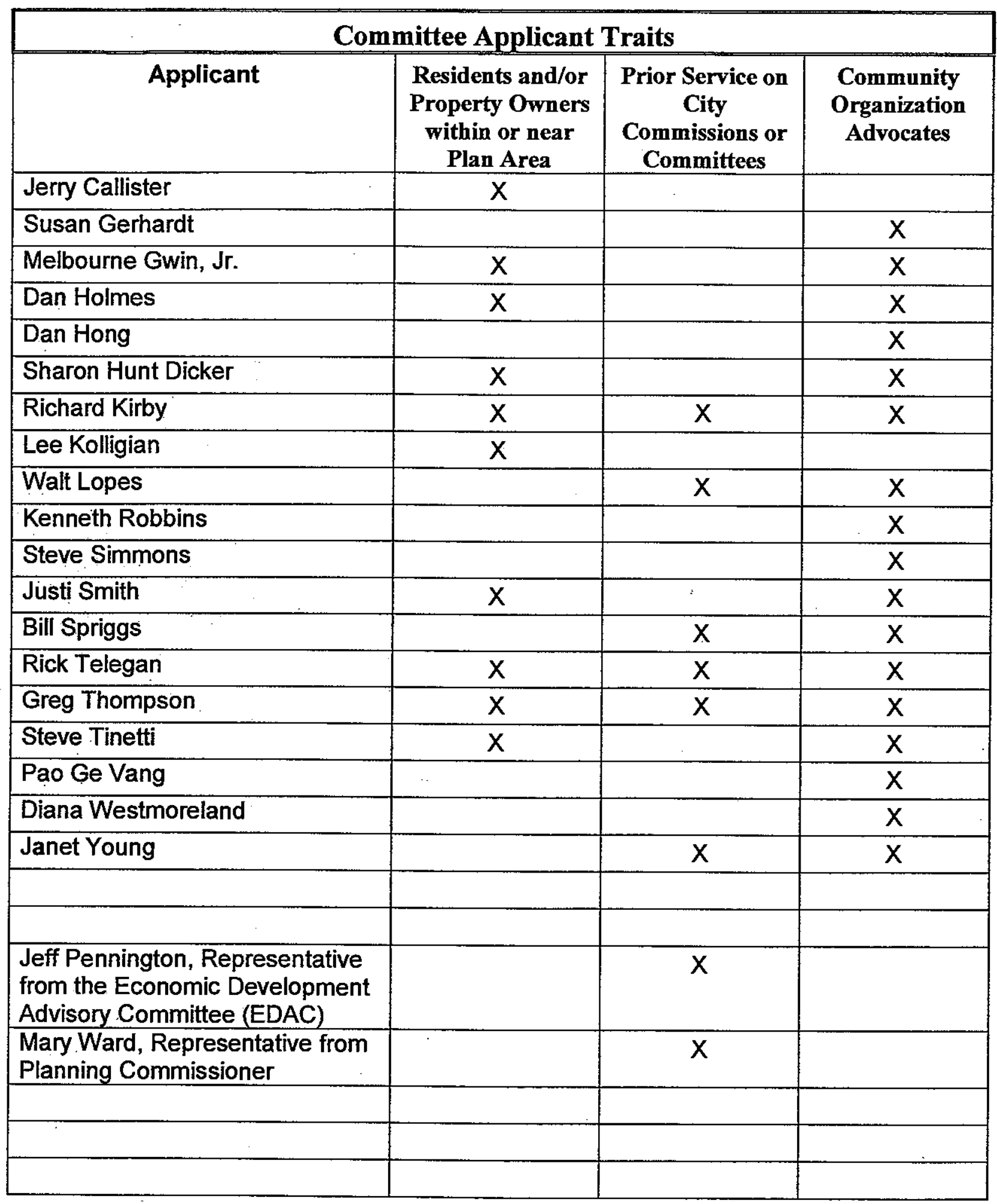


Appendix III. Bellevue Corridor Community Plan Request for Proposal 


\section{REQUEST FOR PROPOSALS BELLEVUE CORRIDOR COMMUNITY PLAN}

-- CITY OF MERCED -

November 1, 2011 


\section{REQUEST FOR PROPOSALS - OUTLINE}

\section{Project Overview}

\section{Background Information/Project Description}

Site Characteristics

City Planning Influences on Project

Grant Influences on Project

III. Project Details

Project Approach

Environmental Review

Project Schedule/Timeline for Milestones \& Deliverables

Budget

Public Involvement Process

IV. Requested Consultant Services

Preferred Consultants

Milestones/Deliverables

Roles

Expertise

Meetings

V. Consultant Scope of Services

Deliverables and Budget

Past Projects of Similar Nature

Who is Project Team? Describe who does what.

Team Member Resumes

Other

VI. RFP Logistics and Process

City Contact

RFP Due Date

Pre-proposal Contact

Selection Schedule

Consultant Evaluation Process

Interview Format

Who Decides

\section{Contractual Topics}




\section{PROJECT OVERVIEW}

The City of Merced requests proposals from qualified consulting firms to partner with the City of Merced Planning Staff to prepare the "Bellevue Corridor Community Plan." While a special focus of the plan is a two-mile segment of Bellevue Road and adjoining properties, the planning area encompasses three square miles of primarily agricultural use on either side of Bellevue Road and between the City of Merced and the newly established University of California, Merced. Key statements in this RFP are shaded red. For a quick general overview, please review those sections.

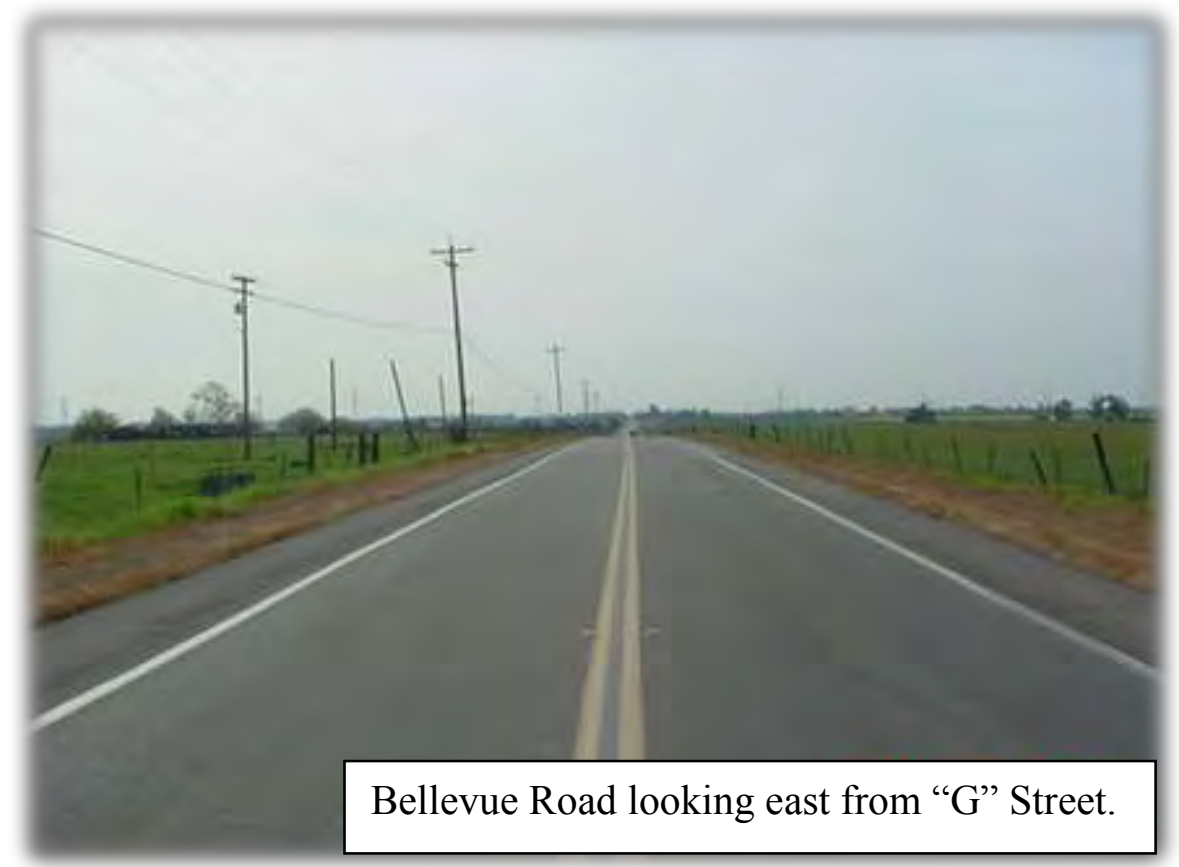

Goal: The goal of the effort is to incorporate sustainable circulation and land use design concepts into a comprehensive planning document, based on grounded market studies. City Staff will design and create the Plan structure and will assemble Plan components from a team of consultants for inclusion into the Bellevue Corridor Community Plan.

Funding: The Project is made possible by a grant from the State of California Strategic Growth Council (SGC). Total grant funds allotted to consultants to work on this project amount to $\$ 143,264$.

Timeline: The grant became effective on August 22, 2011, and the grant end date is August 22, 2014. The Project Timeline sought by the City for this project falls between these dates, and will take 2-years starting November 2011 with the RFP distribution and ending November 2013 with adoption of the Plan and FBC by the City of Merced City Council. 


\section{BACKGROUND INFORMATION / PROJECT DESCRIPTION}

\section{A. Site Characteristics}

The planning area is generally located between "G" Street (city limits) and Lake Road (UCM), and generally $1 / 2$ to 1 mile on either side of the corridor. With exception of a few pockets of rural residential homes, the planning area is predominately used for rangeland. The terrain is generally level, though a low-profile hilltop is situated just south of Bellevue Road in the midsection of the planning area. The eastern portion of the planning area contains a natural drainage and is designated Critical Habitat. The area is located in Merced County, outside of the City limits, but the majority of the site is within the City's Sphere of Influence, with the remainder to be formally included in 2012 .

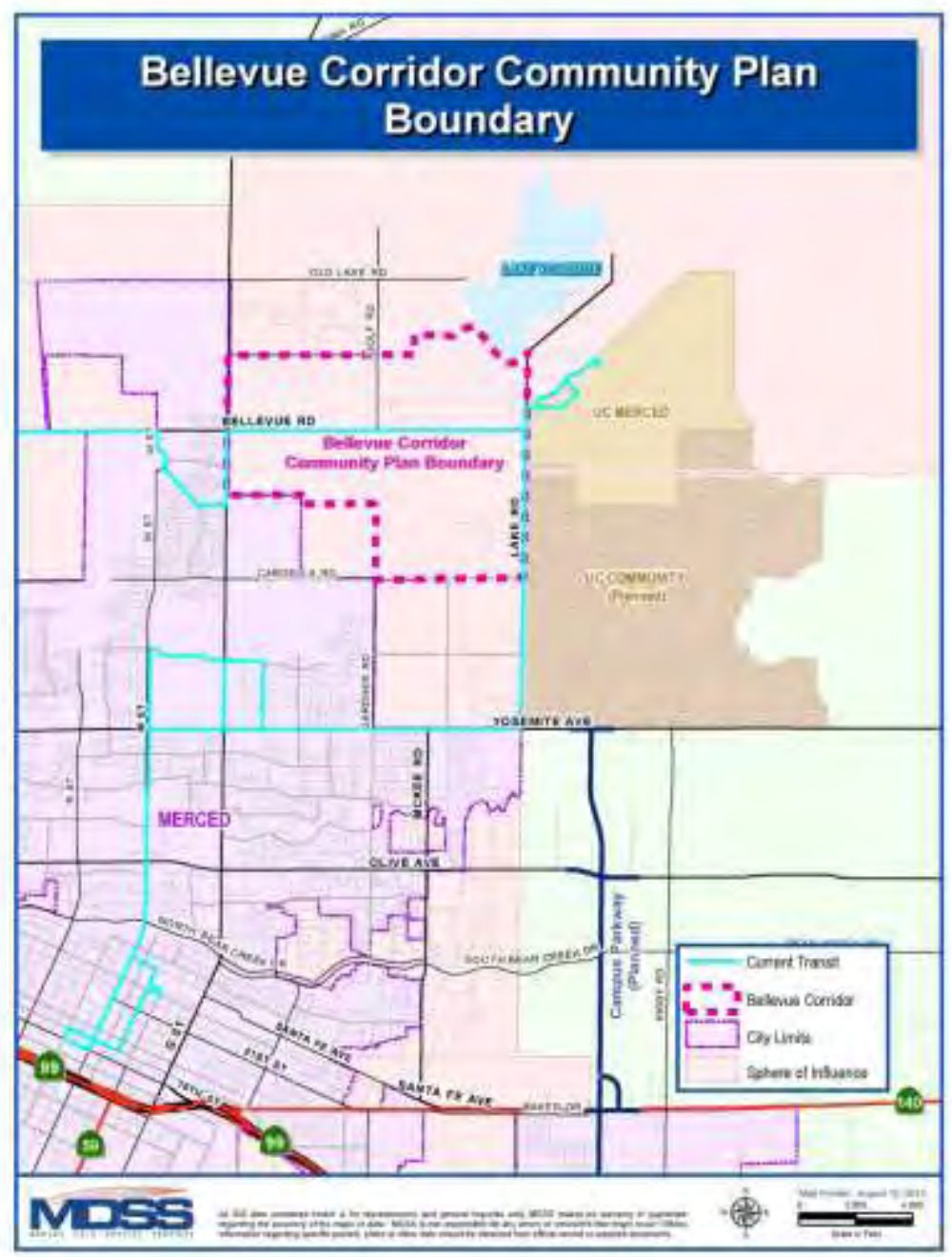




\section{B. City Planning Influences on Project}

\section{General Vision}

The recently adopted Merced Vision 2030 General Plan describes Bellevue Road as a gateway to UC Merced connecting the UC Merced Campus to Castle Airport Aviation and Development Center, other employment centers, and to Downtown Merced via the "G", "M" and "R" Street corridors. As such, the economic development strategies of these nodes should be compatible and complementary. They should also connect to one another via a network of transportation and communications systems that optimize access between and among them. Due to the unique nature of this Planning Area and the complexity of issues, landowners and agencies involved, the Bellevue Corridor Community Plan is being proposed.

The corridor should be designed as a place where services, shops, schools, businesses, public uses, and residences mix in a vibrant setting. The plan should assess the viability of expanding office, commercial, and research and development land use capacities in the plan area. The City's Urban Village will be the backbone concept model for creating core commercial nodes along Bellevue Road connected to neighborhoods to the south and north. Some of the land uses could connect to research and development activities associated with the campus research programs or professional services associated with the campus's professional schools.

It will be essential that adequate rights of ways be reserved along all major corridors. The design cross-section of these corridors may vary depending upon the adjacent land uses, but they should have two characteristics in common. They should be designed as multi-modal access corridors that accommodate automobiles and a public transit system, (rubber tire or light rail), as well as bicycles and pedestrians. Further, they should be designed to unify, rather than separate the elements of the community located on opposite sides of the road. These roads should be designed as landscaped multimodal boulevards.

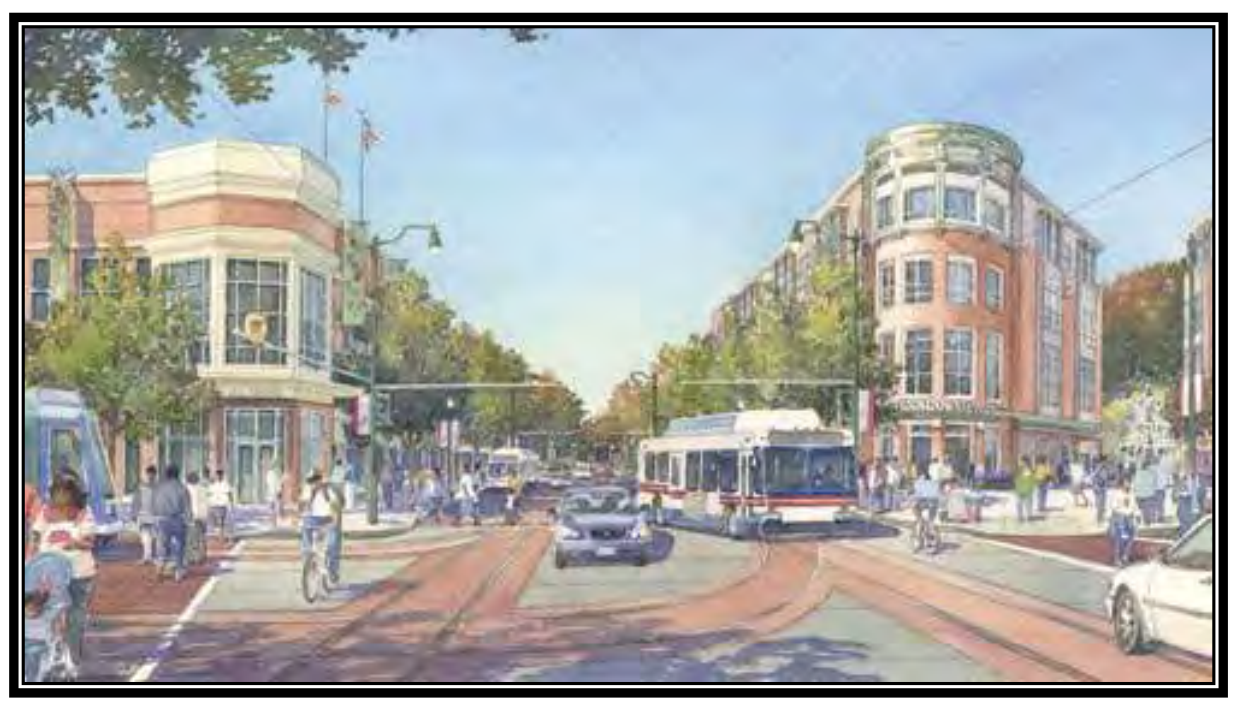




\section{Comprehensive Planning Concepts}

The grant application to the Strategic Growth Council (SGC) was modeled after the comprehensive planning concepts set forth in the Merced Vision 2030 General Plan. The City/SGC contract includes objectives and key deliverables and processes used to attain these concepts. The comprehensive planning concepts are:

\section{Government Code Section 65450 for "Specific Plans"}

As envisioned in the General Plan Land Use Policy L-3.6, a "Community Plan" may or may not conform with the requirements of Government Code Section 65450 for "Specific Plans." The Bellevue Corridor Community Plan does not need to conform with these requirements.

2. $\quad$ Merced Vision 2030 General Plan - Corridor Land Use Design and Function

Section 3.5.5 of the Merced Vision 2030 General Plan (pgs. 3-37-41) describes the Bellevue Corridor Community Planning area as a Commercial and Industrial Employment Corridor. While the corridor will provide for this land use, the overriding character of the corridor will be mixed-use based after the Urban Village Design concept. Specifically, as described on page 3-57 of the Merced Vision 2030 General Plan:

"The composition and pattern of land uses in the Urban Villages near UC Merced along Bellevue Road will have unique designs and functions due to the economic opportunities and connectivity to the university. Each of the "Urban Villages" between Lake Road and "G" Street should contain in addition to "Neighborhood Commercial," "Village Residential," and "Professional Commercial-Office," the opportunity for an expanded urban core comprised of a jobs based office, business park or research and development type land use supported or spun-off from UC Merced. This additional land use potential is represented on the Land Use Diagram by the Community Plan. This, along with other components of the Bellevue Road Corridor Community Plan" is discussed in greater detail in Section 3.7."

\section{3. "Community Plan Guiding Principles" and "Key Features and Issues"}

Through description of "Guiding Principles, Key Features and Issues" (Attachment C), the Merced Vision 2030 General Plan provides a general vision of the Bellevue Corridor Community Plan, and serves as an outline of important elements of the Plan. 
4. $\quad$ Merced Vision 2030 General Plan "Illustrative Community Plan"

The Merced Vision 2030 General Plan includes an illustrative plan (below) for the Bellevue Corridor Community Plan area. Illustrative plans are not adopted plans and are only included in the Merced Vision 2030 General Plan to inform the public of preliminary land use concepts under consideration in each of the Plan areas. NOTE: The land uses shown in the upper right quadrant were part of the formally adopted land use map for the City of Merced.

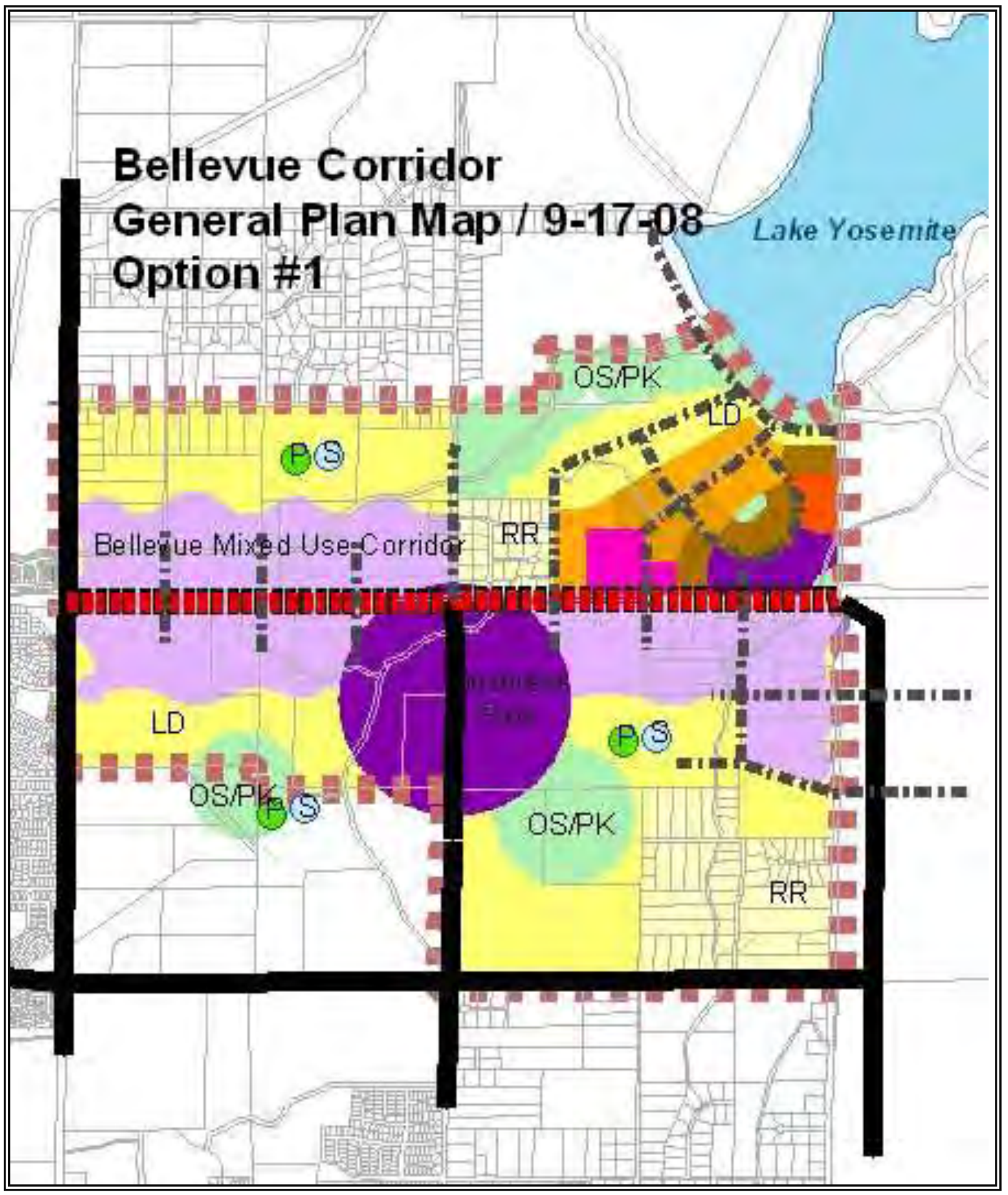


5. The Bellevue Corridor Community Plan will be consistent with the intent of the San Joaquin Valley Regional Blueprint. Land Use Policy L-3.7, implementing action: 3.7.b of the Merced Vision 2030 General Plan reads, "Continue to implement City policies and programs that conform to the Smart Growth Principles of the San Joaquin Valley Regional Blueprint"

- Create a range of housing opportunities and choices.

- Create walkable neighborhoods.

- Encourage community and stakeholder collaboration.

- Foster distinctive, attractive communities with a strong sense of place.

- Make development decisions predictable, fair, and cost effective.

- $\quad$ Mix Land Uses.

- $\quad$ Preserve open space, farmland, natural beauty, and critical environmental areas.

- $\quad$ Provide a variety of transportation choices.

- $\quad$ Strengthen and direct development toward existing communities.

- Take advantage of compact building design.

- Enhance the economic vitality of the region.

- Support actions that encourage environmental resources management.

\section{Grant Influences on Project}

\section{SGC Program Objectives and Key Deliverables of the BCCP}

The BCCP packages the required components of the Strategic Growth Council Grant. Table 1 summarizes this relationship between SGC Program Objectives with key deliverables of the BCCP. This RFP seeks consultants to prepare these key deliverables for incorporation into a broader community plan to be prepared by the City of Merced Planning Staff.

Attachment A is a written description detailing how the key deliverables of the BCCP contribute to attaining the twelve SGC Program Objectives. There are other elements of the BCCP, such as the open-space element and conservation element (not shown in the table), that will also seek to implement these objectives too. 


\begin{tabular}{|c|c|c|c|c|c|}
\hline \multicolumn{6}{|c|}{$\begin{array}{l}\text { Table 1: Relationship between Strategic Growth Council's Program } \\
\text { Objectives with Key Deliverables of the Bellevue Corridor Community Plan. }\end{array}$} \\
\hline \multirow[b]{2}{*}{$\begin{array}{l}\text { Strategic Growth Council } \\
\text { Program Objectives }\end{array}$} & \multicolumn{5}{|c|}{$\begin{array}{ll}\text { Key Deliverables of BCCP } \\
\end{array}$} \\
\hline & $\begin{array}{l}\text { Complete } \\
\text { Streets }\end{array}$ & $\begin{array}{c}\text { Mixed-Use } \\
\text { Form } \\
\text { Based } \\
\text { Code }\end{array}$ & $\begin{array}{l}\text { ROW/Semi- } \\
\text { Public } \\
\text { Templates }\end{array}$ & $\begin{array}{l}\text { Transit } \\
\text { Priority } \\
\text { Projects }\end{array}$ & $\begin{array}{l}\text { Economic } \\
\text { Study }\end{array}$ \\
\hline Improve Air and Water Quality & $x$ & $x$ & & $x$ & \\
\hline Promote Public Health & $x$ & & $x$ & & \\
\hline Promote Equity & $x$ & $x$ & & $x$ & $x$ \\
\hline Increase Housing Affordability & & $x$ & & $x$ & \\
\hline $\begin{array}{l}\text { Promote Infill and Compact } \\
\text { Development }\end{array}$ & $x$ & $x$ & $x$ & $x$ & $x$ \\
\hline $\begin{array}{l}\text { Revitalize Urban and Community } \\
\text { Centers }\end{array}$ & $x$ & $x$ & $x$ & & \\
\hline $\begin{array}{l}\text { Project Natural Resources and } \\
\text { Agricultural Lands }\end{array}$ & & & & & \\
\hline $\begin{array}{l}\text { Reduce Automobile Use and } \\
\text { Fuel Consumption }\end{array}$ & $x$ & & & $x$ & \\
\hline Improve Infrastructure Systems & $x$ & & $x$ & $x$ & \\
\hline Promote Water Conservation & & & & & \\
\hline $\begin{array}{l}\text { Promote Energy Efficiency and } \\
\text { Conservation }\end{array}$ & $x$ & & $x$ & $x$ & \\
\hline Strengthen the Economy & $x$ & $x$ & & & $x$ \\
\hline
\end{tabular}




\section{Key deliverables of the BCCP Required by Strategic Growth Council}

The BCCP will be a comprehensive Community Plan, including typical planning-related elements including land-use, circulation, housing, public facilities, etc. The key deliverables refer to focused efforts within these elements that pull the SGC twelve objectives into the overall Plan. Table 2 below summarizes the key deliverables described in the Project work plan of the SGC Grant, as well as a description of those responsible for said action.

Integrated into the process of drafting the $\mathrm{BCCP}$ are three broad steps for each of the key deliverables, and include:

Step 1 Conducting research and preparing findings and options;

Step 2 Hosting community workshops to gather comments, ideas and direction from stakeholders, project committees, underrepresented groups and the general public, about the work done in Step 1; and,

Step 3 Preparing final language and images for inclusion into an administrative draft Community Plan.

\begin{tabular}{|l|c|c|c|}
\hline \multicolumn{4}{|c|}{ Table 2: Components of Key Deliverables } \\
\hline \multicolumn{1}{||c|}{ Six Key deliverables } & $\begin{array}{c}\text { Step 1: } \\
\text { Research }\end{array}$ & $\begin{array}{c}\text { Step 2: } \\
\text { Workshops }\end{array}$ & $\begin{array}{c}\text { Step 3: } \\
\text { Draft Plan }\end{array}$ \\
\hline Complete Streets & staff & consultant & staff \\
\hline Form Based Code & consultant & consultant & consultant \\
\hline Right-of-Way/Semi-Public Space Templates & consultant & consultant & consultant \\
\hline Transit Priority Project & consultant & consultant & consultant \\
\hline Economic Study & consultant & consultant & NA \\
\hline Quantified Projected Outcomes & consultant & NA & consultant \\
\hline
\end{tabular}

City Staff recognizes that the BCCP has the potential to become greater than the sum of its parts (deliverables), and that it will take collaborative planning between related disciplines to act synergistically to create this outcome. The competitive consultant will also recognize this, and strive to attain these larger and broader concepts, such as laying the foundation to create the framework for development of a "Great Street" and an "Innovation Ecosystem."

\section{Description of the Key Deliverables}

See Section IV, "Requested Consultant Services." 


\section{Relationship of SGC Deliverables to Project-related Goals of the Merced Vision 2030 General Plan.}

The alignment of SGC contract deliverables with Merced Vision 2030 General Plan "Community Plan Guiding Principles" and "Bellevue Corridor Community Plan Key Features and Issues" is charted in Table 4, (Attachment C). The purpose of this Table is to serve as a tool used by Staff and the Consultant(s) to ensure that these Merced Vision 2030 General Plan comprehensive planning concepts are incorporated into the deliverables of the Bellevue Corridor Community Plan. 


\section{PROJECT DETAILS}

The Project timeline and budget is set by terms of the agreement between the City and SGC. These factors and other structural topics are described here.

\section{A. Project Approach \\ City Staff will take a leadership role with this Project. The City seeks assistance from consultants with specialized skills, formed as a team, to contribute components to the BCCP. Thus, the City will take a general contractor role in directing other entities to create components which City Staff will assemble and insert into a final document, which itself will be prepared by the City. It is the City's Project Manager's role to ensure consistency of the various parts with the singular Plan.}

\section{B. Environmental Review}

This RFP does not seek any CEQA-related services from the consultant; City Staff will prepare this document. A programmatic-level CEQA review has already occurred with the preparation of the Merced Vision 2030 General Plan, which will be tiered from for subsequent environmental review for this Project. The Project is consistent with the direction provided for in the Merced Vision 2030 General Plan, and the selected consultant will work to create components for the Plan that are consistent with this Plan.

\section{Project Schedule/Timeline for Milestones \& Deliverables}

A detailed description of Project deliverables is provided in Attachment B, as compared with a summary description of the deliverables that is provided in Attachment D. The Project Timeline sought by the City for this project will take 2 years, starting November 2011, with the RFP distribution and ending November 2013, with adoption of the Plan and Form Based Code (FBC) by the City of Merced City Council. The consultant is welcome to recommend adjustments to the timeline, where appropriate, so long as it does not defer the Project end date. Where reasonable, Staff will seek approval of changes in the City/SGC contract in order to align all Project contracts.

\section{Budget}

The Project is made possible by a grant from the State of California Strategic Growth Council (SGC). Total grant funds allotted to consultants to work on this project amount to \$143,264. 
The consultant is welcome to adjust sub-task costs where appropriate, so long at the total grant funds allotted to the consultant do not change. For example, the consultant may determine that better use of the funds would go toward "document preparation" rather than "studies," especially if the consultant is well-versed in that topic already. Other suggested budget modifications will be welcomed so long as the bottom-line amount does not change. Where reasonable, Staff will seek approval of changes in the City/SGC contract in order to align all Project contracts.

\section{Consultant Budget Summary}

\section{Task 1 Kick-off Meeting $\$ \$ 1,500$}

Task 3 Studies $\$ 80,264$ ( $\$ 18,188$ of which is for the Economic Study)

Task 5 Public Workshops $\$ 17,500$

Task 6 Final Products $\$ 44,000$

\section{E. Public Involvement Process}

Public involvement in the project will occur through: 1) partnerships between local planning professionals; 2) stakeholder participation; 3) directed outreach to underrepresented groups; 4) public workshops; and, 5) an advisory committee. The consultant's scope-of-work will include the design, preparation, and conducting public workshops concerning development of the key deliverables.

\section{Local Planning Professionals}

The Merced County Association of Governments (MCAG) will offer guidance to the City's planning efforts to encourage the Plan's consistency with the San Joaquin Valley Regional Blueprint and its future Regional Transportation Plan, including the Sustainable Community Strategy, as required by SB 375. The consultant will work with MCAG regarding transit issues. MCAG will also be available to advise the City in regard to state and regional regulations concerning transportation, air and water quality, and housing affordability.

As America's first research university of the $21^{\text {st }}$ Century, UC Merced has rooted much of its identity in its commitment to sustainability, calling itself "a living laboratory, piloting sustainability for growing communities." The UC Office of Physical Planning, Design and Construction has offered to assist with design concepts to extend the campus' "green" environment to the outlying neighborhoods. UC Merced Campus planners can contribute their expertise in design and GHG reduction tools and techniques to the BCCP. 
Additionally, through public workshops, UC Merced staff, faculty and students can help to inform many sections of the plan, encouraging compatibility with the sustainability vision of the University and the design and function of homes and commercial districts for future students and faculty members.

\section{Stakeholder Participation}

While the workshops are open to the public and invitations will be provided to all segments and geographies of the community, the subject project area is predominately rangeland and owned by relatively few entities, many of which have development interests. There are some pockets of single-family homes that border the corridor. Staff anticipates a that high level of participation in public workshops will come from these later groups.

The competitive consultant will clearly show relevant project experience in successfully achieving community objectives while maintaining a positive working relationship with private property owner interests.

For more information about Stakeholders, Underrepresented Groups, Public Workshops, and Advisory Committee, see detailed project scope-of-work, Tasks 2, 4, and 5 (Attachment B). 


\section{REQUESTED CONSULTANT SERVICES}

\section{A. Preferred Consultants}

The City does not have a preferred consultant for this project. The City reserves the right to select either a team, managed by a lead consultant, or to select individual consultants to provide the City with the different deliverables of the Project. The desired situation will be the former, however. Proposals must present a team approach and include all deliverables in the proposal. Attachment " $G$ " lists all interested consultants. Issue-specific consultants must partner with other consultants on this list, or other firms not listed. If the later, then please receive City approval of the "general consultant" prior to submitting your proposal.

\section{B. Milestones/Key Deliverables}

Project milestones and deliverables are specified by the agreement between the City and SGC.

Staff has prepared a more detailed Project Scope-of-Work, along with deliverable and identification of responsibilities (Attachment B).

\section{Roles}

See Attachment B.

\section{Expertise}

This RFP was provided to consulting firms with specific skills to accomplish one or more deliverables. The most competitive consultant will be made up of a multi-disciplinary team whose goal is to create high-quality deliverables for inclusion into the BCCP, and who clearly demonstrate that they have assembled individuals with expertise that best matches the desired end-product.

\section{E. Required Meetings (See details in Attachment B)}

Project Kick-off Meeting

Public Workshops

City Council Meeting 


\section{CONSULTANT SCOPE OF SERVICES}

The consultant's proposal should include all of the following topics in the order presented. All topics will be used to assess the consultant's: 1) project understanding; 2) Project interest; and 3) competency. All proposals shall be submitted in writing and be signed by the consultant.

\section{A. Deliverables and Budget}

The grant application to the SGC was modeled after the comprehensive planning concepts established by the Merced Vision 2030 General Plan. The City/SGC contract includes objectives, key deliverables, and processes used to attain these concepts. These deliverables and processes, along with the responsible entity (City of Consultant), are already defined in the SGC/City contract Project Work Plan (Attachment D) and Project Timeline (Attachment E). The City has limited ability to modify the budget and deliverables as these are set in the grant application and contract with the State of California, however.

\section{Deliverables / Consultant Scope-of-Work}

This RFP does not request a Comprehensive Project Work Plan or Timeline for the entirety of the BCCP from the consultant. City Staff will coordinate work based off of the Project Work Plan (Attachment D) and Project Timeline (Attachment E).

Rather, the consultant should include a sub-work plan and sub-timeline in the proposal. Each deliverable should be described separately in terms of work, budget and time. While an ideal candidate will show strength in all deliverables, City Staff may need to elect to form a multidisciplinary team of separate consultants in order to produce the best end-product, but this is not our preferred approach.

\section{Budget}

The following shall be included in describing the budget allocation:

- $\quad$ person hours allocated to each step and total hours allocated for project objectives and overall project (including sub-contractors);

- $\quad$ a breakdown of the employees and professionals to be assigned to each project objective and the hourly rates and person-hour costs assigned (please indicate total number of hours for each project team member along with total hours for each project objective and the entire project);

- $\quad$ personnel charge rates of the firm; 
- $\quad$ classification as to whether or not employees are reimbursed by hourly rate or salary; and,

- list of any subcontractors who may provide technical or other assistance and breakdown of hours/costs associated with the subconsultants.

The proposal shall describe the compensation to perform the services outlined herein, and such discussion needs to be consistent with the established budget. That said, City Staff is open to and may opt to request adjustments from the State. Any exceptions to the budget, timeline, and/or requirements stated herein shall be clearly stated in the proposal, and fully explained.

\section{B. Past Projects of Similar Nature}

Evidence of past work experience closely related to the subject Project will be a key determinant in the selection of a consultant(s). This section should describe why the consultant is a good fit with this Project. Please provide previous relevant experience and references of other public projects for both the project team and consulting firm.

\section{Who is on the Project Team? Describe who does what.}

Describe the members of the project team, along with their roles and duties. Describe past work associations with team members.

\section{Team Member Resumes}

Include team member resumes with the proposal, which desribe their qualifications to prepare the requested deliverables.

\section{E. Other}

The Scope of Work shall discuss other topics, either individually or as part of the above subsections, including:

- The administrative aspects of the project (legal oversight, printing costs, etc.);

- The type of word processing equipment and software used; and,

- Any optional features/analysis proposed. 


\title{
VI. RFP LOGISTICS AND PROCESSES
}

\section{A. Project Manager / City Contact}

Mr. William R. King, AICP, is the City of Merced Project Manager for the Bellevue Corridor Community Plan and will represent the City of Merced and render overall supervision of the progress of the work. All services to be performed by the consultant will be subject to approval and acceptance by the Director of Development Services or his designee, and no payment will be made to the consultant until accepted and approved. Mr. William R. King may be reached at: Phone: (209) 385-6858; EFax:(209) 388-7311; and Email: kingb@cityofmerced.org.

The City's Project Manager will work cooperatively with the consultant(s), by: 1) providing the consultant with whatever information is available regarding its requirements for the project; 2) examining project-related documents submitted by the consultant and rendering decisions promptly to avoid unreasonable delay in the progress of the consultant's work; and, 3) furnishing information required of it as expeditiously as necessary for the orderly progress of work.

\section{B. RFP Due Date / Mailing Address}

Please send four (4) copies of the proposal to:

\author{
William R. King, AICP \\ City of Merced Planning Division \\ 678 West 18th Street \\ Merced, CA 95340
}

To be accepted, the Project Manager must have them in-hand, NOT postmarked, by $\underline{\text { 5:00 }}$ p.m. on December $2^{\text {nd }}, 2011$

\section{Pre-proposal/Scoping Meeting}

There will not be a pre-proposal or scoping meeting for this project. If a consultant has a question, then please direct this to the City's project manager, who will post a reply to all consultants.

\section{Selecting Interview Pool}

Proposals submitted will be reviewed for completeness and qualifications by the following representatives: 1) City of Merced Planning; 2) UC Merced Office of Physical Planning, Design and Construction; and 3) Merced County Association of Governments (MCAG). Approximately 
three (3) consulting firms will be invited to interview with City staff. The interview date is Monday, December 12, 2011, between 1 P.M. and 5 P.M...

\section{E. Interview Format}

The Project Manager will arrange the interviews. The interview room sits eight people and includes a projection screen. The room does not include a projector or laptop. A powerpoint presentation is not required or expected. The purpose of the interview is not to restate the consultant's proposal, but rather to discuss the project with the consultant team members who will actually prepare the deliverables. Failure to include these individuals in the interview is grounds for automatic disqualification.

\section{F. Final Selection Process}

Upon conclusion of the interviews, the interview team will discuss the strengths and weaknesses of the proposals and make a decision as to which team, or independent consultants, will be recommended for final approval by the Merced City Council. The Planning Department will work with the selected consultant(s) to prepare a professional service contract, and to prepare and present the City Council administrative report to the Merced City Council. It is anticipated that formal consultant selection and contract award will be approved by the City Council in January 2012.

\section{G. Review and Selection Schedule}

\begin{tabular}{|c|c|c|}
\hline \multicolumn{3}{|c|}{ Table 3: Review and Selection Schedule } \\
\hline \hline Action & Date & Other \\
\hline Scoping Meeting & NA & NA \\
\hline Proposal Due Date & December 2, 2011 & Received by 5:00 P.M. \\
\hline Consultant Interviews & December 12, 2011 & Block out entire afternoon. \\
\hline City Council Contract Approval & January, 2012 (Tentative) & $\begin{array}{c}\text { 7:00 P.M. (attendance not } \\
\text { required) }\end{array}$ \\
\hline
\end{tabular}




\section{CONTRACTUAL TOPICS}

\section{Labor Code}

The consultant shall comply with Sections 3700 et seq. of the labor code of the State of California, requiring every employer to be insured against liability for worker's compensation.

\section{Insurance}

The Consultant shall also provide liability insurance in the amount of $\$ 1,000,000$ naming the City as additional insured. Please carefully note the endorsement and cancellation causes in the required contract. Please refer to the sample contract (Attachment F)

\section{Conflicts of Interest}

The Consultant must be aware of and comply with conflict of interest rules included in the California Political Reform Act, and Section 1090 et. Seq. of the Government Code. The Political Reform Act requires City offices and committee members to file statements of interest and abide by a Conflict of Interest Code. Section 1090 limits or prohibits a public official from contracting with a body of which an official is a member. Section 1090 applies even where the officer only reviews the contract for the approving body. If the proposer holds no City committee appointment or other relationship, the proposal should simply state that in response to this item.

\section{Form of Contract}

The City's standard form of contract shall be used, and includes other provisions not described here. A standard professional service contract is attached for reference (Attachment F). Please review this very carefully and note in the body of your proposal any exceptions or alterations to the agreement. Alterations or changes to the agreement which were not in the consultant's response will not be made after City Staff selection of the consultant. This includes alterations, exceptions, or changes to the insurance and indemnity provisions. By requiring these requests up front, the City can compare all respondents on an equal footing.

\section{Local Business Enterprise Policy (LBE)}

The City of Merced is committed to ensuring a full and equitable participation by local businesses in the provision of all goods and services to the City. 


\section{Method of Compensation}

The City of Merced reserves the right to award all or part of the project at its discretion. The City of Merced will compensate the consultant(s) based on achieved deliverables of the authorized Scope of Work/Contract, and may elect to offer compensation on a quarterly basis.

\section{Conditions for Responses to Request for Proposals}

The following conditions apply to this RFP process:

- Nothing contained in this RFP shall create any contractual relationship between the respondent and the City.

- This RFP does not obligate the City to establish a list of service providers qualified as prime contractors, or award a contract to any respondent. The City reserves the right to amend or cancel this RFP without prior notice, at any time, at its sole discretion.

- The City shall not be liable for any expenses incurred by any organization in connection with this RFP.

- No conversations or agreements with any officer, agent, or employee of the City shall affect or modify any terms of this RFP. Oral communications or any written/e-mail materials provided by any person other than designated contact staff of City shall not be considered binding.

- The City reserves the right, in its sole discretion, to accept or reject any or all Proposals without prior notice and to waive any minor irregularities or defects in a Proposal. The City reserves the right to seek clarification on a Proposal with any source.

- The dates, times, and sequence of events related to this RFP shall ultimately be determined by the City. The RFP process schedule is subject to change, at the sole discretion of the City, although the City will attempt to follow it and, if it must be altered, will attempt to provide reasonable notice of the changes.

- Respondents shall not issue any news release pertaining to this RFP, or the City without prior written approval of the City.

- All submitted proposals and information included therein or attached thereto shall become public record upon delivery to the Development Services Department.

\section{Strategic Growth Council Consultant Cross-Over Contract Terms}


The following are required and originate from the City's contract with the State. Where applicable, greater detail and additional clauses will be provided in the City's Professional Service Agreement with the selected consultant.

- Maintain Accounting Records: Consultants working on the Project will be required to maintain adequate supporting invoice documentation in such detail so as to provide an audit trail of receipts, expenditures, and disbursements. The consultant will maintain for a period of 3 years, accounting records which include, but are not necessarily limited to, subsidiary ledgers, payroll records, vendor invoices, canceled checks, bank or other financial account records, sub-consultant contracts and billings, volunteer rosters and work logs, and lease or rental agreements. These documents must be readily available for inspection, review and/or audit by the State's Grant Manager or other representatives of the State.

- Insurance Coverage: The Consultant shall obtain and keep in force for the term of its agreement with the City, the following insurance policies that cover any acts or omissions in the provision of services or performance of activities funded: 1) Worker's Compensation Insurance in accordance with the statutory requirement of the State of California; 2) Commercial general liability insurance in the amount of $\$ 1,000,000$ per occurrence and aggregate for bodily injury and property damage; and, 3) Automobile liability in the amount of $\$ 1,000,000$ for each accident for owned or non-owned or hired vehicles, whichever is applicable.

- Consultant Activity Logs: The City is required to maintain reports or other detailed records (e.g., activity logs or timesheets) documenting time spent by the consultant. The consultant will provide such records to the City with each invoice, and meet the following standard: Records used to meet this requirement shall identify: 1) the individual performing the work; 2) the date on which the work was performed; 3) the specific grant-related activities or tasks and deliverables to which the individual's time was devoted; and, 4) the amount of time spent. Such records shall reflect actual time spent, rather than that which was planned or budgeted.

- Nondiscrimination Clause: During the performance of any future agreement with the City, the consultant shall not discriminate, harass, or allow harassment against any employee or applicant for employment because of sex, race, color, ancestry, religious creed, national origin, physical disability (including HIV and AIDS), mental disability, medical condition (cancer), sexual orientation, marital status, and denial of family care leave. The consultant shall ensure that the evaluation and treatment of their employees and applicants for employment are free from discrimination and harassment. The consultant shall comply with the provisions of the California Fair Employment and Housing Act (Government Code, Section 12900 et seq.), and the regulations promulgated there under (California Administrative Code, Title 2, Section 7285 et seq.). The 
applicable regulations of the Fair Employment and Housing Commission implementing Government Code Section 12990(a-f), set forth in Chapter 5 of Division 4 of Title 2 of the California Code of Regulations, will be incorporated to future agreements by reference and made a part of it as if set forth in full. The consultant shall give written notice of their obligations under this clause to labor organizations with which they have a collective bargaining or other agreement.

- State 15\% payment deferment: The State will withhold $15 \%$ of all project related reimbursement until completion of the Project. This withholding will be extended to the selected consultant.

Attachments

A) Strategic Growth Council Project Objectives

B) Detailed Description of Project Deliverables

C) Relationship of Merced Vision 2030 Planning Concepts with SGC Key Deliverables

D) Summary Table of Deliverables, Budget, and Responsibilities

E) Project Timeline

F) RFP Consultant List

G) Sample Professional Services Contract 


\section{Strategic Growth Council Program Objectives}

\section{Improve Air and Water Quality}

Mixed-use zoning, with strategic blend of housing and business opportunities, will allow the City to reduce the need for long commutes. If planned well, the Bellevue Corridor will become a thoroughly walkable community, offering housing, services, recreation, and shopping options within walking distance of each other. "Complete Streets" design concepts will accommodate and, just as importantly, attract -- pedestrians and bicyclists. Public transportation options and off-street bike paths will contribute to the area's layout.

\section{Promote Public Health}

This Complete Streets approach to transportation will result in cleaner air, reducing the incidence of asthma for residents of the Bellevue Corridor. The BCCP would map out the area's first public park space and recreational facilities, encouraging physical activity. The Complete Streets design will encourage travel by walking and cycling.

\section{Promote Equity}

The BCCP will guide the economic growth adjacent to the university, striving for job creation suited for a variety of skill sets. Housing options will be diverse to fit budgets from all income levels, and public transportation will be designed for convenience and efficiency. The creation of public green space will be particularly valuable to this underserved population.

\section{Increase Housing Affordability}

The mixed-use Urban Village design intended for the Bellevue Corridor will be highly conducive to creating housing options for people with limited income. With the university population growing tenfold in the next 20 years, current housing density will need drastic revisions. The project will allow the City to increase the Corridor's housing supply and diversify housing types, tenure, and affordability. The end result will be affordable, high quality, socially integrated, and location-efficient housing.

\section{ATTACHMENT A}




\section{Promote Infill and Compact Development}

The proposed project will convert the City's urban design guidelines (based on Peter Calthorpe's vision of transit-oriented development) to zoning code. Mixed-use zoning will blend residential and commercial areas, creating an Urban Village layout with a town center. High density housing will mix with parks, offices, shops, services, and transit options to create a wellbalanced, walkable community.

\section{Revitalize Urban and Community Centers}

The area's current zoning is agricultural-residential, with no focal point or public facilities. When implemented, the BCCP will lay out a compact community, oriented around an attractive retail and office center integrated with open space.

\section{Protect Natural Resources and Agricultural Land}

The project will be consistent with the California Wildlife Action Plan in that the policies included in the plan will aim to preserve, protect, and/or mitigate the loss of resources, promote the long-term vitality of natural resources within the larger regional context. The City will aim to integrate natural resources into development, promoting the use of drought-tolerant native vegetation for landscaping purposes and connecting open spaces to allow the presence of wildlife within the Bellevue Corridor.

The BCCP will communicate the vision for the Bellevue Corridor as a compact, transit-oriented "Urban Village." Compact design will confine the burgeoning population to a small, but vibrant mixed-use area west of the UC, filling in a gap between the City and UC Merced rather than sprawling into the more pristine wildlife habitats and agricultural lands east of campus.

\section{Reduce Automobile Use and Fuel Consumption}

The project will create a strategy for transit-oriented development. A convenient and affordable transit system will lace through the area and link to several bus lines leading riders to University bus stops, Merced destinations, Greyhound, and beyond. The addition of lighted, tree-lined, offstreet bike paths - plus bike racks and other amenities -will encourage cycling as a feasible and attractive mode of transportation. These bike paths will link to the City's award-winning network of paved recreational trails, which lace through most parts of Merced and will eventually merge with a large regional system. 


\section{Improve Infrastructure Systems}

The BCCP's infrastructure guidelines will expand and improve upon the area's current infrastructure. The Plan will lay out goals and policies for accessible, efficient transportation systems; a solid waste program characterized by source reduction and modern recycling components; sustainable energy infrastructure; and integrated water-related infrastructure that addresses potable water, wastewater, and storm water concerns.

\section{Promote Water Conservation}

The BCCP will discuss multi-objective storm water projects, including construction of permeable surfaces and collection basins and barriers. Consumption of potable water will be minimized through the innovative use of recycled wastewater and storm water, in keeping with the goals of the Merced Integrated Regional Water Management Plan.

\section{Promote Energy Efficiency and Conservation}

A conservation-oriented energy supply will be encouraged through building-related conservation techniques. The Plan will promote renewable energy sources such as solar panels and geothermal designs.

\section{Strengthen the Economy}

Work will include investigation of the area's potential to attract research-based companies and large corporations that provide a significant employment with competitive salaries and benefit packages, as well as the appropriate amounts and mixes of commercial and residential uses. Special attention will be given to secure a diverse set of businesses that cater to the University population, including entertainment options, retail stores, and student-oriented services. 


\section{DETAILED PROJECT SCOPE-OF-WORK}

Consultants are responsible for tasks marked with:

\section{Milestone 1: Project Startup Activities}

\section{Task 1: Organize Staff and Consultant Resources}

\section{Task 1A: Prepare the Consultant Request for Proposal}

City Staff prepares request for proposal (RFP), replies to questions and reviews and ranks proposals.

\section{Task 1B: Consultant Selection Process}

City Staff interviews consultants and prepares an Administrative Report and Professional Service Agreement(s) to the City Council for final selection.

Task 1C: Project Kick-off Meeting and Organization/Adjust Project Scope-of-Work as Needed

Meeting between City Staff, consultant, and partners (Merced County Association of Governments and University of California) to: 1) review and understand the development process of the Plan; 2) discuss roles and expectations; 3) establish communication portals for information sharing and future discussions; 4) timesheets; and, 5) to provide applicable planning documents to selected consultant.

\begin{tabular}{|c|}
\hline Deliverable by City \\
\hline 1A: RFP \\
\hline 1B: Administrative Report and Professional Service Agreement(s) \\
\hline 1C: Written description of Plan Development Process, including participant roles \\
\hline Deliverable by Consultant \\
\hline 1B: Written Reply to RFP \\
\hline
\end{tabular}

\section{ATTACHMENT B}


Task 2: Conduct Initial Public Outreach Activities

\section{Task 2A: Host a Public Outreach Kick-Off Meeting}

City Staff will host a community-based information and orientation open house at UC Merced about the Planning effort and future public workshops. Additionally, the vision of the Plan will be presented, giving an opportunity for understanding and adjustment, where appropriate, based on comments received. This meeting will precede Task 1C.

\section{Task 2B: Solicit, Assess, and Select the Project Citizen Advisory Committee}

The Citizen-based Advisory Committee (CAC) will be comprised of volunteers from existing City committees whose focus will be land use planning, economic development, bicycle planning, community services, and site and building design. One member from each City committee will sit on the Bellevue Corridor CAC during the term of the Project to work with Planning Staff to advise City Staff in their preparation of the BCCP.

\begin{tabular}{|l|}
\hline Deliverable by City \\
\hline 2A: Public Noticing Documentation \\
\hline 2A: Images of Event \\
\hline 2A: Public Comments \\
\hline 2B: Report Requesting Membership from Standing Commissions and Committees \\
\hline 2B: Report to Advisory Committee for Project Orientation \\
\hline Deliverable by Consultant \\
\hline Not Applicable \\
\hline
\end{tabular}

\section{Milestone 2: Project Studies}

\section{Task 3: Prepare Project Studies}

The majority of this research and assessment work will be completed by the consultant. The end-result of the research and assessment is to provide a recommendation of different options of how the topic can become manifest in the BCCP given its location and overall objectives of the City and SGC. These studies, assessments, and recommendations will form the basis of discussion for the community workshops, where these ideas will be presented to the public for comments. The assessment portion of the work will include an identification of potential barriers to implementation and a presentation of tools to overcome them. The work associated with this task will be 
written by the consultant and assembled by staff to form key aspects of the Project's background report.

\section{Task 3A: Research, Collect, and Assess “Complete Streets" General Plan Policies}

City staff will perform the above noted work as it applies to preparation of "Complete Streets" policies. City staff will take the lead to establish a system of collector streets and arterials (the framework of the Plan's official circulation plan) to encourage internal circulation within the Community Plan area. This would include determining the proper alignment and right-of-way for Gardner Road. Staff will incorporate the consultants Task 3C products into the Circulation Chapter of the Plan.

\section{Task 3B: Research, Collect, and Assess Provisions for Urban Village Form-Based Code}

The end goal of the FBC deliverable is to convert the City's urban design guidelines (which are based on Peter Calthorpe's vision of Transit Oriented Development) to a FBC to be applied to the Bellevue Corridor Community Plan area. These code provisions would ensure a quality built environment in areas where housing and commercial uses are in close proximity -namely in the City's "Urban Village" land use designation.

Note that the City of Merced was also awarded a grant through Smart Valley Places to prepare a Form-Based-Code, which will apply to the entire City and to a greater range of land use designations. The work related to this other grant project will likely overlap with the work on the Bellevue Corridor Community Plan, starting approximately 3 to 6 months after the start date of the BCCP project.

\section{Task 3C: Right-of-way/Semi Public Spaces}

In Concert with Tasks $3 \mathrm{~A}$ and $3 \mathrm{~B}$, the consultant will craft prescriptive right-of-way cross sections and design templates for all Plan area streets and adjacent public and semi-public spaces, with particular attention to defining the character of the Bellevue Road corridor function and appearance. Different options for the arterial streets and collectors will be gathered and assessed for use in the Planning Area.

Consistent with the City's General Plan, this work will establish "Bellevue Parkway Planning Principles" describing the design (including appropriate right-of-way, and function, recognizing (1) the proposed land use pattern along Bellevue Parkway; (2) multi-modal access corridor that accommodates both automobiles and public transit 
systems, as well as bikes and pedestrians; and, (3) designed to unify rather than separate the communities located on opposite sides of the road. The consultant will research various street design options that meet the criteria above, and the need to provide for the anticipated high traffic levels. It is important that the City, partners, stakeholders and the consultant not presuppose any arterial street design, recognizing that the success of the corridor has as much to do, if not more, with the street than it does with the adjacent land uses and intervening pedestrian zone. As part of this research, the consultant will describe the expected LOS of each road design, given anticipated cumulative average daily trips.

\section{Task 3D: Through Text and Images, define "Transit Priority Project" (TPP) as used in SB-375 to create a model for use in the corridor plan.}

The transit deliverable includes two key features: (1) using general transit needs as a key driver in laying out land use and design elements of the plan; and (2) to expound and clarify the SB 375 TPP definition; to provide graphic plan and cross-section images of what a TPP could look like; and, assess appropriate locations of a TPP in the BCCP area. The study aspect of the plan will provide an overview describing essential needs of transit and how these can be manifested in the Plan. The consultant will work with City Staff, Merced County Association of Governments (MCAG), and the local transit provider to assess future sites for transit stations within the BCCP plan area.

\section{Task 3E: Prepare an Economic Study to assess need for future commercial uses and potential for research parks.}

Taking into consideration the City's existing and future traits, as well as those of UC Merced and local economic hubs, the consultant will prepare the necessary studies that will aid City Staff to determine size and location of viable research and development office parks, medical/professional offices, retail commercial uses, and various housing units within the Project area. The study would include an assessment of a Lake Road site and/or Gardner Road site for research and development uses within the Bellevue Corridor Community Plan. These studies are key elements of the Project and will drive the land use plan, which in turn will drive broad design aspects of the Plan.

City Staff will utilize this information to craft a land use map for the Planning Area that is consistent with the Project's guiding principles.

The study would also include a general assessment of activities, programs, partners, and infrastructure projects needed to facilitate development of future research parks in the 
Plan area. This needs assessment will identify the City's strengths and weaknesses. City Staff is currently exploring opportunities to work with UC Merced students and faculty on this aspect of the study. Your proposal should include this assessment assuming no involvement from UC, but do recognize that the scope and responsibility of this task may change depending upon the City's coordination with UCM. This item should be resolved by the consultant interview stage of the project.

Task 3F: Prepare a polished document containing these studies for inclusion into the plan.

\begin{tabular}{|c|}
\hline Deliverable by City \\
\hline 3A: Study Findings, Application to Merced, Recommendation(s) \\
\hline 3F: Project Background Report \\
\hline Deliverable by Consultant \\
\hline 3B: Study Findings, Application to Merced, Recommendation(s) \\
\hline 3C: Study Findings, Application to Merced, Recommendation(s) \\
\hline 3D: Study Findings, Application to Merced, Recommendation(s) \\
\hline 3E: Study Findings, Application to Merced, Recommendation(s) \\
\hline 3F: Study Findings, Application to Merced, Recommendation(s) \\
\hline
\end{tabular}

\section{Milestone 3: Public Outreach}

Task 4: Host Outreach Meetings with Specific Interest Groups, make extra effort to meet with Underrepresented Groups, and meet regularly with the Advisory Committees.

Task 4 will be accomplished through efforts of the City Planning Division.

\section{Task 4A: Reach out to Underrepresented Groups to ensure Participation}

In order achieve the equity objectives of the $\mathrm{BCCP}$, many methods will be practiced to include underrepresented communities in the planning effort, including: (a) specific project presentations to underrepresented communities at their meeting locations; (b) press releases placed in the bulletins, newsletters, or other communication tools utilized by underrepresented communities; (c) special VIP invitations to these communities to attend and participate in the outreach efforts; and, (d) as appropriate, translation services at public meetings. 
As with the development of Merced's other Community Plans, City Staff will ensure that economically disadvantaged community members are encouraged to attend projectrelated meetings by advertising meetings in a variety of locations. Special measures will be taken to ensure that low-income participants have easy access to meeting sites (for instance, meetings will be held in areas that have public transportation services), and meeting days and times will vary, to accommodate the diverse work and family schedules of community members.

\section{Task 4B: Host Community Stakeholder Meetings with Government Agencies, Community-based Organizations, and Commercial Interests.}

Government Agencies: As with all planning efforts, there is a standing group of "stakeholder" governmental agencies that will be involved. Notable agencies include Caltrans, Merced County Department of Public Health, Merced Irrigation District, Merced Area Groundwater Pool Interest Group, Valley Air District and three key divisions of the City that will help implement the plan, including the City of Merced Engineering Department, the Merced Parks and Community Services Department, and the Public Works Division. These entities will provide data and guidance in navigating the issues that their offices address on a day-to-day basis. State and Regional entities will provide direction to ensure the BCCP's compliance with State and Regional plans.

Community-Based Organizations: The City of Merced has a proud history of engaging economically and socially underserved populations in its planning processes. Historically these stakeholders have included: NAACP, Hmong Community, Merced Lao Family Community, Hispanic Network, Area Agency on Aging, Merced/Mariposa County Asthma Coalition, Healthy Communities Access Program, Merced County Farm Bureau, Boys and Girls Club, Merced Alliance for Responsible Growth, Merced Bike Coalition, the Community Partnership Alliance, various neighborhood groups, and several faithbased organization such as the Salvation Army.

Commercial Interests: Although there are no businesses currently within the Project boundary, there are important existing and future businesses of note that have strong interests and roles in the outcome and implementation of the Plan. Existing businesses include private community development whose interests are represented by the Building Industry Association of Merced County and Merced Economic Development and Redevelopment. Much of the land owned within the Project area is held by independent private land developers. Long-term interests include the local chambers of commerce and regional interests that would like to see opportunities for large scale employment 
centers in research-based industrial parks as spin-off development located adjacent to UC Merced.

Other Interests: To achieve public health objectives of the BCCP, the City will work with Merced County Department of Public Health, identifying local health risks and their long-term solutions. Staff will request input from health-related community groups to brainstorm strategies that will result in a comprehensive planning document to pave the way to a higher quality of life for Merced's residents. / To achieve the housing affordability objectives of the BCCP, Merced County Association of Governments has published its Regional Housing Need Plan (RHNP) and will advise the City of concepts outlined within the document, including affordability standards. / To achieve economic objectives of the BCCP, City Staff and consultants will work with the Greater Merced Chamber of Commerce, the Hispanic Chamber of Commerce and dozens of stakeholders to establish objectives to maximize the economic vitality of this area.

Task 4C: Meet regularly with the Citizen Advisory Committee and Staff Technical Advisory.

\begin{tabular}{|c|}
\hline Deliverable by City \\
\hline 4A: Public Notices \\
\hline 4A: Public Comments \\
\hline 4B: Public Notices \\
\hline 4B: Public Comments \\
\hline 4C: Public Notices \\
\hline 4C: Public Comments \\
\hline Deliverable by Consultant \\
\hline Not Applicable \\
\hline
\end{tabular}

Task 5: Host Project Public Workshops about “Complete Streets", Urban Village Design FBC, Transportation Priority Projects, and Semi Public Space Design Templates

The consultant will prepare for and conduct a series of separate public workshops, the goal of which is to present different methods to achieve the topic (complete streets, FBC, transit and TPP, etc.) in the Project area, and to receive public feedback for purposes of formulating a singular draft component for each topic for eventual inclusion in the BCCP.

City Staff will advertise and attend the meeting, but will have a limited participation role.

Task 5A: Conduct Land Use / Market Study Workshop 
Task 5B: Conduct Urban Village Design- FBC/TPP Public Workshop

Task 5C: Conduct ROW/Complete Street / Semi Public Space Design Template

Public Workshop

Task 5D: Conduct Final Public Workshop which assembles all draft components into the BCCP.

\begin{tabular}{|c|}
\hline Deliverable by City \\
\hline 5: Public Workshop Notices \\
\hline Deliverable by Consultant \\
\hline 5A: Workshop presentation, written public comments. \\
\hline 5B: Workshop presentation, written public comments. \\
\hline 5C: Workshop presentation, written public comments. \\
\hline 5D: Workshop presentation, written public comments. \\
\hline
\end{tabular}




\section{Milestone 4: Document Preparation and Implementation}

Task 6: Draft Plan Chapters, Ensuring Consistency with State Objectives, Project Studies and Greenhouse Gas Emission Reduction Policies, Programs and Actions, and Quantify Projected Outcomes over the base line using specific indicators.

Tasks $6 \mathrm{~B}$ to $6 \mathrm{D}$, and $6 \mathrm{~F}$ are to be performed by the consultant.

Task 6A: Using the Associated Study and Community Input as a Foundation, Develop Draft BCCP Land Use Map for inclusion into the BCCP.

Task 6B: Using the Associated Study and Community Input as a Foundation, Draft Urban Village Form-Based Code Concepts for inclusion into the BCCP.

Since the BCCP is a comprehensive planning document, and not code, the work on this key deliverable, as it applies to the Plan, will be limited to setting the strong foundation for the final step, which is to prepare and adopt a form-based code for the urban villages in the BCCP area (see Step 7C).

Task 6C: Using the Associated Study and Community Input as a Foundation, Draft "Transit Priority Project" Implementation Actions for inclusion into the BCCP.

The TPP implementation actions refer to the desire of the City for the BCCP to include the discussion, analysis, definition, maps, and policies that support a future TPP development project in the BCCP.

The transit study, workshop and document will be broad enough to also address the transit plan for the Project area. The transit plan is a critical component of the Project and will be used to help "drive" the land use plan and pedestrian zone design. The consultant will be provided data and guidelines that will serve as Plan design drivers, from MCAG. The consultant will use this information and its own expertise in the transit section of the document.

Task 6D: Using the Associated Studies and Community Input as a Foundation, Produce Right-of-Way Design Templates and Graphics for inclusion into the BCCP.

The value of the templates and graphics is the formation of a composite image, and associated text where appropriate, of three elements in land use planning that are typically evaluated separately, these being: 1) the function and design of the road; 2) the 
function and design of the pedestrian zone; and, 3) the function and design of adjacent buildings. The intent of the composite approach is to ensure that a livable and vibrant pedestrian community, suitable for a blending of peoples and ideas, is formed in the space between buildings and the road. This key deliverable needs to be consistent with complete street policies and FBC concepts of the BCCP

Task 6E: Outline, Integrate, and Adopt Greenhouse Gas Emission Reduction Policies, Program,s and Actions.

Task 6E will be prepared by City Staff. The BCCP will outline strategies to avoid, minimize, or mitigate the direct impacts that could contribute to the cumulative effects of GHGs. The principles outlined in Merced's Climate Change Action Plan will be carefully integrated into the BCCP. The BCCP will reduce GHGs by adopting or improving upon strategies outlined in the San Joaquin Valley Blueprint Plan as well as MCAG's Regional Transportation Plan. In regard to GHGs, the three square miles addressed in the BCCP will be most affected by transportation and electricity generation. The City will address these issues by indicating how emission reductions will be achieved via other transportation systems, building techniques, mixed-use development and a jobs-housing balance. The Plan will feature solar design guidelines and other standards for energy efficiency, for example, the Plan will outline proper orientation of structures with regard to solar utilization. The BCCP process will consider "reach" design guidelines for homes and commercial buildings to go beyond the minimum Green Building Standards Code, as well as solar design guidelines for development to benefit from the State's "Million Solar Roofs" program.

\section{Task 6F: Quantify Projected Outcomes over the Base Line Using Specific Indicators.}

This task is to be completed by the consultant, and does not involve the prior "study" and "public workshop" steps. The SGC has requested indicators be described and to quantify projected outcomes using the following categories, and while suggested indicators are provided, the consultant is expected to critique these and delete, add, or amend as appropriate.

\section{$\underline{\text { Indicators }}$}

GHG Emission Reductions: The best indicator of regional GHG emission reductions will be traffic count data, which will be available through Merced County Association of Governments, allowing the City to monitor its success in creating a walkable community, along with high bicycle and transit use. 
Air Quality: Traffic counts by Merced County Association of Governments will be the most accurate indicator for measuring the City's success. Low numbers of vehicles will indicate that the City's goals of reducing auto emissions are being achieved. In addition, the City will evaluate bike path usage and public transit use.

Water Quality: Data gathered from the City's bacteriological tests will reveal water quality in the area's wells, with coliform-negative tests serving as indicators to the BCCP's success in preventing water contamination.

Public Health: Indicators such as local school's physical fitness testing results, incidence of asthma emergencies, employment and crime rates will speak to the area's overall physical, emotional, social, and mental health.

Equity: The City will determine its success in these areas by examining the following indicators: unemployment rates, number of jobs created, entrepreneurial endeavors, median income, transit ridership, housing markets, and park acreage per 1,000 residents.

Housing Affordability: The primary indicator for housing affordability will be the ratio of median income to median housing costs. The City may also track housing inventory and vacancy rates.

Compact Development: The City will measure its success by the area's minimum lot size and number of homes per acre. The City will also consider the number of housing units and businesses within a half-mile of transit.

Urban and Community Centers: To assess the Plan's effectiveness, the City will measure the number of occupied offices, homes, shops, and service centers within a mile radius of the community's main hub.

Natural Resources and Agricultural Land: Indicators of this integration will include the acreage of connected open space and the numbers of native plant species integrated into public landscaping.

Automobile Use and Fuel Consumption:

Infrastructure Systems: Indicators will include water meters, recycling program participation, transit ridership, and ratio of energy generated to energy consumed.

Water Conservation: Water conservation indicators will include reduced residential and commercial water consumption.

Energy Efficiency and Conservation: Results of the City's energy efficiency and conservation efforts will be indicated by below-average residential and commercial energy consumption as documented by local electrical.

Strengthen the Economy: Indicators of a thriving economy will include low unemployment and increased sales tax revenue. 
Task 6G: Prepare a Final Document containing the Studies and Associated Essential Topics noted in Milestone 6.

City Staff will prepare the overall framework, order, and design of the BCCP, and will work with the consultant to incorporate key deliverables into its fabric. City Staff will prepare all typical elements of a community plan, not specifically assigned to Project consultants, including those listed below. As provided for in the City's application to the SGC, the BCCP will include the following in the plan:

- $\quad$ Location and financing of public facilities including a fire station, schools, roadways, offstreet bike and pedestrian paths, and parks/open space.

- Valuable resources such as storm water runoff and recycled water will be managed in a way to minimize the public investment in expensive water conveyance facilities.

- $\quad$ To address impacts of inevitable climate change consequences, the BCCP will include "Urban Water Runoff Reuse" strategies, policies, and incentives to increase local water supplies by maximizing the infiltration and/or capture of storm water through non-traditional, low-impact approaches.

- $\quad$ City Staff will ensure that water quality standards and goals are consistent with the Merced Integrated Regional Water Management Plan (MIRWMP) by reviewing MIRWMP strategies and integrating applicable tools, policies and strategies into the BCCP.

- $\quad$ To maximize water quality for the Bellevue Corridor, committees will address topics such as sewer service, solid waste disposal, storm water drainage, and water facilities.

- In regard to recreation, this project will introduce recreational resources into the area, outlining plans for public parks, off-street bicycle paths, and open spaces. The BCCP would map out the area's first public park space and recreational facilities, encouraging physical activity. The Complete Streets design will encourage travel by walking and cycling.

- $\quad$ Lake Yosemite Inundation Area.

- $\quad$ Sensitive Species and Habitat Conservation.

Deliverable by City

6A: Complete Street Policies for Draft BCCP

6E: GHG Emission Policies for Draft BCCP

6G: Final Draft BCCP 


\begin{tabular}{|l|}
\hline Deliverable by Consultant \\
\hline 6B: Section for BCCP: Form-Based Code Concepts \\
\hline 6C: Section for BCCP: Transit Priority Project \\
\hline 6D: Section for BCCP: ROW \& Semi-Public Space Templates and Graphics \\
\hline 6F: Section for BCCP: Quantified Indicator Outcomes \\
\hline
\end{tabular}

\section{Task 7: Adopt and Distribute Plan, and Prepare and Adopt Urban-Village Form Based Code}

\section{Task 7A: Council Adoption of Plan}

The consultant(s) should plan on attending this meeting.

\section{Task 7B: Distribution and Posting of Completed Plan}

The City will work with the California Chapter of the American Planning Association (CALAPA) and other Central Valley Planners to disseminate BCCP concepts to agencies throughout California. This Plan would be posted online and distributed to planning agencies throughout the Central Valley.

Upon the BCCP's completion, the City will actively promote the concepts addressed in the Plan. The City will notify Valley professional planning firms of the BCCP's completion, mailing the document and directing firms to the City's website. The City's electronic copies will be easily accessible and allow readers to search documents for key terms pertinent to their research.

At local planning roundtable presentations (such as the Valley's Future Forum, held at the Great Valley Center in Modesto), other communities will be invited to make use of the City's research and planning concepts. The City will also submit the finished Plan for local and state planning awards to further promote sustainable community techniques. As the Plan reaches implementation, success indicators will be tracked and published as well.

Task 7C: Draft and Adopt "Urban Village" Form Based Code

The consultant will prepare the FBC, and City Planning Staff will present the FBC to the City Planning Commission and City Council for adoption. The consultant should plan to attend both meetings.

\begin{tabular}{|l|}
\hline Deliverable by City \\
\hline 7A: Admin Report, Environmental, Resolution, Notice \\
\hline 7B: CD's, notices, presentations, \\
\hline 7C: Form Based Code \\
\hline
\end{tabular}




\section{Deliverable by Consultant}

Not Applicable

\section{Milestone 5: Grant Administration}

Task 8: Administer Grant-Related Management, Fiscal and Reporting Requirements

City Staff will manage this aspect of the Project, but will need the consultant's cooperation and compliance with invoice submittal requirements. The State has specific methodology requirements that also apply to the consultant. Payment for services is reliant on the consultant submitting proper invoices to the City. 


\section{ATTACHMENT C}

Table 4: Relationship of Merced Vision 2030 Planning Concepts with SGC Key Deliverables

\section{Community Plan Guiding Principles}

Community Plans which include or are adjacent to established neighborhoods will address the needs of these neighborhoods and potential adverse impacts resulting from plan implementation.

The Community Planning process should be focused on the planning issues or concerns which need to be resolved for that planning area and, to this degree, provide data, information, or policy clarification necessary to carry out the goals of the Merced Vision 2030 General Plan.
Bellevue Corridor Community Plan Key Features and Issues

(Land Use) Interface issues and infill land use patterns adjacent to

and within preexisting "Rural Residential" properties;

(Transportation Circulation) Establish "Bellevue Parkway Planning Principles" describing the design (including appropriate right-ofway, function, and land use pattern along Bellevue Road (to be renamed "Bellevue Parkway") recognizing two key traits: (1) multimodal access corridor that accommodates both automobiles and public transit systems, as well as bikes and pedestrians; and, (b) designed to unify rather than separate the communities located on opposite sides of the road;

--- (Character and Design) Establish through the Community Plan process design guidelines for development along the Bellevue Corridor in accordance with the City's Urban Design principles outlined in Chapter 6 of the General Plan;

--- (Character and Design) The natural hill, which occurs on the south side of Bellevue Road between G Street and Gardner, should be considered as a focal point for the Corridor;

--- (Land Use) The influence and effects of the UC Merced and

University Community land use and circulation plans on adjacent (western) properties;

--- (Transportation Circulation) Establish a system of collector streets and arterials with appropriate rights-of-ways to encourage internal circulation within the Community Plan area. This would include determining the proper alignment and right-of-way for Gardner Road.

\section{SGC Key Deliverables}

Form Based Code

Complete Streets

Form Based Code

ROW/Ped-zone Templates

Transit Priority Project

Economic Study

Public participation by area residents and property owners in the planning process will be emphasized. 


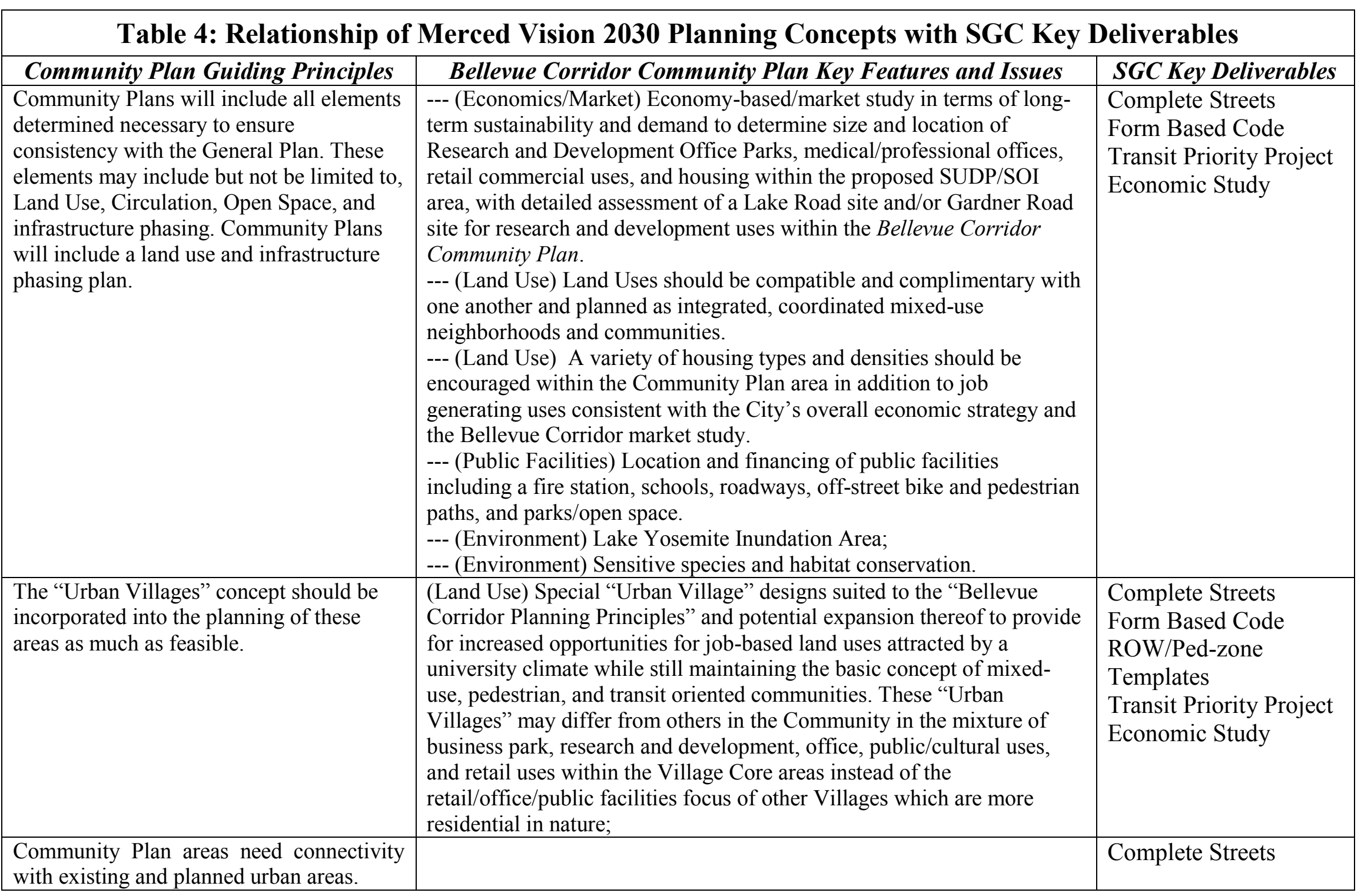




\section{ATTACHMENT D}

Overview: Table 5 shows all tasks and subtasks to occur with the Project. For sub-tasks shown in italicized bold, the consultant is the lead and fully responsible to complete the task including the provision of products and deliverables. In some cases (as noted) City Planning will assist. Details of such assistance are also described below. Information about the grant-approved consultant costs is provided too.

Consultant Costs: The following costs were used in the City's application to the State/Grantor. If changes to these task costs are necessary, then as part of a consultant's proposal to the City, the proposed new costs by task need to be specified. Along with this information, at the "task" level, provide the rates and hours of the individuals performing the work. This information is necessary to update our agreement with the grantor (State of California, Strategic Growth Council).

Description of Staff Assistance: In some cases, City Planning will assist the Consultant in the performance of some sub-tasks. Please note that in these cases, however, the consultant is the lead and fully responsible to complete the task including the provision of products and deliverables. Consider this assistance when reviewing the amounts allocated to the consultant. 


\section{Table 5: High Level Activities/Milestones and Tasks}

\section{PROJECT START-UP ACTIVITIES}

TASK 1: Organize Staff and Consultant Resources $\mathbf{( \$ 1 , 5 0 0 )}$

Sub-Task A Prepare the Consultant Request for Proposal

Sub-Task B Consultant Selection Process

Sub-Task C Project Kick-off Meeting and Organization/Adjust Project Scope-of-Work as Needed

City Staff will attend the kick-off meeting, provide necessary resource documents to the Consultant, and prepare any necessary follow-up with the Grantor.

\section{TASK 2: Conduct Initial Public Outreach Activities}

Sub-Task A Host a Public Outreach Kick-Off Meeting

Sub-Task B Project Citizen Advisory Committee Orientation Meeting

\section{PROJECT STUDIES}

TASK 3: Prepare Project Studies (\$62,076 for sub-task B, C, D and F; and \$18,188 for sub-task E)

Sub-Task A Research, Collect and Assess "Complete Streets" General Plan Policies

Sub-Task B Research, Collect and Assess Provisions for Urban Village Form-Based Code

Sub-Task C In Concert with Tasks $2 A$ and 2B, Craft Prescriptive Right-of-Way Cross Sections and Design Templates for Streets and Adjacent Public and Semi-Public Spaces.

Sub-Task D Through Text and Images, define "Transit Priority Project" (TPP) as used in SB-375 to create a model for use in the corridor plan. 
Sub-Task E Prepare an Economic Study to assess need for future commercial uses and potential for research parks.

Sub-Task F Prepare a polished document containing these studies for inclusion into the plan.

\section{PUBLIC OUTREACH}

TASK 4: Host Outreach Meetings with Specific Interest Groups, make extra effort to meet with Underrepresented Groups, and meet regularly with the Advisory Committees.

Sub-Task A Reach out to Underrepresented Groups to ensure Participation

Sub-Task B Host Community Stakeholder Meetings with Government Agencies, Community-based Organizations and Commercial interests.

Sub-Task C Meet regularly with the Citizen Advisory Committee and Staff Technical Advisory.

TASK 5: Host Project Public Workshops about "Complete Streets", Urban Village Design, Transportation Priority Projects, and Semi Public Space Design Templates $\mathbf{( \$ 1 7 , 5 0 0 )}$

Sub-Task A Conduct Land Use / Market Study Public Workshop

Sub-Task B Conduct Urban Village Design/(TPP) Public Workshop

Sub-Task C Conduct ROW/Complete Street / Semi Public Space Design Template Public Workshop

Sub-Task D Conduct Final Public Workshop

City Staff will provide the meeting space and attend and participate in the workshops, and perform the public noticing and outreach.

\section{DOCUMENT PREPARATION AND IMPLEMENTATION}

TASK 6 Draft Plan Chapters, Ensuring Consistency with State Objectives, Project Studies and Greenhouse Gas Emission Reduction Policies, Programs and Actions, and, Quantify Projected Outcomes over the base line using specific indicators. (\$89,000) 
Sub-Task A Using the Associated Study and Community Input as a Foundation, Develop Draft Land Use Map.

Sub-Task B Using the Associated Study and Community Input as a Foundation, Draft Urban Village Form-Based Code Concepts

Sub-Task C Using the Associated Study and Community Input as a Foundation, Draft "Transit Priority Project" Implementation Actions

Sub-Task D Using the Associated Study and Community Input as a Foundation, Produce Right-of-Way Design Templates and Graphics

Sub-Task E Outline, Integrate and Adopt Greenhouse Gas Emission Reduction Policies, Programs and Actions.

Sub-Task F Quantify Projected Outcomes over the Base Line Using Specific Indicators.

Sub-Task G Prepare a Final Document containing the Studies and Associated Essential Topics noted in Milestone 6.

City Staff will coordinate with consultant project manager as to product design and content; and review draft and admin versions of the various products.

TASK 7: Adopt and Distribute Plan, and Prepare and Adopt Urban-Village Form Based Code

Sub-Task A Council Adoption of Plan

Sub-Task B Distribution and Posting of Completed Plan

Sub-Task C Draft and Adopt "Urban Village" Form Based Code

\section{GRANT ADMINISTRATION}

TASK 8: Administer Grant-Related Management, Fiscal and Reporting Requirements

Sub-Task A Conduct Project Oversight \& Contract Management

Sub-Task B Prepare and Amend Budgets, Track Project Time, and Manage other Fiscal Duties

Sub-Task C Comply with Contract Reporting Requirements 